\title{
Biochemische und mechanistische Charakterisierung von Enzymen der Glycosidhydrolase-Familie 4
}

\author{
Dissertation \\ zur Erlangung des Doktorgrades \\ der Mathematisch-Naturwissenschaftlichen Fakultäten \\ der Georg-August-Universität zu Göttingen
}

vorgelegt von

Volker Hoffmann

aus Celle

Göttingen 2005 
D 7

Referent:

Prof. Dr. W. Liebl

Korreferent:

Prof. Dr. G. Gottschalk

Tag der mündlichen Prüfung:

27.04.2005 
1. Einleitung

1.1. Petrotoga und Thermotoga als Beispielorganismen für extreme Habitate ... 1

1.1.1. Adaptation an extreme Habitate .................................................. 2

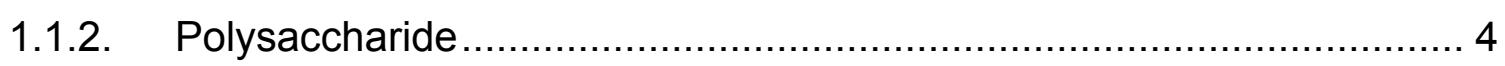

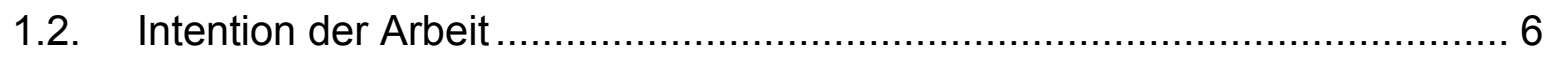

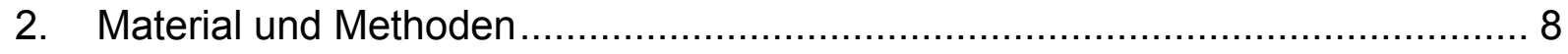

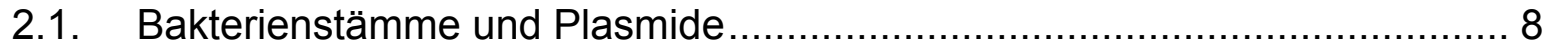

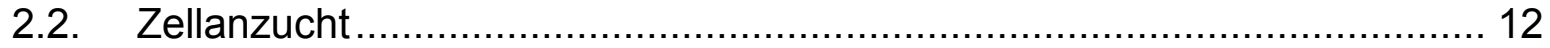

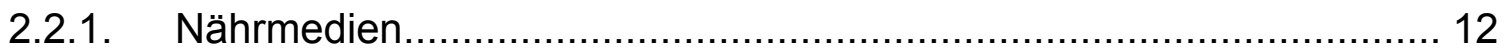

2.2.2. Antibiotika und andere Medienzusätze ........................................ 14

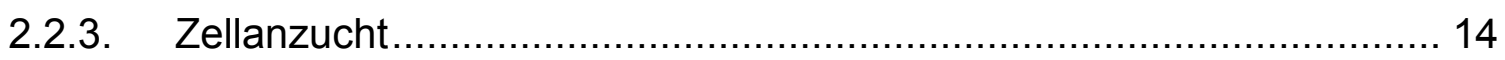

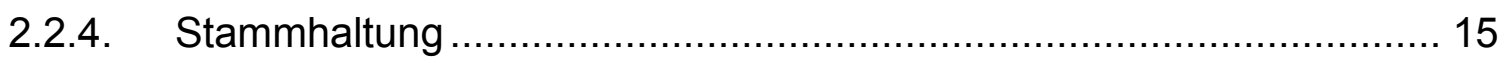

2.2.5. Bestimmung der optischen Dichte............................................. 15

2.3. Molekulargenetische Arbeitstechniken ……........................................ 15

2.3.1. Grundlegende Techniken für das Arbeiten mit DNA ........................ 15

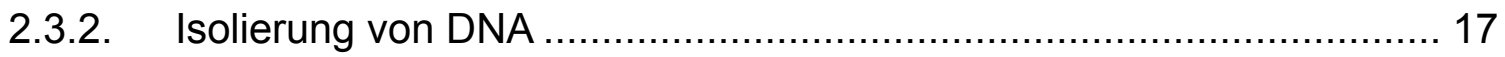

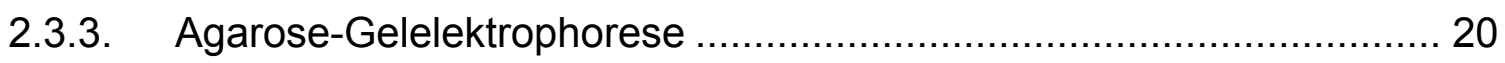

2.3.4. Polymerase-Kettenreaktion (PCR) ................................................. 22

2.3.5. Enzymatische Modifikation von DNA ………............................... 27

2.3.6. Transformation von E. coli......................................................... 29

2.3.7. Sequenzierung doppelsträngiger Plasmid-DNA …............................ 32

2.4. Proteinbiochemische Methoden ........................................................ 33

2.4.1. Standardtechniken für das Arbeiten mit Proteinen .............................. 33

2.4.2. Gewinnung und Aufreinigung von Proteinen ................................... 38

2.4.3. Charakterisierung der Enzymaktivität............................................ 48

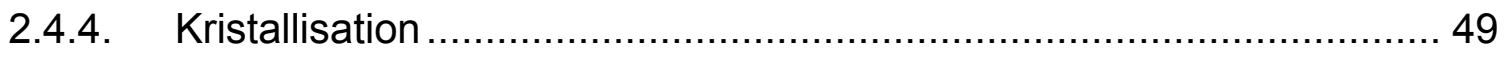

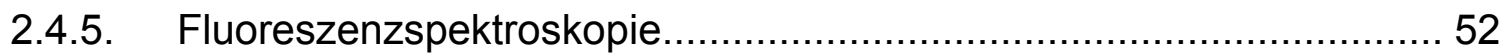

2.4.6. NMR, Physikalische Grundlagen.................................................. 53

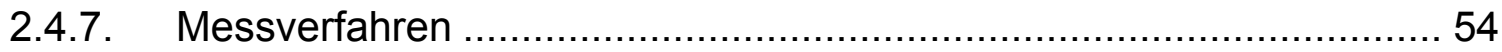

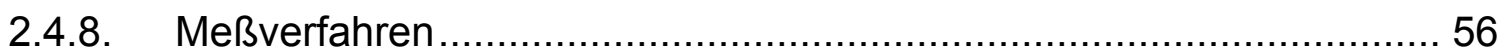

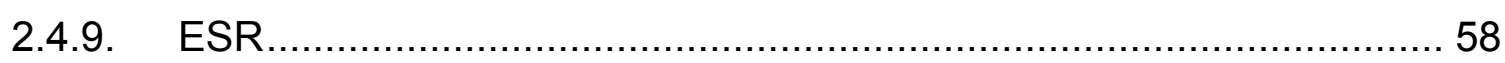

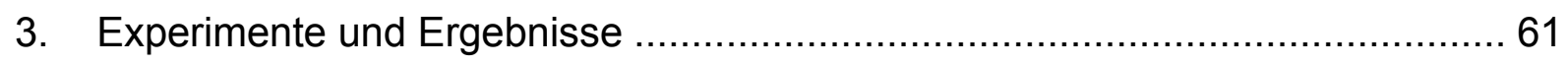

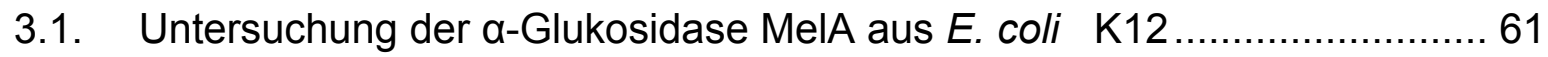


3.1.1. Klonierung des MelA-Gens aus E. coli K12 ….............................. 62

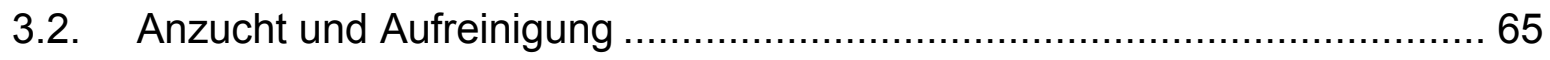

3.3. Charakterisierung der rekombinanten $\alpha$-Galaktosidase MelA ..................67 67

3.3.1. Untersuchungen zum Oligomerisierungsgrad der $\alpha$-Galaktosidase MelA

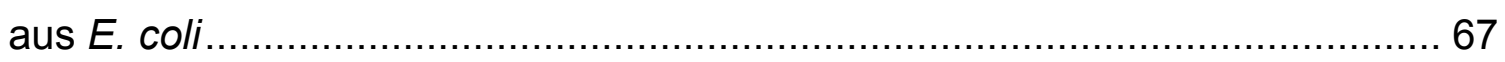

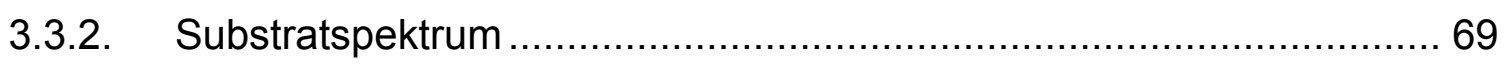

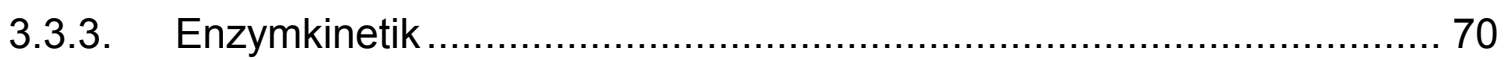

3.3.4. Bestimmung des pH-Optimums .............................................. 72

3.3.5. Bestimmung des „Temperaturoptimums“....................................... 73

3.3.6. Bestimmung der Thermostäbilität................................................. 74

3.3.7. Abhängigkeit der $\alpha$-Galaktosidase von Cofaktoren ............................ 75

3.3.8. Untersuchung zum zeitlichen Verlauf der Substrathydrolyse .............. 78

3.3.9. Spektroskopische Untersuchungen mittels NMR ……..................... 79

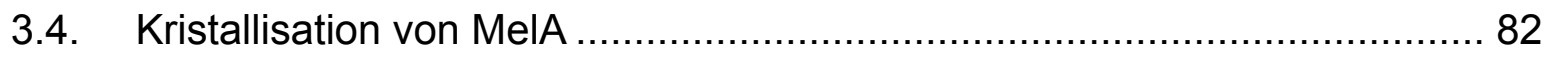

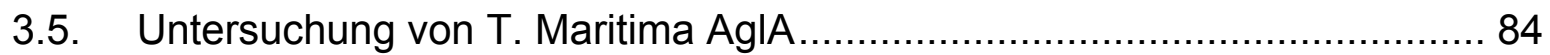

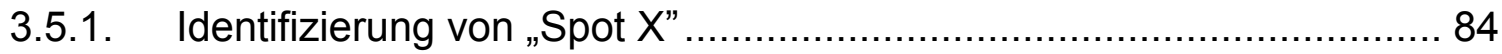

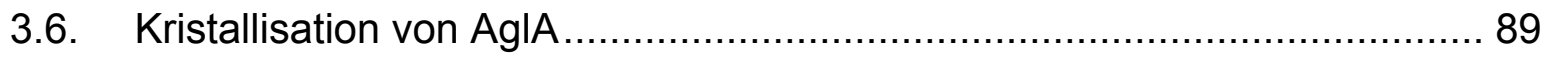

3.7. Anaerobe Aufreinigungen und Anzuchten ............................................ 91

3.8. Fluoreszenz- und Absorbtionsuntersuchungen an AgIA ........................ 92

3.9. Enzyme der Glykosidhydrolase-Familie 4 von Petrotoga miotherma ......... 96

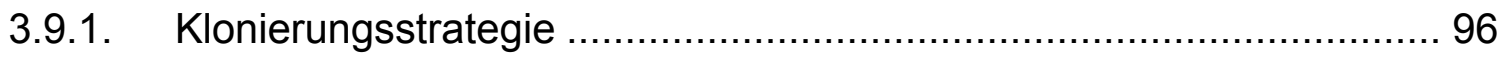

3.10. Untersuchung des ORFs RPMI00511 …....................................... 97

3.10.1. Klonierung von RPMI00511 aus P. miotherma in E.coli BL21 ........ 97

3.10.2. Anzucht und Herstellung eines Rohextrakts ................................101

3.10.3. Aufreinigung des von RPMI00511 kodierten Enzyms mittels FPLC 101

3.10.4. Untersuchungen zum Oligomerisierungsgrad des von RPMI00511

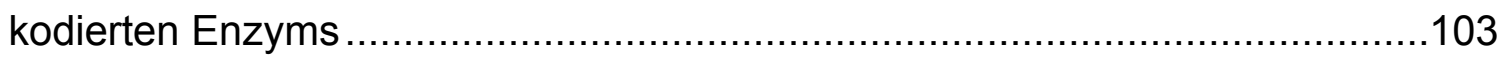

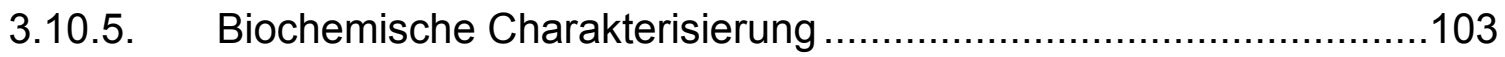

3.11. Untersuchung des ORFs RPMI00720 .........................................104

3.11.1. Klonierung des ORFs RPMI00720 .........................................104

3.11.2. Anzucht und Herstellung eines Rohextrakts ...............................106

3.11.3. Aufreinigung des von RPMI00720 kodierten Enzyms mittels FPLC 106 
3.11.4. Untersuchungen zum Oligomerisierungsgrad von RPMI00720 _....108

3.11.5. Biochemische Charakterisierung ……........................................108

3.12. Untersuchung des ORFs RPMI01263 ….........................................116

3.12.1. Klonierung von RPMI01263 aus P. miotherma in E. coli ...............116

3.12.2. Klonierungsstrategie ..........................................................118

3.12.3. Anzucht und Herstellung eines Rohextraktes ..............................119

3.12.4. Aufreinigung des von RPMI01263 kodierten Enzyms mittels FPLC 119

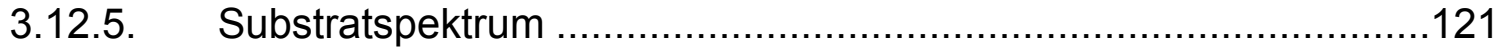

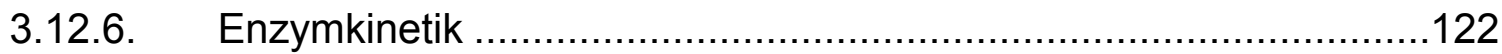

3.12.7. Biochemische Charakterisierung …………...........................123

3.13. ESR-Untersuchungen an E. coli MelA und das in ORF RPMI01263

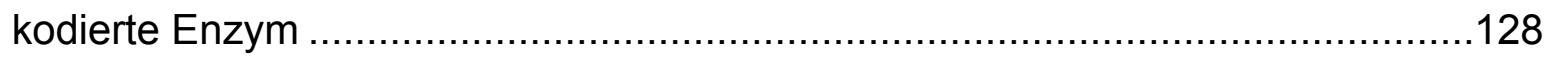

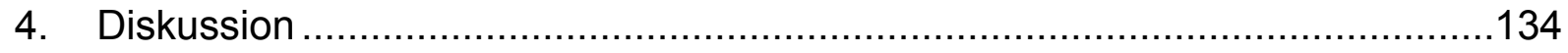

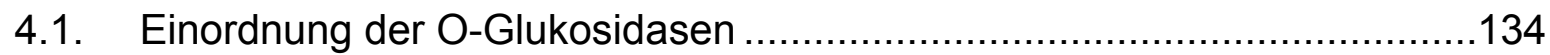

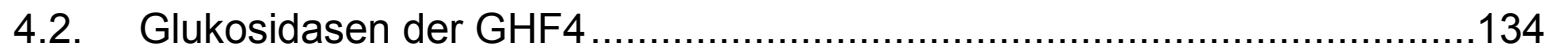

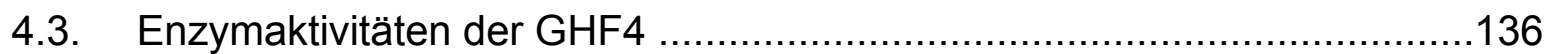

4.3.1. Optimierte Aufreinigung und Charakterisierung von Mela aus E. coli 136

4.3.2. putative $\alpha$-Glukosidase aus ORF RPMI00511 aus $P$. miotherma ......138

4.3.3. RPMI00720 und RPMI01263 aus P. miotherma .............................139

4.4. Mechanistische Untersuchungen ...................................................142

4.4.1. Fluorenszenz- und Absorbtionsspektren .....................................142

4.4.2. NMR-Untersuchungen zum Mechanismus.....................................144

4.4.3. Kristallisation von AgIA aus T. maritima ......................................145

4.5. ESR- und Mechanismusuntersuchungen ..........................................147

4.5.1. Auftreten eines unbekannten Produkts bei der AglA-Reaktion...........154

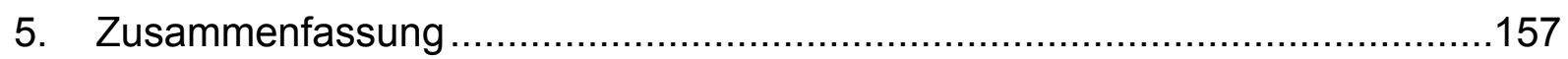

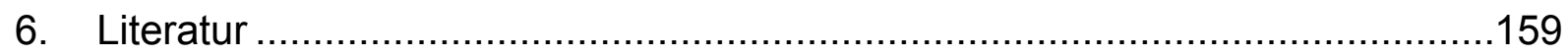

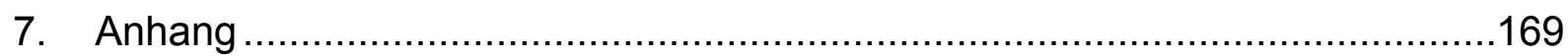




\section{ABKÜRZUNGSVERZEICHNIS}

A

AA

Abb.

Amp.

APS

AS

BCIP

bidest.

bp

BSA

bzw.

${ }^{\circ} \mathrm{C}$

$\mathrm{cm}$

$\mathrm{Da}$

DMSO

DNA

ds

E.

EDTA

et al.

$\mathrm{EtOH}$

$\mathrm{g}$

i.d.R.

IPTG

$\mathrm{k}$

$\mathrm{kb}$

$\mathrm{kDa}$

I

LB

$\mathrm{m}$

M

Ampere

Acrylamid

Abbbildung

Ampicillin

Ammoniumpersulfat

Aminosäure(n)

5-Brom-4-Chlor-3-Indolyl-Phosphat

bidestilliert

Basenpaar(e)

Rinderserumalbumin

beziehungsweise

Grad Celsius

Zentimeter

Dalton

Dimethylsulfoxid

Desoxyribonukleinsäure

doppelsträngig/Doppelstrang-

Escherichia

Ethylendiamintetraacetat

et alii: und andere

Ethanol

Gramm

in der Regel

Isopropyl- $\beta$-d-thiogalactopyranosid

Kilo- $\left(1 \times 10^{3}\right)$

Kilobasen

Kilodalton

Liter

Luria Bertani

Milli- $\left(1 \times 10^{-3}\right)$

Molar (mol/l), molekulare Masse 


\begin{tabular}{|c|c|}
\hline MM & Mineralmedium \\
\hline $\max$. & maximal, Maximum \\
\hline$\mu$ & Mikro- $\left(1 \times 10^{-6}\right)$ \\
\hline MCS & Multiklonierungsstelle (multiple cloning site) \\
\hline $\min$ & Minute \\
\hline $\mathrm{n}$ & Nano- $\left(1 \times 10^{-9}\right)$ \\
\hline NBT & Nitroblue-Tetrazolium \\
\hline $\mathrm{Nr}$. & Nummer \\
\hline OD & optische Dichte \\
\hline ORF & Offener Leserahmen (open reading frame) \\
\hline$P$. & Pseudomonas \\
\hline PAGE & Polyacrylamid-Gelelektrophorese \\
\hline PCR & Polymerase-Ketten-Reaktion (polymerase chain reaction) \\
\hline Pfu-Polymerase & Polymerase auf Pyrococcus furiosus \\
\hline $\mathrm{pH}$ & negativer dekadischer Logarithmus der Protonenkonzentration \\
\hline r & resistent/Resistenz \\
\hline RNA & Ribonukleinsäure \\
\hline RNase & Ribonuklease \\
\hline RT & Raumtemperatur \\
\hline sek & Sekunde \\
\hline SDS & Sodiumdodecylsulfat \\
\hline sog. & sogenannt(en) \\
\hline ss & einzelstränig/Einzelstrang- \\
\hline Tab. & Tabelle \\
\hline TAE & Tris-Acetat-EDTA-Puffer \\
\hline Taq-Polymerase & Polymerase auf Thermus aquaticus \\
\hline TE & Tris-EDTA-Puffer \\
\hline TEMED & $\mathrm{N}, \mathrm{N}, \mathrm{N}^{\prime}, \mathrm{N}^{\prime}$-tetramethylethylendiamin \\
\hline Tris & Tris(hydroxymethyl-)aminomethan \\
\hline$U$ & Unit (Einheit der Enzymaktivität) \\
\hline ÜN & über Nacht \\
\hline Upm & Umdrehungen pro Minute \\
\hline UV & Ultraviolett \\
\hline V & Volt \\
\hline
\end{tabular}


$\mathrm{v} / \mathrm{v} \quad$ Volumen pro Volumen

Vol. Volumen

w/v Gewicht pro Volumen

X-Gal 5-Brom-4-Chlor-3-Indolyl- $\beta$-D-galactopyranosid

z.B. zum Beispiel

Nukleotidbasen
A Purinbase Adenin
G Purinbase Guanin
$\mathrm{T}$ Pyrimidinbase Thymidin
C Pyrimidinbase Cytosin

Aminosäuren
A Alanin
M Methionin
C Cystein
$\mathrm{N} \quad$ Asparagin
D Aspartat
P Prolin
E Glutamat
Q Glutamin
F Phenylalanin
$\mathrm{R} \quad$ Arginin
G Glycin
S Serin
$\mathrm{H} \quad$ Histidin
$\mathrm{T}$ Threonin
I Isoleucin
V Valin
K Lysin
W Tryptophan
L Leucin
Y Tyrosin 


\section{Einleitung}

\subsection{Petrotoga und Thermotoga als Beispielorganismen für extreme Habitate}

Thermotoga maritima (DSM 3109) wurde ursprünglich aus geothermal erhitzten marinen Sedimenten bei Vulcano, Italien, isoliert. Charakteristisch für dieses Gramnegative Stäbchen mit einem GC-Gehalt von etwa $46 \%$ ist die sogenannte Toga, die an den Zellpolen ähnlich zwei Ballons aufgetrieben vorliegt. Im sequenzierten Genom von T. maritima wurde festgestellt, daß fast $24 \%$ seiner Gene am ähnlichsten zu Genen aus Archaeen sind. Bei diesem Organismus handelt es sich um ein nicht-sporenbildendes, stäbchenförmiges Bakterium (Huber et al., 1986). T. maritima ist in der Lage in einem Temperaturbereich von $55^{\circ} \mathrm{C}-90^{\circ} \mathrm{C}$ und einem $\mathrm{pH}$ Bereich von 5,5 - 9,0 zu wachsen, das Wachstumsoptimum liegt bei $80^{\circ} \mathrm{C}$ und $\mathrm{pH}$ 6,5. Es handelt sich um ein obligat heterotrophes Bakterium, welches Kohlenhydrate, wie z.B. Stärke strikt anaerob zu L(+)-Lactat, Acetat, $\mathrm{CO}_{2}$ und $\mathrm{H}_{2}$ fermentiert (HUBER et al., 1986). Verstoffwechselt werden verschiedene einfache und komplexe Substrate, wie Glukose, Saccharose, Stärke, Xylan und Cellulose (Huber und Stetter, 1992), die zu 85 \% über den Embden-Meyerhoff-Parnas-Weg (EMP-Weg) und zu 15 \% über den Entner-Doudoroff-Weg (ED-Weg) metabolisiert werden (Selig et al., 1997). Im rein fermentativ ablaufenden Stoffwechsel bildet T. maritima Acetat, $\mathrm{CO}_{2}$, $\mathrm{H} 2$ und in geringen Mengen L-Lactat.

Petrotoga miotherma wurde ursprünglich aus Erdölreservoirs in Texas und Oklahoma, USA, isoliert, ähnlich wie P. mexicana (Miranda-Tello et al., 2004). Es besitzt im Gegensatz zu P. mobilis (Lien T. et al., 1998), P. olearia (L'Haridon et al., 2002) keine Flagellen und wächst unter strikt anaeroben Bedingungen. $P$. miotherma hat mit $40 \mathrm{~mol} \%$ einen ähnlich hohen GC-Gehalt wie T. maritima. Das Temperaturoptimum liegt bei $55^{\circ} \mathrm{C}$, wohingegen in einem Bereich von $35-65^{\circ} \mathrm{C}$ Wachstum zu beobachten ist. Das Wachstums-pH-Optimum von $P$. miotherma liegt bei 6,5, Wachstum ist aber in einem Bereich von $\mathrm{pH}$ 5,5-9,0 zu verzeichnen. Verschiedene Substrate wie Arabinose, Mannose, Stärke, Maltodextrin, Glukose, 
Lactose, Sucrose, Galaktose, Maltose und Xylose werden verwertet, wobei nach Wachstum auf Glukose die Fermentationsprodukte $\mathrm{H}_{2}, \mathrm{CO}_{2}$, Acetat und Ethanol gefunden wurden. Xylan und Cellulose können nicht verwertet werden (Davey et al., 1993). P. miotherma toleriert im Gegensatz zu T. maritima zwischen $2 \%$ und $10 \%$ $\mathrm{NaCl}$. P. miotherma besitzt die Fähigkeit, elementaren Schwefel $z u \mathrm{H}_{2} \mathrm{~S} z u$ reduzieren

\subsubsection{Adaptation an extreme Habitate}

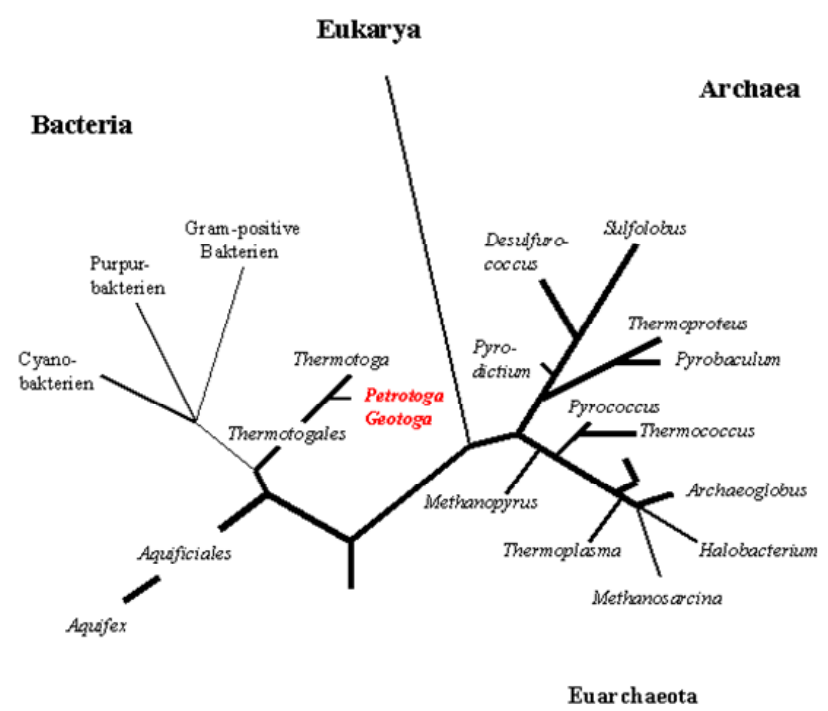

Abbildung 1: Auf 16S rRNA beruhender phylogenetischer Stammbaum. Die Positionen hyperthermophiler Organismen sind mit dicken Linien gekennzeichnet. (nach Selig et al., 1997, modifiziert)

Thermophile und noch stärker hyperthermophile Organismen stehen vor dem Problem, bei extremen Temperaturen oder $\mathrm{pH}-$ Werten ihren Stoffwechsel aufrecht erhalten zu müssen, bei denen Proteine normalerweise denaturieren. Unter solch widrigen Umständen müssen sie gegen chemische Reaktionen, wie z.B. Desaminierung, $\beta$-Eliminierungen, Hydrolyse, Oxidation und Maillard-Reaktionen, resistent sein (Daniel et al., 1996; Jaenicke und Böhm, 1998).

Wie sich die Organismen vor diesen Bedingungen schützen und die Proteine stabilisieren, ist noch nicht vollständig geklärt (Sterner und Liebl., 2001), es gibt aber Hinweise auf diverse Faktoren, die näher untersucht wurden (Jaenicke und Böhm, 1998): 
1. vermehrte Wasserstoffbrückenbindungen

2. zusätzliche hydrophobe Interaktionen und Salzbrücken

3. erhöhte Dichte oder kürzere Aminosäureketten

4. vermehrte $\alpha$-Helizes

5. Metallionenbindungen

6. Ersatz von instabilen Aminosäuren durch Glycin

7. vermehrte Anzahl von Prolin und $\beta$-verzweigte Aminosäuren in den Loops

8. weniger thermolabile Aminosäuren, wie Asparaginsäure, Glutamin, Cystein und Methionin

Die Lipide der Archaea besitzen Etherbindungen zwischen Glycerin und deren hydrophoben Seitenketten. Diese Seitenketten sind ungewöhnlicherweise verzweigt, sie bestehen aus sich wiederholenden Isopreneinheiten. Glycerindiether und Glycerintetraether sind die wesentlichen Lipidklassen der Archaea. In einem Tetraethermolekül sind die Phytanylseitenketten zweier Glycerinmoleküle kovalent miteinander verbunden (Madigan et al., 2001). Dies führt in einer Membranstruktur zu einer einlagigen Lipidschicht, die hitzebeständiger ist als die Lipiddoppelschicht der Bakterien und Eukaryoten.

Proteine aus extremen Habitaten haben ein hohes biotechnologisches Potential (Nissen et al., 1992). Bei der Verzuckerung von Stärke kommen bereits thermostabile Amylasen und Entzweigungsenzyme zum Einsatz. Durch Anwendung einer Cyclodextringlycosyltransferase (CGTase) aus dem thermophilen Bakterium Anaerobranca gottschalkii lassen sich aus Stärke sogenannte Cyclodextrine herstellen (Grote und Antranikian, 2001; Stetter et al., 1996). Diese ringförmigen Zuckermoleküle, die einen hydrophoben Hohlraum besitzen, in dem Moleküle wie z.B. Pharmaka oder Duftstoffe eingeschlossen werden können, werden u.a in der Pharmazie, Kosmetik und Lebensmittelindustrie eingesetzt (Andrade et al., 1999). In letzterer haben auch Pullulanasen und saccharolytische Amylasen Einzug gefunden, um verschiedene Zuckersirups aus Stärke herzustellen (Crabb et al., 1996). Diverse Xylanasen verwendet man zum Klären von Fruchtsäften (Ferreira-Filho et al., 1994). Xylanasen kommen bei der Tierfutterherstellung und Papierbleiche zum Einsatz. 
Hitzestabile Proteasen und Cellulasen finden als Additive in Wasch- und Geschirrspülmitteln Anwendung.

Viele Reaktionen können bei hohen Temperaturen in Kombination mit organischen Lösungsmitteln durchgeführt werden (Andrade et al., 1999). Dazu kommt, daß ein höherer Diffusionskoeffizient durch niedrigere Viskosität des Lösungsmittels wesentlich höhere Umsatzraten möglich macht (Krahe et al., 1996; Becker et al., 1997; Eichler et al., 2001). Außerdem lassen sich bestimmte Reaktionen wesentlich kostengünstiger durchführen, als auf dem klassischen Weg der chemischen Synthese, da sich kostspielige Lösungsmittel durch kostengünstiges Wasser ersetzen lassen und Reaktionen zugänglich sind, die sich sonst nur auf Umwegen verwirklichen lassen.

In der Biotechnologie haben insbesondere DNA-Polymerasen Einzug gefunden. Die Taq-DNA-Polymerase von T. aquaticus ist das klassische Enzym für die Amplifikation von DNA-Fragmenten mit PCR. Durch ihre hohe Genauigkeit bei der DNA-Synthese sind die Pfu-Polymerase aus $P$. furiosus (Lundberg et al., 1991) und KODPolymerase aus Pyrococcus sp. Strain KOD1 (Takagi et al., 1997) im Laboralltag weit verbreitet.

\subsubsection{Polysaccharide}

Die meisten in der Natur vorkommenden Kohlenhydrate liegen als Polysaccharide vor. Die auch als Glycane bezeichneten Polysaccharide unterscheiden sich in der Art ihrer sich wiederholenden Monosaccharideinheiten, in ihrer Kettenlänge, in der Form der Bindungen zwischen den Einheiten und im Ausmaß der Verzweigung. Homopolysaccharide bestehen nur aus einem einzigen Typ des entsprechenden Monomers. Dagegen enthalten Heteropolysaccharide zwei oder mehr unterschiedliche monomere Untereinheiten. Diese Polysaccharide dienen meist als Speicher für Brennstoffe (z. B. Stärke und Glycogen). Andere Homopolysaccharide dienen als Strukturelement in den Zellwänden von Pflanzen (z.B. Cellulose) oder als Außenskelett (z.B. Chitin) bei Tieren. Stärke aus Pflanzen stellt eine ubiquitär vorhandene Energiequelle dar, die ausschließlich aus a-Glukose-Einheiten aufgebaut ist. Stärke ist ein natürliches a-D-Glukan, aufgebaut aus Amylose (20-30 $\%$ ) und Amylopectin (70-80 \%). Diese wiederum setzt sich aus unverzweigten Ketten 
der D-Glukose zusammen, die a-1,4-glyosidisch miteinander verknüpft sind. Die Glukoseketten nehmen eine schraubenförmige Konformation ein. Amylopektin hat denselben Aufbau und ist zusätzlich alle ca. 25 Untereinheiten über eine 1,6-Stellung verzweigt. Amylopectin hingegen verfügt neben linearen Bereichen zusätzlich über $\alpha-$ 1,6-glycosidisch verknüpfte Verzweigungen. Neben Cellulose ist Stärke das zweithäufigste von Pflanzen produzierte Polysaccharid und dient ausschließlich als Speichersubstanz. Die Stärketypen verschiedener Herkunft unterscheiden sich bezüglich der Verzweigung, des Polymerisationsgrades und anderer Eigenschaften erheblich (SCHLEGEL, 1992).

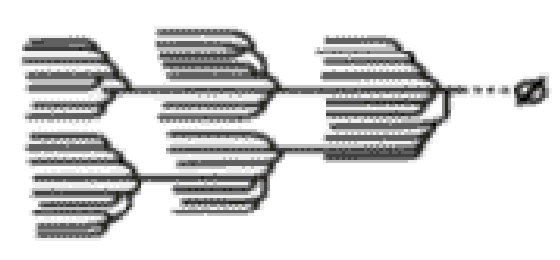

Abbildung 2: schematische Darstellung Amylopektin

Die glykosidische Bindung ist die stabilste Verknüpfung aller natürlich vorkommenden Biopolymere mit einer Halbwertszeit von ca. fünf Millionen Jahren (Wolfenden et al., 1998). Glukosidasen haben im Laufe der Evolution hochspezialisierte aktive Zentren zur Stabilisierung des Übergangszustandes gebildet, mit denen die Hydrolyse des Acetals ungefähr um den Faktor $10^{17}$ beschleunigt wird. Sie lassen sich zum einen in endo- und zum anderen in exoGlukosidasen einteilen, je nachdem ob die Modifikation an endständigen oder internen Kohlenhydraten stattfindet und zum anderen in $\alpha$ - und $\beta$-Glukosidasen, je nach Konfiguration des anomeren Zentrums der Glykoside. Eine Vielzahl an Mikroorganismen ist in der Lage Stärke als C-Quelle zu nutzen. Entscheidend für ein Wachstum auf diesem komplexen Kohlenhydrat sind extrazelluläre amylolytische Enzyme zur Spaltung der a-1,4- bzw. a-1,6-glykosidischen Bindungen. Der enzymatische Abbau von Glukanen kann in drei Typen eingeteilt werden. Im Falle der Phosphorolyse durch Phosphorylasen wird ein Glykosylrest zwischen einem Zucker- Hydroxyl und einem Phosphat-Hydroxyl übertragen. Eine weitere Art des Glukanabbaus ist die Hydrolyse einer glykosidischen Bindung durch Übertragung 
eines Glykosylrestes zwischen einem Zucker-Hydroxyl und einem OH-Rest aus dem Wasser. Die Hydrolyse wird wiederum in Retention, d.h. unter Beibehaltung der anomeren Konfiguration (z.B. a-Glukosidasen) (Brown et al., 1966; Brown et al., 1993) und Inversion, also unter Umkehrung der anomeren Konfiguration (z.B. $\beta$ Amylasen) unterschieden. Die dritte Art ist die Transglycolysierung, bei welcher die Übertragung eines Glykosylrestes von einem Zucker-Hydroxyl auf ein anderes stattfindet (Glykosyltransferasen).

Extrem thermophile Bakterien und Archaeen sind eine wichtige Quelle für interessante Biokatalysatoren (Niehaus et al., 1999). Die den hohen Temperaturen entsprechend angepaßten Enzyme besitzen ein breites Anwendungspotential in den verschiedenen Bereichen der modernen Biotechnologie. Thermostabile amylolytische Enzyme (Bragger et al., 1989) werden heute bereits in der stärkeverarbeitenden Industrie, bei der Stärkeumwandlung und der Herstellung von Zuckersirups, in der Brotherstellung und der Bierproduktion eingesetzt (Cowan, 1996, Bertoldo und Antranikian 2001).

\subsection{Intention der Arbeit}

Diese Arbeit beschäftigt sich mit drei $\alpha$-Glukosidasen aus $P$. miotherma, einer $\alpha-$ Galaktosidase aus E. coli K12 und einer a-Glukosidase aus T. maritima, die alle zur GHF4 gehören. Die Enzyme der GHF4 sind NAD+-abhängig und besitzen N-terminal gelegen eine hochkonservierte Sequenz Gly-Xxx-Gly-Ser (GXGS). Dieses Motiv hat gewisse Ähnlichkeit mit einem konservierten Sequenzmotiv des Rossmann-Fold, bestehend aus einer alternierenden Abfolge von $\beta$-Strängen und $\alpha$-Helizes ( $\beta \alpha \beta \alpha \beta)$, die eine konservierte strukturelle Region für die Bindung eines Cofaktors in Proteinen darstellt. Im klassischen Rossmann-Fold Motiv ist eine glycinreiche Sequenz innerhalb des ersten $\beta$-Strangs wichtig (GXGXXG), die über eine Schleife den ersten $\beta$-Strang mit der folgenden $\alpha$-Helix verbindet. Diese ist maßgeblich an der $\mathrm{NAD}^{+}-$ Bindung beteiligt. Neben der Abhängigkeit von $\mathrm{NAD}^{+}$benötigen die Enzyme für ihre Funktion $\mathrm{Mn}^{2+}$-Ionen und stark reduzierende Bedingungen durch Anwesenheit von DTT (Raasch et al., 2000).

Das Gen für die a-Glukosidase AglA aus T. mairtima wurde im Rahmen der Dissertation von C. Raasch kloniert und charakterisiert. Im Rahmen dieser Arbeit 
wurden weitergehende Untersuchungen zum Reaktionsmechanismus des Enzyms angestellt. Die drei a-Glukosidasen RPMI00511, RPMI00720 und RPMI01263 aus $P$. miotherma wurden heterolog in E. coli exprimiert und anschließend charakterisiert. Ebenso wurde mit der a-Galaktosidase MelA aus E. coli K12 verfahren, um sie anschließend zu kristallisieren. Zum Reaktionsmechanismus wurden NMR-, Fluoreszenz- und ESR-spektroskopische Untersuchungen vorgenommen. 


\section{Material und Methoden}

\subsection{Bakterienstämme und Plasmide}

Alle in der Arbeit verwendeten Bakterienstämme mit ihren charakteristischen Merkmalen sind in Tab. 1 aufgeführt.

Tab. 1: Verwendete Bakterienstämme

\begin{tabular}{|c|c|c|}
\hline Spezies und Stamm & Genotyp & Referenz \\
\hline $\begin{array}{l}\text { Escherichia coli BL21 } \\
\text { (DE3) }\end{array}$ & $\begin{array}{c}\text { hsdF, gal( } \lambda \mathrm{c} / \mathrm{ts} 857 \text { ind1 } \\
\text { Sam7 nin5 lacUV5-T7 } \\
\text { gene1) }\end{array}$ & $\begin{array}{l}\text { Studier und Moffat, } \\
1986\end{array}$ \\
\hline Escherichia coli XL1-Blue & $\begin{array}{l}\text { thi1, endA1, gyrA96 }\left(\mathrm{Nal}^{\mathrm{r}}\right) \text {, } \\
\text { supE44, recA1, hsdR17, } \lambda \text {, } \\
\text { lac }, \operatorname{rpsL}\left(\mathrm{Sm}^{r}\right),\left[\mathrm{F}^{`} \operatorname{traD} 36,\right. \\
\operatorname{proAB,} \operatorname{lac}^{q}, \operatorname{lacZ} \Delta M 15, \\
\left.\operatorname{Tn} 10\left(\mathrm{Tc}^{\mathrm{r}}\right)\right]\end{array}$ & Bullock et al., 1987 \\
\hline Petrotoga miotherma & Typstamm (DSM 10691) & Davey et al., 1993 \\
\hline E. coli JM 83 & $\begin{array}{l}\text { ara, } \Delta[\text { lac-proAB], } r s p L, \\
\text { [Ф80lacZ } \Delta M 15]\end{array}$ & $\begin{array}{c}\text { Yanisch- Peron et al } \\
1985\end{array}$ \\
\hline E. coli M15 & $\begin{array}{c}\text { pREP4 (Repressor- } \\
\text { Plasmid) }\end{array}$ & Qiagen (Hilden) \\
\hline
\end{tabular}


Alle in der Arbeit verwendeten Plasmide sind in Tab. 2 aufgeführt.

Tab. 2: Verwendete Plasmide

\begin{tabular}{|c|c|c|c|}
\hline Plasmid & $\begin{array}{c}\text { Relevante } \\
\text { Eigenschaften }\end{array}$ & Resistenz & Herkunft/Referenz \\
\hline pBluescript II SK & lac POZ' & Amp $^{r}$ & $\begin{array}{c}\text { Stratagene, San Diego, } \\
\text { Cal., USA }\end{array}$ \\
\hline pET-24c(+) & T7 Promoter, lacl & Kan $^{r}$ & $\begin{array}{c}\text { Stratagene, San Diego, } \\
\text { Cal., USA }\end{array}$ \\
\hline pQE-30 & ColE1, 6x His Tag & Amp $^{r}$ & Qiagen, Hilden \\
\hline pET - 21a (+) & T7 Promoter, lacl & Amp $^{r}$ & $\begin{array}{c}\text { Stratagene, San Diego, } \\
\text { Cal., USA }\end{array}$ \\
\hline pDrive & T7 Promoter, lacZ & Kan $^{r}$ & Qiagen, Hilden \\
\hline
\end{tabular}

Das Plasmid pBluescript II $\mathrm{SK}^{+}$ist ein Klonierungsvektor mit einem Ampicillinresistenzgen. Das in der Multiple- Cloning-Site (MCS) enthaltende lacZ'-Gen ermöglicht eine blau/weiß-Selektion.

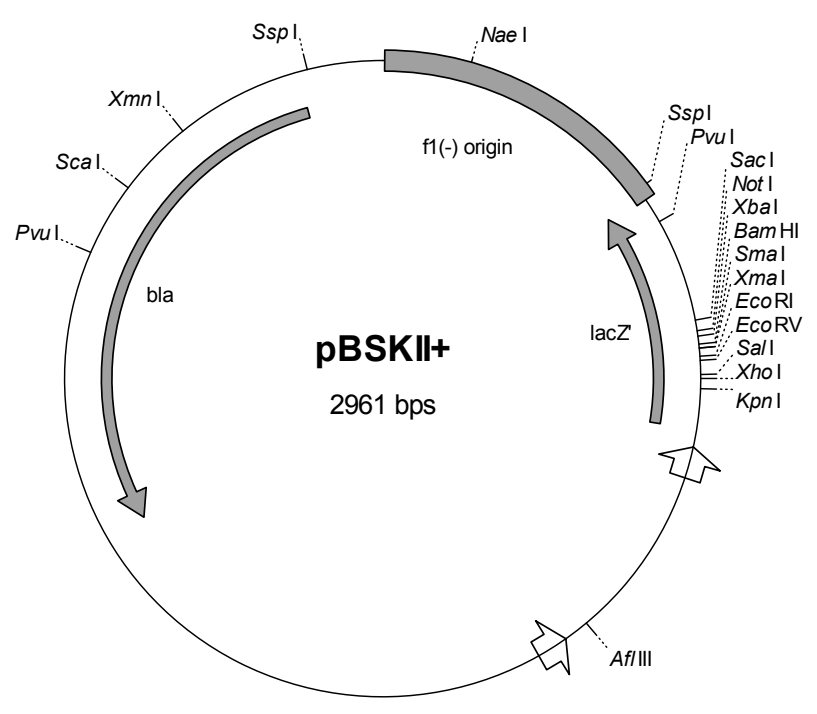


Das Plasmid pET-21a ist ein Überexpressionsvektor mit einem Ampicillinresistenzgen.

Die klonierten Gene stehen unter der Kontrolle eines starken T7Promoters und können mit IPTG induziert werden

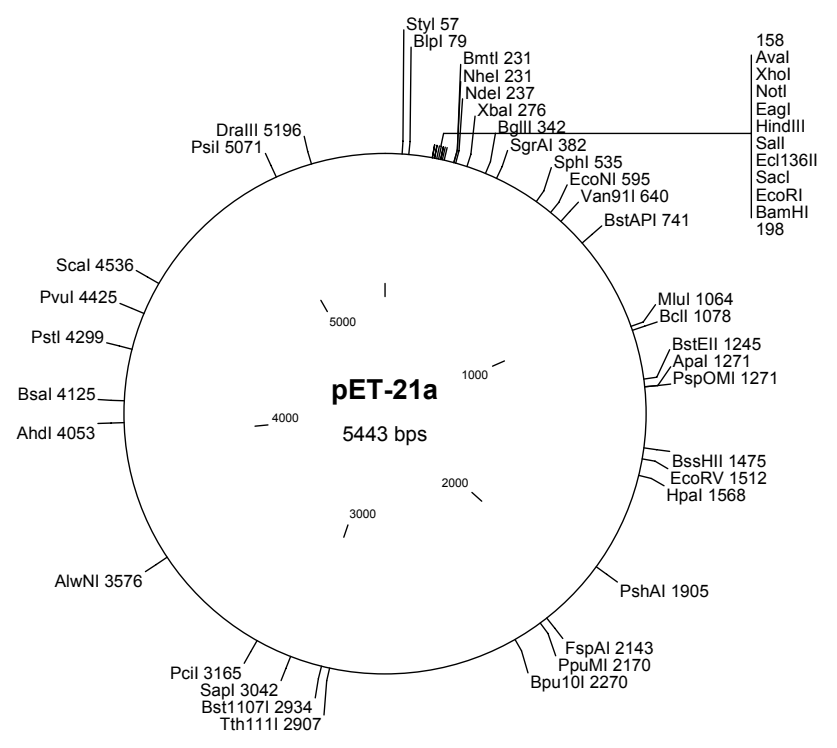

Das Plasmid pET24c ist ein Überexpressionsvektor mit einem Kanamycinresistenzgen.

Die klonierten Gene stehen unter der Kontrolle eines starken T7Promoters und können mit IPTG induziert werden.

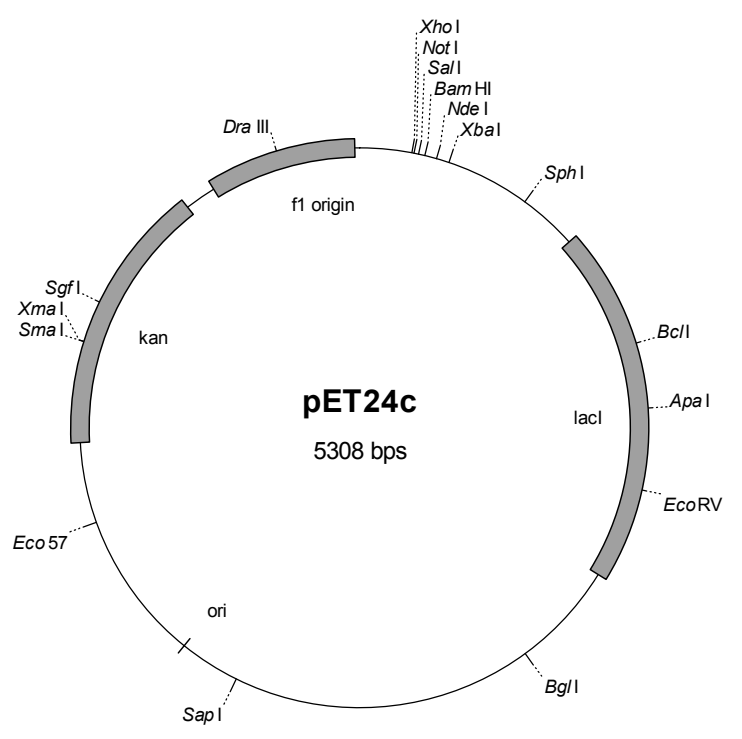


Das Plasmid pQE-30 ist ein Überexpressionsvektor mit einem Kanamycinresistenzgen. Die klonierten Gene stehen unter der Kontrolle eines starken T7Promoters und können mit IPTG induziert werden.

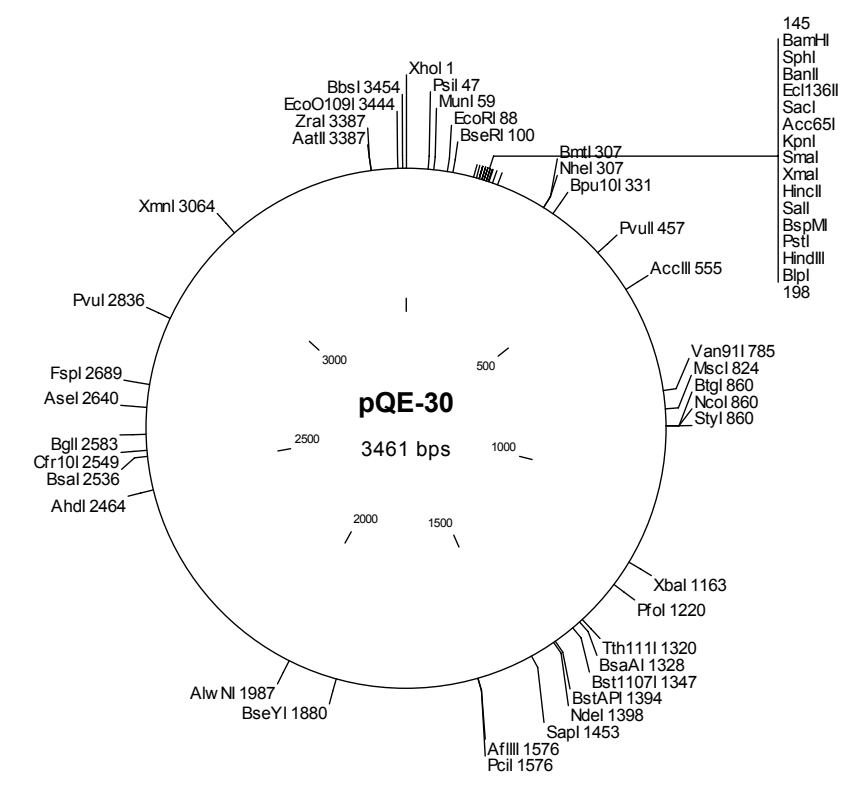

Das Plasmid pDrive ist ein Klonierungsvektor mit einem Ampicillinresistenzgen.

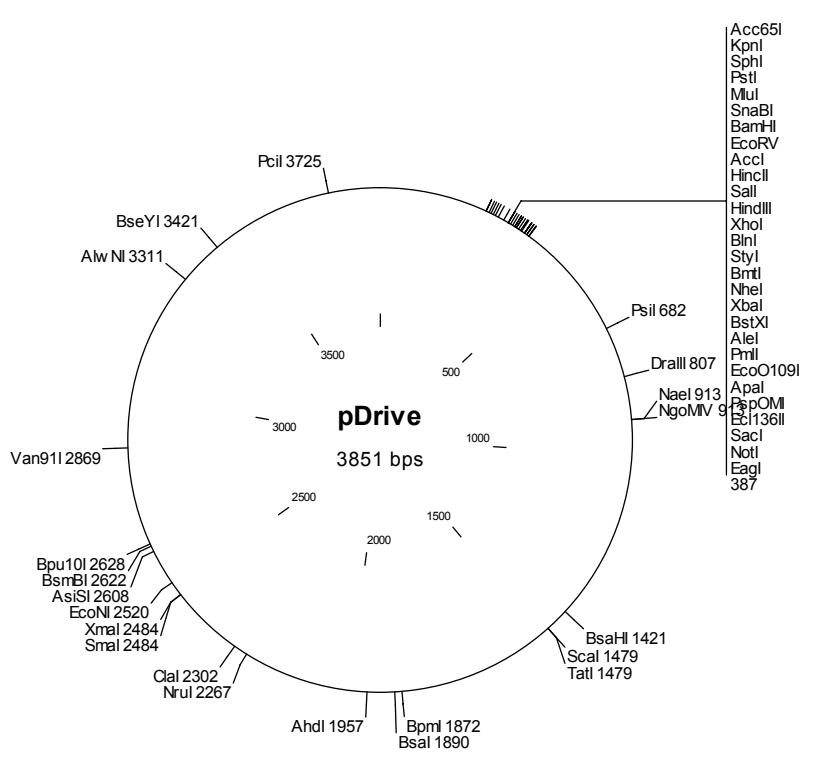




\subsection{Zellanzucht}

\subsubsection{Nährmedien}

Alle Medien wurden, falls nicht anders angegeben, durch 20-minütiges Autoklavieren sterilisiert.

2.2.1.1. Nährmedien für E. coli-Stämme:

LB-Medium (Sambrook et al., 1989):

$\begin{array}{ll}\text { Trypton } & 10 \mathrm{~g} \\ \text { Hefeextrakt } & 5 \mathrm{~g} \\ \mathrm{NaCl} & 5 \mathrm{~g} \\ \mathrm{H}_{2} \mathrm{O}_{\text {bidest }} & \text { ad } 1000 \mathrm{ml}\end{array}$

\section{LB-Agarplatten:}

Für LB-Agarplatten wurde dem Medium Agar in einer Endkonzentration von 1,5\% $(w / v)$ zugegeben.

Anaerob-Medium (mündl. Mitteilung)

$\begin{array}{ll}\text { Trypton } & 32 \mathrm{~g} \\ \text { Hefe } & 20 \mathrm{~g} \\ \mathrm{Na}_{2} \mathrm{HPO}_{4} & 6 \mathrm{~g} \\ \mathrm{KH}_{2} \mathrm{PO}_{4} & 3 \mathrm{~g} \\ \mathrm{NaCl} & 0,5 \mathrm{~g} \\ \text { Glukose } & 3,6 \mathrm{~g} \\ \text { L-Tryptophan } & 0,5 \mathrm{~g} \\ \text { Spurenelementelösung (Widdel et al., 1984) } 10 \mathrm{ml} \\ \mathrm{H}_{2} \mathrm{O}_{\text {bidest }} & \text { ad } 1000 \mathrm{ml}\end{array}$


Die Erlenmeyerkolben wurden unter aeroben Bedingungen angeimpft und mit einem Gummiestopfen luftdicht verschlossen. Die Kultur hat sich anschließend selbst anaerobisiert.

\subsubsection{Nährmedien für $P$. miotherma:}

Grundmedium (Davey et al., 1993):

$\begin{array}{ll}\text { Stärke } & 1 \mathrm{~g} \\ \text { Hefeextrakt } & 0,5 \mathrm{~g} \\ \mathrm{NaCl} & 33,3 \mathrm{~g} \\ \mathrm{CaCl}_{2} \times 2 \mathrm{H}_{2} \mathrm{O} & 7,6 \mathrm{~g} \\ \mathrm{MgCl}_{2} \times 6 \mathrm{H}_{2} \mathrm{O} & 2,5 \mathrm{~g} \\ \mathrm{Pipes} & 6,8 \mathrm{~g} \\ \mathrm{NH}_{4} \mathrm{Cl} & 0,5 \mathrm{~g} \\ \mathrm{Spurenelementelösung} & 1 \mathrm{ml} \\ \text { Resazurin } & 1 \mathrm{mg} \\ \alpha-G l y c e r o p h o s p h a t & 0,4 \mathrm{~g} \\ \text { Ascorbinsäure } & 0,02 \% \\ \text { Cystein- } \mathrm{HCl} & 0,01 \% \\ \mathrm{H}_{2} \mathrm{O}_{\text {bidest }} & \mathrm{ad} 1000 \mathrm{ml}\end{array}$

Spurenelementelösung (Widdel et al., 1984):

$\begin{array}{ll}\mathrm{HCl}(25 \%) & 10 \mathrm{ml} \\ \mathrm{FeCl}_{2} \times 4 \mathrm{H}_{2} \mathrm{O} & 1,5 \mathrm{~g} \text { in HCl lösen } \\ \mathrm{CoCl}_{2} \times 6 \mathrm{H}_{2} \mathrm{O} & 190 \mathrm{mg} \\ \mathrm{MnCl}_{2} \times 4 \mathrm{H}_{2} \mathrm{O} & 100 \mathrm{mg} \\ \mathrm{ZnCl}_{2} & 70 \mathrm{mg} \\ \mathrm{H}_{3} \mathrm{BO}_{3} & 6 \mathrm{mg} \\ \mathrm{Na}_{2} \mathrm{MoO}_{4} \times 2 \mathrm{H}_{2} \mathrm{O} & 36 \mathrm{mg} \\ \mathrm{NiCl}_{2} \times 6 \mathrm{H}_{2} \mathrm{O} & 24 \mathrm{mg} \\ \mathrm{CuCl}_{2} \times 2 \mathrm{H}_{2} \mathrm{O} & 2 \mathrm{mg} \\ \mathrm{H}_{2} \mathrm{O}_{\text {bidest }} & \text { ad } 1000 \mathrm{ml}\end{array}$


Für die Anzucht von Petrotoga miotherma, einem strikt anaeroben Organismus, musste das Medium sauerstofffrei gemacht werden. Dazu wurde es nach Verschließen der Serumflasche mit einem Druck von 1 bar je dreimal ent- bzw. mit Stickstoff begast. Vor dem Autoklavieren musste durch Abziehen der Schläuche von den Kanülen der Druck in den Flaschen auf Null gebracht werden. Der zu Beginn violette Redoxindikator Resazurin entfärbt sich unter anaeroben Bedingungen beim Autoklavieren. Beim Eindringen von Sauerstoff schlägt er nach rot um.

Die Spurenelementelösung wurde nach dem Autoklavieren des Mediums zugegeben.

\subsubsection{Antibiotika und andere Medienzusätze}

Von den in Tab. 3 aufgeführten Antibiotika und Medienzusätzen wurden Stammlösungen angesetzt, sterilfiltriert und bei $-20^{\circ} \mathrm{C}$ gelagert. Die Lösungen wurden dem autoklavierten Medium nach dessen Abkühlung auf unter $55^{\circ} \mathrm{C}$ in entsprechender Menge zugegeben.

Tab. 3: Konzentration der verwendeten Antibiotika und der weiteren Medienzusätze

\begin{tabular}{|c|c|c|c|}
\hline Substanz & Stammlösung $[\mathrm{mg} / \mathrm{ml}]$ & Lösungsmittel & Endkonzentration \\
\hline Ampicillin & 100 & $\mathrm{H}_{2} \mathrm{O}_{\text {bidest }}$ & $100 \mu \mathrm{g} / \mathrm{ml}$ \\
\hline Kanamycin & 50 & $\mathrm{H}_{2} \mathrm{O}_{\text {bidest }}$ & $25 \mu \mathrm{g} / \mathrm{ml}$ \\
\hline IPTG & 24 & $\mathrm{H}_{2} \mathrm{O}_{\text {bidest }}$ & $24 \mu \mathrm{g} / \mathrm{ml}$ \\
\hline X-Gal & 20 & Dimethylformamid & $64 \mu \mathrm{g} / \mathrm{ml}$ \\
\hline
\end{tabular}

\subsubsection{Zellanzucht}

Die Anzucht von E. coli-Stämmen erfolgte schwenkend und aerob bei $37^{\circ} \mathrm{C}$. Flüssigkulturen bis zu $5 \mathrm{ml}$ wurden direkt mit einer Einzelkolonie von der Agarplatte, größere Anzuchten mit 2-3 \% des Volumens einer gut angewachsenen Vorkultur angeimpft. Plasmidtragende Stämme wurden durch Zugabe des entsprechenden Antibiotikums unter Selektionsdruck gehalten. Die Kultivierung auf Agarplatten erfolgte bei $37^{\circ} \mathrm{C}$ über Nacht. 
Zur Expression rekombinanter Proteine, die unter Kontrolle des lac-Promoters stehen, wurden Kulturen bei einer OD $_{600}$ von 0,6-0,8 mit IPTG induziert.

Die Anzucht von P. miotherma erfolgte in Serumflaschen unter aneroben Bedingungen bei $55^{\circ} \mathrm{C}$ für etwa 5 Tage. Da sich Medienbestandteile schnell absetzen und somit für die Bakterien schwieriger zugänglich sind, wurden die Kulturen unter Schütteln inkubiert.

\subsubsection{Stammhaltung}

Für Zeiträume von bis zu vier Wochen wurden E. coli-Stämme auf LB-Agarplatten bei $4^{\circ} \mathrm{C}$ gelagert. Für eine längere Konservierung wurden $500 \mu \mathrm{l}$ einer gut gewachsenen Flüssigkultur (gegebenenfalls unter Selektionsdruck) mit $500 \mu \mathrm{l}$ Glycerin (87 \% (w/v)) vermischt und bei $-70^{\circ} \mathrm{C}$ gelagert.

Zur Stammhaltung von $P$. miotherma konnte eine gut bewachsene Serumflasche über mehrere Monate hinweg bei $4^{\circ} \mathrm{C}$ gelagert und daraus neu beimpft werden.

\subsubsection{Bestimmung der optischen Dichte}

Die optische Dichte von Flüssigkulturen wurde in Einmalküvetten mit einer Schichtdicke von $1 \mathrm{~cm}$ bei einer Wellenlänge von $600 \mathrm{~nm}$ bestimmt (Pharmacia Biotec; Ultraspec 3000). Als Referenz wurde unbewachsenes Medium verwendet. Bei OD-Werten über 0, 6 wurden die Proben mit dem entsprechenden Medium verdünnt, da bei Werten über 0,6 keine lineare Beziehung zwischen der Bakterienzahl $/ \mathrm{ml}$ und $\Delta \mathrm{E}_{600}$ gegeben ist.

\subsection{Molekulargenetische Arbeitstechniken}

\subsubsection{Grundlegende Techniken für das Arbeiten mit DNA}

\subsubsection{Behandlung von Materialien und Lösungen für das Arbeiten mit Nukleinsäuren}

Um eine Kontamination mit Nukleasen zu vermeiden, wurden alle thermostabilen Geräte, Lösungen und Materialien autoklaviert. Nicht autoklavierbare Materialien 
sowie der Arbeitsplatz wurden mit 70 \%-igem (v/v) Ethanol behandelt. Thermolabile Lösungen wie Antibiotika wurden sterilfiltriert.

\subsubsection{Phenol/Chloroform/lsoamylalkohol-Extraktion}

Zur Entfernung von Proteinen und anderen Verunreinigungen aus DNA-Lösungen wurden diese i.d.R. mit einem Volumen eines 25:24:1 (v/v/v)-Gemisches aus Phenol, Chloroform und Isoamylalkohol versetzt und kräftig gemischt. Nach zehnminütiger Zentrifugation bei 13.000 Upm wurde die obere wässrige, DNA enthaltende Phase vorsichtig abgenommen. Zur Entfernung von Phenolresten wurde anschließend mit einem Volumen Chloroform/Isoamylalkohol (24:1, (v/v)) extrahiert.

\subsubsection{Fällung von DNA}

\subsubsection{Fällung von DNA mit Ethanol}

Dazu wurde die DNA-Lösung mit 2,5 Volumen eiskaltem unvergälltem Ethanol (96 \% $(\mathrm{v} / \mathrm{v}))$ versetzt. Nach Durchmischung erfolgte eine Lagerung bei $-20^{\circ} \mathrm{C}$ für $0,5-12 \mathrm{~h}$. Die gefällte DNA wurde durch 30-minütige Zentrifugation bei $13.000 \mathrm{Upm}$ und $4^{\circ} \mathrm{C}$ pelletiert. Das Pellet wurde anschließend mit $70 \%$-igem (v/v) Ethanol (mindestens $500 \mu \mathrm{l})$ gewaschen, in der Vakuumzentrifuge (Speed Vac ${ }^{\circledR}$ Plus SC110A, Savant) getrocknet und in 30-50 $\mu$ l sterilem $\mathrm{H}_{2} \mathrm{O}_{\text {bidest }}$ aufgenommen.

\subsubsection{Fällung von DNA mit Isopropanol}

Die DNA-Lösung wurde mit 0,1 Volumen einer $3 \mathrm{M} \mathrm{Na-Acetat-Lösung}(\mathrm{pH} \mathrm{5,2)} \mathrm{und}$ 0,7 Volumen Isopropanol versetzt. Die Fällung erfolgte für $15 \mathrm{~min}$ bei Raumtemperatur. Die gefällte DNA wurde durch 30-minütige Zentrifugation bei 13.000 Upm und $4^{\circ} \mathrm{C}$ pelletiert. Das Pellet wurde anschließend mit $70 \%$-igem (v/v) Ethanol (mindestens $500 \mu \mathrm{l}$ ) gewaschen, in der Vakuumzentrifuge (Speed $\mathrm{Vac}^{\circledR}$ Plus SC110A, Savant) getrocknet und in 30-50 $\mu$ l sterilem $\mathrm{H}_{2} \mathrm{O}_{\text {bidest }}$ aufgenommen. 


\subsubsection{Isolierung von DNA}

\subsubsection{Isolierung genomischer DNA}

Durchführung:

Für die Isolierung genomischer DNA wurde eine $10 \mathrm{ml}$-Kultur durch fünfminütige Zentrifugation bei $13.000 \mathrm{Upm}$ und $4^{\circ} \mathrm{C}$ geerntet. Das Pellet wurde in $100 \mu \mathrm{l} 1 \mathrm{M}$ $\mathrm{NaCl}$-Lösung resuspendiert und $1 \mathrm{~h}$ auf Eis inkubiert. Anschließend erfolgte eine Zentrifugation für $20 \mathrm{~min}$ bei $13.000 \mathrm{Upm}$ und $4^{\circ} \mathrm{C}$. Nach Aufnahme des Pellets in $500 \mu \mathrm{l}$ TE-Saccharose-Puffer $(20 \%(\mathrm{w} / \mathrm{v}))$ wurden $400 \mu \mathrm{L}$ DEP und $100 \mu \mathrm{l}$ SDSLösung (1\% Endkonzentration) zugegeben. Die Lyse erfolgte für $2-4 \mathrm{~h}$ bei $37^{\circ} \mathrm{C}$. Der DNA-Extrakt wurde anschließend mit $100 \mu$ Sarkosyl-ProteinaseK-Lösung versetzt und über Nacht bei $37^{\circ} \mathrm{C}$ unter Schütteln inkubiert. Um die DNA-Lösung aufzureinigen erfolgte eine Phenol-Chloroform-Extraktion, wobei $20 \mathrm{~min}$ auf Eis inkubiert wurde, bevor die Probe für $20 \mathrm{~min}$ bei $13.000 \mathrm{Upm}$ und $4^{\circ} \mathrm{C}$ zentrifugiert wurde. Die Extraktion wurde im Anschluss daran wiederholt. Der Überstand wurde vorsichtig abgehoben, in einen geeigneten Dialyseschlauch überführt, und für 5-7 $\mathrm{h}$ bei $4^{\circ} \mathrm{C}$ gegen $0,5 \mathrm{I}$ TE-Puffer dialysiert. Im Anschluss daran erfolgte eine Dialyse gegen 1 I TE-Puffer bei $4^{\circ} \mathrm{C}$ über Nacht.

\section{Lösungen:}

\section{TE-Puffer:}

Tris- $\mathrm{HCl} \quad 10 \mathrm{mM}$

EDTA $\quad 1 \mathrm{mM}$

$\mathrm{pH} 8,0$

TE-Saccharose-Puffer :

Saccharose $20 \mathrm{~g}$

TE-Puffer $\quad 100 \mathrm{ml}$

DNA-Extraktionspuffer (DEP):

Tris $100 \mathrm{mM}$

$\mathrm{Na}_{2}$ EDTA $\quad 100 \mathrm{mM}$

$\mathrm{Na}_{2} \mathrm{HPO}_{4} \quad 100 \mathrm{mM}$

$\mathrm{NaCl} \quad 1,5 \mathrm{M}$ 
CTAB $\quad 1 \%$

$\mathrm{pH} 8,0$

Sarkosyl-Lösung:

Sarkosyl $\quad 5 \mathrm{~g}$

$\mathrm{H}_{2} \mathrm{O}_{\text {bidest }} \quad 100 \mathrm{ml}$

ProteinaseK-Lösung:

$20 \%(w / v)$, steril filtrieren

Sarkosyl-ProteinaseK-Lösung:

Sarkosyl-Lösung $1 \mathrm{ml}$

ProteinaseK-Lösung $\quad 25 \mu \mathrm{l}$

\subsubsection{Plasmidisolierung durch alkalische Lyse}

Grundlegend für diese Methode der Plasmidisolierung (nach Birnboim und Doly, 1979, mod.) ist, daß chromosomale DNA in einem pH-Bereich zwischen 12 und 12,5 denaturiert, während die als ccc-Form vorliegende Plasmid-DNA weitestgehend erhalten bleibt. Bei niedrigen Temperaturen erfolgt unter der Einwirkung von SDS und $\mathrm{NaOH}$ (Puffer 2) eine Lyse der Bakterienzellwand und die Denaturierung der hochmolekularen chromosomalen DNA. Durch einen hohen $\mathrm{pH}-$ Wert sowie durch EDTA in Puffer 1 wird DNase-Aktivität verhindert. Bei der Zugabe von Puffer 3 erfolgt eine Neutralisierung, welche eine Aggregation der chromosomalen DNA bewirkt. Weiterhin kommt es zur Präzipitation von Protein-SDS-Komplexen und hochmolekularer RNA. Durch Zentrifugation sedimentieren die Makromoleküle und hochmolekularen Komplexe, während die Plasmid-DNA im Überstand bleibt, aus dem sie mit Hilfe von Ethanol (2.3.1.4) oder Isopropanol (2.3.1.5) gefällt werden kann.

Durchführung:

Eine $5 \mathrm{ml}$ Kultur wurde unter Selektionsdruck über Nacht bei $37^{\circ} \mathrm{C}$ angezogen. Anschließend wurden $3 \mathrm{ml}$ der Zellen in einem E-Cup durch Zentrifugation (13.000 Upm, 30-60 s) geerntet. Das Pellet wurde in $200 \mu \mathrm{l} 1$ (mit RNase A) vollständig 
resuspendiert. Durch Zugabe von $200 \mu \mathrm{l}$ P2 und vorsichtigem Schwenken bei RT wurden die Zellen lysiert. Die Lyse sollte jedoch nicht länger als 5 min erfolgen. Zur Fällung von Proteinen und chromosomaler DNA wurde der Ansatz mit $200 \mu \mathrm{l}$ P3 neutralisiert, 2x geschwenkt und für 5 min auf Eis inkubiert. Im Anschluss wurde die Probe bei $13.000 \mathrm{Upm}$ und $4^{\circ} \mathrm{C}$ für 30 min zentrifugiert. Der Überstand wurde in ein neues E-Cup überführt, bei Bedarf mit Phenol extrahiert (II 3.1.2) und anschließend mit Ethanol (2.3.1.4) oder Isopropanol (2.3.1.5) gefällt.

\section{Lösungen:}

P1 (TE-Puffer):

Tris- $\mathrm{HCl} \quad 50 \mathrm{mM}$

EDTA $\quad 10 \mathrm{mM}$

RNase A $\quad 1 \mathrm{mg} / \mathrm{ml}$

$\mathrm{pH} 8,0$

Es wurde eine Rnase A-Stammlösung angesetzt. Gelöst wurde die RNase A in 10 $\mathrm{mM}$ Tris- $\mathrm{HCl}$ und $15 \mathrm{mM} \mathrm{NaCl}(\mathrm{pH} \mathrm{7,5)}$ oder in $50 \mathrm{mM}$ Tris-HCl und $10 \mathrm{mM}$ EDTA (pH 8,0). Die Stammlösung wurde $15 \mathrm{~min}$ im Wasserbad gekocht und konnte nach dem Abkühlen bei $-20^{\circ} \mathrm{C}$ gelagert werden.

Die Zugabe der RNase zum TE-Puffer erfolgte nach dem Autoklavieren. Der Puffer konnte anschließend bei $4^{\circ} \mathrm{C}$ gelagert werden.

P2 (Lysis-Puffer):

$\begin{array}{ll}\mathrm{NaOH} & 0,2 \mathrm{M} \\ \mathrm{SDS} & 1 \%(\mathrm{w} / \mathrm{v})\end{array}$

P3 (Neutralisationspuffer):

Kaliumacetat $3 \mathrm{M}$

$\mathrm{pH}$ mit Eisessig auf 5,5 einstellen

\subsubsection{Plasmidisolierung durch „QIAprep Spin Miniprep“}

Dieser Plasmidisolierungskit der Firma QIAGEN (Hilden) ermöglicht die Präparation kleinerer Mengen hochreiner DNA (etwa $20 \mu \mathrm{g}$ aus 1,5 ml ü.N.-Kultur von E. coli). 
Die Methode basiert ebenfalls auf der alkalischen Lyse in Verbindung mit der Verwendung einer Säule, welche selektiv Plasmid-DNA bindet. Proteine und andere zelluläre Verunreinigungen können nicht binden und werden somit abgetrennt. Die Aufreinigung erfolgte gemäß der vom Hersteller mitgelieferten Versuchsvorschrift.

\subsubsection{Agarose-Gelelektrophorese}

\subsubsection{Analytische Agarose-Gelelektrophorese}

Die Agarose-Gelelektrophorese ist eine Standardmethode zur Auftrennung von DNAFragmenten nach Molekülgröße. Die negativ geladenen Nukleinsäuren wandern im elektrischen Feld zur Anode, wobei die Migrationsgeschwindigkeit der DNAFragmente von mehreren Faktoren abhängt, z.B. der Größe der Gelporen (bestimmt durch die Agarosekonzentration), der angelegten Spannung und der Salzkonzentration des Puffers. Die Auftrennung der DNA-Fragmente erfolgt entsprechend ihrer Größe, da die Laufgeschwindigkeit der Fragmente umgekehrt proportional zu ihrer Molekularmasse ist.

\section{Durchführung:}

Für die gelelektrophoretische Auftrennung von Nukleinsäuren wurden horizontale Elektrophoresekammern (Hoefer ${ }^{\circledR}$ HE33 Mini Horizontal Submarine Unit; Pharmacia Biotech) verwendet. Die Agarose-Gele wurden aus 0,8 \% (w/v) Agarose in 1 x TAEPuffer, welcher zugleich auch als Elektrophoresepuffer diente, hergestellt. Die DNAProben wurden im Verhältnis 5:1 mit DNA-Auftragspuffer gemischt, der sowohl zur Beschwerung der Proben als auch zur Markierung der Lauffront bei 500 bp diente. Die Auftrennung erfolgte bei einer konstanten Spannung von 70-100 V. Nach Beendigung der Gelelektrophorese wurden die Nukleinsäuren im Gel in einer wässrigen Ethidiumbromid-Lösung $(1 \mu \mathrm{g} / \mathrm{ml})$ für 10-20 min gefärbt und anschließend im Wasserbad kurz entfärbt. In der Gel-Dokumentationsanlage (BioRad ${ }^{\circledR}$ GelDoc 1000) konnte die DNA bei UV-Licht durch das eingelagerte Ethidiumbromid sichtbar gemacht, photographisch dokumentiert und eventuell nachträglich bearbeitet werden (Multi-Analyst-V.1.1.1.-Dokumentationsprogramm). 


\section{Lösungen:}

50x TAE-Puffer:

Tris- $\mathrm{HCl} 242 \mathrm{~g}$

Eisessig $\quad 57,1 \mathrm{ml}$

$\mathrm{Na}_{2}$ EDTAx2 $\mathrm{H}_{2} \mathrm{O} \quad 37,2 \mathrm{~g}$

$\mathrm{H}_{2} \mathrm{O}_{\text {bidest }} \quad$ ad $1000 \mathrm{ml}$

$\mathrm{pH} \mathrm{8,5}$

10x DNA-Auftragspuffer (Beschwerlösung):

Ficoll $400 \quad 7,5 \mathrm{~g}$

Bromphenolblau $\quad 50 \mathrm{mg}$

$\operatorname{EDTA}(0,5 \mathrm{M}) \quad 10 \mathrm{ml}$

$\mathrm{H}_{2} \mathrm{O}_{\text {bidest }} \quad$ ad $50 \mathrm{ml}$

Ethidiumbromid-Färbebad:

$250 \mu$ l einer $2 \mathrm{mg} / \mathrm{ml}$ Ethidiumbromidlösung wurden in $500 \mathrm{ml} \mathrm{H} \mathrm{O}_{\text {bidest }}$ gelöst.

\subsubsection{Präparative Agarose-Gelelektrophorese}

Prinzipiell wurde bei der präparativen Gelelektrophorese wie bei dem unter II 3.3.1 beschriebenen analytischen Verfahren vorgegangen. Um Interkalations- und UVinduzierte Schäden zu minimieren, wurden der Färbeschritt und die anschließende UV-Exposition möglichst kurz gehalten. Nach der Elektrophorese wurden definierte Banden mit einem Skalpell aus dem Gel herausgeschnitten. Zur Präparation der DNA aus dem Gelstück wurde das „QIAQuick Gel Extraction Kit“ (QIAGEN, Hilden) verwendet. Alle benötigten Protokolle und Reagenzien lagen dem Kit bei.

\subsubsection{Größen- und Konzentrationsbestimmung von DNA- Fragmenten in Agarosegelen}

Die Bestimmung der Größe von DNA-Fragmenten erfolgte nach Auftrennung im Agarosegel anhand der Laufstrecken eines mitaufgetrennten internen Standards. Als Größenstandard diente dabei eine 1 kb-Leiter (Gene Ruler ${ }^{\mathrm{TM}} 1 \mathrm{~kb}$ DNA Ladder, MBI 
Fermentas), welche in einer Konzentration von $0,05 \mu \mathrm{g} / \mu \mathrm{l}$ eingesetzt wurde. Die Fragmentgrößen der 1 kb-Leiter sind in Tab. 4 aufgeführt.

Tab. 4: Fragmentgrößen der 1kb-Leiter

\begin{tabular}{|l|c|c|c|c|c|c|c|c|c|c|c|c|c|c|}
\hline Fragment & 1 & 2 & 3 & 4 & 5 & 6 & 7 & 8 & 9 & 10 & 11 & 12 & 13 & 14 \\
\hline Größe [kb] & 10 & 8 & 6 & 5 & 4 & 3,5 & 3 & 2,5 & 2 & 1,5 & 1 & 0,75 & 0,5 & 0,25 \\
\hline
\end{tabular}

\subsubsection{Polymerase-Kettenreaktion (PCR)}

Bei der PCR wird ein DNA-Molekül (Template) in vitro vervielfältigt. Falls erforderlich, werden die zu amplifizierenden DNA-Bereiche mit neuen Restriktionsschnittstellen versehen, weshalb die Primer entsprechend der neuen Schnittsequenzen Fehlpaarungen zum Matrizenstrang aufweisen. Das zwischen den beiden Primern liegende DNA-Stück wird über das folgende, mehrfach zu durchlaufende Zyklenschema amplifiziert:

Zunächst wird die DNA denaturiert, wobei sich die beiden Stränge der Template-DNA trennen. Danach hybridisieren die Oligonukleotid-Primer bei optimaler Bindungstemperatur an die einzelsträngige Template-DNA. Durch Erhöhung der Temperatur auf das entsprechende Temperaturoptimum der DNA-Polymerase werden die Primer verlängert, bis wieder eine doppelsträngige DNA vorliegt, die der ursprünglichen Template-DNA gleicht.

Die Hybridisierungs- (Annealing-) Temperatur ist von der Länge und der Zusammensetzung der Oligonukleotid-Primer abhängig. Je höher der G+C-Gehalt ist, desto höher liegt die Annealingtemperatur. Es gilt folgende Näherung:

$\mathrm{T}_{\mathrm{A}}\left({ }^{\circ} \mathrm{C}\right)=69,3+0,41 \times(\% \mathrm{GC})-(650 /$ Länge Oligos $)$

Zur Durchführung der PCR-Läufe wurden programmierbare Thermoblöcke (Primus 96 ${ }^{\text {plus }}$, MWG-Biotech) verwendet. Die Primer wurden bei der MWG-Biotech AG (Ebersberg) in Auftrag gegeben. Für die PCR wurden die Taq-Polymerase (Eigenherstellung) oder Pfu-Polymerase (Promega) verwendet oder KODPolymerase (Novagen). 
Die PCR wurde zur Amplifikation der zu klonierenden P. miotherma DNA und der zu klonierenden E. coli DNA und zur späteren Überprüfung der Klone eingesetzt.

Zur Amplifikation der potentiellen Glukosidase-Gene aus P. miotherma wurde die KOD-Polymerase verwendet, da diese eine „proof-reading“-Funktion besitzt, wodurch die Fehlerrate bei der Elongation gegenüber der Taq-Polymerase um ein Wesentliches verringert wird. Die Reinigung des für die Klonierung einzusetzenden PCR-Amplifikats von Primern, Polymerase und evtl. Nebenprodukten erfolgte durch präparative Agarose-Gelelektrophorese und Aufreinigung mit Hilfe eines Kits (2.3.2.3).

Primer für die PCR-Amplifikation des MelA-Gens aus genomischer E. coli-DNA sind in Tabelle 5 aufgeführt:

Tabelle 5: Primer für die Amplifizierung des MelA-Gens

\begin{tabular}{|l|l|c|}
\hline Bezeichnung & \multicolumn{1}{|c|}{ Primer-Sequenz $\left(5^{\prime} \rightarrow 6^{\prime}\right)$} & Schnittstelle \\
\hline MelA_forward & $\begin{array}{l}\text { GGG GGA TCC ATG ATG TCT GCA CCC } \\
\text { AAA ATT ACA }\end{array}$ & BamHI \\
\hline MelA_reverse & $\begin{array}{l}\text { GGG AAG CTT TTA ACG GTG CAA CCA } \\
\text { GCC }\end{array}$ & HindIII \\
\hline
\end{tabular}


Der PCR-Ansatz ist in Tabelle 6 aufgeführt.

Tabelle 6: PCR-Ansatz für die Amplifizierung des MelA-Gens

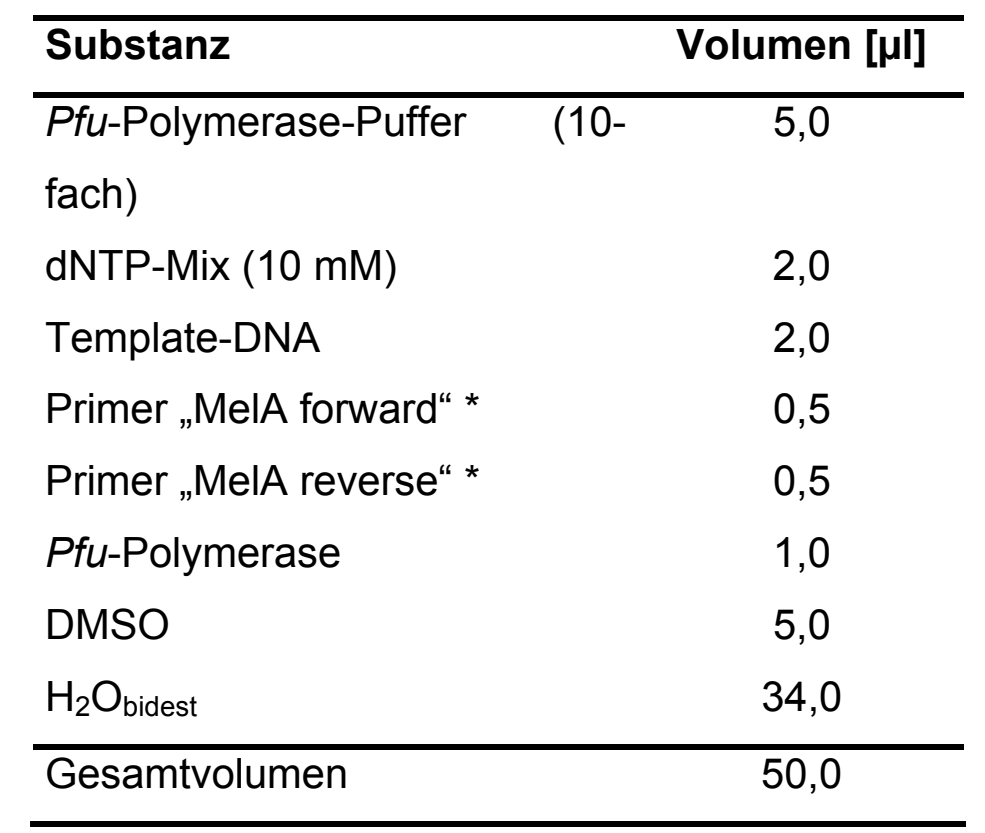

Das Programm für die PCR ist in Tabelle 7 aufgeführt.

Tabelle 7: Programm für die PCR des MelA-Gens

$\left.\begin{array}{cccc}\hline & \text { Temperatur }\left[{ }^{\circ} \mathbf{C}\right] & \text { Zeit [min] } & \text { Reaktion } \\ & & & \\ \hline 1 & 95,0 & 10: 00 & \text { Denaturierung } \\ 2 & 95,0 & 1: 00 & \text { Denaturierung } \\ 3 & 40,0-50,0 \text { Gradient } & 0: 45 & \text { Primer-Annealing } \\ 4 & 72,0 & 2: 00 & \text { Primer-Verlängerung } \\ 5 & 72,0 & 10: 00 & \text { End-Verlängerung } \\ 6 & 8,0 & \infty & \text { Kühlen }\end{array}\right\} 34 x$




\subsubsection{A-Überhänge an Pfu-PCR-Produkt}

Der pDrive Cloning Vektor ist Teil eines Qiagen PCR Cloning Kits, welches einen linearisierten Klonierungsvektor enthält, der an seinen Enden einen einzelsträngigen U-Überhang trägt. Durch diese „sticky ends“ wird eine hochspezifische Hybridisierung mit A-Überhang tragenden PCR-Fragmenten gewährleistet. AÜberhänge werden durch Amplifikation mit Taq-Polymerase und anderen DNAPolymerasen ohne Korrekturleseaktivität erhalten, nicht jedoch durch Amplifikation mit der hier verwendeten Pfu-Polymerase, die Korrekturleseaktivität aufweist. Deshalb werden auf folgende Weise die A-Überhänge angefügt:

$\begin{array}{lc}\text { Pfu-Produkt (aus Gelextraktion 2.3.3.2) } & 50 \mu \mathrm{l} \\ \text { Taq-Polymerase } & 2 \mathrm{U} \\ \text { dATP }(100 \mathrm{mM}) & 1 \mu \mathrm{l} \\ \text { Puffer (10x) } & 10 \mu \mathrm{l} \\ \mathrm{H}_{2} \mathrm{O}_{\text {bidest }} & 38 \mu \mathrm{l}\end{array}$

Diesen Ansatz lässt man für $1 \mathrm{~h}$ bei $72^{\circ} \mathrm{C}$ inkubieren und arbeitet es wie folgt auf. Man überschichtet den Ansatz mit $100 \mu$ Chloroform, schüttelt es vorsichtig und zentrifugiert anschließend für zwei Minuten bei $4^{\circ} \mathrm{C}$. Die obere Phase neutralisiert man mit $10 \mu \mathrm{l}$ NaAcetat (pH 5,2). Danach fällt man die DNA (2.3.1.3) und nimmt sie in $10 \mu \mathrm{l} \mathrm{H}_{2} \mathrm{O}_{\text {bidest }}$ auf.

Im folgenden sind die Bedingungen für die Klonierung der $P$. miotherma-Enzyme aufgeführt. 
Tabelle 8: PCR-Ansatz der P. miotherma-Enzyme

\begin{tabular}{|lc|}
\hline Substanz & Volumen [ $\mu \mathrm{l}]$ \\
\hline PCR Grade Water & 28,6 \\
dNTP-Mix (2 mM) & 5 \\
Template-DNA & 1 \\
Primer „forward“ & 4 \\
Primer "reverse“ & 4 \\
KOD HiFi DNA Polymerase & 0,4 \\
MgCl $_{2} 10$ mM & 5,0 \\
10x Puffer & 5 \\
\hline Gesamtvolumen & 50,0 \\
\hline
\end{tabular}

Tabelle 9: Pcr-Prgramm der P. miotherma-Enzyme

\begin{tabular}{|c|c|c|}
\hline Temperatur $\left[{ }^{\circ} \mathbf{C}\right.$ ] & Zeit [sek] & Reaktion \\
\hline 98 & 15 & Denaturierung \\
\hline Gradient $60-80$ & 5 & Primerannealing \\
\hline 72 & 40 & Primerverlängerung \\
\hline
\end{tabular}


Tabelle 10: Verwendete Primer der PCR

\begin{tabular}{|c|c|c|c|}
\hline Bezeichnung & Sequenz $\left(5^{\prime} \rightarrow 3^{\prime}\right)$ & $\begin{array}{l}\text { Schmelz- } \\
\text { temperatur }\end{array}$ & $\begin{array}{c}\text { Bseonderheiten/ } \\
\text { Anwendung }\end{array}$ \\
\hline 511_for +400 & ggg cct ttg gtt gaa tct cct gta & $62,7^{\circ} \mathrm{C}$ & Template \\
\hline 511_rev+200 & $\begin{array}{l}\text { ggg ttt ttg taa agg aaa gat } \\
\text { agt tac cga }\end{array}$ & $62,7^{\circ} \mathrm{C}$ & Template \\
\hline 511_gen_for & $\begin{array}{c}\text { ggg cat agt cca gtt aaa att tct } \\
\text { ttt ata gga }\end{array}$ & $63,3^{\circ} \mathrm{C}$ & $\begin{array}{c}\text { Schnittstelle } \\
\text { Ndel }\end{array}$ \\
\hline 511_gen_rev & $\begin{array}{l}\text { ggg aag ctt tta cct tct ata atg } \\
\text { ctc ctt cat tcc }\end{array}$ & $68,3^{\circ} \mathrm{C}$ & $\begin{array}{c}\text { Schnittstelle } \\
\text { HindllI }\end{array}$ \\
\hline 720_for_+400 & ggg aat tcc ccc tgc ttt ttt tgt & $61,0^{\circ} \mathrm{C}$ & Template \\
\hline 720_rev+200 & $\begin{array}{l}\text { ggg agc tat tcc tga aga agt } \\
\text { gga }\end{array}$ & $62,7^{\circ} \mathrm{C}$ & Template \\
\hline 1263_720_for_gen & $\begin{array}{c}\text { ggg cat atg aca gct atc aag } \\
\text { tta }\end{array}$ & $59,3^{\circ} \mathrm{C}$ & $\begin{array}{c}\text { Schnittstelle } \\
\text { Ndel }\end{array}$ \\
\hline 1263_720_gen_rev & $\begin{array}{c}\text { ggg aag ctt cta ttt ttt gct gta } \\
\text { gtg ctt }\end{array}$ & $64,0^{\circ} \mathrm{C}$ & $\begin{array}{c}\text { Schnittstelle } \\
\text { HindllI }\end{array}$ \\
\hline
\end{tabular}

\subsubsection{Enzymatische Modifikation von DNA}

\subsubsection{Verdau von DNA durch Restriktionsendonukleasen}

Diese Methode des Schneidens von DNA beruht auf der hohen Spezifität der aus Prokaryonten isolierten Restriktionsendonukleasen (Typ II) gegenüber ihrer meist palindromischen Erkennungssequenz im DNA-Doppelstrang. Die Enzyme hydrolysieren an definierten Stellen die Phosphodiester-Bindungen zwischen zwei Basen in beiden Strängen, woraus überhängende oder glatte Enden resultieren können.

\section{Durchführung:}

Die DNA-Lösungen wurden mit 1/10 Volumen des vom Hersteller empfohlenen 10fach konzentrierten Restriktionspuffers und dem gewünschten Restriktionsenzym (1$5 \mathrm{U} / \mu \mathrm{g}$ DNA) versetzt und für 2-4 h inkubiert. Bei Doppelverdauansätzen konnte man 
nach verschiedenen Methoden verfahren. Zum einen konnte man einen Puffer, in dem beide Enzyme gut schneiden, verwenden. Gab es keinen für beide Enzyme kompatiblen Puffer, so wurde die DNA-Lösung nach dem Schneiden mit dem ersten Enzym aufgereinigt (2.3.2.3) und anschließend mit dem zweiten Enzym und dem dazugehörigen Puffer erneut verdaut.

\section{Standard-Restriktionsansatz:}

DNA-Lösung $\quad \mathrm{x} \mu \mathrm{l}$

Restriktionspuffer (10x) $2 \mu \mathrm{l}$

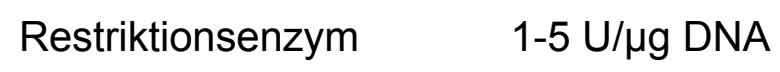

$\mathrm{H}_{2} \mathrm{O}_{\text {bidest }} \quad$ ad $20 \mu \mathrm{l}$

\subsubsection{Dephosphorylierung von DNA-Fragmenten}

Um eine Religation restriktionsverdauter Plasmid-DNA zu vermeiden, konnten die 5'Phosphatgruppen enzymatisch mit Antarctic Phosphatase (Novagen) abgespalten werden.

\section{Durchführung:}

$\mathrm{Zu}$ einem $100 \mu \mathrm{l}$ Restriktionsverdau wurden $20 \mu \mathrm{H}_{2} \mathrm{O}_{\text {bidest, }} 15 \mu$ l Phosphatase und $15 \mu \mathrm{l}$ 10x Phosphatasepuffer zugegeben. Nach einer Inkubation für $45 \mathrm{~min}$ bei $37^{\circ} \mathrm{C}$ erfolgte eine Hitzeinaktivierung des Enzyms für $20 \mathrm{~min}$ bei $65^{\circ} \mathrm{C}$. Wenn die DNA für weitere Präparationen verwendet werden sollte, erfolgte im Anschluss eine Phenol/Chloroform/Isoamylalkohol-Extraktion (II 2.3.1.2) mit anschließender Ethanolbzw. Isopropanolfällung (II 2.3.1.3).

\subsubsection{Ligation von DNA-Fragmenten}

Bei einer Ligation wird eine Phosphodiesterbindung zwischen doppelsträngigen DNA-Fragmenten gebildet, die mindestens ein freies 3'-Hydroxyende und 5'Phosphatende besitzen. Sollen zwei verschiedene Fragmente miteinander verknüpft werden, so empfiehlt sich das kleinere Fragment im Überschuss hinzuzufügen. 
Ligationsansatz:

$\begin{array}{ll}\text { Vektor DNA* } & 3 \mu \mathrm{l} \\ \text { Insert DNA* } & 12 \mu \mathrm{l} \\ \text { 10x Ligationspuffer } & 2 \mu \mathrm{l} \\ \text { T4-DNA-Ligase (Promega) } & 1 \mathrm{U} \\ \mathrm{H}_{2} \mathrm{O} & \text { ad } 20 \mu \mathrm{l}\end{array}$

Inkubation bei $16^{\circ} \mathrm{C}$ ü.N.

${ }^{*}$ bei gleicher Konzentration

\subsubsection{Transformation von $E$. coli}

\subsubsection{Transformation durch Elektroporation}

Bei dieser Methode wird die Zellmembran durch kurze elektrische Impulse für DNA passierbar gemacht. Die Transformationseffizienz liegt hier bei ca. $10^{9}-10^{10}$ Transformanden pro $\mu \mathrm{g}$ DNA. Entscheidend bei der Methode sind die Stärke des elektrischen Feldes, die Dauer des Pulses und die Konzentration der DNA.

Lösungen:

LB-Medium:

2.2.1.1

SOC-Medium:

Caseinpepton $\quad 2 \%$

Hefeextrakt $\quad 0,5 \%$

$\mathrm{MgCl}_{2} \quad 10 \mathrm{mM}$

$\mathrm{MgSO}_{4} \quad 10 \mathrm{mM}$

$\mathrm{NaCl} \quad 10 \mathrm{mM}$

$\mathrm{KCl} \quad 2,5 \mathrm{mM}$

Glukose $\quad 20 \mathrm{mM}$

Mit $\mathrm{NaOH}$ auf pH 7,0 einstellen und aliquotieren (ca. $25 \mathrm{ml}$ ). Die Glukoselösung wurde getrennt autoklaviert. 
Herstellung elektrokompetenter Zellen:

$500 \mathrm{ml}$ Medium wurden mit 2,5 ml einer Übernachtkultur angeimpft. Die Zellen wurden unter starkem Schütteln bis zu einer $\mathrm{OD}_{600}$ von $0,5-0,6$ angezogen. Die Zellsuspension wurde anschließend rasch für 10-15 min auf Eis gekühlt. Nach Abzentrifugieren der Zellen (GSA-Rotor, $5.000 \mathrm{Upm}, 20 \mathrm{~min}, 4^{\circ} \mathrm{C}$ ) wurde das Pellet mit $500 \mathrm{ml}$ sterilem $\mathrm{MQ}$ oder $\mathrm{H}_{2} \mathrm{O}_{\text {bidest }}$ gewaschen. Darauf folgte eine erneute Zentrifugation unter den beschriebenen Bedingungen. Danach wurden die Zellen in $40 \mathrm{ml} 10 \%(\mathrm{w} / \mathrm{v})$ Glycerin aufgenommen und gut gemischt. Nach erneuter Zentrifugation unter den beschriebenen Bedingungen für $10 \mathrm{~min}$ wurde das Volumen des Pellets abgeschätzt und das gleiche Volumen $10 \%$ Glycerin zugegeben. Die Zellen wurden gut resuspendiert, aliquotiert $(60-100 \mu \mathrm{l})$ und bei $-70^{\circ} \mathrm{C}$ gelagert.

\section{Transformation:}

Die kompetenten Zellen wurden auf Eis aufgetaut und mit der DNA-Lösung gemischt (die DNA-Lösung sollte keine Salze enthalten, gegebenenfalls erfolgte eine Dialyse gegen $\mathrm{H}_{2} \mathrm{O}_{\text {bidest }}$ ). Es folgte eine Inkubation des Ansatzes für $20 \mathrm{~min}$ auf Eis. Die Zellen wurden dann in eine Elektroporationsküvette pipettiert und in einem Elektroporationsgerät (Gene-Pulser ${ }^{\circledR} \mathrm{II}$, Bio-Rad $\mathrm{GmbH}$, München) unter folgenden Bedingungen elektroporiert:

Kapazität $25 \mu \mathrm{F}$

Spannung $2500 \mathrm{~V}$

Widerstand $200 \Omega$

Die Entladungszeit sollte zwischen 4,5 und 5 ms liegen. Im Anschluss wurden die Zellen sofort mit $1 \mathrm{ml} \mathrm{SOC}$ - oder LB-Medium gemischt und für $1 \mathrm{~h}$ bei $37^{\circ} \mathrm{C}$ inkubiert. Danach erfolgte eine Plattierung unterschiedlich großer Aliquots auf LB-Agar mit dem entsprechenden Selektionsdruck und anschließender Inkubation ü.N. bei $37^{\circ} \mathrm{C}$. 


\subsubsection{Transformation nach Inoue et al. (1990)}

Lösungen:

SOB-Medium (Hanahan, 1983):

Trypton $2 \%$

Hefeextrakt $\quad 0,5 \%$

$\mathrm{NaCl} \quad 10 \mathrm{mM}$

$\mathrm{KCl} \quad 2,5 \mathrm{mM}$

$\mathrm{MgCl}_{2} \quad 10 \mathrm{mM}$

$\mathrm{MgSO}_{4} \quad 10 \mathrm{mM}$

Die Magnesiumsalze wurden aus getrennt autoklavierten Stammlösungen (1 M $\mathrm{MgCl}_{2} / 1 \mathrm{M} \mathrm{MgSO}_{4}$ ) zugegeben.

TB-Puffer:

$\begin{array}{ll}\text { PIPES } & 10 \mathrm{mM} \\ \mathrm{MnCl}_{2} & 55 \mathrm{mM} \\ \mathrm{CaCl}_{2} & 15 \mathrm{mM} \\ \mathrm{KCl} & 250 \mathrm{mM}\end{array}$

$\mathrm{pH} \mathrm{6,7}$

Herstellung kompetenter Zellen:

Die Hauptkultur (250 ml SOB-Medium, in 1 l-Schikanekolben) wurde mit $1 \mathrm{ml}$ einer exponentiell wachsenden E.coli-LB-Vorkultur angeimpft und unter kräftiger Belüftung bei $18^{\circ} \mathrm{C}$ bis zu einer $\mathrm{OD}_{600}$ von 0,6 inkubiert. Nach rascher Abkühlung der Suspension in Eiswasser wurden die Zellen durch Zentrifugation (GSA-Rotor, 5.000 Upm, $10 \mathrm{~min}, 4^{\circ} \mathrm{C}$ ) geerntet, in $80 \mathrm{ml}$ eiskaltem TB-Puffer resuspendiert, weitere 10 min auf Eis gestellt und nochmals abzentrifugiert. Das Pellet wurde in $20 \mathrm{ml}$ kaltem TB-Puffer aufgenommen, erneut 10 min auf Eis gestellt und als $100 \mu$ l- und $200 \mu \mathrm{l}$ Aliquots in vorgekühlte E-Cups portioniert. Nach Schockgefrieren in flüssigem Stickstoff wurden die Zellen bei $-70^{\circ} \mathrm{C}$ gelagert.

\section{Transformation:}

Die kompetenten Zellen wurden auf Eis aufgetaut, mit der DNA-Lösung (kompletter Ligationsansatz) vorsichtig gemischt und zur Adsorption der DNA an die Zellen für 30-60 min auf Eis inkubiert. Die Transformation erfolgte für $90 \mathrm{~s}$ bei $42^{\circ} \mathrm{C}$ im 
Heizblock. Nach Zugabe von $1 \mathrm{ml}$ kaltem LB-Medium wurde der Ansatz $1 \mathrm{~h}$ bei $37^{\circ} \mathrm{C}$ inkubiert. Anschließend wurden Aliquots unterschiedlicher Größe auf Agarplatten unter Selektivbedingungen ausplattiert.

\subsubsection{X-Gal-Test zur Detektion rekombinanter Klone}

Dieser Test wurde neben den plasmidkodierten Antibiotikaresistenzen zur Selektion rekombinanter Klone verwendet. Er basiert auf der Grundlage, daß die $\beta$ Galaktosidase X-Gal (5-Brom-4-Chlor-3-indolyl- $\beta$-D-galaktopyranosid) enzymatisch spaltet. Das Reaktionsprodukt wird durch Luftoxidation zu einem blauen Indigofarbstoff (5-Brom-4-Chlor-indigo) umgewandelt. Plasmide der pBluescript-Reihe enthalten neben dem Promoter- und Operatorbereich des lac-Operons auch das 5 '-Ende

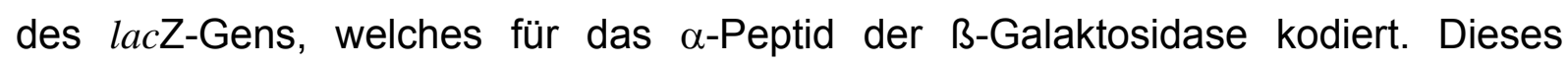
wiederum kann die durch eine Deletion verkürzte, inaktive ß-Galaktosidase verschiedener E. coli-Klonierungsstämme (DH5 $\alpha, \mathrm{XL1}$-Blue) komplementieren ( $\alpha$ Komplementation). IPTG wird dabei als künstlicher Induktor der ß-GalaktosidaseGene in den Zellen verwendet. Für den Test wurde ein Aliquot einer transformierten E. coli-Suspension auf selektiven Nährböden, die IPTG und X-Gal enthielten, ausplattiert.

Im lacZ-Gen liegt die multiple Klonierungsstelle des Vektors. Wenn das lacZ-Gen durch den Einbau von DNA-Fragmenten unterbrochen wird, kann im Wirtsorganismus keine aktive $\beta$-Galaktosidase gebildet werden.

Daher konnten die gewachsenen Kolonien anhand ihrer Färbung unterschieden werden. Blaue Kolonien enthielten nur das religierte Plasmid, während bei weißen Klonen mit hoher Wahrscheinlichkeit eine Insertion in der Multiklonierungsstelle (MCS) des lacZ-Gens stattgefunden hatte, so daß entweder kein vollständiges Transkript mehr gebildet wurde (wenn die integrierte DNA einen Transkriptionsterminator trug) oder es zur Bildung eines Hybridproteins kam, welches keine funktionelle $\alpha$-Komplementation im Wirtsorganismus ermöglichte.

\subsubsection{Sequenzierung doppelsträngiger Plasmid-DNA}

Alle Sequenzierungen doppelsträngiger Plasmid-DNA wurden, nach Bereitstellung der entsprechenden hochreinen Plasmid-DNA (2.3.2.3), vom Laboratorium für 
Genomanalyse (Institut für Mikrobiologie und Genetik, Göttingen) mit dem firmeninternen Verfahren durchgeführt. Sie dienten dem Vergleich der amplifizierten und klonierten DNA zum Originalgenom.

\subsection{Proteinbiochemische Methoden}

\subsubsection{Standardtechniken für das Arbeiten mit Proteinen}

\subsubsection{Quantitative Proteinbestimmung (Bradfordtest)}

Für einen quantitativen Nachweis von Proteinen wurde der „Protein Assay Kit“ von Bio-Rad verwendet, der auf der kolorimetrischen Methode von Bradford (1976, mod.) basiert. Proteine und Peptide mit einer Molekularmasse $>3 \mathrm{kDa}$ bilden mit dem in saurer Lösung anionisch vorliegenden Farbstoff Coomassie Brilliant Blue G250 einen blauen Farbkomplex, der photometrisch gemessen werden kann. Die untere Nachweisgrenze dieses Tests liegt bei $1 \mu \mathrm{g}$. Maximal können Proteinmengen bis 10 $\mu \mathrm{g}$ bestimmt werden.

\section{Durchführung:}

Mit der nach Angaben des Herstellers (Bio-Rad, München; Konzentrat-Verdünnung 1:5 mit $\mathrm{H}_{2} \mathrm{O}_{\text {bidest }}$ ) angefertigten Färbelösung wurde eine Eichgerade mit Rinderserumalbumin (BSA) im Bereich von 0-20 $\mu \mathrm{g}$ Protein/Ansatz erstellt. Die Proteinlösung wurde dazu mit $1 \mathrm{ml}$ Färbelösung versetzt, der Ansatz gut gemischt und für $10 \mathrm{~min}$ bei RT im Dunkeln inkubiert. Nach nochmaligem Durchmischen erfolgte die Messung der OD bei $595 \mathrm{~nm}$ gegen eine Nullprobe ohne Protein.

Die Proteinkonzentration einer unbekannten Probe konnte nach folgender Formel bestimmt werden:

Protein $[\mathrm{mg} / \mathrm{ml}]=\mathrm{OD}_{595} \times \mathrm{m} / \mathrm{V} \quad \mathrm{m}=$ Steigung der Eichgeraden

$\mathrm{V}=$ Probenvolumen $[\mu \mathrm{l}]$

\subsubsection{SDS-Polyacrylamid-Gelelektrophorese (SDS-PAGE)}

Mit Hilfe der SDS-PAGE (nach Laemmli, mod., 1970) lassen sich Proteine entsprechend ihrer molekularen Masse auftrennen. SDS bindet und denaturiert Proteine, wodurch deren Tertiär- und Quartärstruktur zerstört wird. Proteine, die aus 
Dimeren oder Multimeren bestehen, werden in ihre Untereinheiten zerlegt. Durch das Einlagern der zahlreichen negativen Dodecylsulfatreste wird die Eigenladung des Proteins überdeckt. Entsprechend der Peptidkettenlänge wird eine äquivalente negative Ladung angelagert, wodurch die Auftrennung nach der molekularen Masse ermöglicht wird. Für die Trennleistung in einem bestimmten Molekularmassenbereich ist der Vernetzungsgrad des SDS-Gels entscheidend. Zur Auftrennung von Proteinen mit Molekularmassen im Bereich von 10-180 kDa wurde ein $10 \%$-iges Gel verwendet.

\section{Lösungen:}

Acrylamid-Stammlösung (AA):

$40 \%$ (w/v) Fa. Feinchemikalien GmbH Biomol, Mannheim

Trenngel-Stammlösung:

Tris $18,2 \mathrm{~g}$

SDS $0,4 \mathrm{~g}$

$\mathrm{H}_{2} \mathrm{O}_{\text {bidest }}$ ad $100 \mathrm{ml}$

mit $\mathrm{HCl}_{\text {konz. }}$ auf $\mathrm{pH}$ 8,8 einstellen

Sammelgel-Stammlösung:

$\begin{array}{ll}\text { Tris } & 6,1 \mathrm{~g} \\ \text { SDS } & 0,4 \mathrm{~g} \\ \mathrm{H}_{2} \mathrm{O}_{\text {bidest }} & \text { ad } 100 \mathrm{ml} \\ \text { mit } \mathrm{HCl}_{\text {konz. auf } \mathrm{pH} 6,8 \text { einstellen }} & \end{array}$


10x Elektrophoresepuffer:

Tris

$30 \mathrm{~g}$

Glycin

$144 \mathrm{~g}$

SDS

$10 \mathrm{~g}$

$\mathrm{H}_{2} \mathrm{O}_{\text {bidest }}$

ad $1000 \mathrm{ml}$

mit Glycin auf pH 8,3 einstellen

4x Probenpuffer:

Glycerin

$\beta$-Mercaptoethanol

SDS

Bromphenolblau (0,2 \% (w/v))

Tris

$\mathrm{H}_{2} \mathrm{O}_{\text {bidest }}$
$7,5 \mathrm{ml}$

$2,5 \mathrm{ml}$

$1,2 \mathrm{~g}$

$0,5 \mathrm{ml}$

$0,4 \mathrm{~g}$

ad $50 \mathrm{ml}$

mit $\mathrm{HCl}_{\mathrm{konz}}$ auf $\mathrm{pH} 6,8$ einstellen, aliquotieren und bei $-20^{\circ} \mathrm{C}$ aufbewahren

Ammoniumpersulfat (APS):

$10 \%$ Ammoniumpersulfat (w/v) in $\mathrm{H}_{2} \mathrm{O}_{\text {bidest }}$ aliquotieren und bei $-20^{\circ} \mathrm{C}$ aufbewahren.

$\underline{\mathrm{N}, \mathrm{N}, \mathrm{N} \text { ',N'-Tetramethylethylendiamin (TEMED): }}$

Fa. Feinchemikalien GmbH Biomol, Mannheim

\section{Herstellung der Gele:}

Für die Elektrophorese wurde eine Mini-Protean-II-Apparatur (Bio-Rad, München) verwendet. Nach Reinigung der Glasplatten und Spacer mit 70 \%-igem (v/v) Ethanol wurden diese nach Angaben des Herstellers in den Gießstand eingesetzt. Das Trenngel wurde nach dem folgenden aufgeführten Schema zusammenpipettiert, 
wobei APS und TEMED zuletzt zugegeben wurden. Nach gründlichem Mischen wurde der Ansatz bis $2 \mathrm{~cm}$ unter den oberen Rand der Glasplatten gegossen und mit $\mathrm{H}_{2} \mathrm{O}_{\text {bidest }}$ überschichtet. Nach Polymerisation des Trenngels wurde das Sammelgel ebenfalls nach dem unten aufgeführten Schema zusammenpipettiert und auf das Trenngel gegossen. Danach wurde der Kamm möglichst luftblasenfrei eingesetzt.

Pipettierschema für ein Gel:

\begin{tabular}{|c|c|c|}
\hline & Trenngel $(12 \%)$ & Sammelgel $(4 \%)$ \\
\hline Trenngel-Stammlösung & $1 \mathrm{ml}$ & --- \\
\hline Sammelgel-Stammlösung & --- & $0,48 \mathrm{ml}$ \\
\hline $\mathrm{H}_{2} \mathrm{O}_{\text {bidest }}$ & $1,8 \mathrm{ml}$ & $1,32 \mathrm{ml}$ \\
\hline Acrylamid-Stammlösung & $1,2 \mathrm{ml}$ & $0,2 \mathrm{ml}$ \\
\hline APS (10\% (w/v) & $30 \mu \mathrm{l}$ & $15 \mu \mathrm{l}$ \\
\hline TEMED & $3 \mu \mathrm{l}$ & $2 \mu \mathrm{l}$ \\
\hline
\end{tabular}

\section{Probenvorbereitung:}

Die Proteinproben wurden mit Probenpuffer gemischt (1:4) und anschließend 10 min bei $95^{\circ} \mathrm{C}$ denaturiert. Nach Abkühlen der Proben auf Eis wurden die Ansätze kurz abzentrifugiert.

\section{Elektrophorese:}

Das SDS-Gel wurde in der Elektrophoreseapparatur fixiert und der Anoden- und Kathodenraum mit 1x Elektrophoresepuffer gefüllt. Die Geltaschen konnten mit bis zu $20 \mu \mathrm{l}$ der vorbereiteten Proben gefüllt werden. Die Elektrophorese wurde dann bei einer konstanten Stromstärke von $30 \mathrm{~mA}$ durchgeführt, bis die Lauffront das untere Ende des Gels erreicht hatte (ca. $60 \mathrm{~min}$ ). 


\subsubsection{Coomassie-Färbung von Proteinen}

Nach Beendigung der Elektrophorese wurden die SDS-Gele kurz mit $\mathrm{H}_{2} \mathrm{O}_{\text {bidest }}$ gespült und dann für $30 \mathrm{~min}$ in der Färbelösung auf einer Wippe gefärbt. Nach Spülen mit $\mathrm{H}_{2} \mathrm{O}_{\text {bidest }}$ wurde das $\mathrm{Gel}$ in Entfärbelösung, welche mehrmals erneuert wurde, geschwenkt, bis der Hintergrund des Gels farblos war. Die fertigen Gele konnten dann luftblasenfrei zwischen 2 Lagen Cellophanfolie im Gel-Air-Dryer (BioRad, München) für 2-3 h getrocknet werden.

Lösungen:

Färbelösung:

Coomassie Brilliant Blue R250 $\quad 1,5 \mathrm{~g}$

Methanol $455 \mathrm{ml}$

Eisessig $\quad 80 \mathrm{ml}$

$\mathrm{H}_{2} \mathrm{O}_{\text {bidest }} \quad$ ad $1000 \mathrm{ml}$

filtrieren, kann mehrmals verwendet werden

Entfärbelösung:

$\begin{array}{ll}\text { Methanol } & 250 \mathrm{ml} \\ \text { Eisessig } & 350 \mathrm{ml} \\ \mathrm{H}_{2} \mathrm{O}_{\text {bidest }} & \text { ad } 5000 \mathrm{ml}\end{array}$

\subsubsection{Größenbestimmung von Proteinen}

Die Bestimmung der Proteingrößen nach der Auftrennung im Polyacrylamidgel erfolgte anhand eines im Gel mit aufgetrennten internen Standards. Dazu wurde der „High Molecular Weight Standard“ verwendet, der aus folgenden 6 Proteinen besteht:

\section{Markerproteine}

Ferritin

Ketolase

Aldolase

Albumin, Rind

ChymotrypsinogenA

\section{Molekularmasse [Da]}

450000

240000

158000

68000

25000 


\subsubsection{Konzentrierung und Dialyse von Proteinlösungen}

Aufkonzentrierung in Mikrokonzentratoren:

Zur Aufkonzentrierung einer Proteinlösung wurden „Amicon Ultra“ (Millipore) mit einer Ausschlussgrenze von $30 \mathrm{kDa}$ und einem maximalen Probenvolumen von $15 \mathrm{ml}$ verwendet. Sie funktionieren nach dem Prinzip der zentrifugalbetriebenen Filtration und können nicht trocken laufen.

\section{Umpufferung durch Dialyse:}

Zur Entsalzung und Umpufferung von Proteinlösungen wurde eine Dialyse in Dialyseschläuchen (VISKING ${ }^{\circledR}$ Dialysis Tubing, Serva, Heidelberg) durchgeführt. Dazu wurde ein entsprechend großes Schlauchstück abgeschnitten, für 10-15 min in $\mathrm{H}_{2} \mathrm{O}_{\text {bidest }}$ aufgekocht, mit der Proteinlösung gefüllt und an beiden Enden mit Dialyseklammern abgedichtet. Die Dialyse erfolgte, falls nicht anders angegeben, über Nacht unter leichtem Rühren gegen 2-5 I Puffer bei $4^{\circ} \mathrm{C}$.

\subsubsection{Gewinnung und Aufreinigung von Proteinen}

Zur Gewinnung von cytosolischen Proteinen wurden Bakterienstämme je nach Verwendungszweck in Maßstäben von $5 \mathrm{ml}$ bis 4,5 I unter den entsprechenden Bedingungen angezogen. Zum Testen von Enzymaktivitäten im Rohextrakt vor der Aufreinigung des Proteins wurden 30 ml-Kulturen angezogen. Für die 4,5 lHauptkultur wurden 3x1,5 I Erlenmeyerkolben mit Schikane verwendet.

\subsubsection{Präparation des Zellextraktes}

Je nach Volumen der Anzucht wurden die Zellextrakte unterschiedlich hergestellt. Kulturen mit einem Volumen von bis $\mathrm{zu} 30 \mathrm{ml}$ wurden durch Ultraschall aufgeschlossen, während größere Volumina per French Pressure Cell aufgeschlossen wurden.

Entsprechend der weiteren Vorgehensweise wurden die Zellextrakte während der Präparation in unterschiedlichen Puffern aufgenommen. Sollten weitere Aufreinigungsschritte folgen, so wurde $20 \mathrm{mM}$ Tris- $\mathrm{HCl} \mathrm{pH} \mathrm{8,0} \mathrm{verwendet.}$ 
Puffer:

$20 \mathrm{mM}$ Tris-HCl:

Tris

$$
2,42 \mathrm{~g}
$$

$\mathrm{H}_{2} \mathrm{O}_{\text {bidest }}$

ad $1000 \mathrm{ml}$

\subsubsection{Zellaufschluss durch Ultraschall}

Dazu wurde die Kultur (bis $30 \mathrm{ml}$ ) durch Zentrifugation bei 10.000 Upm für 15 min geerntet. Nach Waschen der Zellen in 20 mM Tris-HCl pH 8,0 wurden diese in $2 \mathrm{ml}$ des Puffers pro Gramm Nassgewicht gründlich resuspendiert. Das Mindestvolumen für den anschließenden Zellaufschluss sollte jedoch $500 \mu$ l betragen. Unter Verwendung einer Ultraschallsonde (Ultraschallprozessor UP 200s, Dr. Hielscher $\mathrm{GmbH}$ ) wurden die Zellen bei einer Amplitude von 35 und einem Cycle von 0,5 für 5 min auf Eis aufgeschlossen. Im Lichtmikroskop wurde die Vollständigkeit der Lyse kontrolliert und der Aufschluss im Ultraschallprozessor gegebenenfalls wiederholt. Die Zelltrümmer wurden anschließend bei $13.000 \mathrm{Upm}$ und $4^{\circ} \mathrm{C}$ für $30 \mathrm{~min}$ abzentrifugiert. Der Überstand (=Rohextrakt) wurde in ein neues E-Cup überführt.

\subsubsection{Zellaufschluss mit der French Pressure Cell}

Dazu wurden die Zellen bei $7.000 \mathrm{Upm}$ und $4^{\circ} \mathrm{C}$ für 20 min geerntet und in dem entsprechenden Puffer gewaschen. Nach erneuter Zentrifugation unter denselben Bedingungen wurde das Pellet in $2 \mathrm{ml}$ Puffer pro Gramm Nassgewicht gründlich resuspendiert. Anschließend wurden die Zellen in der French Pressure Cell (American Instrument Company, Silver Spring, USA) mit 1000 psi (=6,9 Mpa) in zwei Passagen aufgeschlossen. Der Zellaufschluss wurde unter dem Lichtmikroskop kontrolliert und bei Bedarf wiederholt. Die Zelltrümmer wurden hochtourig abzentrifugiert (13.000 Upm, $4^{\circ} \mathrm{C}, 30 \mathrm{~min}$ ) und der Rohextrakt abgehoben.

\subsubsection{Abtrennung thermolabiler Proteine durch Hitzedenaturierung}

Um ein thermostabiles heterologes Protein aus dem Zellextrakt eines mesophilen Wirtes anzureichern, eignet sich in vielen Fällen eine Hitzedenaturierung, bei dem ein Großteil der wirtseigenen Proteine präzipitieren. Dabei ist zu beachten, daß die gewählte Temperatur und Zeitdauer dieses Schrittes für jedes anzureichernde Protein neu bestimmt werden muss. Aufgrund der Aufheizzeiten verschieden großer 
Volumina sind Ergebnisse aus Experimenten im E-Cup keinesfalls auf größere Volumina beziehbar. Zur Aufreinigung der putativen Glukosidasen aus $P$. miotherma wurde die Hitzedenaturierung bei $60^{\circ} \mathrm{C}$ für $20 \mathrm{~min}$ im Heizblock durchgeführt. Die denaturierten Proteine wurden im Anschluss bei $13.000 \mathrm{Upm}$ und $4^{\circ} \mathrm{C}$ für $20 \mathrm{~min}$ abzentrifugiert und der Überstand mit dem angereicherten Protein abgenommen.

\title{
2.4.2.5. 6x His Tag-Aufreinigung
}

Die Zellen wurden bei 7000 Upm in GS3-Bechern geerntet, in LEW-Puffer des Protino ${ }^{\circledR} \mathrm{Ni} 2000$ Kit von Machery-Nagel aufgenommen und mittels einer French Pressure Cell aufgeschlossen. Den Rohextrakt reinigte man gemäß Protokoll der Firma Machery-Nagel weiter auf.

\subsubsection{Fast Protein Liquid Chromatography (FPLC)}

\subsubsection{Geräte und Säulen}

Folgende FPLC-Anlagen und Säulen wurden verwendet:

Geräte:

1) BioCAD ${ }^{\circledR}$ SPRINT ${ }^{\mathrm{TM}}$ Perfusion Chromatography ${ }^{\circledR}$ System

2) ÄKTA FPLC UPC-900 Amersham Biosciences

Säulen:

\author{
SOURCE 15Q (50 ml) \\ Phenyl Sepharose HP XK 16/10 \\ Superose 6 10/300 GL
}

Die Puffer und Proben müssen vor dem Auftragen auf die Säule durch Filtration (0,2 $\mu \mathrm{m}$ bzw. 0,45 $\mu \mathrm{m}$ Porenweite) partikelfrei gemacht werden. Für die verschiedenen Säulen müssen jeweils die Parameter der Bindungskapazität, der optimalen Flussrate, des Rückdruckes sowie der chemischen und physikalischen Stabilität und Regenerierung beachtet werden. Die Säulen werden in $20 \%$ (v/v) Ethanol gelagert und vor der Umpufferung zu einem salzhaltigen Eluenten mit $\mathrm{H}_{2} \mathrm{O}_{\text {bidest }}$ gespült. Um das Eindringen von Luft in das System zu verhindern, sollten die Anschlüsse „drop to drop" verbunden werden. 


\subsubsection{Trennprinzipien}

lonenaustausch-Chromatographie (IEC)

\section{Prinzip:}

Die Trennung beruht auf elektrostatischen Wechselwirkungen zwischen den Proteinen und den funktionellen Gruppen des Gelmaterials. Dabei treten geladene Gruppen auf der Proteinoberfläche mit entgegengesetzt geladenen Gruppen auf der Austauschermatrix in Wechselwirkung und führen so zu einer Bindung an die Säule, wobei die Stärke dieser Bindung von den individuellen Ladungseigenschaften der einzelnen Polypeptide abhängt. Entscheidende Parameter sind die Ionenstärke (Salzkonzentration) und der pH-Wert. Die Elution erfolgt durch eine Erhöhung der lonenstärke, die zu einer Schwächung der elektrostatischen Wechselwirkung zwischen Protein und Gelmaterial führt.

Bei dieser Chromatographie wurde der starke Anionenaustauscher SOURCE 15Q in einer selbstgepackten XK 26/60 Säule (50 ml Säulenvolumen) verwendet. Der Durchmesser des aus monodispersen Partikeln bestehenden Materials beträgt 15 $\mu \mathrm{m}$. Dadurch wird eine hohe Stabilität und ein geringer Rückdruck gewährleistet. Die funktionelle Gruppe des SOURCE $15 Q$ ist ein quartäres Amin, das über einen hydrophilen Spacer an die Säulenmatrix gebunden ist. Die Proteinbindungskapazität beträgt bis zu 25 mg pro ml Gelbett. Die empfohlene Flussrate wird mit 30-600 cm/h (0,5-10 $\mathrm{ml} / \mathrm{min})$ bei einem maximalen Rückdruck von $5 \mathrm{MPa}$ angegeben.

\section{Methodik:}

Zunächst wurde die Säule mit 2 Säulenvolumina Elutionspuffer B gespült, um funktionelle Gruppen mit Gegenionen abzusättigen. Anschließend wurde das Medium mit 10 Säulenvolumen Auftragspuffer $A$ auf die Startbedingungen äquilibriert. Die Probe, die sich am besten in Puffer A befinden sollte, wurde unter Niedrigsalzbedingungen auf die Säule aufgetragen und in einem ansteigenden Salzgradienten (8,5 Säulenvolumen) eluiert.

Puffer A: $20 \mathrm{mM}$ Tris- $\mathrm{HCl} \mathrm{pH} 8,0$

Puffer B: $\quad 20 \mathrm{mM}$ Tris- $\mathrm{HCl} \mathrm{pH} \mathrm{8,0+1M} \mathrm{NaCl}$ 
Hydrophobe Interaktionschromatographie (HIC):

Prinzip:

Bei dieser Methode werden Unterschiede in der Oberflächenhydrophobizität der einzelnen Proteine als Trennprinzip genutzt. Durch Auftragung der Proteine in einem Puffer mit hoher lonenstärke entstehen starke Wechselwirkungen zwischen hydrophoben Oberflächenbereichen der Polypeptide und den hydrophoben Liganden der Säulenmatrix. Treibende Kraft für diese Wechselwirkung ist die Entropie, die durch die Aggregation unpolarer Gruppen in polarer Umgebung zunimmt. Die Elution erfolgt durch eine Verringerung der Polarität des Puffers. Dies kann durch Reduzierung der lonenstärke, den Austausch des Salzes gegen eines mit geringerem Aussalzeffekt (Hofmeister-Serie) oder durch Zugabe von unpolaren Agenzien (Ethylenglykol, Harnstoff, Detergenzien, organische Lösungsmittel) erfolgen.

Für diese Methode wurde eine Phenyl Sepharose HP XK 16/10 Fertigsäule mit 20 $\mathrm{ml}$ Säulenvolumen verwendet. Die Gelmatrix besteht aus stark quervernetzten Agarosepartikeln (24-44 $\mu \mathrm{m}$ Durchmesser), die über ungeladene, chemisch stabile Etherbindungen mit Phenylresten derivatisiert sind. Die empfohlene Flussrate liegt bei $50-150 \mathrm{~cm} / \mathrm{h}$ bei maximal 0,3 MPa Rückdruck.

\section{Methodik:}

Vor dem Auftragen der Probe wurde mit 2 Säulenvolumen Puffer B auf Hochsalzbedingungen äquilibriert. Die Probe muss sich ebenfalls in einem Milieu hoher lonenstärke befinden. Dazu wurde sie in mehreren Schritten vorsichtig auf $5 \mathrm{M}$ $\mathrm{NaCl}$ hochgesalzt. Die Elution erfolgte im absteigenden Salzgradienten, wobei evtl. mit $\mathrm{H}_{2} \mathrm{O}_{\text {bidest }}$ nacheluiert werden muss, um stark hydrophobe Proteine wieder von der Säule zu lösen.

Puffer A: $20 \mathrm{mM}$ Tris- $\mathrm{HCl} \mathrm{pH} 8,0$

Puffer B: $\quad 20 \mathrm{mM}$ Tris- $\mathrm{HCl} \mathrm{pH} \mathrm{8,0+5} \mathrm{M} \mathrm{NaCl}$ 
Gelfiltration:

Prinzip:

Die Gelfiltration ist im Gegensatz zur lonenaustausch-Chromatographie und hydrophoben Interaktions-Chromatographie eine nicht-adsorptive Methode, bei der die Trennung der Proteine aufgrund ihrer Größe erfolgt. Gelfiltrations-Medien sind inerte, poröse Matrizes, die den Proteinen in Abhängigkeit von ihrer Größe ein mehr oder weniger großes Verteilungsvolumen bieten. Dadurch eluieren größere Moleküle früher als kleinere.

Puffer: $\quad 20 \mathrm{mM}$ Tris- $\mathrm{HCl} \mathrm{pH} 8,0$

\section{Molekularmassenbestimmung eines Proteins:}

Aufgrund der Korrelation des Elutionsvolumens mit der Größe eines Proteins kann die Gelfiltration zur Bestimmung der Nativ-Molekularmasse von Proteinen eingesetzt werden. Dazu wurden die Superdex 200 prep grade XK 16/60 und die Superose 6 10/300 GL verwendet.

Folgende Säulenparameter müssen bekannt sein:

- das gesamte Säulenvolumen $\mathrm{V}_{\mathrm{t}}$

- das Ausschlussvolumen der Säule $V_{0}$

- das Elutionsvolumen des Proteins $\mathrm{V}_{\mathrm{e}}$

Anhand dieser Größen konnte man den Verteilungskoeffizienten $\mathrm{K}_{\mathrm{av}}$ eines Proteins ermitteln, der folgendermaßen definiert ist:

$$
\mathrm{K}_{\mathrm{av}}=\frac{V e-V o}{V t-V o}
$$

Durch Kalibrierung der Gelfiltrationssäule mit Eichproteinen kann man anhand der oben aufgeführten Formel den jeweiligen Verteilungskoeffizienten für die einzelnen Proteine bestimmen. Mit Hilfe einer Auftragung des dekadischen Logarithmus der Molekularmasse gegen den $\mathrm{K}_{\mathrm{av}}$-Wert erhält man eine Eichgerade, aus der man die Molekularmasse eines beliebigen Proteins anhand seines Verteilungskoeffizienten berechnen kann. 
Als Säulenpuffer wurde 50 mM Tris-HCl + 1 mM EDTA (pH 7,5 (Superose 6 Säule)) verwendet.

\subsubsection{Hydrolyse von para-Nitrophenyl-Substraten}

Para-Nitrophenyl (pNP)-Glycoside sind synthetische Testsubstrate für hydrolytische Enzyme. Durch die enzymatische Spaltung der arylglycosidischen Bindung wird pNitrophenol freigesetzt, das sich durch seine gelbe Färbung photometrisch bei 420 $\mathrm{nm}$ bestimmen läßt:

$$
\begin{array}{ccc}
\text { p-Nitrophenyl-Glycosid } & \rightarrow & \text { p-Nitrophenol }+ \text { Zucker } \\
\text { (farblos) } & \text { (gelb) }
\end{array}
$$

Testansatz für das zu dem ORF PM0720 korrespondierende Protein:

$\begin{array}{lll}\text { Probe } & & \mathrm{x} \mu \mathrm{l} \\ \text { Tris-Cl pH } 7^{\left(60^{\circ} \mathrm{C}\right)}: & 0,5 \mathrm{M} & 30 \mu \mathrm{l} \\ \mathrm{MnCl}_{2}: & 6 \mathrm{mM} & 30 \mu \mathrm{l} \\ \mathrm{NAD}^{+}: & 2,7 \mathrm{mM} & 30 \mu \mathrm{l} \\ \text { Dithiothreitiol (DTT): } & 0,5 \mathrm{M} & 15 \mu \mathrm{l} \\ \mathrm{H}_{2} \mathrm{O}_{\text {bidest.: }} & & 185-\mathrm{xl}\end{array}$

Testansatz für das zu dem ORF PM1263 korrespondierende Protein:

$\begin{array}{lll}\text { Probe } & & \mathrm{x} \mu \mathrm{l} \\ \text { Tris-Cl pH } 7^{\left(60^{\circ} \mathrm{C}\right)}: & 0,5 \mathrm{M} & 30 \mu \mathrm{l} \\ \mathrm{MnCl}_{2}: & 6 \mathrm{mM} & 30 \mu \mathrm{l} \\ \mathrm{NAD}^{+}: & 9 \mathrm{mM} & 30 \mu \mathrm{l} \\ \text { Dithiothreitiol (DTT): } & 0,5 \mathrm{M} & 15 \mu \mathrm{l} \\ \mathrm{H}_{2} \mathrm{O}_{\text {bidest.: }} & & 185-\mathrm{x \mu l}\end{array}$


Durchführung:

- 5 min Präinkubation des Testansatzes bei $60^{\circ} \mathrm{C}$.

- Start durch Zugabe von $10 \mu \mathrm{l}$ p-Nitrophenyl-a-D-glukopyranosid (0,1 M in DMSO, Lagerung bei $-20^{\circ} \mathrm{C}$ ) und Inkubation bei $60^{\circ} \mathrm{C}$ für eine definierte Zeit (Gelbfärbung).

- Abstoppen auf Eis durch Zugabe von $250 \mu$ I EDTA $(0,5 \mathrm{M} ; \mathrm{pH} 8,0) 250 \mu \mathrm{l}$ $\mathrm{Na}_{2} \mathrm{CO}_{3}(2,4 \mathrm{M})$.

- Bestimmung der Extinktion bei $420 \mathrm{~nm}$ gegen eine Negativkontrolle ohne Enzym.

Testansatz für MelA aus E. coli:

$\begin{array}{lll}\text { Probe } & & \mathrm{x \mu l} \\ \text { HEPES pH } 7^{\left(37^{\circ} \mathrm{C}\right):} & 0,5 \mathrm{M} & 30 \mu \mathrm{l} \\ \mathrm{MnCl}_{2}: & 1,5 \mathrm{mM} & 30 \mu \mathrm{l} \\ \mathrm{NAD}^{+}: & 5 \mathrm{mM} & 30 \mu \mathrm{l} \\ \text { Dithiothreitiol (DTT): } & 0,5 \mathrm{M} & 15 \mu \mathrm{l} \\ \mathrm{H}_{2} \text { Obidest.: } & & 185-\mathrm{x} \mu \mathrm{l}\end{array}$

Durchführung:

- 5 min Präinkubation des Testansatzes bei $37^{\circ} \mathrm{C}$.

- Start durch Zugabe von $10 \mu \mathrm{l}$ p-Nitrophenyl-a-D-galaktopyranosid (0,1 M in $\mathrm{H}_{2} \mathrm{O}$, Lagerung bei $-20^{\circ} \mathrm{C}$ ) und Inkubation bei $37^{\circ} \mathrm{C}$ für eine definierte Zeit (Gelbfärbung).

- Abstoppen auf Eis durch Zugabe von $250 \mu$ I EDTA (0,5 M; pH 8,0) $250 \mu \mathrm{l}$ $\mathrm{Na}_{2} \mathrm{CO}_{3}(2,4 \mathrm{M})$.

- Bestimmung der Extinktion bei $420 \mathrm{~nm}$ gegen eine Negativkontrolle ohne Enzym.

\subsubsection{Abhängigkeit der Enzymaktivität von Cofaktoren}

Der Einfluß von Cofaktoren auf die Aktivität der a-Glukosidasen wurde mit dem in 2.4.2.9 beschriebenen Standard-Test mit den dort beschriebenen Konzentrationen 
der Cofaktoren durchgeführt. Zur Ermittlung des Effektes (der Konzentration) eines Cofaktors auf die enzymatische Aktivität der a-Glukosidase wurden die beiden anderen Cofaktoren jeweils in ihren optimalen Konzentrationsverhältnissen zugesetzt.

\subsubsection{Reduzierende Agenzien}

Der stimulierende Effekt von DTT legte nahe, daß ein reduzierendes Agenz für die $\alpha-$ Glukosidase/Galaktosidase-Aktivität benötigt wurde. Aus diesem Grunde wurde das DTT aus dem Standard-Test entfernt und durch variable Konzentrationen von 2Mercaptoethanol oder L-Cystein ersetzt. Da L-Cystein leicht eine Änderung des $\mathrm{pH}$ Wertes im Testansatz bewirken kann, wurde es in einem geeignetem Puffer gelöst und der $\mathrm{pH}$ - Wert der Testansätze bei den verschiedenen L-Cystein-Konzentrationen auf seine Konstanz hin überprüft.

\subsubsection{Produktanalyse durch Dünnschichtchromatographie (TLC)}

Die Dünnschichtchromatographie ist eine Form der Verteilungschromatographie zwischen einer hydrophilen (stationären) und einer hydrophoben (mobilen) Phase. Verschiedene Stoffgemische organischer Verbindungen wie Zucker, Aminosäuren und Nukleotide können dabei analysiert bzw. aufgetrennt werden. Auf eine mit Kieselgel beschichtete Aluminium-Folie (Kieselgel 60, $F_{254}$, Merck) wurde das zu analysierende Stoffgemisch aufgetragen. In einer geschlossenen Kammer bewirken Kapillarkräfte das Aufsteigen eines Lösungsmittelgemisches aus einer wässrigen und einer organischen Komponente. Während die wässrige Komponente mit dem Sorbtionsmittel eine stationäre Phase bildet, bewirkt die organische Komponente als mobile Phase eine Auftrennung des Stoffgemisches entsprechend der Polarität. Unpolare Moleküle laufen dabei schneller als polare. Nach dem Lauf wurde die Folie getrocknet und mit einer bestimmten Reagenzlösung eingesprüht. Bei $140^{\circ} \mathrm{C}$ und einer Inkubationszeit von 15 min bildeten die Moleküle mit der Sprühlösung gefärbte Produkte, die anhand eines Maltooligosaccharid-Standards (G1-G7) identifiziert werden konnten. 
Lösungen:

Laufmittel 1:

1-Propanol $\quad 50 \%$

Nitromethan $\quad 30 \%$

$\mathrm{H}_{2} \mathrm{O}_{\text {bidest }} \quad 20 \%$

Entwicklung: $1 x$ bei RT

Laufmittel 2:

$\begin{array}{ll}\text { 1-Propanol } & 60 \% \\ \text { Ethylacetat } & 10 \% \\ \mathrm{H}_{2} \mathrm{O}_{\text {bidest }} & 30 \%\end{array}$

Entwicklung: 2x bei RT

Sprühreagenz 1:

$\begin{array}{ll}\text { Anilin } & 1 \mathrm{ml} \\ \text { Diphenylamin } & 1 \mathrm{~g} \\ \text { Aceton } & 100 \mathrm{ml}\end{array}$

Sprühreagenz 2:

Diphenylhydrazin $\quad 0,1 \mathrm{~g}$

$\mathrm{H}_{2} \mathrm{SO}_{4(\text { konz) }} \quad 5 \mathrm{ml}$

Ethanol $_{a b s} \quad$ ad $100 \mathrm{ml}$

Lagerung lichtgeschützt bei $4^{\circ} \mathrm{C}$

Vor dem Besprühen der Folie wurde ein entsprechendes Volumen des Sprühreagenz 2 entnommen (ca. $5 \mathrm{ml}$ pro Folie) und in Falle von Sprühreagenz 1 mit orthoPhosphorsäure (85 \% (v/v)) versetzt, bis die Lösung wieder aufklarte (ca. $10 \%(v / v))$.

\subsubsection{Präparative Dickschichtchromatographie (PDC)}

Eine Aufschlämmung von je $55 \mathrm{~g}$ Kieselgel P/UV 254 (Macherey-Nagel \& Co) in $120 \mathrm{ml}$ Wasser schichtet man auf waagerecht liegende Glasplatten $(20 \times 40 \mathrm{~cm}$ oder $20 \times 20$ $\mathrm{cm})$, läßt an der Luft trocknen und aktivierte $3 \mathrm{~h}$ bei $130{ }^{\circ} \mathrm{C}$. 
Die Proben trägt man mit einer Pasteurpipette auf und läßt es gut trocknen. Anschließend entwickelt man die PDC wie eine DC (2.4.2.12) mit dem gleichen Laufmittel. Im Gegensatz zur DC wird das Sprühreagenz nach dem Trocknen nicht auf die gesamte Oberfläche aufgetragen, sondern nur ein schmaler Rand besprüht. Diesen entwickelt man mit einem Heißluftfön und sorgt dafür, daß der Rest der Platte nicht mit erwärmt wird. Aus den gefärbten Banden extrapoliert man über die nicht besprühten Bereiche der Platte und kratzt die einzelnen Banden mit einem Skalpell von der Glasplatte. Das heruntergekratzte Material wird mit Methanol überschichtet und gut vermischt. Das Kieselgel wird über einen Filter vom Methanol getrennt und danach im Vakuum entfernt am Rotationsverdampfer das Methanol entfernt.

\subsubsection{Charakterisierung der Enzymaktivität}

\subsubsection{1. pH-Abhängigkeit der Enzymaktivität}

Hierfür wurde die Aktivität der $\alpha$-Galaktosidase mit pNP-Galaktose in einem pHBereich zwischen 5,5 und 10 bestimmt. Es wurden folgende Puffer für die verschieden $\mathrm{pH}-B e r e i c h e$ verwendet: Natriumsuccinat $(\mathrm{pH}$ 5.5-7.0), HEPES ( $\mathrm{pH} 7.0$ 8.5), 3-(Cyclohexylamino)-1-propanesulfonsäure (CAPS; pH 9.0-10). Die pH-Werte wurden im Falle der Enzyme aus $P$. miotherma bei $60^{\circ} \mathrm{C}$ und bei MelA aus $E$. coli bei $37^{\circ} \mathrm{C}$ eingestellt.

Ansatz: Siehe 2.4.2.9. Es wurden lediglich die o. g. Puffer stattdessen eingesetzt.

Vor Zugabe des Enzyms erfolgte eine Vortemperierung des Ansatzes für 5 min bei der entsprechenden Temperatur. Nach Zugabe des Enzyms wurde für weitere 3min inkubiert. Angegeben wird die relative Aktivität (in \%) bezogen auf die höchste gemessene Aktivität in der Messreihe.

\subsubsection{Temperaturabhängigkeit der Aktivität}

Ansatz: Siehe 2.4.2.9.

Nach Präinkubation des Ansatzes für 5 min bei der jeweiligen Temperatur erfolgte die Zugabe des Proteins und eine weitere Inkubation für 3 min. 


\subsubsection{Thermische Inaktivierung}

Um die Abhängigkeit der Enzymaktivität von der Inkubationstemperatur und Inkubationszeit zu verfolgen, wurde für jede Temperatur ein Pool gebildet, der Enzym, Puffer bei der jeweiligen Temperatur und $\mathrm{H}_{2} \mathrm{O}_{\text {bidest }}$ enthielt. Die E-Cups wurden im Heizblock oder Heizschrank bei den entsprechenden Temperaturen präinkubiert. Nach verschiedenen Zeitpunkten wurde ein Aliquot entnommen und auf die verbliebene Restaktivität im pNP-Test untersucht.

Ansatz (Enzym-Pool): Siehe 2.4.2.9.

Vor Zugabe des Enzyms aus dem jeweiligen Pool und der anschließenden Inkubation für $3 \mathrm{~min}$ bei der entsprechenden Temperatur erfolgte keine Vortemperierung. Angegeben wird die verbliebene Restaktivität (in \%) bezogen auf die Aktivität eines Aliquots aus dem jeweiligen Pool ohne Präinkubation.

\subsubsection{Bestimmung des Substratspektrums}

Zur Bestimmung des Umsatzes polymerer Substrate wurden die Enzyme mit der entsprechenden Substanz unter den in 2.4.2.9. aufgeführten Bedingungen inkubiert. Lediglich das pNP-Substrat wurde durch das zu testende Substrat ersetzt. Das entstandene Substratspektrum wurde durch Dünnschichtchromatographie analysiert.

\subsubsection{Kristallisation}

\subsubsection{Sitting-Drop}

Es existieren zwei gängige Methoden zur Kristallisation mittels Dampfdiffusion, die "Sitting-Drop"- und die "Hanging-Drop"-Methode. Erstere wurde hier angewandt. Die Sitting-Drop-Methode kam hauptsächlich bei den Fertigscreens zum Einsatz. Die 24 'er-Platten wurden mit je $1 \mathrm{ml}$ Reservoir gefüllt, und die Tröpfchen bestanden aus 
je $1 \mu$ l Proteinlösung und $1 \mu$ l Mutterlösung. Die mit Crystal-Clear versiegelten Platten kamen zur Lagerung in einen $18^{\circ} \mathrm{C}$-Kristallisationsschrank.

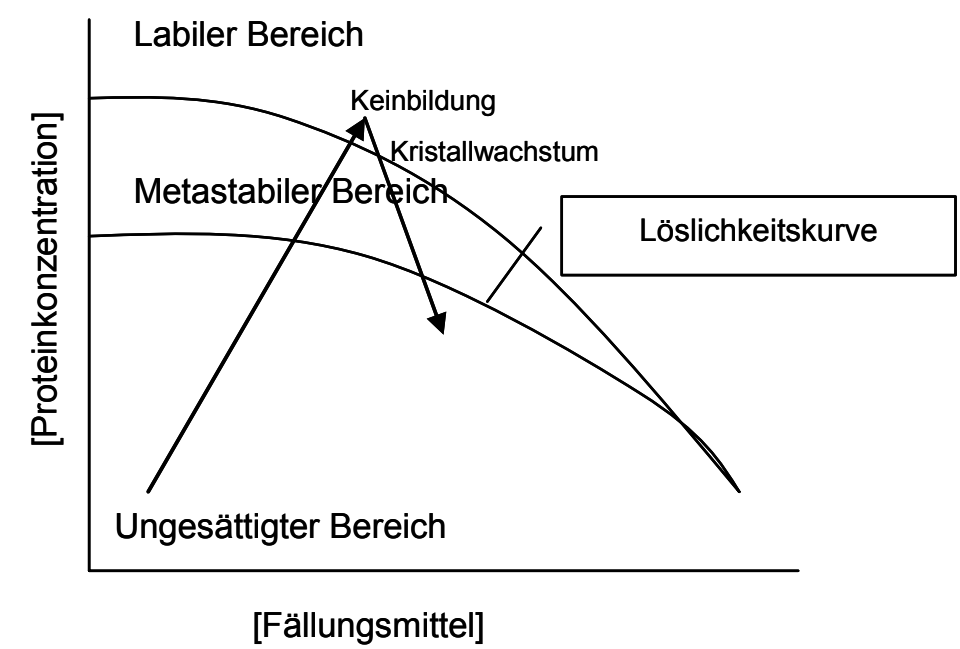

\begin{abstract}
Abbildung 3: Phasendiagramm. Die Pfeile repräsentieren den Konzentrations-Zeit-Verlauf während des Kristallisationsprozesses.
\end{abstract}

Grundvoraussetzung für die erfolgreiche Kristallisation von biologischen Makromolekülen ist zunächst einmal eine sehr reine Proteinlösung. Das Problem, das sich gleich unmittelbar anschließt, ist die Überwindung der sogenannten Keimbildungsbarriere. Allgemein können sich Kristallisationskeime nur in übersättigten Lösungen bilden (siehe Abbildung 3). Dieser Bereich ist jedoch für das Wachstum des Kristalls sehr ungünstig, da hier bevorzugt viele kleine Kristalle entstehen. Für die Züchtung von ,,großen"' Kristallen sollte die Lösung daher im metastabilen Bereich gehalten werden. Nur werden dort eben keine Kristallisationskeime gebildet. Um dieses Problem zu lösen, wurde die sogenannte Dampdiffusionsmethode entwickelt. Hierbei wird die Proteinlösung mit einer Mutterlösung, bestehend aus einem Fällungsmittel und diversen anderen Zusätzen, gemischt und in einem versiegelten Raum einem sehr viel größeren Reservoir derselben Mutterlösung gegenübergestellt. Aufgrund der geringeren Fällungsmittelkonzentration im Proteintröpfchen tritt ein Transport von Wassermolekülen in Richtung Reservoir ein. Die Fällungsmittelkonzentration im Tropfen nimmt zu und irgendwann wird die Keimbildungsbarriere überschritten. Es kommt nun zur Bildung von Kristallisationskeimen. Als Konsequenz daraus verringert 
sich die Proteinkonzentration im Tropfen und im Idealfall nähert sie sich dem metastabilen Bereich (Pfeile in Abbildung 3). In diesem Bereich entstehen keine neuen Kristalle mehr und die vorhandenen Kristallisationskeime können langsam weiterwachsen. Es entstehen wenige große Kristalle.

Im folgenden sind die einzelnen Verfeinerungen der verschieden Screenings aufgeführt.

Material: $\quad$ Cryschem Plate ${ }^{\mathrm{TM}} 24$ Well, Hampton Research (Aliso Viejo, USA) Crystal Clear Sealing Tape, Hampton Research (Aliso Viejo, USA) Fertig-Screenings, Hampton Research (Aliso Viejo, USA) 


\begin{tabular}{|c|c|c|}
\hline \multicolumn{2}{|l|}{ Crystal Screen } & Reagent Formulation Organized By Buffer \\
\hline Tube Number Salt & Tube Number Buffer ${ }^{\prime}$ & Tube Number Precipitant \\
\hline 2. None & 2. None & 2. $0.4 \mathrm{M}$ Potassium Sodium Tartrate tetrahydrate \\
\hline 3. None & 3. None & 3. $0.4 \mathrm{M}$ mono-Ammonium dilhydrogen Phosphate \\
\hline 30. $0.2 \mathrm{MAmmonium} \mathrm{Sulfate}$ & 30. None & 30. $30 \%$ w/v Polyethylene Glycol 8000 \\
\hline 31. $0.2 \mathrm{M}$ Ammonium Sulfate & 31. None & 31. $30 \%$ w/V Polyethylene Glycol 4000 \\
\hline 32. None & 32. None & 32. $2.0 \mathrm{M}$ Ammonium Sulfate \\
\hline 33. None & 33. None & 33. $4.0 \mathrm{M}$ Sodium Formate \\
\hline 42. $0.05 \mathrm{M}$ mono-Potassium dithydrogen Phosphate & 42. None & 42. $20 \%$ w/v Polyethylene Glycol 8000 \\
\hline 43. None & 43. None & 43. $30 \%$ w/V Polyethyene Glycol 1500 \\
\hline 44. None & 44. None & 44. $0.2 \mathrm{M}$ Magnesium Formate \\
\hline 49. 1.0 M Lithium Sulfate monohydrate & 49. None & 49. $2 \%$ wiv Polyethylene Glycol 8000 \\
\hline 50. 0.5 M Lithium Sulfate monohydrate & 50. None & 50. $15 \%$ w/v Polyethylene Glycol 8000 \\
\hline 1. $0.02 \mathrm{M}$ Calcium Chloride dilyydrate & 1. 0.1 M Sodium Acetate trihydrate $\mathrm{pH} 4.6$ & 1. $30 \%$ v/V 2-Methy-2,4-pentanediol \\
\hline 10. $0.2 \mathrm{M}$ Ammonium Acetate & 10. $0.1 \mathrm{M}$ Sodium Acetate trihydrate $\mathrm{pH} 4.6$ & 10. $30 \%$ w/v Polyethylene Glycol 4000 \\
\hline 20. $0.2 \mathrm{M}$ Ammonium Sulfate & 20. 0.1 M Sodium Acetate trihydrate $\mathrm{pH} 4.6$ & 20. $25 \%$ w/v Polyethylene Glycol 4000 \\
\hline 24. $0.2 \mathrm{M}$ Calcium Chloride dihydrate & 24. $0.1 \mathrm{M}$ Sodium Acetate trihydrate $\mathrm{pH} 4.6$ & 24. $20 \%$ v/v iso-Propanol \\
\hline 34. None & 34. $0.1 \mathrm{M}$ Sodium Acetate trihydrate $\mathrm{pH} 4.6$ & 34. $2.0 \mathrm{M}$ Sodium Formate \\
\hline 37. None & 37. $0.1 \mathrm{M}$ Sodium Acetate trihydrate $\mathrm{pH} 4.6$ & 37. $8 \%$ w/v Polyethylene Glycol 4000 \\
\hline 47. None & 47. $0.1 \mathrm{M}$ Sodium Acetate tribydrate $\mathrm{pH} 4.6$ & 47. 2.0 M Ammonium Sulfate \\
\hline 9. $0.2 \mathrm{M}$ Ammonium Acetate & 9. $0.1 \mathrm{M}$ tri-Sodium Citrate dihydrate $\mathrm{pH} 5.6$ & 9. $30 \%$ w/V Polyethylene Glycol 4000 \\
\hline 11. None & 11. $0.1 \mathrm{M}$ tri-Sodium Citrate dihydrate $\mathrm{pH} 5.6$ & 11. $1.0 \mathrm{M}$ mono-Ammonium dihydrogen Phosphate \\
\hline 26. $0.2 \mathrm{M}$ Ammonium Acetate & 26. $0.1 \mathrm{M}$ tri-Sodium Citrate dihydrate $\mathrm{pH} 5.6$ & 26. $30 \%$ wv 2-Methyl-2,4-pentanediol \\
\hline 40. None & 40. $0.1 \mathrm{M}$ tri-Sodium Citrate dihydrate $\mathrm{pH} 5.6$ & 40. $20 \%$ v/V iso-Propanol, $20 \%$ W/V Polyethylene Glycol 4000 \\
\hline 25. None & 25. $0.1 \mathrm{M}$ Imidazole $\mathrm{pH} 6.5$ & 25. $1.0 \mathrm{M}$ Sodium Acetate trihydrate \\
\hline 7. None & 7. $0.1 \mathrm{M}$ Sodium Cacodyate $\mathrm{pH} 6.5$ & 7. $1.4 \mathrm{M}$ Sodium Acetate trihydrate \\
\hline 8. $0.2 \mathrm{M}$ tri-Sodium Citrate dihydrate & 8. $0.1 \mathrm{M}$ Sodium Cacodyate $\mathrm{pH} 6.5$ & 8. $30 \%$ v/v iso-Propanol \\
\hline 15. $0.2 \mathrm{M}$ Ammonium Sulfate & 15. $0.1 \mathrm{M}$ Sodium Cacodylate $\mathrm{pH} 6.5$ & 15. $30 \%$ w/v Polyethylene Glycol 8000 \\
\hline 18. 0.2 M Magnesium Acetate tetrahydrate & 18. $0.1 \mathrm{M}$ Sodium Cacodylate $\mathrm{pH} 6.5$ & 18. $20 \%$ Polyethylene Glycol 8000 \\
\hline 21. 0.2 M Magnesium Acetate tetrahydrate & 21. $0.1 \mathrm{M}$ Sodium Cacodylate $\mathrm{pH} 6.5$ & 21. $30 \%$ v/v 2-Methyl-2,4-pentanediol \\
\hline 28. $0.2 \mathrm{M}$ Sodium Acetate trihydrate & 28. 0.1 M Sodium Cacodylate $\mathrm{pH} 6.5$ & 28. $30 \%$ W/V Polyethylene Glycol 8000 \\
\hline 45. $0.2 \mathrm{M}$ Zinc Acetate dihydrate & 45. $0.1 \mathrm{M}$ Sodium Cacodylate $\mathrm{pH} 6.5$ & 45. $18 \%$ w/v Polyethylene Glycol 8000 \\
\hline 46. 0.2 M Calcium Acetate hydrate & 46. $0.1 \mathrm{M}$ Sodium Cacodylate $\mathrm{pH} 6.5$ & 46. $18 \%$ w/v Polyethylene Glycol 8000 \\
\hline 5. $0.2 \mathrm{M}$ tri-Sodium Citrate dihydrate & 5. $0.1 \mathrm{M}$ HEPES - Na pH 7.5 & 5. $30 \%$ viv 2-Methyl-2,4-pentanediol \\
\hline 12. 0.2 M Magnesium Chloride hexahydrate & 12. $0.1 \mathrm{M}$ HEPES - $\mathrm{Na} \mathrm{pH} 7.5$ & 12. $30 \% \mathrm{v} / \mathrm{v}$ iso-Propanol \\
\hline 14. 0.2 M Calcium Chloride dihydrate & 14. $0.1 \mathrm{M}$ HEPES - $\mathrm{Na} \mathrm{pH} 7.5$ & 14. $28 \%$ V/V Polyettrylene Glyool 400 \\
\hline 16. None & 16. $0.1 \mathrm{M}$ HEPES - $\mathrm{Na} \mathrm{pH} 7.5$ & 16. $1.5 \mathrm{M}$ Lithium Sulfate monohydrate \\
\hline 23. $0.2 \mathrm{M}$ Magnesium chloride hexahydrate & 23. $0.1 \mathrm{M}$ HEPES - $\mathrm{Na}$ pH 7.5 & 23. $30 \%$ v/V Polyethylene Glyool 400 \\
\hline 27. $0.2 \mathrm{M}$ tri-Sodium Citrate dihydrate & 27. $0.1 \mathrm{M}$ HEPES - $\mathrm{Na}$ pH 7.5 & 27. $20 \%$ v/v iso-Propanol \\
\hline 29. None & 29. $0.1 \mathrm{M}$ HEPES - $\mathrm{Na} \mathrm{pH} 7.5$ & 29. 0.8 M Potassium Sodium Tartrate tetrahydrate \\
\hline 35. None & 35. $0.1 \mathrm{M}$ HEPES - Na pH 7.5 & $\begin{array}{l}\text { 35. } 0.8 \mathrm{M} \text { mono-Sodium ditydrogen phosphate } \\
0.8 \mathrm{M} \text { mono-Potassium dihydrogen phosphate }\end{array}$ \\
\hline 38. None & 38. $0.1 \mathrm{M}$ HEPES - $\mathrm{Na} \mathrm{pH} 7.5$ & 38. $1.4 \mathrm{M}$ tri-Sodium Citrate dihydrate \\
\hline 39. None & 39. $0.1 \mathrm{M}$ HEPES - $\mathrm{Na}$ pH 7.5 & 39. $2 \%$ v/v Polyethylene Glyool 400,2.0 M Ammonium Sulfate \\
\hline 41. None & 41. $0.1 \mathrm{M}$ HEPES - $\mathrm{Na} \mathrm{pH} 7.5$ & 41. $10 \%$ v/v iso-Propanol, $20 \%$ w/v Polyethylene Glycol 4000 \\
\hline 4. None & 4. $0.1 \mathrm{M}$ Tris Hydrochloride $\mathrm{pH} 8.5$ & 4. $2.0 \mathrm{M}$ Ammonium Sulfate \\
\hline 6. $0.2 \mathrm{M}$ Magnesium Chloride hexahydrate & 6. $0.1 \mathrm{M}$ Tris Hydrochloride $\mathrm{pH} 8.5$ & 6. $30 \%$ w/v Polyethylene Glycol 4000 \\
\hline 13. $0.2 \mathrm{M}$ tri-Sodium Citrate dihydrate & 13. $0.1 \mathrm{M}$ Tris Hydrochloride $\mathrm{pH} 8.5$ & 13. $30 \%$ V/V Polyethylene Glyool 400 \\
\hline 17. $0.2 \mathrm{M}$ Lithium Sulfate monohydrate & 17. $0.1 \mathrm{M}$ Tris Hydrochloride $\mathrm{pH} 8.5$ & 17. $30 \%$ Polyethylene Glycol 4000 \\
\hline 19. 0.2 M Ammonium Acetate & 19. $0.1 \mathrm{M}$ Tris Hydrochloride $\mathrm{pH} 8.5$ & 19. $30 \%$ v/v iso-Propanol \\
\hline 22. $0.2 \mathrm{M}$ Sodium Acetate trihydrate & 22. $0.1 \mathrm{M}$ Tris Hydrochloride $\mathrm{pH} 8.5$ & 22. $30 \%$ w/v Polyethylene Glycol 4000 \\
\hline 36. None & 36. $0.1 \mathrm{M}$ Tris Hydrochloride $\mathrm{pH} 8.5$ & 36. $8 \%$ w/v Polyethylene Glycol 8000 \\
\hline 48. None & 48. $0.1 \mathrm{M}$ Tris Hydrochloride $\mathrm{pH} 8.5$ & 48. $2.0 \mathrm{M}$ mono-Ammonium dihydrogen Phosphate \\
\hline & 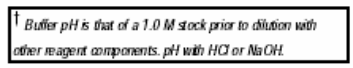 & \\
\hline
\end{tabular}

Crystal Screen contains fifty unique reagents. To determine the formulation of each reagent, simply read across the page.

34 Journey
Aliso Viejo, CA 92656 U.S.A.
Tel: (949) 425-1321 • Fax: (949) 425-1611
e-mail: tech@hrmail.com
Website: www.hampton research.com

\section{Abbildung 4: Original User-Guide der Firma Hampton Research Corp.}

\subsubsection{Fluoreszenzspektroskopie}

Fluoreszenz nennt man die Emission von elektromagnetischer Strahlung bei Belichtung einer Probe. Charakteristisch für die Fluoreszenz ist, daß sie sofort erlischt, wenn die Lichtquelle entfernt wird, daß sie größere Wellenlängen als die einfallende Strahlung besitzt und daß die Schwingungsstruktur des 
Fluoreszenzspektrums für den elektronischen Grundzustand der Probe charakteristisch ist. Der Mechanismus der Fluoreszenz besteht in der Anregung in einen höheren elektronischen Zustand des Moleküls, auf den ein strahlungsloser Übergang in den Schwingungsgrundzustand dieses Zustandes folgt, wobei Energie in Form von thermischer Bewegung an die Umgebung abgegeben wird. Sowie das Molekül den Schwingungsgrundzustand erreicht hat, emittiert es seine überschüssige Energie in Form von elektromagnetischer Strahlung und fällt dabei auf den elektronischen Grundzustand zurück (Abbildung 5).

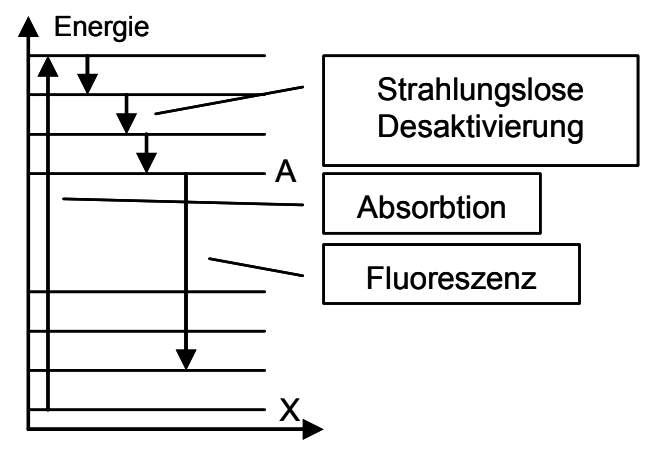

Abbildung 5: Schematische des Darstellung des Mechanismus der Fluoreszenz.

Die Messungen wurden mit freundlicher Unterstützung von Dr. Markus Rudolph auf einem SPEX Fluoromax-3 der Firma Jobin Yvon Horiba durchgeführt.

\subsubsection{NMR, Physikalische Grundlagen}

Manche Atomkerne haben einen Eigendrehimpuls, den man Spin nennt. Durch diese Eigenschaft baut der Kern ein Magnetfeld auf. Der Betrag des Spin ist $|I|=\hbar \sqrt{I(I+1)}$. Wird die Probe in ein Magnetfeld eingebracht, orientiert sich das magnetische Kernspinmoment relativ zu dem Magnetfeld, dabei präzediert es um die Richtung von $\mathrm{B}_{0}$ mit der Larmorfrequenz $v_{L}=\left|\frac{\gamma}{2 \pi}\right| B_{0}$.

Für die Komponente in Richtung des Magnetfeldes $\left|\vec{\mu}_{I}\right|_{Z}=g_{I} \mu_{K} m_{I}=m_{I} \gamma \hbar$ gibt es (2I+1) Einstellungsmöglichkeiten relativ zum Magnetfeld; für deren Energiedifferenz mit $\Delta \mathrm{m}_{\mathrm{l}}=1$ gilt: $\Delta E=\hbar \hbar B_{0}$.

Die Besetzung der einzelnen Energieniveaus folgt aus der Boltzmann-Verteilung und ist abhängig von der Größe der Aufspaltung: 


$$
\frac{N_{m_{I}+1}}{N_{m_{I}}}=\exp \left(-\Delta E / k_{B} T\right) \approx 1-\frac{\Delta E}{k_{B} T}=1-\frac{\not \hbar B_{0}}{k_{B} T} .
$$

Um eine Absorption durch Anregung in ein höheres Energieniveau zu beobachten, muß die Besetzung hinreichend unterschiedlich sein, weiterhin muß die Energie des Zusatzfeldes $\mathrm{B}_{1}$ mit der Energiedifferenz der Niveaus übereinstimmen: $\Delta E=h v_{1}$ bzw. $\gamma \hbar B_{0}=h v_{1}$, daraus folgt die Resonanzbedingung: $v_{1}=\frac{\gamma}{2 \pi} B_{0}=v_{L}$.

Durch die unterschiedlichen Eigenschaften der Molekülgruppen der Probesubstanz ist das Magnetfeld, das auf einen bestimmten Kern wirkt, ungleich dem äußeren Magnetfeld $\mathrm{B}_{0}$.

Es folgt daraus: $v_{1}=\frac{\gamma}{2 \pi} B_{e f f}=\frac{\gamma}{2 \pi}(1-\sigma) B_{0}$ mit der Abschirmkonstante $\sigma$.

Daraus resultiert eine charakteristische Frequenz für bestimmte Kerne, die von der chemischen Umgebung des Kerns abhängig ist. Auch Nachbarkerne beeinflussen die Spinresonanz: Diese Kopplung wird über Bindungselektronen vermittelt und führt bei $n$ chemisch äquivalenten Nachbarkernen mit der Spinquantenzahl $/ \mathrm{zu} 2 n /+1$ Signalen.

\subsubsection{Messverfahren}

\subsubsection{PFT-Verfahren}

Bei dem Pulse-Fourier-Transform-Verfahren werden durch einen Hochfrequenzimpuls gleichzeitig alle Kerne einer Sorte (z.B. alle $\left.{ }^{1} \mathrm{H}-K e r n e\right)$ angeregt. Der Impuls enthält ein kontinuierliches Frequenzband; die Impulslänge $\tau_{\mathrm{P}}$ liegt in der Größenordnung von einigen $\mu$ s.

Man läßt den Impuls in x-Richtung auf die Substanz einwirken, dadurch präzidieren die magn. Kernspinmomente nicht mehr in statistischer Verteilung um die z-Achse, sondern werden "gebündelt" (Phasenkohärenz) und die Energieniveaus sind gleich besetzt. Daraus resultiert ein Magnetisierungsvektor $\vec{M}$, dessen Komponente in zRichtung 0 ist, der aber eine $y$-Komponente $M_{y} \neq 0$ hat. Diesen Effekt nennt man Quermagnetisierung. Durch Relaxation kehrt das Spinsystem in seinen Gleichgewichtszustand zurück. 
Gemessen wird die zeitliche Abnahme der Quermagnetisierung (freier Induktionsabfall).

Durch Fourier-Transformation werden daraus die Resonanzfrequenzen und Intensitäten berechnet.

a.)

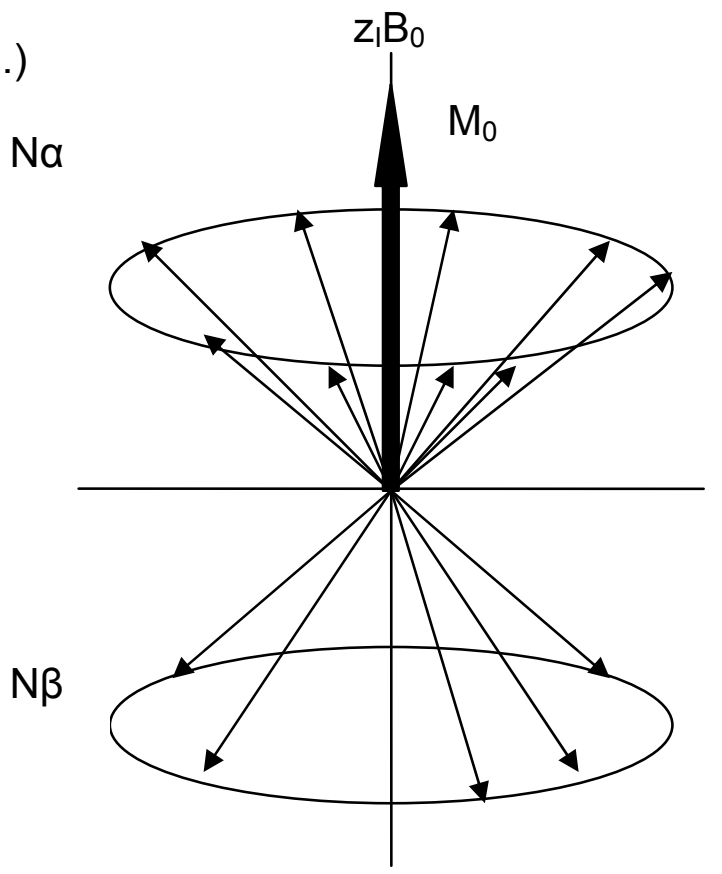

b.)

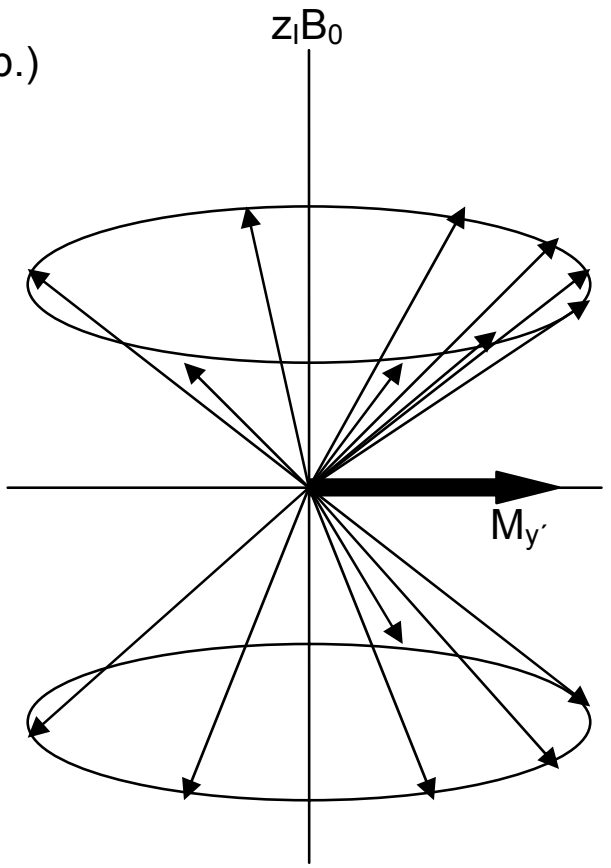

Abbildung 6: a.) Verteilung von $N(=N \alpha+N \beta)$ Kernen auf den Doppelpräzessionskegel. Da $N \alpha>$ $N \beta$, resultiert eine makroskopische Magnetisierung $M_{0}$. b.) Anschauliches Bild der Phasenkohärenz: Nach einem $90^{\circ}$-Impuls präzidieren einige, aber nicht alle, Kerne gebündelt, in Phase, um die Feldrichtung $z$.

\subsubsection{Relaxation}

Die Relaxation erfolgt durch zwei Prozesse, die nach 1.Ordnung ablaufen, und kann durch zwei Relaxationszeiten $\mathrm{T}_{1}$ und $\mathrm{T}_{2}$ beschrieben werden. Betrachtet man die Vektoren in einem Koordinatensystem $x^{\prime}$, $y^{\prime}$, das mit der Lamorfrequenz um die zAchse rotiert, so erhält man die Geschwindigkeitsgesetze: 


$$
\begin{gathered}
\frac{d M_{z}}{d t}=-\frac{M_{z}-M_{0}}{T_{1}} \\
\frac{d M_{x^{\prime}}}{d t}=-\frac{M_{x^{\prime}}}{T_{2}} \text { und } \frac{d M_{y^{\prime}}}{d t}=-\frac{M_{y^{\prime}}}{T_{2}}
\end{gathered}
$$

$\mathrm{T}_{1}$ ist hierbei die Spin-Gitter- bzw. Iongitudinale Relaxationszeit, $\mathrm{T}_{2}$ die Spin-Spinoder transversale Relaxationszeit.

Die longitudinale Relaxation kommt dadurch zustande, daß das Spinsystem wieder seine Gleichgewichtsbesetzung der Energieniveaus einnimmt, d.h. das tieferliegende Energieniveau ist stärker besetzt $\rightarrow$ Es resultiert ein magn. Moment in z-Richtung.

Bei transversaler Relaxation wird die Phasenkohärenz der einzelnen Kernspinmomente wieder aufgehoben, das magn. Moment in $y$-Richtung $\mathrm{M}_{\mathrm{y}^{\prime}}$ wird wieder 0, d.h. die Kernspinmomente präzidieren wieder in statistischer Verteilung um die z-Achse. Dieser Prozeß wird durch die Inhomogenität des Magnetfeldes induziert.

\subsubsection{Spektren}

Im Spektrum wird die Verschiebung $\delta$ gegen die Signalintensität aufgetragen. Die chemische Verschiebung berechnet man nach:

$$
\delta=\frac{v_{\text {Substanz }}-v_{\text {Re ferenz }}}{v_{\text {Re ferenz }}} * 10^{6} \quad \text { mit TMS als Referenzsubstanz }
$$

Die Feinstruktur der Spektren entsteht durch die Kopplung der Kerne untereinander; jeder Kern mit einem Kernspin $\vec{I} \neq 0$ erzeugt ein eigenes Magnetfeld, daß das effektive Magnetfeld am Ort eines benachbarten Kerns beeinflußt. Dadurch ändert sich die Resonanzbedingung, das Signal spaltet auf, da die Kopplung das Magnetfeld verstärken oder schwächen kann.

\subsubsection{Meßverfahren}

\subsubsection{CW-Spektrometer}

Bei dem Continous-Wave-Spektrometer gibt es zwei Arten der Messung: 
Bei der ersten wird das Magnetfeld $B_{0}$ konstant gehalten und die eingestrahlte Frequenz $v_{1}$ kontinuierlich verändert, bei der zweiten wird $v_{1}$ konstant gehalten und $\mathrm{B}_{0}$ variiert.

Magnetische Flußdichten bis zu 2,1 T werden durch Dauer- oder Elektromagneten erzeugt, höhere Flußdichten durch Kryomagnete.

\subsubsection{PFT-Verfahren}

Bei dem Pulse-Fourier-Transform-Verfahren werden durch einen Hochfrequenzimpuls gleichzeitig alle Kerne einer Sorte (z.B. alle $\left.{ }^{1} \mathrm{H}-K e r n e\right)$ angeregt. Der Impuls enthält ein kontinuierliches Frequenzband; die Impulslänge $\tau_{\mathrm{P}}$ liegt in der Größenordnung von einigen $\mu \mathrm{s}$.

Man läßt den Impuls in x-Richtung auf die Substanz einwirken, dadurch präzidieren die magn. Kernspinmomente nicht mehr in statistischer Verteilung um die z-Achse, sondern werden "gebündelt" (Phasenkohärenz) und die Energieniveaus sind gleich besetzt. Daraus resultiert ein Magnetisierungsvektor $\vec{M}$, dessen Komponente in zRichtung 0 ist, der aber eine $y$-Komponente $M_{y} \neq 0$ hat. Diesen Effekt nennt man Quermagnetisierung. Durch Relaxation kehrt das Spinsystem in seinen Gleichgewichtszustand zurück.

Gemessen wird die zeitliche Abnahme der Quermagnetisierung (freier Induktionsabfall).

Durch Fourier-Transformation werden daraus die Resonanzfrequenzen und Intensitäten berechnet.

1H-NMR-Spektren: Varian XL 200 (200 MHz), Varian VXR 200 (200 MHz), Varian Unity $300(300.1 \mathrm{MHz})$, Bruker AMX 300 (300.1 MHz), Varian INOVA 500 (499.8 MHz). Chemische Verschiebung $\delta$ in ppm relativ zu Tetramethylsilan als internem Standard. Kopplungskonstanten $(\mathrm{J})$ in Hz. Abkürzungen: $\mathrm{s}=$ Singulett, $\mathrm{d}=$ Dublett, $\mathrm{dd}=$ Doppeldublett, $\mathrm{t}=$ Triplett, $\mathrm{q}=$ Quartett, $\mathrm{m}=$ Multiplett, $\mathrm{br}=$ breit.

${ }^{13}$ C-NMR-Spektren: Varian XL-200 (50.3 MHz), Varian VXR-200 (50.3 MHz), Varian Unity 300 (300.1 MHz) Bruker WM 300 (75.5 MHz), Varian INOVA 500 (125.7 MHz). Chemische Verschiebung $\delta$ in ppm relativ zu Tetramethylsilan als internem Standard. 
Abkürzungen: APT (Attached Proton Test): $\mathrm{CH} / \mathrm{CH}_{3}$-Signale zeigen nach oben, $\mathrm{C} / \mathrm{CH}_{2}$-Signale zeigen nach unten.

Massenspektren: EI-MS mit Varian MAT 731 (70 eV), Varian 311A (70 eV), AMD402 (70 eV); Hochauflösungen wurden mit Perfluorkerosin als Vergleichssubstanz durchgeführt; DCI-MS mit Finnigan MAT 95 A, Reaktandgas: $\mathrm{NH}_{3}$; ESI-MS mit Quattro Triple Quadrupole Mass Spectrometer, Finnigan TSQ 7000 mit nano-ESIAPI-lonenquelle.

\subsubsection{ESR}

\subsubsection{Grundprinzip der ESR}

Bei spektroskopischen Messungen werden Energiedifferenzen zwischen Atom- oder Molekülzuständen gemessen, um Stoffe zu identifizieren, zu quantifizieren oder Einsicht in deren Struktur $z u$ bekommen. Die in der ESR untersuchten Energiedifferenzen stammen hauptsächlich von der Wechselwirkung ungepaarter Elektronen mit einem statischen Magnetfeld $B_{0}$, welches von einem starken Elektromagneten oder einem supraleitenden Magneten erzeugt wird (typische Werte liegen zwischen $B_{0}=0.1 \quad T$ und $B_{0}=5 \mathrm{~T}$ ). Dieser Effekt wird Elektron-Zeeman Wechselwirkung genannt. Da ein Elektron ein magnetisches Moment $\mu$ besitzt, verhält es sich wie eine Kompassnadel in einem Magnetfeld. Dieses magnetische Moment ist quantisiert und kann somit nur diskrete Werte annehmen. Die Energiedifferenz zwischen den Levels ist proportional zu $B_{0}$. Diese Energiedifferenz ist beim freien Elektron, welches wie der größte Teil der untersuchten Proben einen Spin $S=1 / 2$ besitzt und somit zwei verschiedene Zustände annehmen kann, gegeben durch

$$
\Delta E=h v=g_{e} \beta_{e} B_{0}
$$

wobei $\beta_{e}=9.27402 \mathrm{e}^{-24} \mathrm{JT}^{-1}$ und $g_{e}=2.00232$ sind. Für reale Proben ist $g$ ein Proportionalitätsfaktor, der häufig orientierungsabhängig (anisotrop) ist. Sein Wert hängt von der Elektronenkonfiguration des untersuchten Radikals oder Metallions ab. Eine der Hauptinformationsquellen in der ESR-Spektroskopie ist $g$. Die Wechselwirkung zwischen den ungepaarten Elektronen und den Kernspins wird als 
Hyperfeinaufspaltung bezeichnet. Diese besteht aus einem isotropen Anteil, der Kontaktwechselwirkung, welche die Aufenthaltswahrscheinlichkeit eines ungepaarten Elektrons am Kernort wiedergibt, sowie einem geringem anisotropen Anteil aufgrund der Dipol-Dipol-Wechselwirkung zwischen den magnetischen Momenten des Elektron- und des Kernspins. Die Hyperfeinaufspaltung ist die zweite wichtige Informationsquelle in ESR-Experimenten. Man erhält daraus Informationen über die Elektronendichte beim Kern, den Abstand und die Orientierung zwischen dem Kern und dem Ion mit dem ungepaarten Elektron, oder der Anzahl äquivalenter Kerne, welche mit dem Elektron gekoppelt sind. Weitere Wechselwirkungen, welche das ESR-Spektrum beeinflussen, sind die Nullfeldaufspaltung oder FeinstrukturWechselwirkung bei Proben mit $S>1 / 2$, die Kern-Quadrupol-Wechselwirkung aufgrund des elektrischen Quadrupolmoments von Kernen mit I > 1/2, und die KernZeeman Wechselwirkung.

\subsubsection{Experimentelles Vorgehen}

In einem typischen continuous wave (cw) ESR-Experiment wird die Probe mit einem Mikrowellenfeld mit konstanter Frequenz $v$ und Amplitude bestrahlt, und $B_{0}$ wird über die Resonanzlinie abgestimmt. Dies ist instrumentell einfacher zu realisieren als $v$ abzustimmen bei konstantem $B_{0}$, da es für eine empfindliche Messung wichtig ist, einen Resonator mit hoher Güte $Q$ (gewöhnlich bis $Q=10000$ in cw Experimenten) verwenden zu können. Da die Aufspaltung der Energieniveaus abhängig von $B_{0}$ ist, kann es bei gewissen Proben sinnvoll sein, Messungen bei verschiedenen Frequenzen aufzunehmen. Die verschiedenen Mikrowellenbereiche werden in sogenannte "Bänder" aufgeteilt. Die in der ESR-Spektroskopie wichtigsten Bänder sind in Tabelle 11 aufgeführt. 
Tabelle 11: Übersicht über die verschiedenen ESR-Bänder

\begin{tabular}{|c|c|c|}
\hline Mikrowellenband & $\begin{array}{c}\text { Frequenz } \\
(\mathrm{GHz})\end{array}$ & $B_{0}(\mathrm{~T})$ \\
\hline $\mathrm{L}$ & 1 & 0,036 \\
\hline $\mathrm{S}$ & 3 & 0,11 \\
\hline $\mathrm{X}$ & 9,5 & 0,36 \\
\hline $\mathrm{Q}$ & 35 & 1,25 \\
\hline $\mathrm{W}$ & 95 & 3,4 \\
\hline
\end{tabular}

Um die Empfindlichkeit zu erhöhen, wird $B_{0}$ sinusoid moduliert mit einer Frequenz von typischerweise $100 \mathrm{kHz}$ und einer Amplitude, welche deutlich unter der Breite der Resonanzlinie liegt. Nach der Demodulation erhält man aus diesem Grund nicht direkt das Absorptionssignal, sondern dessen erste Ableitung.

Die Spektren wurden in Zusammenarbeit mit Frau Dr. A.C. Stückl und Herrn Prof. F. Meyer (Institut für anorganische Chemie, Göttingen) auf einem Elexsys X-Band ESR von Brucker aufgenommen. 


\section{Experimente und Ergebnisse}

\subsection{Untersuchung der $\alpha-$ Galaktosidase MelA aus E. coli K12}

Das Gen für die a-Glukosidase MelA aus E. coli K12 wurde bereits früher (Nagao et al., 1988) kloniert und sequenziert. Dieses Enzym begründete eine neue Glycosidhydrolase-Familie, die GHF4. E. coli benötigt zusätzlich für den Melibioseumsatz einen Transporter MelB, der sehr stark temperatursensitiv ist (Tamai et al, 1988). Alle Mitglieder der GHF4 sind NAD+-abhängig und besitzen Nterminal gelegen eine hochkonservierte Sequenz Gly-Xxx-Gly-Ser (GXGS). Dieses Motiv hat gewisse Ähnlichkeit mit einem konservierten Sequenzmotiv des Rossmann-Fold, bestehend aus einer alternierenden Abfolge von $\beta$-Strängen und $\alpha-$ Helices $(\beta \alpha \beta a \beta)$, die eine konservierte strukturelle Region für die Bindung eines Cofaktors in Proteinen darstellt. Im klassischen Rossmann-Fold Motiv ist eine glycinreiche Sequenz innerhalb des ersten $\beta$-Strangs wichtig (GXGXXG), die über eine Schleife den ersten $\beta$-Strang mit der folgenden $\alpha$-Helix verbindet. Diese ist maßgeblich an der $\mathrm{NAD}^{+}$-Bindung beteiligt. MelA weist ohne $\mathrm{NAD}^{+}$nur eine sehr geringe Aktivität auf. Neben der Abhängigkeit von $\mathrm{NAD}^{+}$benötigt das Enzym für seine Funktion $\mathrm{Mn}^{2+}$-Ionen und stark reduzierende Bedingungen durch Anwesenheit von DTT (Raasch et al., 2000). Die Funktionalität des oben genannten Motivs für die Bindung in einem GHF4-Enzym wurde über ortsspezifische Mutagenese nachgewiesen (Raasch et al., 2002).

Aufgrund seiner hohen Instabilität konnte MelA nicht charakterisiert werden. Im Rohextrakt konnte letztlich eine Teilcharakterisierung vorgenommen werden, bei der die ungewöhnliche Kombination der Cofaktoren $\mathrm{Mn}^{2+}, \mathrm{NAD}^{+}$und Mercaptoethanol auffiel (Nagao et al., 1988). Damit begründete dieses Enzym eine neue Familie, die sich durch eine hohe Abhängigkeit von zweiwertigen Metallionen, meist $\mathrm{Mn}^{2+}, \mathrm{NAD}^{+}$ und einer Thiolkomponente auszeichnen. In einer vorangegangenen Arbeit (Raasch et al., 2001) wurde das Gen für die a-Glukosidase AglA aus T. maritima kloniert und 
charakterisiert. Auch AgIA zeigte eine hohe Instabilität, die sich aber auf einer Restaktivität stabilisierte. Bei der Kristallisation von AgIA fiel das Cys174 auf, welches eine hochkonservierte Aminosäure in dieser Enzymfamilie darstellt. Es liegt direkt im aktiven Zentrum und ist in AglA doppelt oxidiert (Lodge et al., 2003).

\subsubsection{KIonierung des MelA-Gens aus E. coli K12}

Die Isolierung von MelA erfolgte aus der genomischen DNA von E. coli K12 mit Hilfe von Amplifikation durch PCR. Die verwendeten Primer waren 27 bzw. 33 bp lang und enthielten für die Klonierung geeignete Restriktionsschnittstelle

\begin{tabular}{|l|l|c|}
\hline Bezeichnung & \multicolumn{1}{|c|}{ Primer-Sequenz $\left(5^{\prime} \rightarrow 6^{\prime}\right)$} & Schnittstelle \\
\hline MelA_forward & $\begin{array}{l}\text { GGG GGA TCC ATG ATG TCT GCA CCC } \\
\text { AAA ATT ACA }\end{array}$ & BamHI \\
\hline MelA_reverse & $\begin{array}{l}\text { GGG } \text { AAG CTT TTA ACG GTG CAA CCA } \\
\text { GCC }\end{array}$ & HindlII \\
\hline
\end{tabular}

\begin{tabular}{|c|c|}
\hline$\overline{\text { Substanz }}$ & Volumen $[\mu \mathrm{l}]$ \\
\hline $\begin{array}{l}\text { Pfu-Polymerase-Puffer } \\
\text { fach) }\end{array}$ & $(10-$ \\
\hline dNTP-Mix (10 mM) & 2,0 \\
\hline Template-DNA & 2,0 \\
\hline Primer „MelA forward“ * & 0,5 \\
\hline Primer „MelA reverse“ * & 0,5 \\
\hline Pfu-Polymerase & 1,0 \\
\hline DMSO & 5,0 \\
\hline $\mathrm{H}_{2} \mathrm{O}_{\text {bidest }}$ & 34,0 \\
\hline Gesamtvolumen & 50,0 \\
\hline
\end{tabular}


Tabelle 12: PCR-Bedingungen

$\left.\begin{array}{cccc}\hline & \text { Temperatur }\left[{ }^{\circ} \mathbf{C}\right] & \text { Zeit }[\mathrm{min}] & \text { Reaktion } \\ \hline 1 & 95,0 & 10: 00 & \text { Denaturierung } \\ 2 & 95,0 & 1: 00 & \text { Denaturierung } \\ 3 & 40,0-50,0 \text { Gradient } & 0: 45 & \text { Primer-Annealing } \\ 4 & 72,0 & 2: 00 & \text { Primer- } \\ & & & \text { Verlängerung } \\ 5 & 72,0 & 10: 00 & \text { End-Verlängerung }\end{array}\right\}$

Der PCR-Ansatz wurde bei den angegebenen Bedingungen inkubiert und anschließend wurde das 1,4 kb PCR-Produkt nach der elektrophoretischern Auftrennung aus dem Agarose-Gel extrahiert. Der pDrive Cloning Vektor ist Teil eines Qiagen PCR Cloning Kits, welches einen linearisierten Klonierungsvektor enthält, der an seinen Enden einen einzelsträngigen U-Überhang trägt. Durch diese „sticky ends" wird eine hochspezifische Hybridisierung mit A-Überhang tragenden PCR-Fragmenten gewährleistet. A-Überhänge werden durch Amplifikation mit TaqPolymerase und anderen DNA-Polymerasen ohne Korrekturleseaktivität erhalten, nicht jedoch durch Amplifikation mit der hier verwendeten Pfu-Polymerase, die Korrekturleseaktivität aufweist. Aus diesem Grund wurde an das unter amplifizierte 1,4 kb große MelA-DNA Fragment ein A-Überhang angefügt, der die Ligation mit dem pDrive Cloning Vektor ermöglichte.

Dieses wurde nun mit dem pDrive-Vektor ligiert und in E. coli XL1blue transformiert. Nach Kolonie-PCR mit den in Tabelle 13 aufgeführten Primern (Bedingungen siehe Tabelle 12) wurde ein Klon mit korrekt inseriertem PCR-Fragment ausgewählt und unter Verwendung der neu eingefügten Schnittstellen BamHI/ Hindlll in den Vektor pQE30 kloniert (Abbildung 7). Dieses neue Konstrukt wurde nun zur heterologen Expression in den Stamm E. coli M15 elektroporiert.

Tabelle 13: Primer für die Kolonie-PCR

\begin{tabular}{|l|l|}
\hline Bezeichnung & \multicolumn{1}{|c|}{ Primer-Sequenz $\left(5^{\prime} \rightarrow 6^{\prime}\right)$} \\
\hline M13forward & GTAAAACGACGGCCAGT \\
\hline M13reverse & GTTTTCCCAGTCACGAC \\
\hline
\end{tabular}




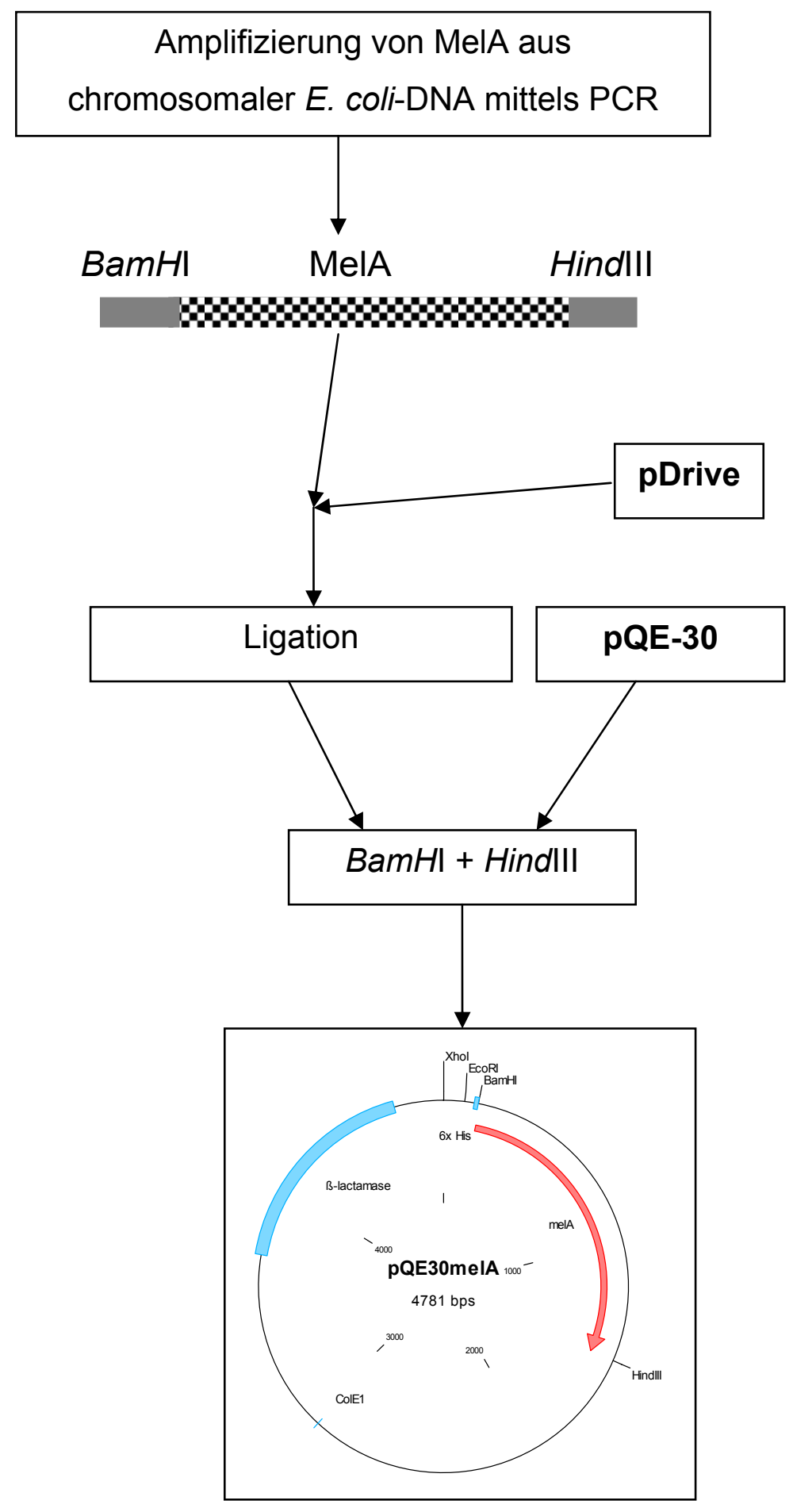

Abbildung 7: Klonierungsstrategie 


\subsection{Anzucht und Aufreinigung}

Für eine Charakterisierung wurde MelA im präparativen Maßstab gewonnen. Hierfür wurden 1,5 I LB Amp $_{\text {mit }} 30 \mathrm{ml}$ Inokulum angeimpft und bei einer $\mathrm{OD}_{600}$ von 0,5-0,6 mit 0,5 mM (Endkonzentration) IPTG induziert. Danach wurde über Nacht unter kräftiger Belüftung bei $37^{\circ} \mathrm{C}$ inkubiert. Die Zellen wurden anschließend bei $7000 \mathrm{Upm}$ in GS3Bechern geerntet, in LEW-Puffer des Protino ${ }^{\circledR} \mathrm{Ni} 2000$ Kit von Machery-Nagel aufgenommen und mittels einer French Pressure Cell aufgeschlossen. Der Rohextrakt wurde zur Reinigung der mit einem $\mathrm{His}_{6}$-tag versehenen MelA-Proteins gemäß Protokoll der Firma Machery-Nagel weiter aufgearbeitet.

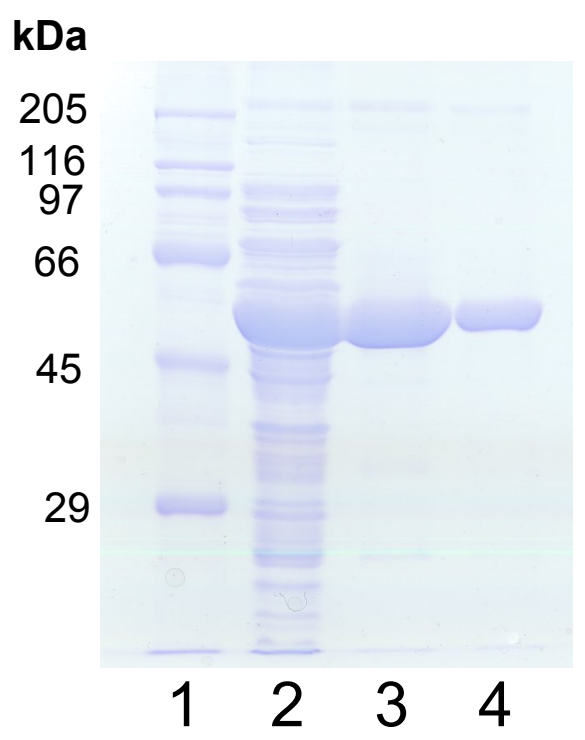

Abbildung 8: SDS-PAGE-Analyse der Reinigungsschritte von MelA (Spur 1: Marker, Spur 2: Rohextrakt, Spur 3: Waschfraktion, Spur 4: MelA)

Das Enzym zeigte in reiner Form eine stark schwankende Anfangsaktivität. Trotz identischer Aufreinigungsbedingungen ließ sich keine reproduzierbare Aktivitätsbestimmung durchführen. Weitere Versuche, die Bedingungen zu optimieren scheiterten zunächst. Bei all diesen Versuchen war die Stammlösung des Substrats (para-Nitrophenyl-a-D-galaktopyranosid) standardmäßig in DMSO gelöst. Nachdem dieses Lösungsmittel durch Wasser ersetzt wurde, ließen sich stabile Anfangsaktivitäten ermitteln. Trotzdem verlor das Enzym innerhalb weniger Stunden seine Aktivität. Eine Charakterisierung war unter diesen Bedingungen noch nicht 
möglich. Thompson et al., beschrieb 1999, daß sich der Aktivitätsverlust eines anderen GHF4-Enzyms, GlvA von B. subtilis, durch Zugabe der entsprechenden Cofaktoren deutlich herauszögern ließ. Daraufhin wurden verschiedene Kombinationen der Cofaktoren in $1 \mathrm{mM}$ Endkonzentration zugegeben und der Aktivitätsverlust über eine längere Zeit verfolgt (Abbildung 9). Bei Zugabe von NAD ${ }^{+}$ und $\mathrm{Mn}^{2+}$ konnte die Aktivität über zwei Wochen fast zu $80 \%$ konserviert werden.

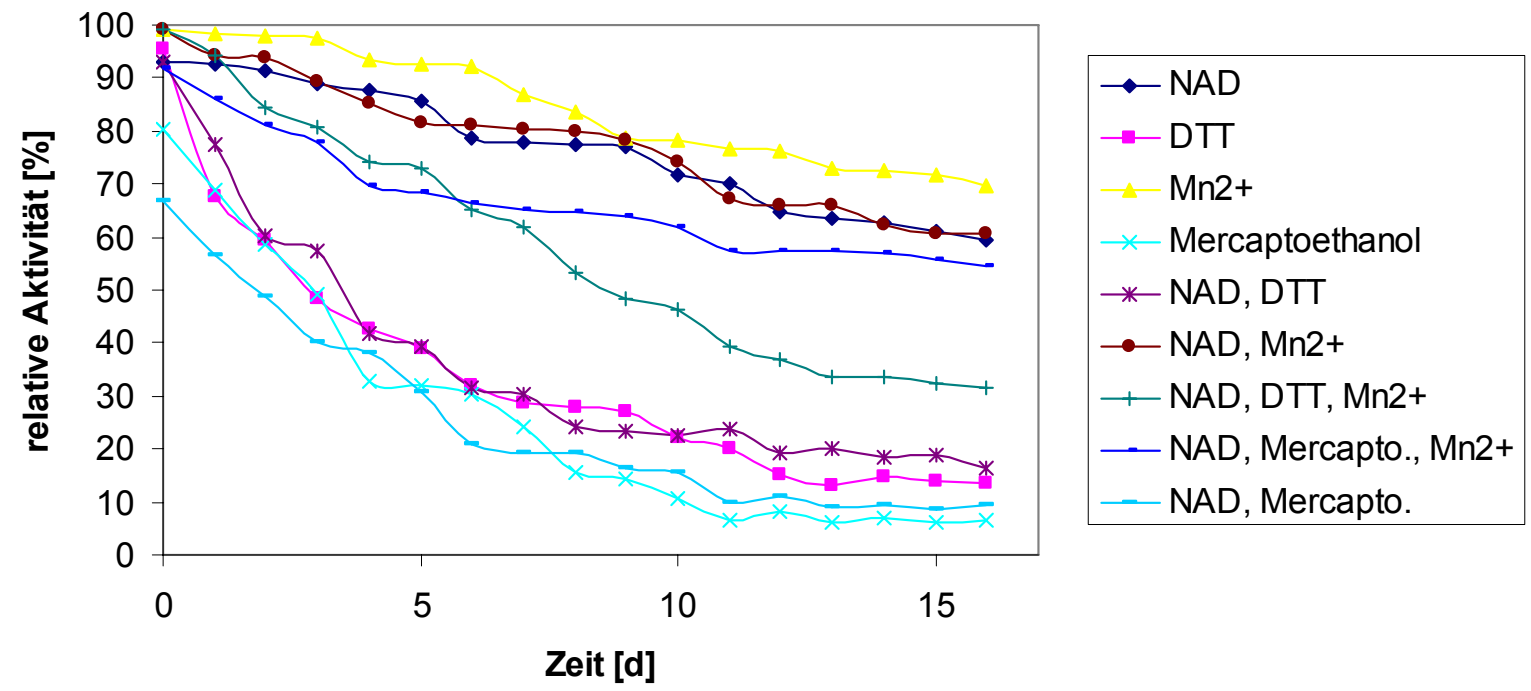

\section{Abbildung 9: Lagerungsbedingungen}

Schon die alleinige Anwesenheit von $\mathrm{Mn}^{2+}$-Ionen reicht aus, um die Aktivität über fast eine Woche praktisch unverändert zu erhalten (Abbildung 9). Damit war eine genaue Charakterisierung möglich. 


\subsection{Charakterisierung der rekombinanten $\alpha$-Galaktosidase} MelA

\subsubsection{Untersuchungen zum Oligomerisierungsgrad der $\alpha$ - Galaktosidase MelA aus E. coli}

Der Oligomerisierungsgrad wurde über Gelfitration ermittelt. Hierfür diente eine Superose-6-Gelfiltrationssäule der Firma Pharmacia.

Parameter des Superose 6 Säulenlaufs

Medium: $\quad$ Superose 6

Säule: $\quad 10 / 300 \mathrm{GL}$

Säulenvolumen: $\quad 23,56 \mathrm{ml}$

Probe: $\quad 1000 \mu \mathrm{g}$

Puffer A: $\quad 50 \mathrm{mM}$ HEPES, $\mathrm{pH}=7$

Flussrate: $\quad 0,5 \mathrm{ml} / \mathrm{min}$

Equilibrierung: 2 SV Puffer A

Lauf: $\quad 100 \%$ Puffer A (1,5 SV)

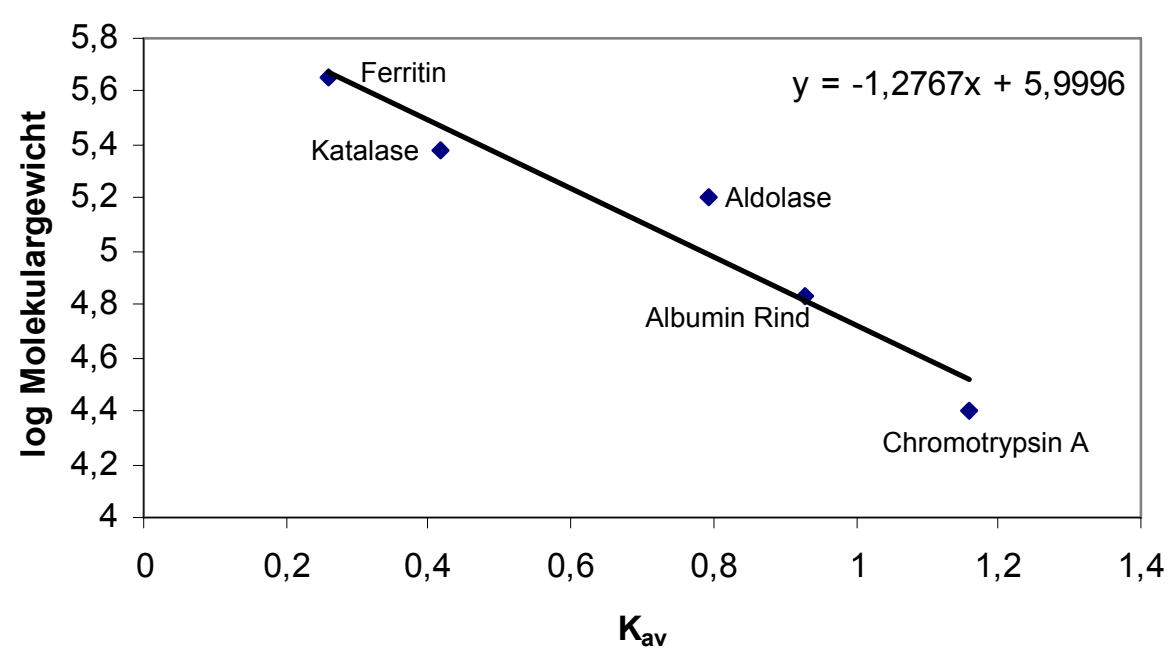

Abbildung 10: Eichgerade zur Superose 6 17/300 GL Säule 


$$
\text { Es gilt: } K_{a v}=\frac{\left(v_{e}-v_{0}\right)}{\left(v_{t}-v_{0}\right)} \text { mit } \mathrm{v}_{0}=7,77 \mathrm{ml} \text { und } \mathrm{v}_{\mathrm{t}}=23,56 \mathrm{ml}
$$

Für MelA wurde ein Elutionsvolumen von 13,61 ml ermittelt. Mit der aus der Regressionsgraden abgeleiteten Formel

$$
\log M W[k D a]=-1,2767^{*} K_{a v}+5,9996
$$

errechnete sich für das native Enzym eine Molekularmasse von 336 kDa. Das entspricht etwa der sechsfachen Masse der aus dem SDS-Gel abgeleiteten Größe

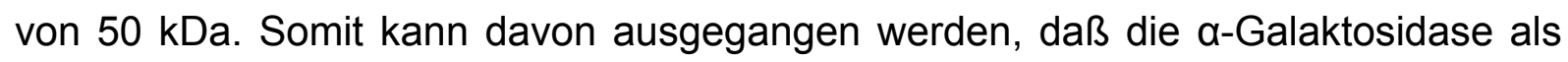
Hexamer vorliegt. Aus Vorversuchen war bekannt, daß das Enzym seine Aktivität schnell verlor. Forcierte man diesen Aktivitätsverlust durch eine erhöhte Lagerungstemperatur ohne Cofaktoren, ergab sich ein neues Bild bei der Gelfiltration. Der Hauptpeak bei $13,61 \mathrm{ml}$ wurde etwas kleiner, und ein neuer Peak bei 22,95 ml tauchte zusätzlich auf. Dieser entspricht einer Molekularmasse von ca. 59 kDa. Da dieser Lauf aus derselben Fraktion stammte, wie der erste, kann man davon ausgehen, daß durch die Alterung und bereits deutlich messbare Inaktivierung, sich der Olimerisierungsgrad des Enzyms geändert hat. Es scheint sich im inaktiven Zustand als Monomer darzustellen. 


\subsubsection{Substratspektrum}

Ein sehr breit angelegtes Screening mit verschiedenen $\alpha-, \beta$-Substraten und zudem mit unterschiedlichem Oligomerisierungsgrad zeigte, daß MelA im Gegensatz zu AglA aus T. maritima (Raasch et al. 2001), nur a-galaktosidische Bindungen spalten kann (2.4.3.4).

\begin{tabular}{|l|c|}
\hline Substrate & MelA \\
\hline Polymere & \\
\hline $\begin{array}{l}\text { A-Dextran, Glycogen, Dextran, } \\
\text { Amylopectin }\end{array}$ & - \\
Stärke & \\
\hline Maltoologosaccharide & - \\
\hline Maltotriose, Maltotetraose, Maltopantaose, \\
Maltohexaose, Maltoheptaose & \\
\hline Cyclodextrine & \\
\hline Y-Cyclodextrin, $\beta$-Cydclodextrin, & - \\
$\alpha-C y c l o d e x t r i n$ & \\
\hline Disccharide & - \\
\hline $\begin{array}{l}\text { Maltose } \\
\text { Raffinose } \\
\text { Saccharose } \\
\text { Cellobiose } \\
\text { Melibiose } \\
\text { Lactose }\end{array}$ & - \\
\hline Synthetische Substrate & - \\
\hline $\begin{array}{l}\text { pNP- } \alpha-D-G l u k o s e \\
\text { pNP- } \beta-D-G l u k o s e \\
\text { pNP- } \alpha-D-G a l a k t o s e\end{array}$ & - \\
pNP- $\beta-D-G a l a k t o s e$ & - \\
\hline
\end{tabular}




\subsubsection{Enzymkinetik}

Für die Ermittlung der kinetischen Daten der a-Galaktosidase MelA wurde die Aktivität des Enzyms mit steigender Konzentration an para-Nitrophenyl-a-Dgalaktopyranosid (pNP- $\alpha-G a l$ ) bestimmt (2.4.2.9) (Abbildung 11). In den folgenden Abbildungen finden sich die entsprechenden Michaelis-Menten-, Lineweaver-Burkeund Eadie-Hofstee-Auftragungen zur Berechnung von $K_{m}$ und $v_{\max }$.

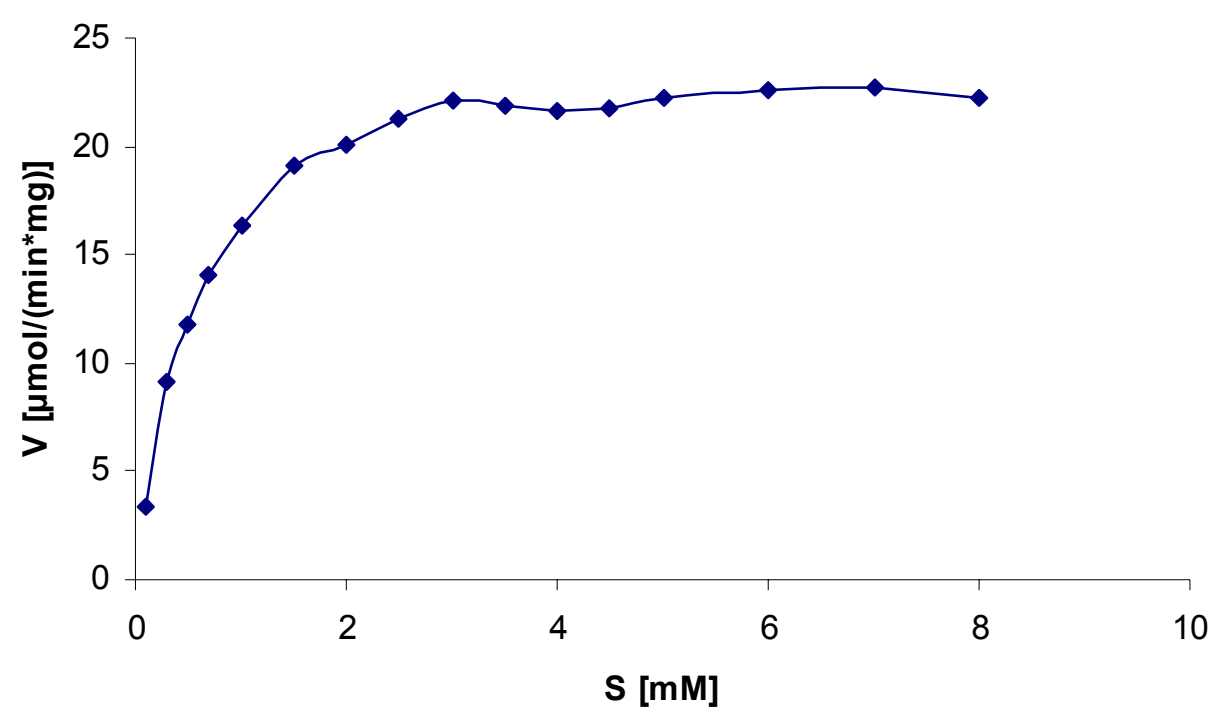

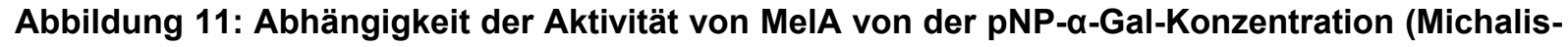
Menten-Diagramm). 


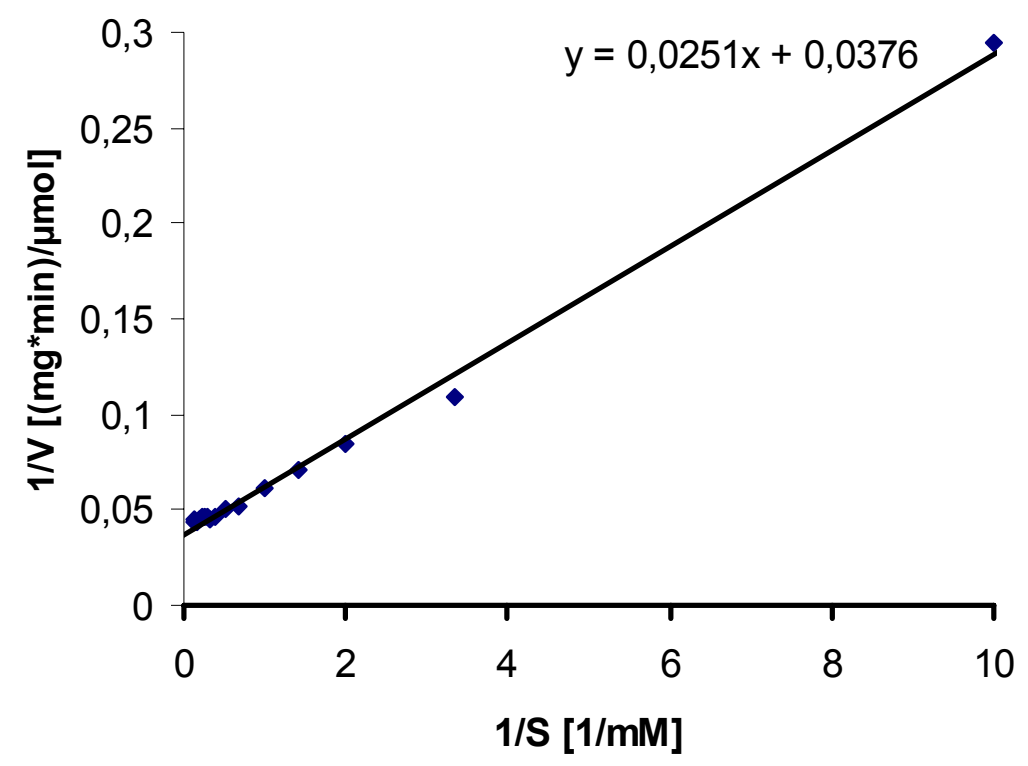

Abbildung 12: Darstellung der Daten aus Abbildung 11 als Lineweaver-Burke-Diagramm

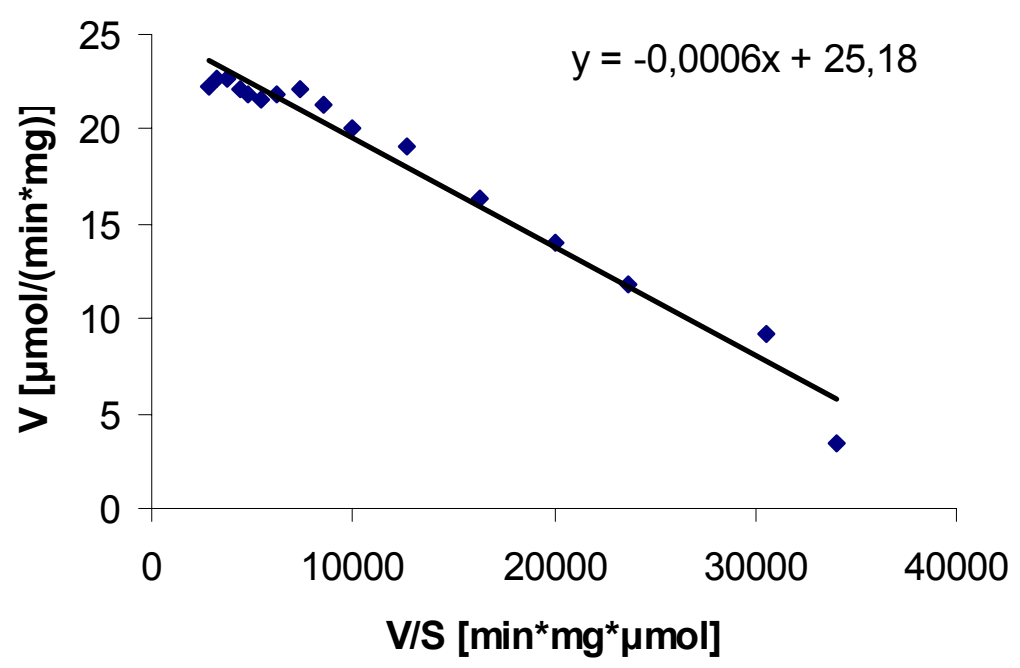

Abbildung 13: Darstellung der Daten aus Abbildung 11 als Eadie-Hofstee-Diagramm 
Für die Aktivität an pNP-a-Gal ergeben sich aus dem Lineweaver-Burke- und EadieHofstee-Diagramm ergeben sich die in Tabelle 14 dargestellten Werte für $K_{\mathrm{m}}$ und $v_{\max }:$

Tabelle 14: Kinetische Parameter der pNP- $\alpha-$ Gal-Hydrolyse durch MelA.

\begin{tabular}{|c|c|c|}
\hline & Lineweaver-Burke & Eadie-Hofstee \\
\hline$K_{\mathrm{m}}$ & $0,04 \mathrm{mM}$ & $0,02 \mathrm{mM}$ \\
\hline $\mathrm{V}_{\max }$ & $25,1 \mu \mathrm{mol} / \mathrm{min}^{*} \mathrm{mg}$ & $25,2 \mu \mathrm{mol} / \mathrm{min}^{*} \mathrm{mg}$ \\
\hline
\end{tabular}

\subsubsection{Bestimmung des $\mathrm{pH}-O p t i m u m s$}

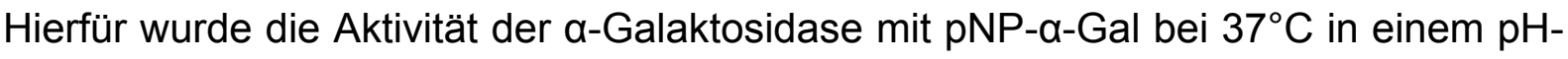
Bereich zwischen 5,5 und 10 bestimmt. Es wurden folgende Puffer für die verschieden $\mathrm{pH}-$ Bereiche verwendet: Natriumsuccinat $(\mathrm{pH}$ 5.5-7.0), HEPES (pH 7.08.5), 3-(cyclohexylamino)-1-propanesulfonsäure (CAPS; pH 9.0-10).

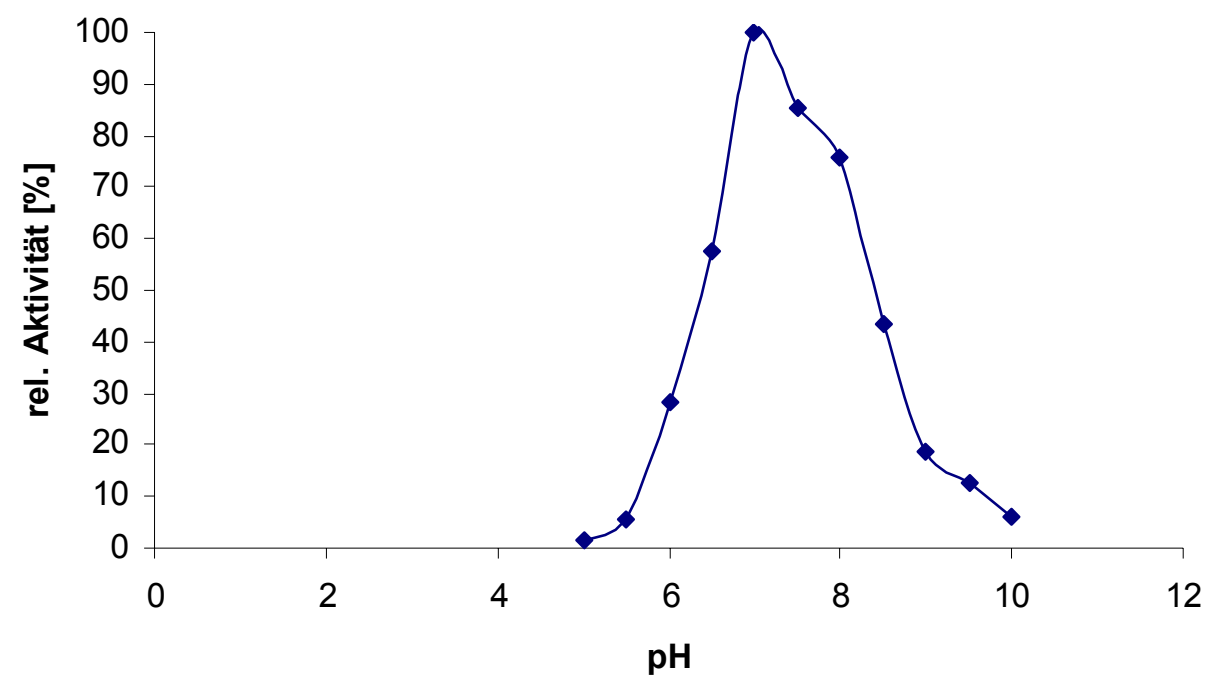

Abbildung 14: Bestimmung des pH-Optimums der $\alpha$-Galaktosidase 
Es zeigte sich ein Aktivitätsmaximum bei einem $\mathrm{pH}-$ Wert von 7 , wobei alle Meßpunkte prozentual in Relation zur höchsten Aktivität gesetzt wurden.

\subsubsection{Bestimmung des „Temperaturoptimums“}

Analog zur Messung der optimalen Aktivität, in Abhängigkeit von der $\mathrm{H}^{+}$lonenkonzentration, wurde in diesem Fall der Temperaturbereich gesucht, in dem das Enzym seine größte Aktivität an pNP-a-Gal entfaltet (2.4.3.2).

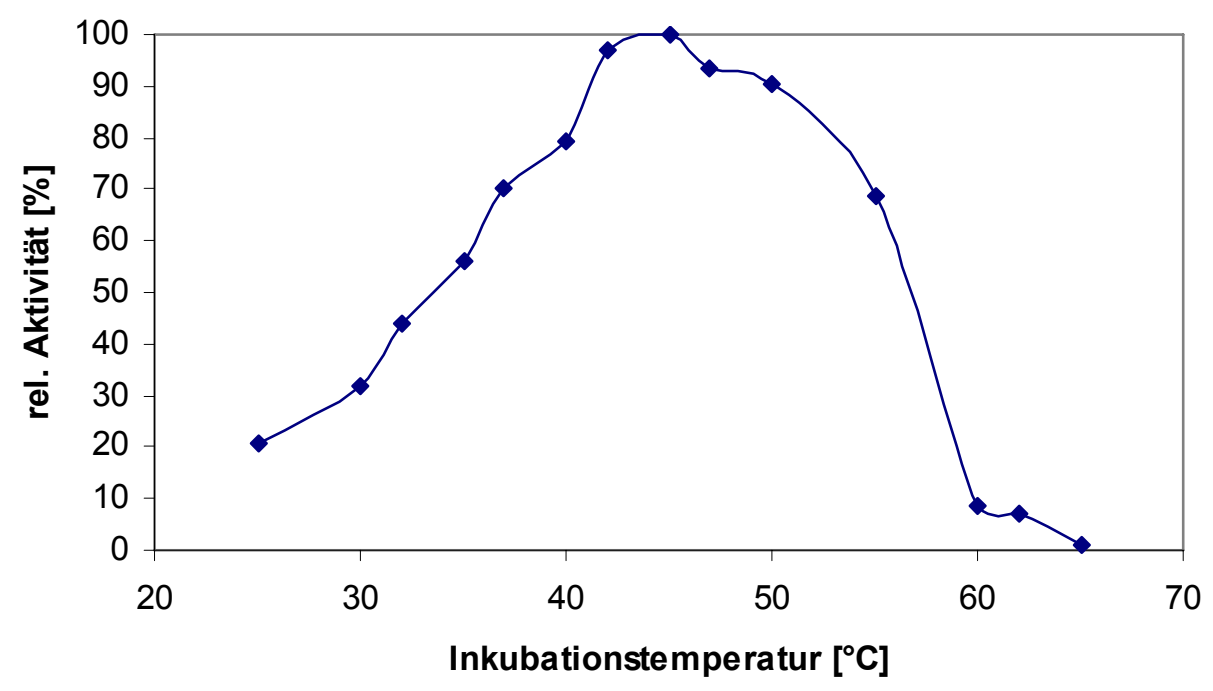

Abbildung 15: Bestimmung des „Temperaturoptimums“ der $\alpha$-Galaktosidase MelA in 100 mM HEPES pH 7.

Die höchste Aktivität der $\alpha$-Galaktosidase wurden bei $42^{\circ} \mathrm{C}$ und $\mathrm{pH} 7$ ermittelt. Alle nachfolgenden Tests wurden dann bei $37^{\circ} \mathrm{C}$ und $\mathrm{pH} 7$ durchgeführt. Eine Inkubationstemperatur von $5^{\circ} \mathrm{C}$ unter dem Temperaturoptimum sollte verhindern, daß das Enzym während der Aktivitätsbestimmung zu stark inaktiviert wurde und somit die Messungen verfälschte. 


\subsubsection{Bestimmung der Thermostäbilität}

Es wurde wie unter 2.4.2.9 beschrieben vorgegangen. Die Ansätze wurden bei den entsprechenden Temperaturen vorinkubiert. Dabei wurden jeweils $10 \mu \mathrm{g}$ Enzym pro Messung eingesetzt. Die Vorinkubation erfolgte bei 37, 42, 45, 50 und $60^{\circ} \mathrm{C}$. Das Ergebnis der thermischen Inaktivierung ist in Abbildung 16 dargestellt.

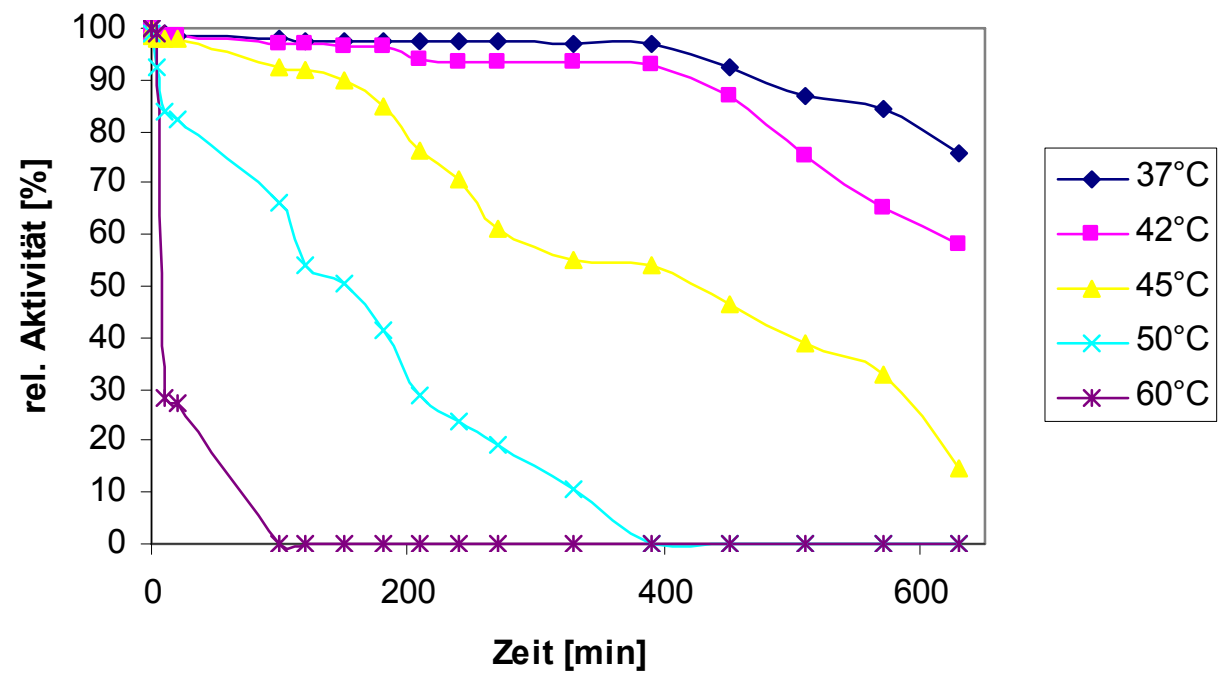

\section{Abbildung 16:Temperaturinaktivierung}

Wie aus Abbildung 16 hervorgeht, wurde die Aktivität nach über acht Stunden bei $37^{\circ} \mathrm{C}$ nicht beeinträchtigt. Bei Temperaturen über $45^{\circ} \mathrm{C}$ tritt jedoch nach drei Stunden ein zügiger Aktivitätsverlust ein. 


\subsubsection{Abhängigkeit der $\alpha$-Galaktosidase von Cofaktoren}

Wie schon aus der GHF4 bekannt ist, benötigt MelA für seine Aktivität verschiedene Cofaktoren. Nagao et al. (1988) haben bereits eine erste Charakterisierung von MelA im Rohextrakt vorgenommen. Für das gereinigte MelA wurden nun folgende optimale Endkonzentrationen der Cofaktoren ermittelt:

$\begin{array}{ll}\mathrm{NAD}^{+} & 0,6 \mathrm{mM} \\ \text { DTT } & 0,25 \mathrm{M} \\ \mathrm{Mn}^{2+} & 0,15 \mathrm{mM} \\ \text { HEPES pH } 7^{37^{\circ} \mathrm{C}} & 0,1 \mathrm{M}\end{array}$



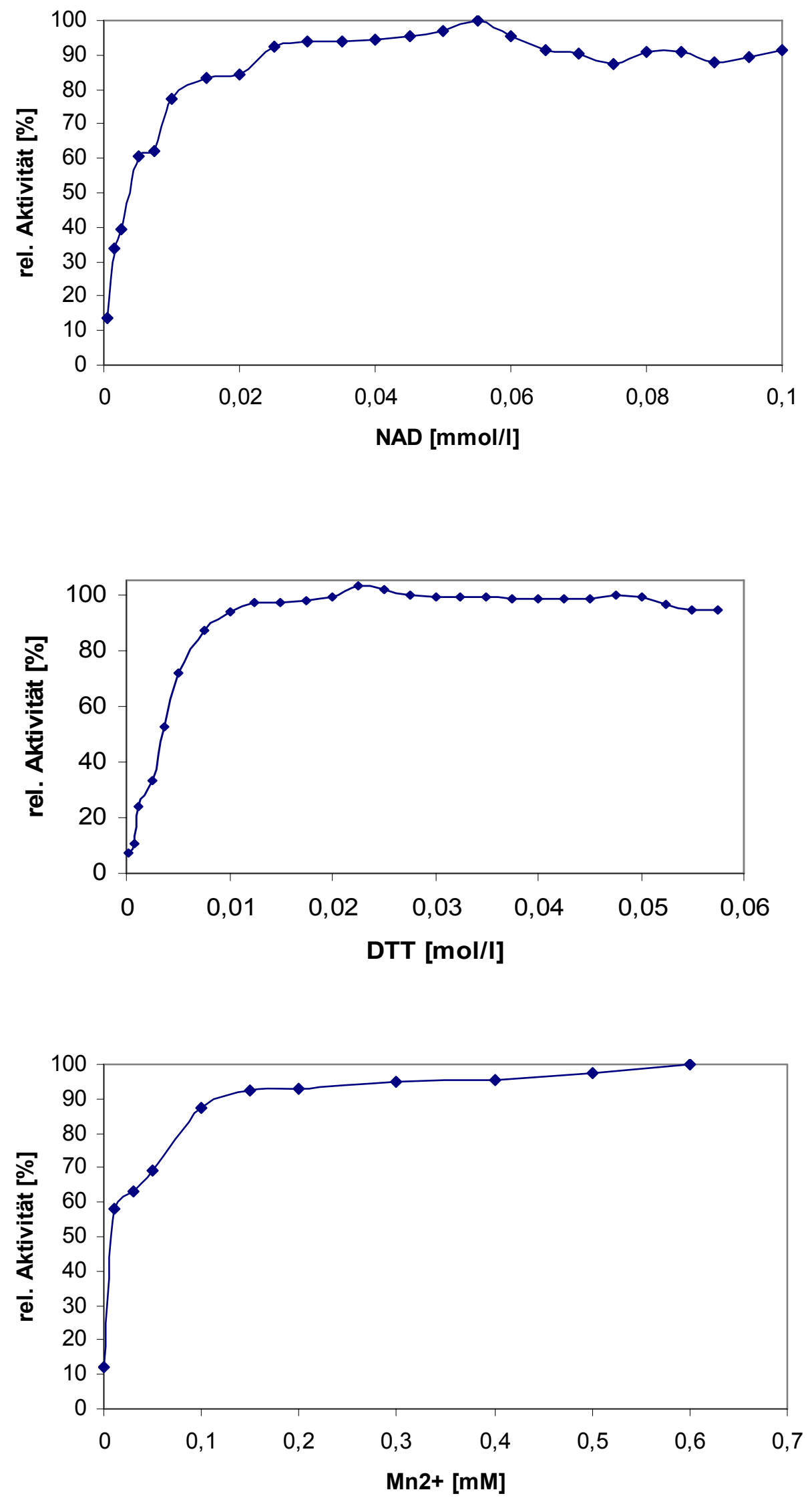

Abbildung 17: Zusammenfassung der Cofaktoren 
Erstaunlicherweise ist MelA nur durch $\mathrm{Mn}^{2+}$-Ionen zu aktivieren. Alle getesteten zweiwertigen lonen $\left(\mathrm{Ca}^{2+}, \mathrm{Co}^{2+}, \mathrm{Zn}^{2+}, \mathrm{Ba}^{2+}, \mathrm{Ni}^{2+}, \mathrm{Cu}^{2+}, \mathrm{Sr}^{2+}, \mathrm{Mg}^{2+}\right.$ und $\left.\mathrm{Fe}^{2+}\right)$ konnten das Enzym nicht aktivieren.

DTT brachte eine deutliche Aktivitätssteigerung gegenüber Mercaptoethanol. Im folgenden Diagramm (Abbildung 18) sind beide Reduktionsmittel im Vergleich zusammengestellt.

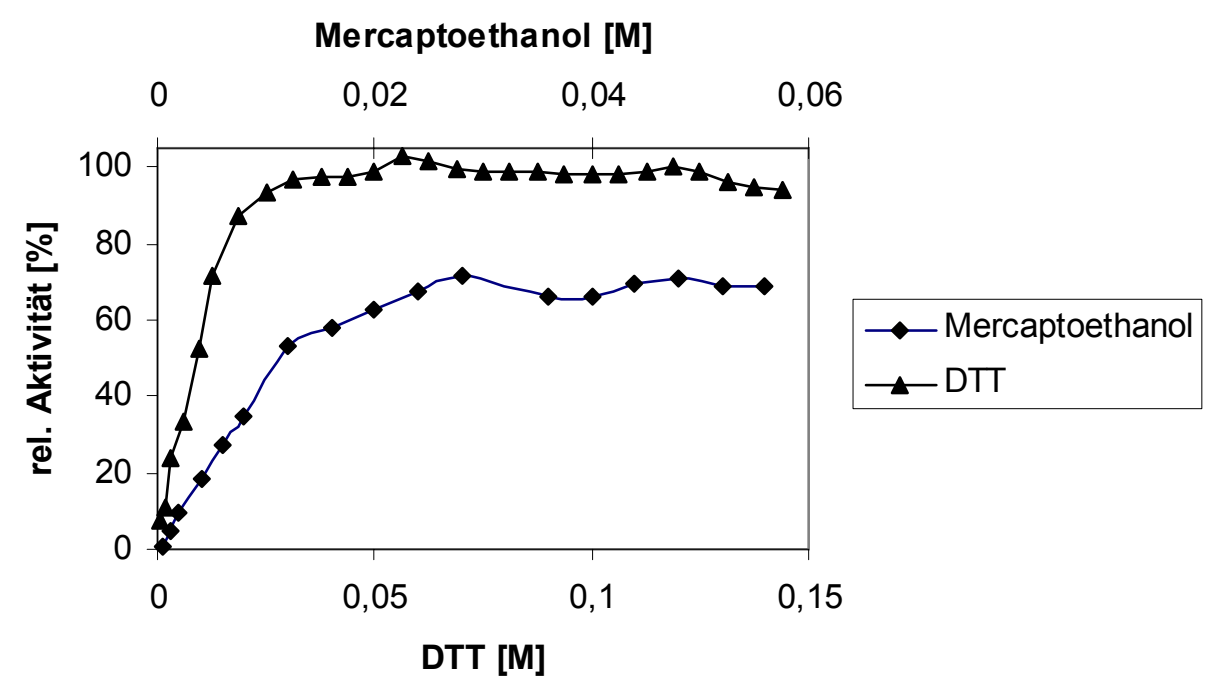

Abbildung 18: Gegenüberstellung von DTT und Mercaptoethanol 


\subsubsection{Untersuchung zum zeitlichen Verlauf der Substrathydrolyse}

Im Gegensatz zu AglA aus T. maritima vermag MelA seine Substrate $(0,04 \%)$ praktisch vollständig abzubauen. Stellvertretend für die Substrate ist in der folgenden DC der Abbau von Melibose dargestellt. Es wurden im Abstand von 5 min Proben entnommen und sofort bei $-20^{\circ} \mathrm{C}$ gelagert, um einen weiteren Umsatz durch das Enzym zu stoppen.

Der Inkubationsansatz enthielt folgende Komponeneten:

$\begin{array}{ll}\mathrm{Mn}^{2+}(6 \mathrm{mM}) & 50 \mu \mathrm{l} \\ \operatorname{NAD}^{+}(1,5 \mathrm{mM}) & 50 \mu \mathrm{l} \\ \operatorname{DTT}(0,25 \mathrm{M}) & 50 \mu \mathrm{l} \\ \text { HEPES }(0,1 \mathrm{M}) & 100 \mu \mathrm{l} \\ \text { Melibiose } 2 \% & 10 \mu \mathrm{l} \\ \text { Enzym }(5 \mathrm{mg} / \mathrm{ml}) & 10 \mu \mathrm{l} \\ \mathrm{H}_{2} \mathrm{O}_{\text {bidest }} & 220 \mu \mathrm{l}\end{array}$

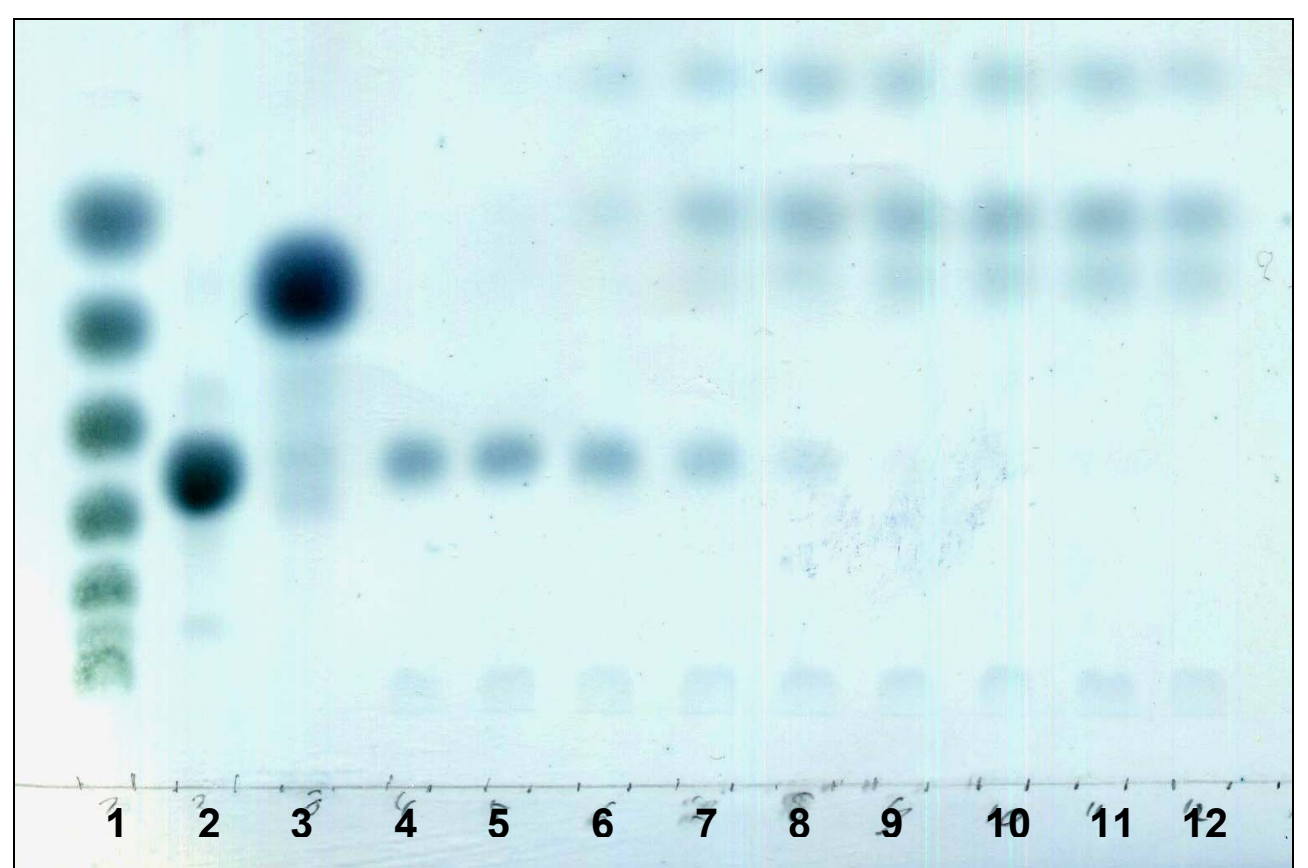

Abbildung 19: Dünnschichtchromatographie über den Abbau von Melibiose. Spur 1: Marker G1-G7; Spur 2: Melibiose; Spur 3: Galaktose; Spuren 4-12: 5-min-Aliquots 
Die Enzymmenge betrug $5 \mu \mathrm{g}$ pro $500 \mu \mathrm{l}$. Als Laufmittel diente 1-Propanol, Essigester und $\mathrm{H}_{2} \mathrm{O}_{\text {bidest }}$ im Verhältnis 70:10:20. Es wurden je Ansatz $2 \mu \mathrm{l}$ aufgetragen und mit folgendem Sprühreagenz entwickelt $\left(10 \mathrm{~min}, 140^{\circ} \mathrm{C}\right)$ :

\section{Sprühreagenz:}

$\begin{array}{ll}\text { Anilin } & 1 \mathrm{ml} \\ \text { Diphenylamin } & 1 \mathrm{~g} \\ \text { Aceton } & 100 \mathrm{ml}\end{array}$

Lagerung lichtgeschützt bei $4^{\circ} \mathrm{C}$

Kurz vor dem Auftragen auf die DC wurden 1/10 Vol. Phosphorsäure zugegeben.

\subsubsection{Spektroskopische Untersuchungen mittels NMR}

Da nicht geklärt war, ob die Enzyme der GHF4 die Spaltung der Kohlenhydrate unter Inversion oder Retention am anomeren Zentrum durchführten, wurde versucht, durch ${ }^{1} \mathrm{H}-\mathrm{NMR}$ den Verlauf der Reaktion bei MelA zu dokumentieren. Die Messungen wurden auf einem Varian Unity $300(300.1 \mathrm{MHz})$ durchgeführt. Als Substrat für die Reaktion diente pNP- $\alpha-G a l$. Alle Cofaktoren wurden in $\mathrm{D}_{2} \mathrm{O}$ gelöst und in optimalen Konzentrationen für den Umsatz eingesetzt. Das Gesamtvolumen betrug $600 \mu \mathrm{l}$. Lediglich die Endkonzentration von $\mathrm{Mn}^{2+}$-Ionen wurde auf 1/10 der optimalen Konzentration reduziert, um eine zu starke Signalverbreiterung zu verhindern, aber trotzdem noch eine meßbare Aktivität zu erhalten.

$\begin{array}{llll}\text { Ansatz: } & \text { Enzym } & 10 \mathrm{mg} / \mathrm{ml} & 10 \mu \mathrm{l} \\ & \mathrm{NAD}^{+} & 5 \mathrm{mM} & 60 \mu \mathrm{l} \\ \mathrm{MnCl}_{2} & 0,015 \mathrm{mM} & 60 \mu \mathrm{l} \\ \text { DTT } & 0,25 \mathrm{M} & 60 \mu \mathrm{l} \\ \text { HEPES } & 0,1 \mathrm{M} & 60 \mu \mathrm{l} \\ \text { pNP- } \alpha-G a l & 0,1 \mathrm{M} & 10 \mu \mathrm{l} \\ \mathrm{D}_{2} \mathrm{O} & & 360 \mu \mathrm{l}\end{array}$




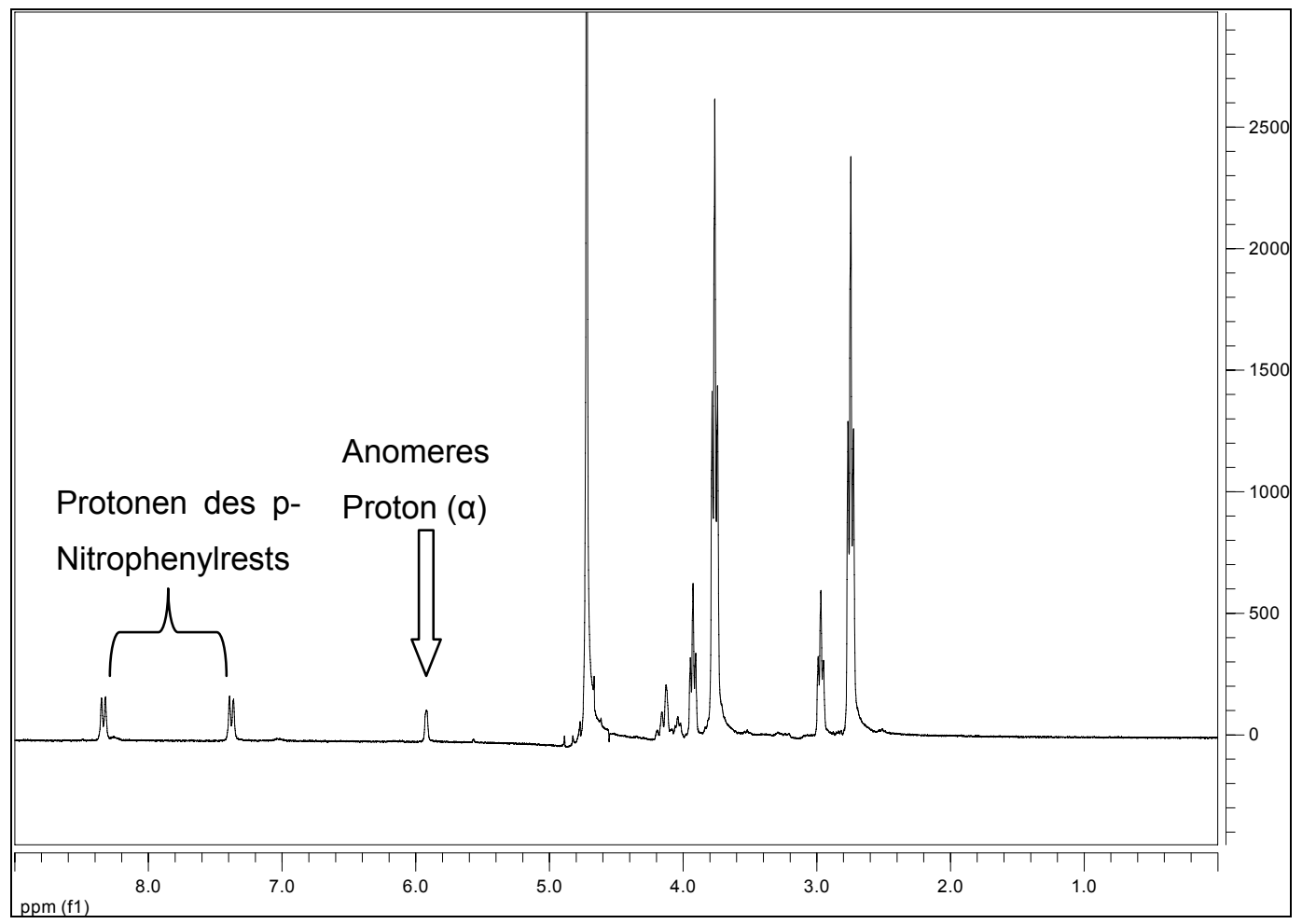

Abbildung 20: ${ }^{1} \mathrm{H}-\mathrm{NMR}\left(\mathrm{D}_{2} \mathrm{O}, 300 \mathrm{MHz}\right)$ von pNP- $\alpha-G a l$

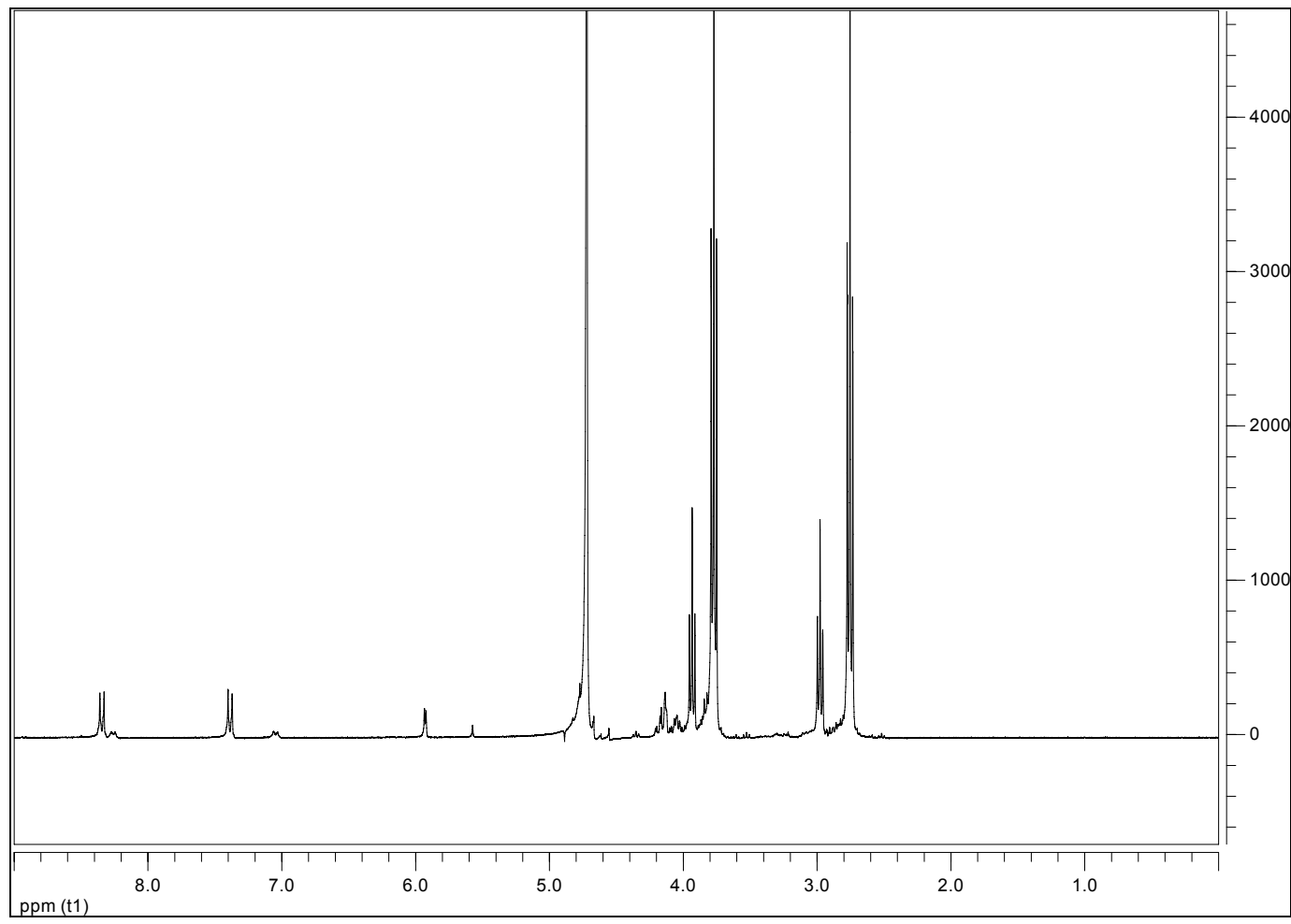

Abbildung 21: ${ }^{1} \mathrm{H}-\mathrm{NMR}\left(\mathrm{D}_{2} \mathrm{O}, 300 \mathrm{MHz}\right)$ von pNP- $\alpha-G a l$ und Enzym vor Inkubation 


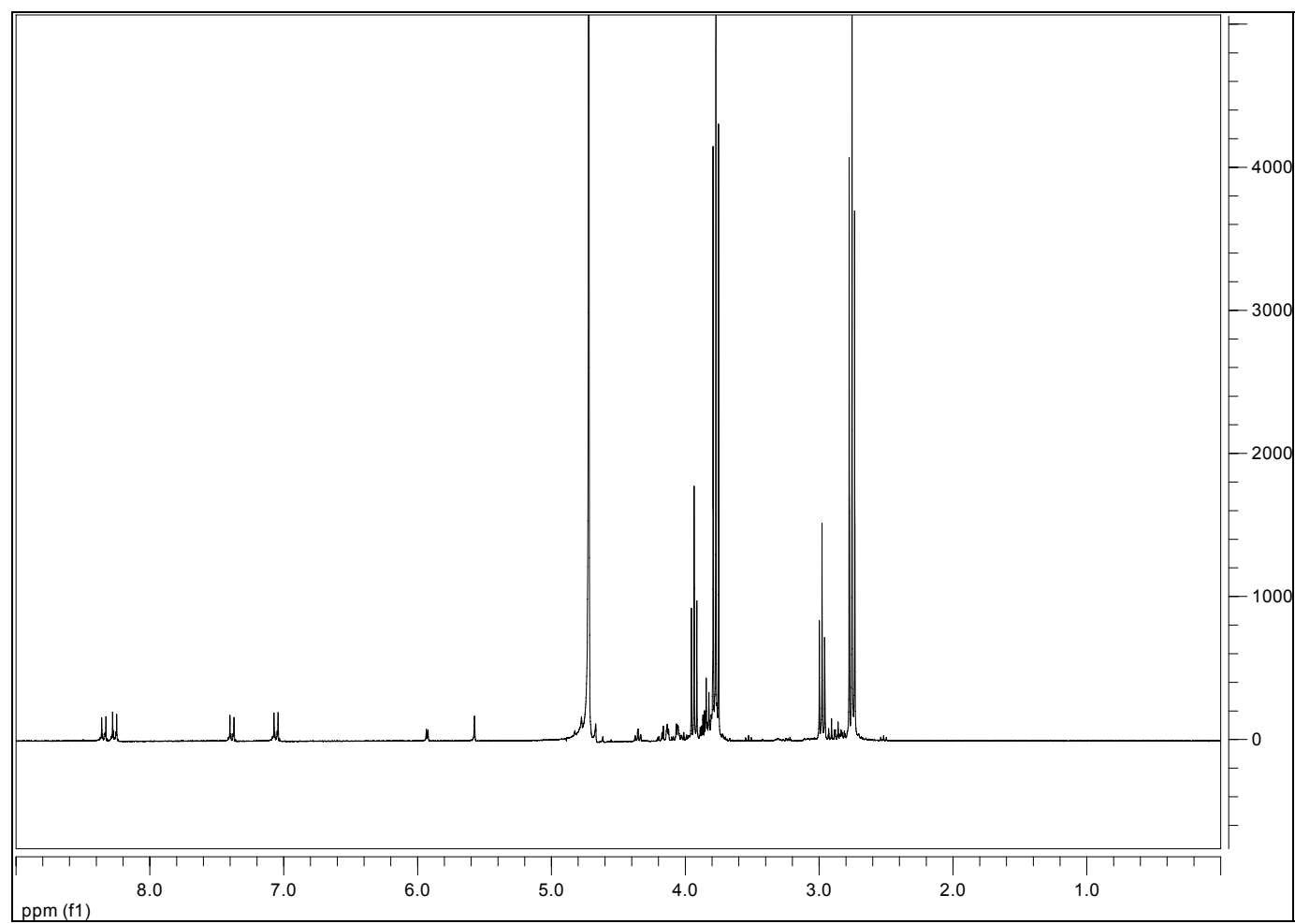

Abbildung 22: ${ }^{1} \mathrm{H}-\mathrm{NMR}\left(\mathrm{D}_{2} \mathrm{O}, 300 \mathrm{MHz}\right)$ von pNP- $\alpha-G a l$ und Enzym nach 15 min Inkubation bei $37^{\circ} \mathrm{C}$

Es ist zu sehen, daß sich im Tieffeld zusätzliche Signale bilden. Die Signale bei 7,1 ppm und 8,3 ppm gehören zu den Protonen des gebildeten p-Nitrophenols. Zusätzlich taucht ein Signal bei 5,6 ppm auf, welches sich der gebildeten a-Glukose zuordnen läßt. Das Signal der $\beta$-Glukose ist leider nicht eindeutig auszuschließen, da es unter dem Wassersignal bei 4,8 ppm liegen könnte und damit verdeckt würde. Das Enzym wurde noch längere Zeit weiter inkubiert, um einen vollständigen Umsatz zu verfolgen. Durch die Versuchsbedingungen schien das Enzym nach 15 min inaktiviert worden zu sein, da kein weiterer Umsatz mehr zu verzeichnen war, was daran zu erkennen ist, daß das Signal bei 5,9 ppm, das zum Substrat gehört (Abbildung 20), nicht vollständig verschwindet. Da aber nur suboptimale Mengen an $\mathrm{Mn}^{2+}$-Ionen zugesetzt werden konnten, war ein vollständiger Umsatz trotz mehrer Versuche nicht möglich. Höhere $\mathrm{Mn}^{2+}$-Ionenkonzentrationen führten $\mathrm{zu}$ starker Signalverbreiterung, so daß beide anomere H-Atome unter dem Wassersignal verschwinden würden.

Mit diesen Versuchen konnte leider nicht endgültig geklärt werden, ob nicht auch das $\beta$-Anomer bei dem enzymatischen Umsatz gebildet wurde, da es aufgrund seiner chemischen Verschiebung unter dem $\mathrm{H}_{2} \mathrm{O}$-Signal liegen kann. Da aber die Signale 
der gebildeten $\alpha$-Galaktose proportional zur Abschwächung des $\alpha$-pNPGalaktosesubstrats angewachsen sind, steht zu vermuten, daß die $\beta$-Galaktose nicht gebildet wurde.

\subsection{Kristallisation von MelA}

Da bei der Kristallisation von AglA aus T. maritima ein doppelt oxidiertes Cys174 im aktiven Zentrum gefunden wurde (Lodge et al., 2003), sollte die Oxidationsstufe des Cys172 im aktiven Zentrum von MelA auf demselben Weg geklärt werden. Hierbei wurde mit freundlicher Unterstützung durch Herrn Dr. M. Rudolph versucht, das Enzym zu kristallisieren. Hiebei wurde die „sitting drop“-Methode angewandt.

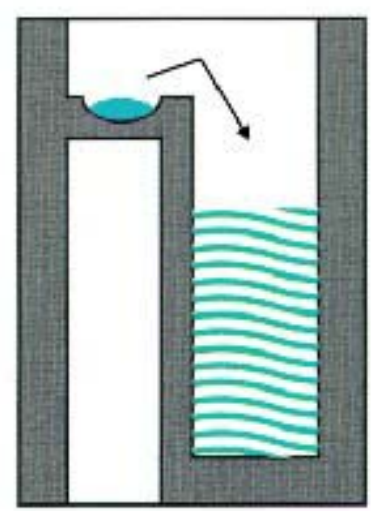

Abbildung 23: „Vapor Diffusion"'-Kristallisation, Sitting-Drop-Verfahren (Abbildung aus McPherson 1999)

Folgende Screenings der Firma Hampton Research Corp. wurden hierfür durchgeführt:

\begin{tabular}{|l|}
\hline Crystal Screen I, II \\
\hline Magic Screen I-IV \\
\hline Footprint I, II, III \\
\hline Crystal Strukture \\
\hline
\end{tabular}


Hierbei handelt es sich um ein Standardscreening, in dem die ungefähren Kristallisationsbedingungen auf ein engeres Spektrum eingrenzen lassen. Für die Kristallisation wurden $1 \mathrm{ml}$ des jeweiligen Kristallisationsansatzes im Reservoir vorgelegt und dann mit $1 \mu \mathrm{l}$ Enzym (8 $\mathrm{mg} / \mathrm{ml}$ ) und $1 \mu \mathrm{l}$ der Reservoirlösung vermischt. Anschließend wurden die mit Crystal-Clear versiegelten Platten zur Lagerung in einen $18^{\circ} \mathrm{C}$-Kristallisationsschrank gegeben.

Beispielhaft für die verschieden Screenings ist hier nur der Crystal Screen dargestellt.

Unter folgenden Bedingungen wurden Vorstufen von Kristallen gefunden:

Magic Screen Tube 3 (5\% i-Propanol, 0,1 M Na-Cacodylat $\mathrm{pH}$ 6,5, 0,2 M Zn-Acetat)

Crystal Screen Tube 2 (0,4 M Na,K-Tartrat), Tube 21 (18\% PEG 8000, 0,1 M Na-Cacodylat pH 6,5, 0,2 M Ca-Acetat)

Structure Screen Tube 34 (15\% PEG 4000, 1\% MPD, pH 7,5), Tube 66 (15\% PEG 8000,040\% i-Propanol, pH 6,5)

Footprint Tube 2 (18\% PEG 600, 0,1 M HEPES pH 7,5), Tube 8( 27\% PEG 600 0,1 M HEPES pH 7,5), Tube 14 ( 36\% PEG 600, $0,1 \mathrm{M}$ HEPES $\mathrm{pH} 7,5)$

Die Nummern stehen jeweils für die Nummer des Kristallisationsansatzes des jeweiligen Screening Kits.

Die jeweiligen Bedingungen wurden nun weiter verfeinert. Die einzelnen Ansätze können dem Anhang entnommen werden.

Im Rahmen dieser Arbeit konnten jedoch keine meßbaren Kristalle erhalten werden. Versuche zur Kristallisation unter den Bedingungen unter denen AglA aus $T$. maritima Kristalle bildete, stehen noch aus. 


\subsection{Untersuchung von T. Maritima AgIA}

\subsubsection{Identifizierung von „Spot X”}

Die a-Glukosidase AglA aus T. maritima wurde im Rahmen der Dissertation von C. Raasch (2001) charakterisiert. Bei der Aufreinigung von Reaktionsprodukten DC war ein ungewöhnlicher Zusatzspot aufgefallen, der kurz über dem Glukosespot lief. Es stand zu vermuten, daß es sich hierbei um ein Zwischenprodukt des bis dato unbekannten Reaktionsmechanismus handelt. Zunächst wurde versucht, diesen Spot im größeren Maßstab darzustellen, um inn anschließend aufzureinigen und seine chemische Natur aufzuklären.

Parallel dazu wurden Nebenanfärbungen durch Cofaktoren ausgeschlossen und weiter untersucht, ob dieser Spot auch mit anderen Kohlenhydraten auftrat.

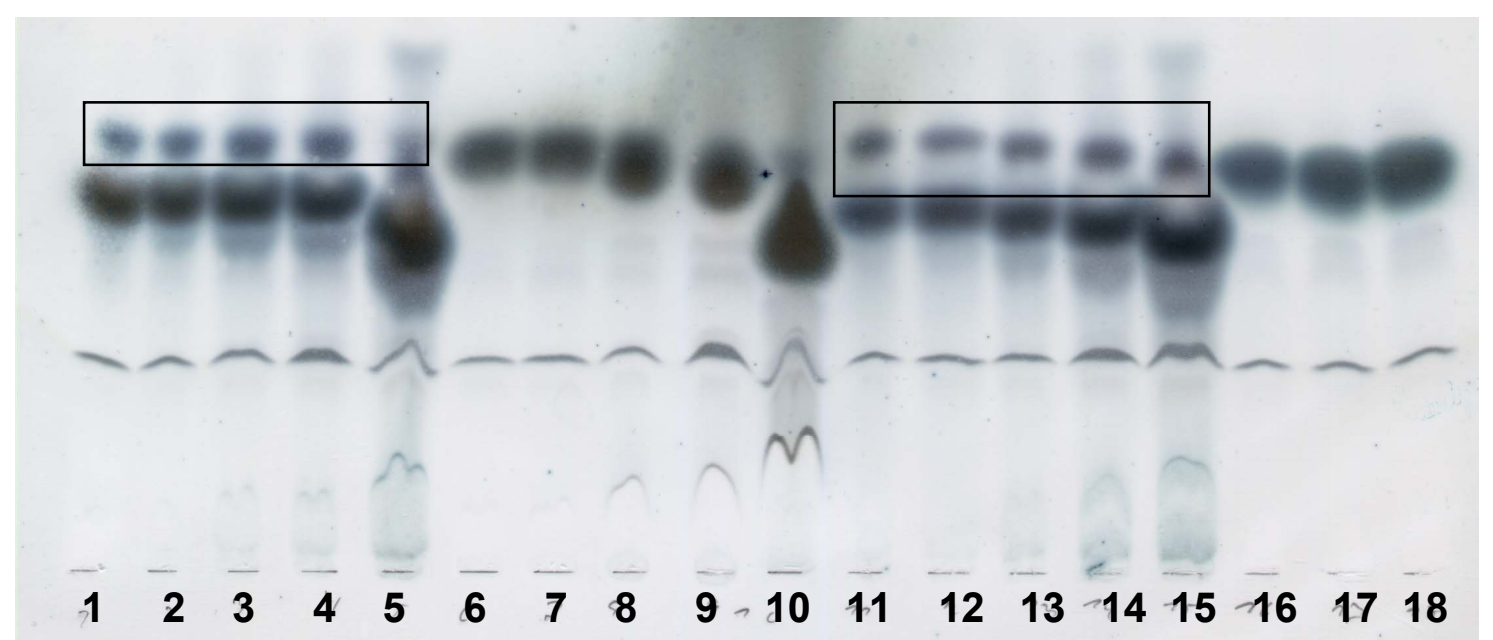

Abbildung 24: Zeitlicher Verlauf der Spotbildung (Spot im Kasten) bei verschiedenen Substraten. Spur 1-5: Substrat Glukose, Proben im einstündigen Abstand, Spur 6-10: Substrat Xylose, Proben im einstündigen Abstand; Spur 11-15: Substrat Galaktose, Proben im einstündigen Abstand, Spur 16-18: Substrat Sorbose

Bei den Untersuchungen ließ sich der Spot nur mit den Substraten bzw. GlykonProdukten von AglA beobachten.

Um Nebenanfärbungen auszuschließen, wurden die Komponenten des Reaktionsansatzes einzeln und in Kombination aufgetragen. Für den Vollansatz wurde folgender Ansatz verwendet: 


$\begin{array}{lll}\text { Enzym } & (7 \mathrm{mg} / \mathrm{ml}) & 10 \mu \mathrm{l} \\ \mathrm{H}_{2} \mathrm{O} & & 6 \mu \mathrm{l} \\ \text { Tris-HCl } & \left(0,5 \mathrm{M} \mathrm{pH} 7^{\left.60^{\circ} \mathrm{C}\right)}\right. & 4 \mu \mathrm{l} \\ \mathrm{MnCl}_{2} & (10 \mathrm{mM}) & 4 \mu \mathrm{l} \\ \mathrm{NAD}^{+} & (9 \mathrm{mM}) & 4 \mu \mathrm{l} \\ \text { DTT } & (1 \mathrm{M}) & 2 \mu \mathrm{l} \\ \text { Glukose } & 2 \% & 10 \mu \mathrm{l}\end{array}$

Dieser Ansatz wurde bei $60^{\circ} \mathrm{C}$ für $4 \mathrm{~h}$ inkubiert und anschließend auf die DC aufgetragen.

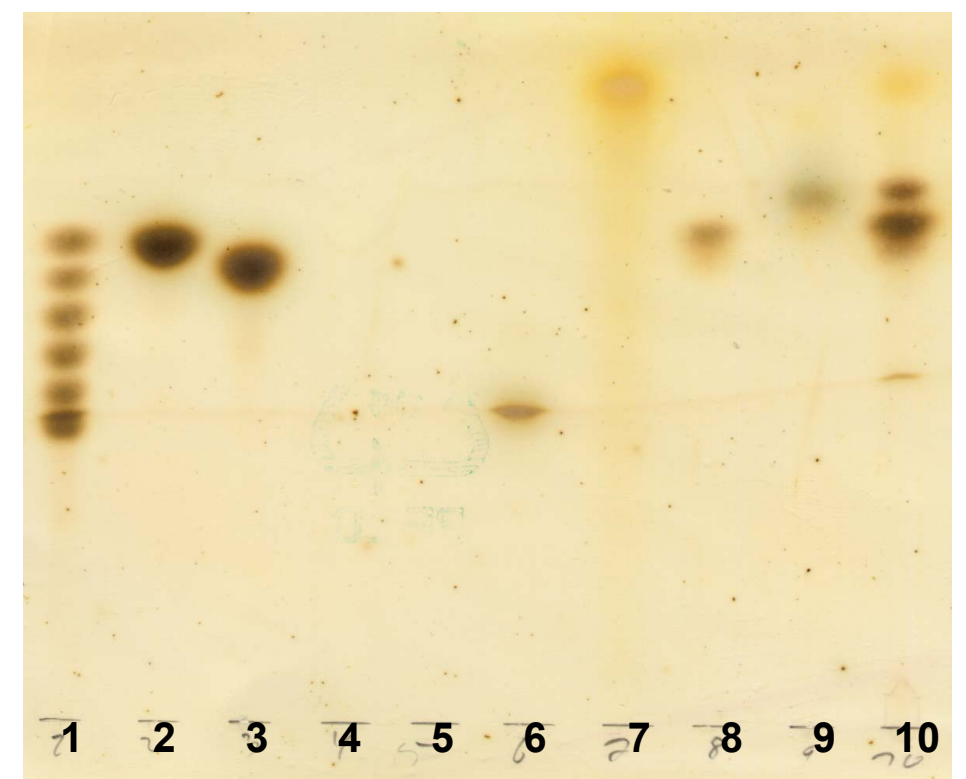

Abbildung 25: Nebenanfärbungen, Sprühreagenz: Dinitrophenlyhydrazin / konz. H2SO4 / EtOH, Spur 1: Marker G1-G7, Spur 2: Glukose, Spur 3: Galaktose, Spur 4: Tris, Spur 5: $\mathrm{MnCl}_{2}, \mathrm{Spur}$ 6: NAD ${ }^{+}$, Spur 7:DTT, Spur 8: 2-Ketoglukose, Spur 9: 2-Ketogalaktose, Spur 10: Vollansatz 


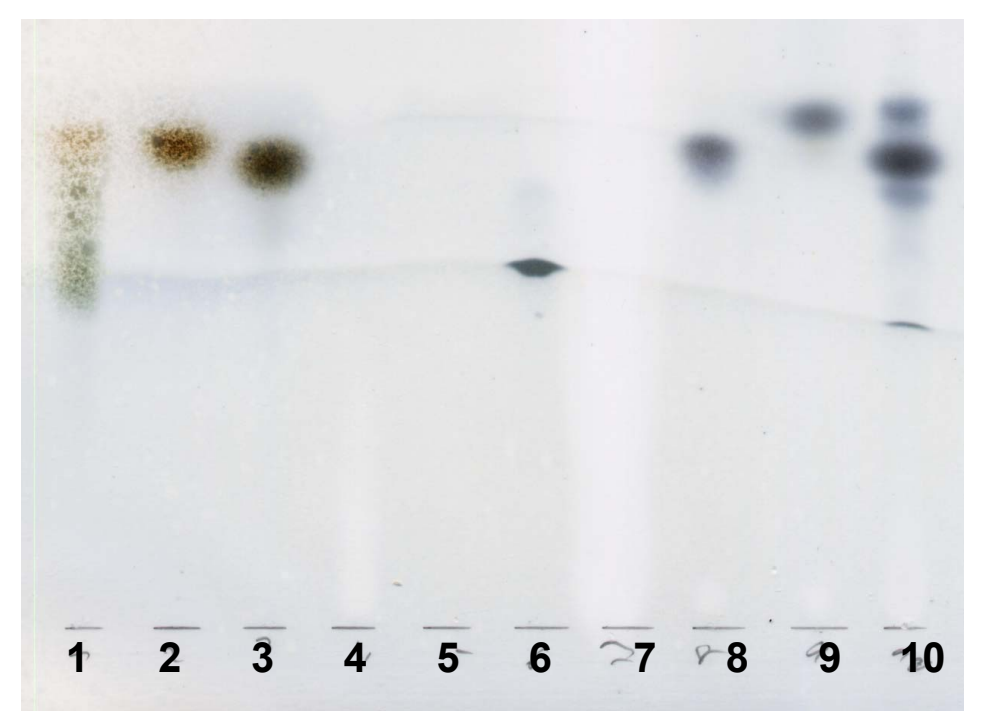

Abbildung 26: Lauf- und Anfärbeverhalten von Reaktionsansätzen und möglichen (Zwischen-) Produkten, Sprühraegenz: Anilin / Diphenylamin / Aceton / $\mathrm{H}_{3} \mathrm{PO}_{4}$, Spur 1: Marker G1-G7, Spur 2: Glukose, Spur 3: Galaktose, Spur 4: Tris, Spur 5: $\mathrm{MnCl}_{2}$, Spur 6: $\mathrm{NAD}^{+}$, Spur 7:DTT, Spur 8: 2Ketoglukose, Spur 9: 2-Ketogalaktose, Spur 10: Vollansatz

Folgende Sprühreagenzien wurden eingesetzt:

1)

1)
$0,4 \mathrm{~g}$
$4 \mathrm{ml}$
$40 \mathrm{ml}$

1)
$0,4 \mathrm{~g}$
$4 \mathrm{ml}$
$40 \mathrm{ml}$

1)
$0,4 \mathrm{~g}$
$4 \mathrm{ml}$
$40 \mathrm{ml}$
2)

$1 \mathrm{ml}$

$1 \mathrm{~g}$

$100 \mathrm{ml}$

$1 / 10 \mathrm{vol}$
Anilin

Diphenylamin

Aceton

$\mathrm{H}_{3} \mathrm{PO}_{4}$ frisch dazu

Als Laufmittel diente 1-Propanol/ Essigester/ $\mathrm{H}_{2} \mathrm{O}_{\text {bidest }}$ (60:10:30). Beide Sprühreagenzien wurden bei $140^{\circ} \mathrm{C}$ für 10 min entwickelt.

Wie zu sehen ist, lassen sich nur DTT, die Substrate und der unbekannte Spot anfärben. In Ansätzen, in denen kein DTT eingesetzt wurde, erschien der zusätzliche Spot nicht. Zunächst wurde versucht, die Bedingungen in denen SpotX auftrat, im präparativen Maßstab zu optimieren. Leider ließ er sich hieraus nicht aufgereinigen, ohne zerstört zu werden. Aus den NMR-Spektren konnte nur reine Glukose nachgewiesen werden. 1-Mercapto-2-propanol bot sich aufgrund seiner hohen Ähnlichkeit zu DTT an, dieses zu ersetzen. Auch mit 1-Mercapto-2-propanol war der zusätzliche Spot auf der DC zu beobachten (SpotX2) und lief bei der DC mit demselben $\mathrm{R}_{\mathrm{f}}$-Wert. Im Gegensatz dazu waren Versuche mit 1-Amino-2-propanol und 1,2-Propandiol erfolglos. Hier wurde der Spot nicht dargestellt. Der mit 1- 
Mercapto-2-propanol erhaltene „SpotX2“ ließ sich nun von Kieselgel extrahieren und bot in Vorversuchen ein von der Glukose unterschiedliches NMR-Spektrum. Um eine größere Substanzmenge für eine Charakterisierung zu erhalten, wurde nun mit 1Mercapto-2-propanol der Enzymansatz optimiert.

Zur präparativen Darstellung des „SpotX2“ diente folgender Ansatz:

$\begin{array}{lll}\text { Enzym } & (7 \mathrm{mg} / \mathrm{ml}) & 0,25 \mathrm{ml} \\ \mathrm{H}_{2} \mathrm{O} & & 0,15 \mathrm{ml} \\ \text { Tris- } \mathrm{HCl} & \left(0,5 \mathrm{M} \mathrm{pH} 7^{\left.60^{\circ} \mathrm{C}\right)}\right. & 0,1 \mathrm{ml} \\ \mathrm{MnCl}_{2} & (10 \mathrm{mM}) & 0,1 \mathrm{ml} \\ \mathrm{NAD}^{+} & (9 \mathrm{mM}) & 0,1 \mathrm{ml} \\ \text { 1-Mercapto-2-propanol } & & 0,05 \mathrm{ml} \\ \text { Glukose } & 20 \% & 0,25 \mathrm{ml}\end{array}$

Dieser Inkubationsansatz wurde für $4 \mathrm{~h}$ bei $60^{\circ} \mathrm{C}$ inkubiert und anschließend auf präparative Dickschichtchromatographieplatten aufgetragen, um mit oben genannten Laufmittel entwickelt zu werden. Anschließend wurde der Rand der DC gefärbt und die Bande von der Platte gekratzt, um das Kieselgel mit Methanol zu waschen. Dieses wurde nun bis zur Trockene am Rotationsverdampfer eingedampft. Es blieben ca. 0,2 mg Feststoff übrig. Dieser Vorgang wurde mehrfach wiederholt, um insgesamt ca. $10 \mathrm{mg}$ des unbekannten Spots zu erhalten.

Bei einer anschließenden Untersuchung der Masse mittels ESI-MS konnte eine Masse von $254 \mathrm{~g} / \mathrm{mol}$ ermittelt werden. Im Spektrum (Abbildung 27) sind zwei deutliche Peaks bei $277,3 \mathrm{~m} / \mathrm{z}$ und $531,1 \mathrm{~m} / \mathrm{z}$ im plus-Modus und bei $253,4 \mathrm{~m} / \mathrm{z}$ und $507,4 \mathrm{~m} / \mathrm{z}$ zu sehen. Im plus-Modus wird die tatsächlich detektierte Masse dargestellt, die sich aus dem Produkt und der Masse des lonisierungsmittels Natrium zusammensetzt. Im minus-Modus wird die Masse des Natriums bereits durch die Bearbeitungssoftware abgezogen. Häufig treten im Massenspektrum Dimere auf, die durch die lonisierung miteinander in Wechselwirkung treten. 


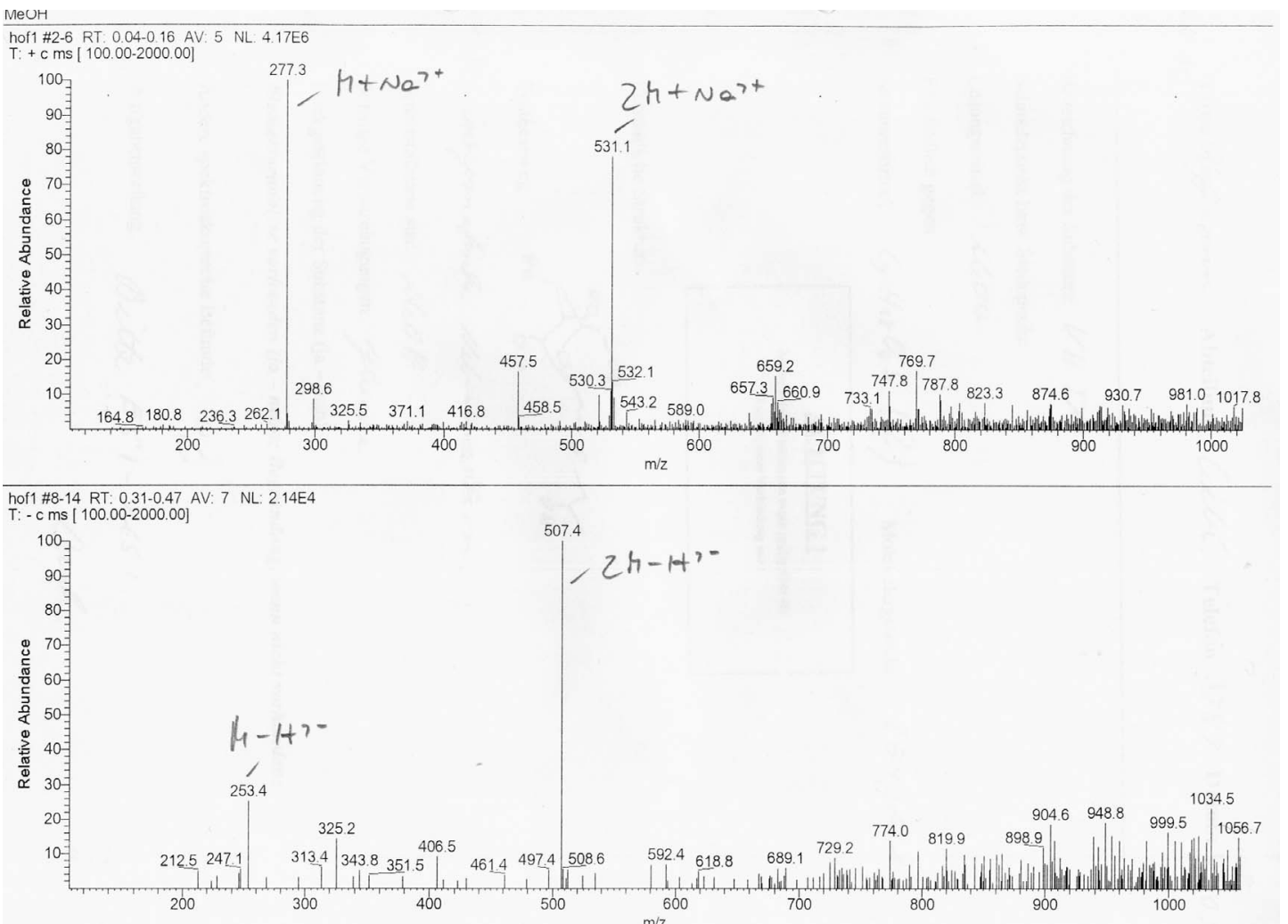

Abbildung 27: ESI-MS-Spektrum von „SpotX2“

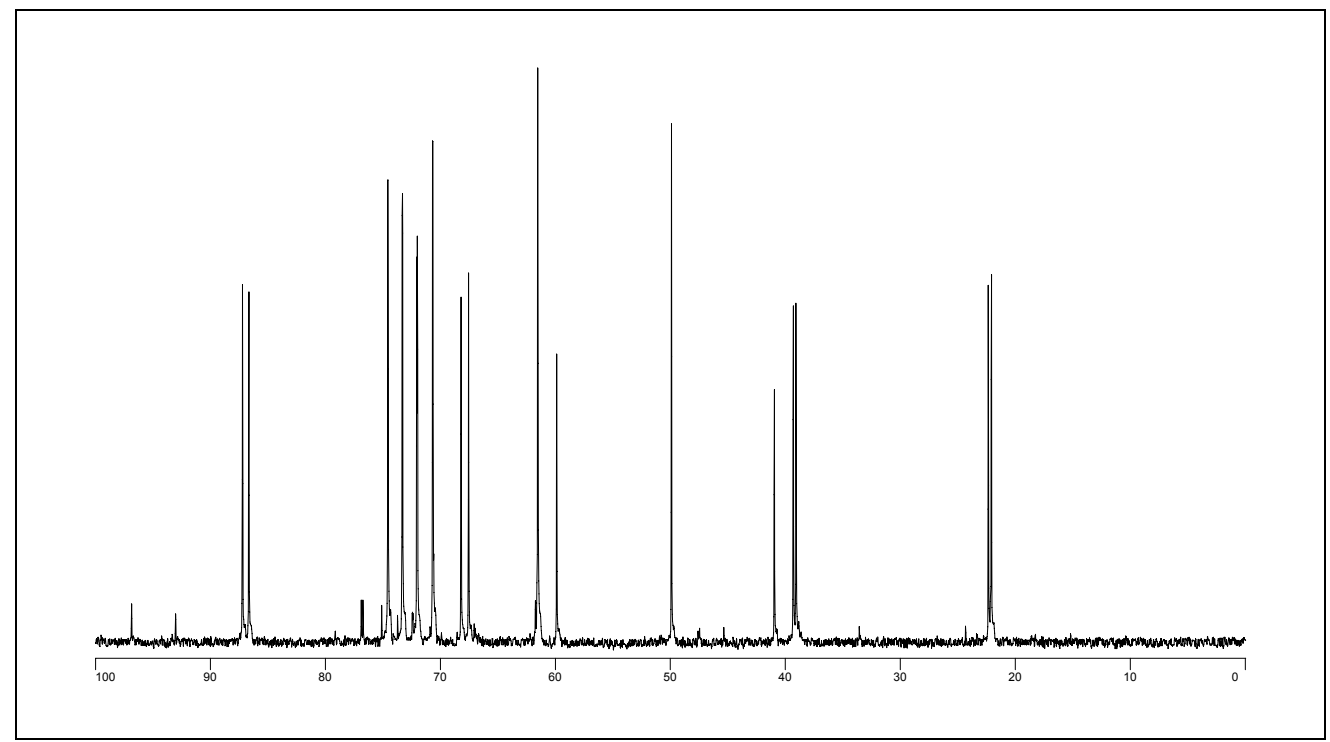

Abbildung 28: ${ }^{13} \mathrm{C}-\mathrm{NMR}, \mathrm{MeOD}, 300 \mathrm{MHz}$

Aus dem NMR- und ESI-MS-Spektrum konnte folgende Verbindung ermittelt werden: 


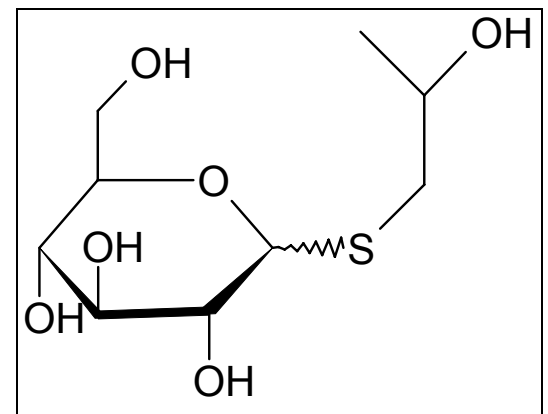

Abbildung 29: 2-Hydroxymethyl-6-(2-hydroxypropylsulfanyl)-glukopyranosid

${ }^{-13} \mathrm{C}-\mathrm{NMR}\left(\mathrm{CDCl}_{3}, 75.479 \mathrm{MHz}\right): \delta=\left[22,1\left(\mathrm{CH}_{3}\right), 22,4\left(\mathrm{CH}_{3}\right)\right] \mathrm{C} 1,\left[39,0\left(\mathrm{CH}_{2}\right), 39,3\right.$ $\left.\left(\mathrm{CH}_{2}\right)\right] \mathrm{C} 1_{\text {iPropyl }}, \quad\left[59,9 \quad\left(\mathrm{CH}_{2} \mathrm{OH}\right), \quad 61,5 \quad\left(\mathrm{CH}_{2} \mathrm{OH}\right)\right] \mathrm{C} 6, \quad[67,6 \quad(\mathrm{CHOH}), \quad 68,2$ $(\mathrm{CHOH})] \mathrm{C} 2$ iPropyl, $[70,7(\mathrm{CHOH})] \mathrm{C} 4,[72,0(\mathrm{CHOH})] \mathrm{C} 2,[73,3(\mathrm{CHOH})] \mathrm{C} 3,[74,6$ $(\mathrm{CHC})] \mathrm{C} 5,[86,7$ (CHS), 87,2 (CHS)]C1

Auffallend ist, daß sowohl das $\alpha$ - als auch das $\beta$-Anomer dieses Zuckerderivats auftraten. Leider war aus dem ${ }^{13} \mathrm{C}-\mathrm{NMR}$-Spektrum keine Zuordnung der Signale zum jeweiligen Anomer möglich.

\subsection{Kristallisation von AgIA}

In Kooperation mit Prof. N. Sträter ist AglA kristallisiert und anschließend mittels Röntgenbeugung vermessen worden (Lodge et al, 2003). AglA ist die erste Glukosidase, die aus der GHF4 kristallisiert wurde. Im Kristall konnte die NAD+Bindedomäne bestätigt werden. $\mathrm{NAD}^{+}$wurde an dem zuvor postulierten (Raasch et al., 2001) Rossmann-Fold gefunden und der Nicotinamidring ragt in das aktive Zentrum hinein. Wie aus anderen manganabhängigen Enzymen bereits bekannt ist, sind verschiedene Histidine an der Metallkoordination beteiligt. His-175 und His-177 konnten als wahrscheinliche Bindepartner verifiziert werden. Trotz der Anwesenheit von Mangan im Kristallisationsansatz ließ es sich nicht im aktiven Zentrum nachweisen. Hierfür sind zwei mögliche Erklärungen denkbar. Erstens ist der niedrige $\mathrm{pH}$ von 4,6 zu nennen, bei dem die Histidine protoniert vorliegen und zweitens der erstaunliche Befund, daß das Cys-174 doppelt oxidiert ist. 


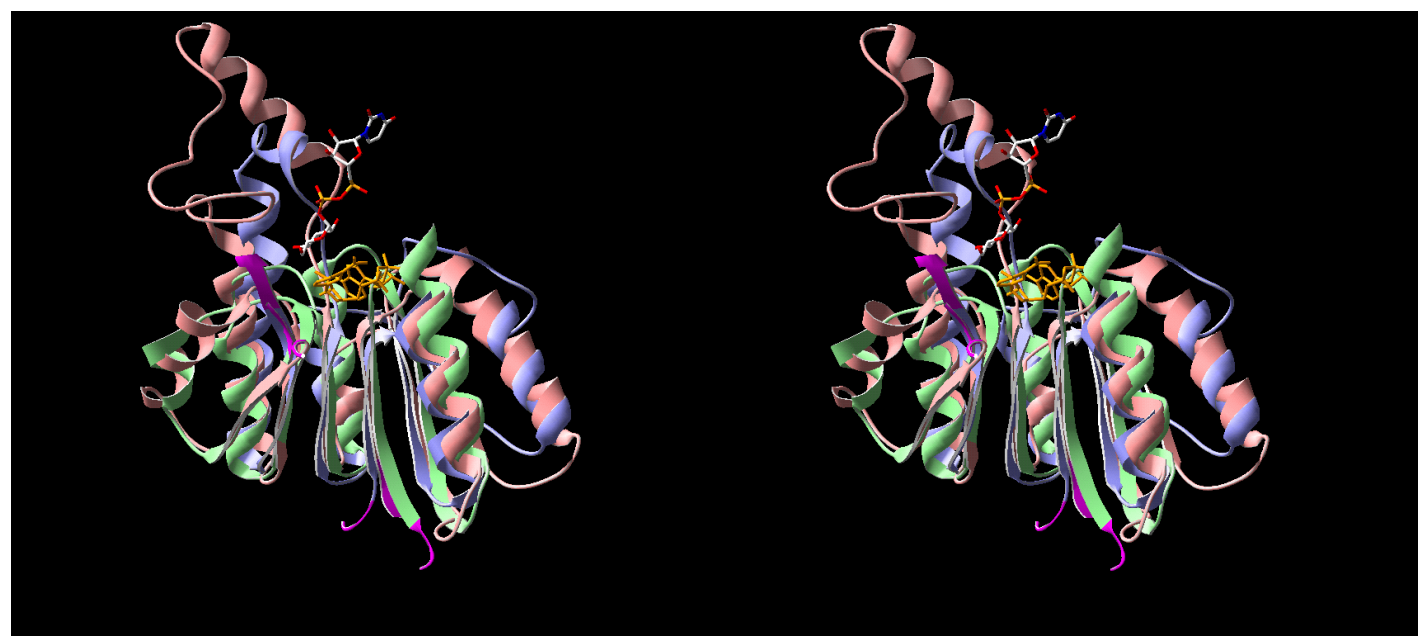

Abbildung 30: Stereodarstellung der Elektonendichte. rot $\rightarrow$ T. maritima AglA (pos. 4-177), grün $\rightarrow$ Glucose/galactose-binding protein (1GCA) (pos. 1-110) blau $\rightarrow$ UDP-Galactose-4epimerase (1EK6) (pos. 2-133) mit NAD und UDP-GIc

Die Kristalle von AglA aus T. maritima konnten bis auf 1,9 $\AA$ aufgelöst werden. Das Enzym liegt als Dimer vor. Das Cys174 konnte bereits durch direkte Mutagenese (C. Raasch, persönliche Mitteilung) als für die Katalyse essentiell bestimmt werden. Mutanten, in denen das Cystein durch ein Serin ersetzt wurde, waren komplett inaktiv. Im Rahmen der Röntgenbeugung wurde diese Aminosäure als doppelt oxidiert identifiziert (Abbildung 31). Cys174 liegt in AglA als Sulfinsäure vor, was in dieser Enzymfamilie noch nicht beobachtet wurde.

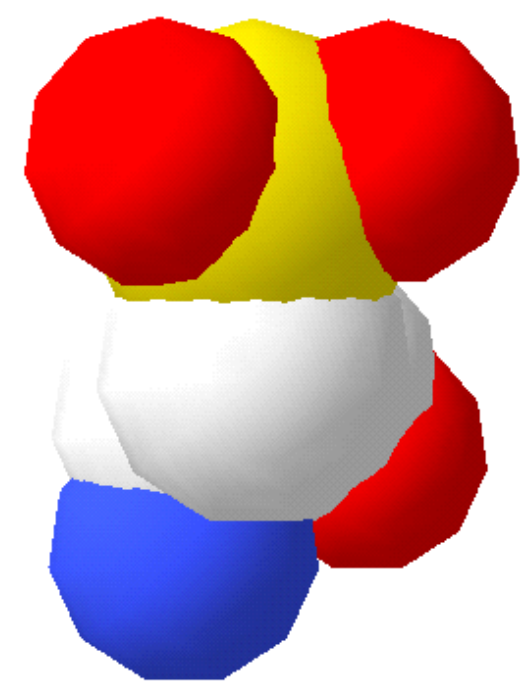


AgIA liegt im Kristall anscheinend inaktiv vor, da das cokristallisierte Substrat Maltose nicht umgesetzt wurde. Es sollte versucht werden, dieses Enzym in nicht oxidierter Form zu erhalten.

\subsection{Anaerobe Aufreinigungen und Anzuchten}

Zunächst wurde versucht, AglA-produzierenden Stamm E. coli JM83 aerob anzuziehen und anschließend das exprimierte Enzym anaerob aufzureinigen. Hierfür wurden die Puffer entgast und das gereinigte Enzym unter Stickstoffatmosphäre gelagert. Dies führte aber zu keiner weiteren Aktivitätssteigerung. Daraufhin sollte auch der AglA-produzierenden Stamm in verschiedenen Standardmedien zur anaeroben Anzucht wachsen. Die Zellen wuchsen nur zu einer sehr geringen optischen Dichte heran und es kam zu keiner Überexpression. Folgende Abwandlung des M9-Mediums führte zu einem Zellwachstum und erbrachte nach sieben Tagen Inkubation bei $37^{\circ} \mathrm{C}$ und $0,5 \mathrm{mg}$ Enzym aus $4 \mathrm{~g}$ Zellmasse.

$\begin{array}{lll}\text { Für einen Liter: } & \text { Trypton } & 32 \mathrm{~g} \\ & \text { Hefe } & 20 \mathrm{~g} \\ & \mathrm{Na}_{2} \mathrm{CO}_{3} & 6 \mathrm{~g} \\ \mathrm{KH}_{2} \mathrm{PO}_{4} & 3 \mathrm{~g} \\ & \mathrm{NaCl} & 0,5 \mathrm{~g} \\ & \text { Glukose } & 3,6 \mathrm{~g} \\ \text { L-Tryptophan } & 0,5 \mathrm{~g} \\ \text { Ampicillin } & 100 \mathrm{mg} \\ & \text { IPTG } & 0,5 \mathrm{mM}\end{array}$

Aber auch bei dieser Aufreinigung war keine weitere Aktivitätssteigerung zu verzeichnen. 


\subsection{Fluoreszenz- und Absorbtionsuntersuchungen an AglA}

Wegen dem ungewöhnlichen Bedarf an $\mathrm{NAD}^{+}$wurde vermutet, daß es sich bei der Bindungsspaltung um einen Redox-Mechanismus handeln könnte. In dem Fall sollte im Reaktionszyklus NADH auftreten. NADH zeigt zwei sehr eindeutige Eigenschaften, mit denen sich die Anwesenheit von NADH sehr empfindlich nachweisen lässt. Zum einen die Absorbtion von UV-Licht bei $340 \mathrm{~nm}$ und zum anderen die Fluoreszenz bei $460 \mathrm{~nm}$. Durch UV-Absoptions- und Fluoreszenzspektroskopie-Messungen mit freundlicher Unterstützung durch Herrn Dr. M. Rudolph wurde versucht, die NADH-Bildung durch AgIA nachzuweisen.

Zunächst wurden die Absorbtionsspektren von AglA (Abbildung 32) und NADH (Abbildung 33) aufgenommen.

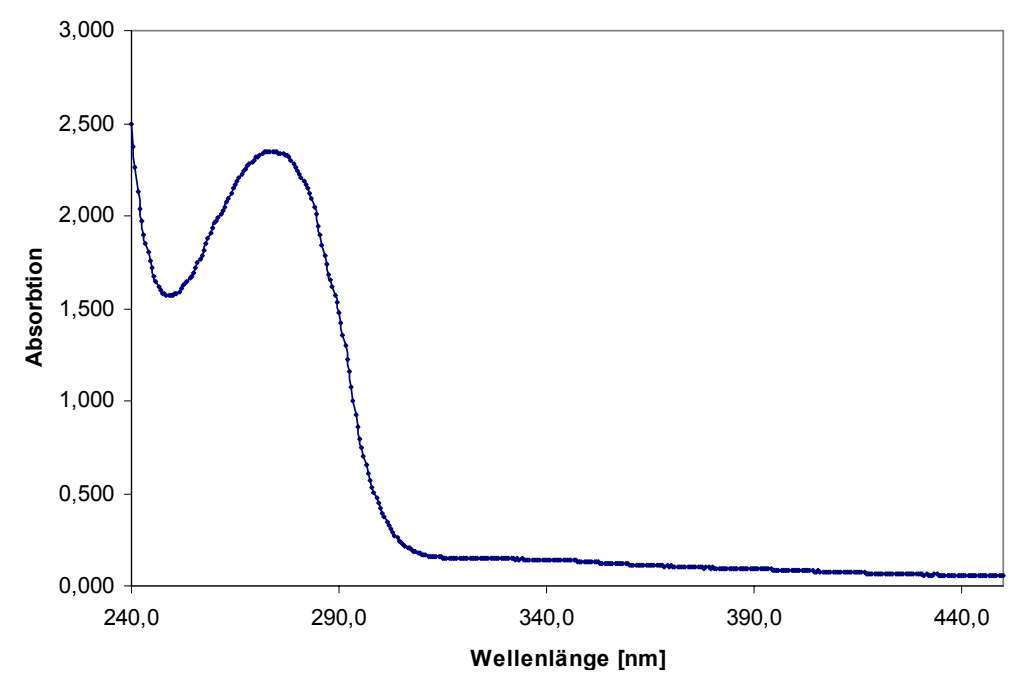

Abbildung 32: Absorbtionsspektrum von AglA 


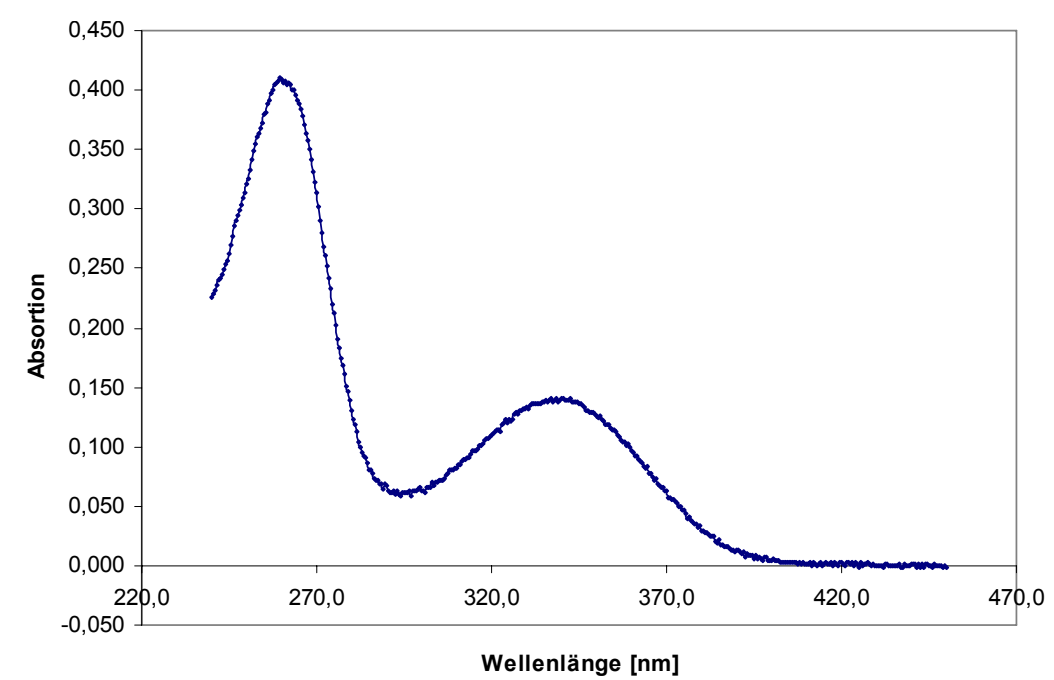

Abbildung 33: Absorbtionsspektrum von NADH

Wie in der Ausschnittsvergrößerung (Abbildung 34) konnte mittels Absorbtion NADH nicht eindeutig nachgewiesen werden. Es ist zwar ein Signal bei $340 \mathrm{~nm} z u$ erkennen, ist aber zu schwach, um eine eindeutige Aussage zu treffen.

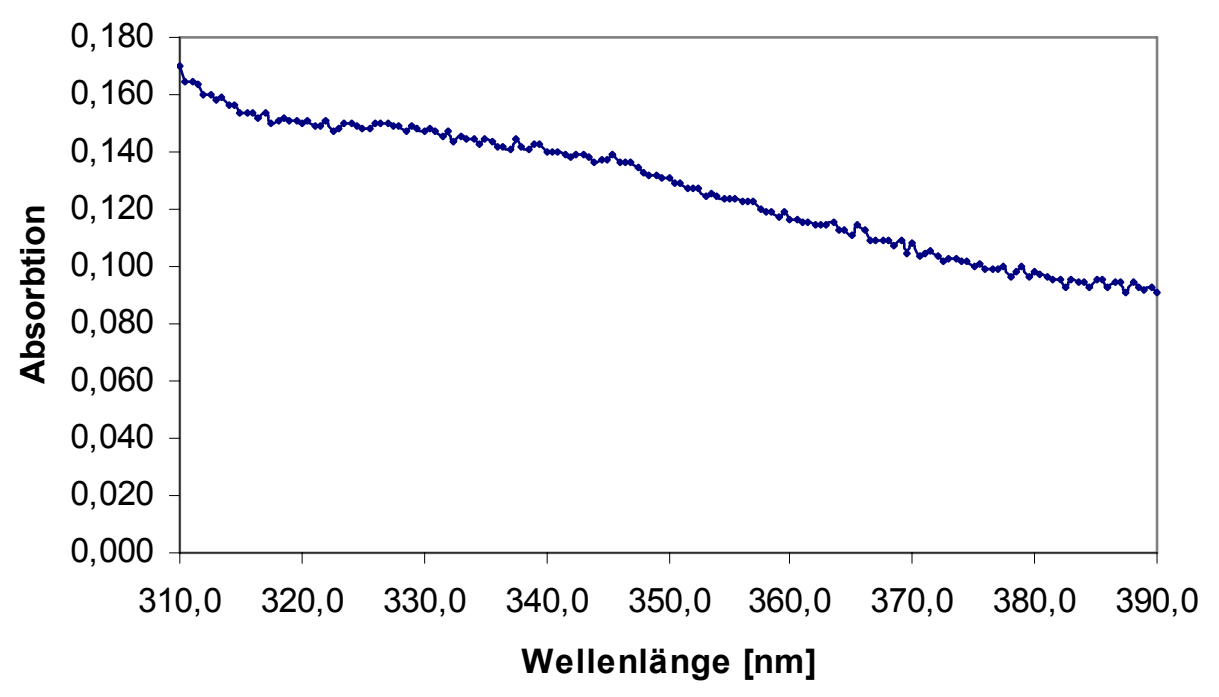

Abbildung 34: Auschnittsvergrößerung von 320-390 nm des Absorbtionsspektrum von AgIA

Das Enzym wurde mittels Fluoreszenz untersucht. Hierbei stellte sich heraus, daß das Enzym allein schon eine sehr starke Fluoreszenz zeigte, obwohl noch keine Cofaktoren anwesend waren. 


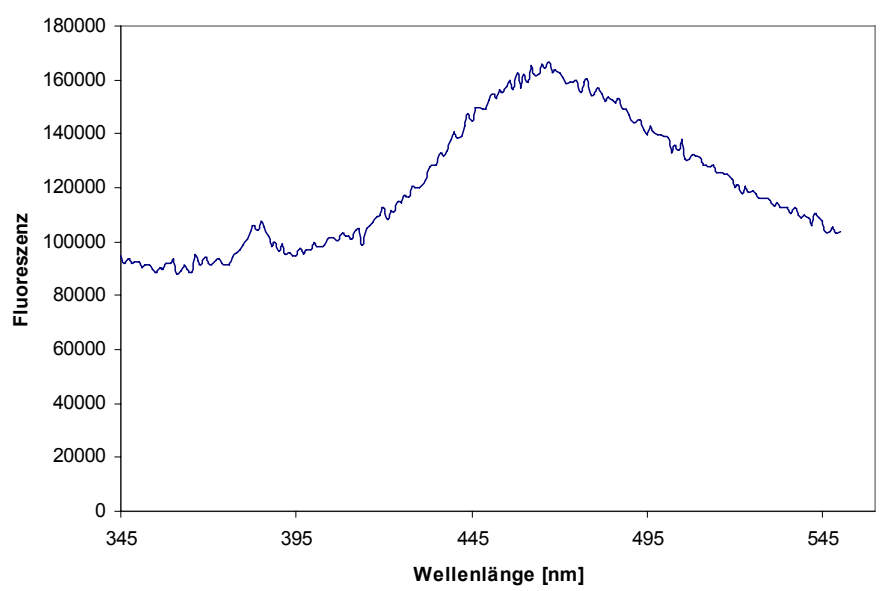

Abbildung 35: Fluoreszenzspektrum von AgIA allein ohne Cofaktoren

Für das Fluoreszenzspektrum ohne Enzym wurde folgender Messansatz verwandt:

$\begin{array}{lll}\mathrm{H}_{2} \mathrm{O} & & 0,65 \mathrm{ml} \\ \text { Tris- } \mathrm{HCl} & \left(0,5 \mathrm{M} \mathrm{pH} 7^{\left.60^{\circ} \mathrm{C}\right)}\right. & 0,1 \mathrm{ml} \\ \mathrm{MnCl}_{2} & (10 \mathrm{mM}) & 0,1 \mathrm{ml} \\ \mathrm{NAD}^{+} & (9 \mathrm{mM}) & 0,1 \mathrm{ml} \\ \text { DTT } & (1 \mathrm{M}) & 0,05 \mathrm{ml}\end{array}$

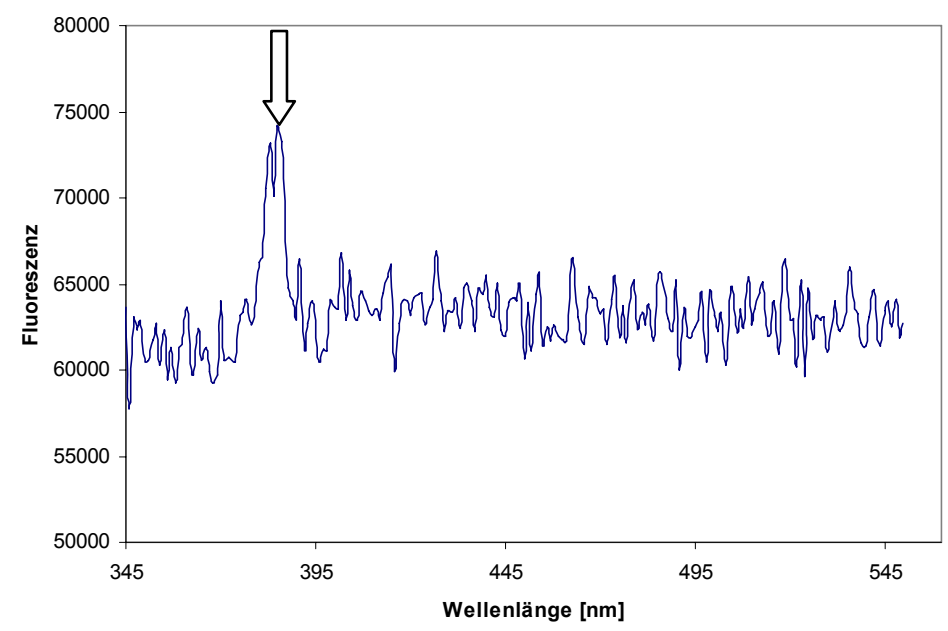

Abbildung 36: Fluoreszenzspektrum aller Cofaktoren ohne Zugabe von Enzym. Pfeil: Ramanpeak des Wassers. 
Wie in Abbildung 36 zu sehen ist, zeigt der Ansatz ohne Enzym keine Fluoreszenz. Es ist nur der Raman-Peak des Wassers zu sehen.

Da nicht klar war, ob das Enzym selbst diese Fluoreszenz zeigt, oder noch im Rossmann-Fold gebundenes NADH die Strahlung auf das Molekül überträgt, wurde das Enzym mit Perchlorsäure bei $90^{\circ} \mathrm{C}$ gefällt. Hierfür diente folgender Reaktionsansatz:

$$
\begin{array}{ll}
\operatorname{AglA}(7 \mathrm{mg} / \mathrm{ml}) & 1 \mathrm{ml} \\
\mathrm{HClO}_{3}(1 \mathrm{M}) & 0,75 \mathrm{ml}
\end{array}
$$

Nach Inkubation für $5 \mathrm{~min}$ bei $90^{\circ} \mathrm{C}$ wurde mit $0,25 \mathrm{ml}$ Kaliumacetat $(3 \mathrm{M})$ neutralisiert. Das Präzipitat wurde anschließend bei $13000 \mathrm{rpm}$ für $10 \mathrm{~min}$ abzentrifugiert und danach der Überstand vermessen.

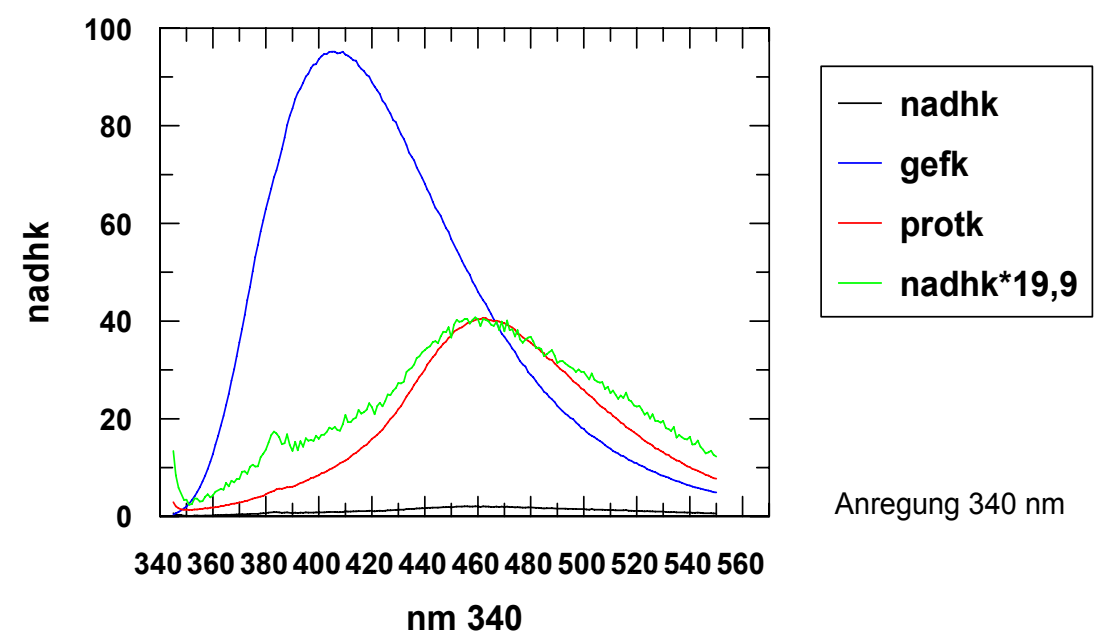

Abbildung 37: Überlagerung der Emissionsspektren. NADH Stammlösung (5 $\mu \mathrm{M})$ (schwarz), AglA (5 $\mu \mathrm{M})$ (rot), AglA (gefällt) (blau) und NADH Stammlösung (5 $\mu \mathrm{M})$ mit dem Faktor 19,9 multipliziert (grün), das $\mathrm{k}$ am Ende der Bezeichnungen steht für gegen Puffer und Cofaktoren bereinigte Werte.

Erstaunlicherweise zeigt der Überstand des gefällten Proteins eine hohe Fluoreszenz. Sie liegt aber deutlich außerhalb des Emissionsmaximums von NADH und scheint durch Aminosäuren verursacht zu sein, die durch die Fällungsreaktion mit Perchlorsäure abgespalten wurden. Eine NADH Stammlösung die äquimolar zum Enzym gemessen wurde, zeigte eine fast 20x schwächere Emission, als die 
entsprechende Enzymlösung. Die Emissionsmaxima der $\mathrm{NADH}-$ und der Enzymlösung liegen beide bei $460 \mathrm{~nm}$.

\subsection{Enzyme der Glykosidhydrolase-Familie 4 von Petrotoga miotherma}

\subsubsection{Klonierungsstrategie}

In $P$. miotherma sind drei ORFs für GHF4-Enzyme anotiert. Aufgrund ihrer hohen Sequenzähnlichkeit bzw. Identität am Anfang und am Ende der ORFs war es nicht möglich, die drei putativen a-Glukosidasen RPMI00511, RPMI00720 und RPMI01263 direkt mittels PCR aus der genomischen DNA zu amplifizieren. Um die drei Enzyme zu klonieren, mussten zuerst durch PCR geeignete Templates erstellt werden. Dafür wurden Primer gewählt, die ein beträchtliches Stück sequenzauf- bzw. abwärts vom Start- und Stopcodon entfernt banden. Diese Templates waren ca. 600 bp größer, als das zu klonierende Gen. Mit innen war es nun möglich, das gesuchte ORF zu klonieren und gleichzeitig die Schnittstellen Ndel und BamHIII einzufügen. 


\subsection{Untersuchung des ORFs RPMI00511}

3.10.1. Klonierung von RPMI00511 aus $P$. miotherma in E.coli BL21

Die Isolierung des Templates für RPMI00511 erfolgte aus der genomischen DNA von P. miotherma mit Hilfe von Amplifikation durch PCR. Die verwendeten Primer waren 24 bzw. 30 bp lang.

\begin{tabular}{|l|r|}
\hline Bezeichnung & Primersequenz $\left(5^{\prime} \rightarrow 3^{\prime}\right)$ \\
\hline $511 \_$for+400 & ggg cct ttg gtt gaa tct cct gta \\
\hline $511 \_r e v+200$ & ggg ttt ttg taa agg aaa gat agt tac cga \\
\hline
\end{tabular}

\begin{tabular}{|c|c|}
\hline Substanz & Volumen $[\mu \mathrm{l}]$ \\
\hline$\overline{P C R}$ Grade Water & 28,6 \\
\hline dNTP-Mix (2 mM) & 5 \\
\hline Template-DNA & 1 \\
\hline Primer „forward“ & 4 \\
\hline Primer "reverse" & 4 \\
\hline KOD HiFi DNA Polymerase & 0,4 \\
\hline $\mathrm{MgCl}_{2} 10 \mathrm{mM}$ & 5,0 \\
\hline 10x Puffer & 5 \\
\hline Gesamtvolumen & 50,0 \\
\hline
\end{tabular}




\begin{tabular}{|c|c|c|}
\hline Temperatur $\left[{ }^{\circ} \mathrm{C}\right]$ & Zeit [sek] & Reaktion \\
\hline 98 & 15 & Denaturierung \\
\hline Gradient $60-80$ & 5 & Primerannealing \\
\hline 72 & 40 & Primerverlängerung \\
\hline
\end{tabular}

Der PCR-Ansatz wurde bei den angegebenen Bedingungen inkubiert. Anschließend extrahierte wurde das 2 kb PCR-Produkt auf einem 0,8 \%igen Agarosegel aufgetrennt und aus dem Gel herausgeschnitten und extrahiert. Dieses Fragment diente nun als Template für die folgende PCR, in der die Schnittstellen Ndel und Hindlll eingefügt wurden.

\begin{tabular}{|l|r|}
\hline Bezeichnung & Primersequenz $\left(5^{\prime} \rightarrow 3^{\prime}\right)$ \\
\hline $511 \_g e n \_f o r$ & ggg cat agt cca gtt aaa att tct ttt ata gga \\
\hline $511 \_g e n \_r e v$ & ggg aag ctt tta cct tct ata atg ctc ctt cat tcc \\
\hline
\end{tabular}

\begin{tabular}{|c|c|}
\hline Substanz & Volumen $[\mu \mid]$ \\
\hline$\overline{\text { PCR Grade Water }}$ & 28,6 \\
\hline dNTP-Mix (2 mM) & 5 \\
\hline Template-DNA & 1 \\
\hline Primer „MelA forward“ * & 4 \\
\hline Primer „MelA reverse“ * & 4 \\
\hline KOD HiFi DNA Polymerase & 0,4 \\
\hline $\mathrm{MgCl}_{2} 10 \mathrm{mM}$ & 5,0 \\
\hline 10x Puffer & 5 \\
\hline Gesamtvolumen & 50,0 \\
\hline
\end{tabular}




\begin{tabular}{|c|c|c|}
\hline Temperatur $\left[{ }^{\circ} \mathbf{C}\right]$ & Zeit [sek] & Reaktion \\
\hline 98 & 15 & Denaturierung \\
\hline Gradient $60-80$ & 5 & Primerannealing \\
\hline 72 & 40 & Primerverlängerung \\
\hline
\end{tabular}

Dieses wurde nun mit dem EcoRV geschnittenen $\mathrm{pBSK}^{+}-$Vektor ligiert und in $E$. coli XL1blue transformiert. Nach Blau-Weiß-screening wurde ein Klon mit korrekt inseriertem PCR-Fragment ausgewählt und unter Verwendung der neu eingefügten Schnittstellen Ndel/ Hindlll in den Vektor pET24c kloniert (Abbildung 38). Dieses neue Konstrukt wurde nun zur heterologen Expression in den Stamm E. coli BL21 elektroporiert. 


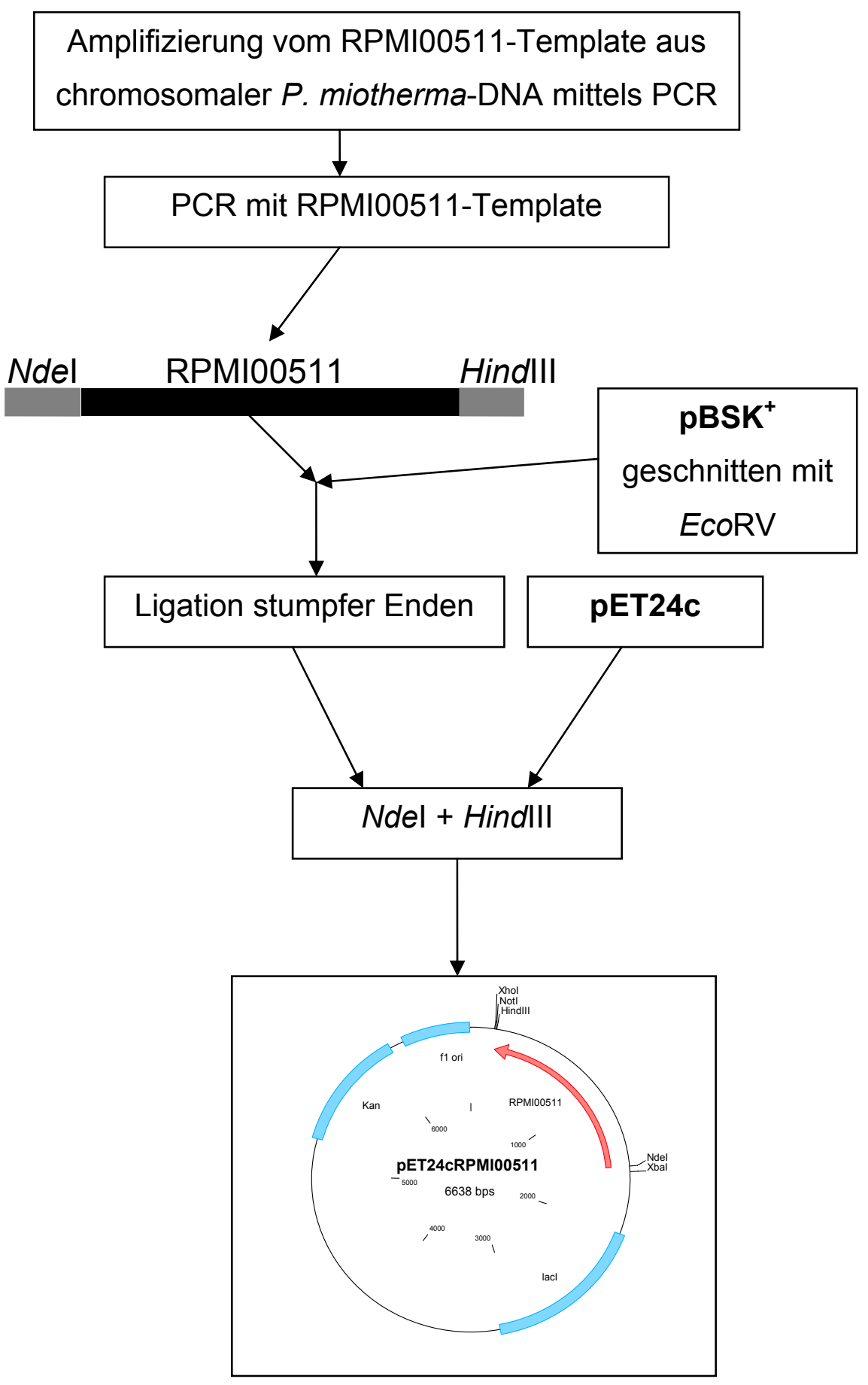

Abbildung 38: Klonierungsstrategie für $P$. miotherma ORF RPMI00511 


\subsubsection{Anzucht und Herstellung eines Rohextrakts}

Für eine Charakterisierung wurde RPMI00511 im präparativen Maßstab angezogen. Hierfür impfte man 1,5 I LB Kan mit $30 \mathrm{ml}$ Inokulum an und induzierte bei einer $\mathrm{OD}_{600}$ von 0,5-0,6 mit 0,5 mM (Endkonzentration) IPTG. Danach inkubierte man über Nacht unter kräftiger Belüftung bei $37^{\circ} \mathrm{C}$. Die Zellen wurden anschließend bei 7000 Upm in GS3-Bechern geerntet, in $20 \mathrm{mM}$ Tris- $\mathrm{HCl}$ pH 7 aufgenommen und mittels einer French Pressure Cell aufgeschlossen. Die Zelltrümmer wurden bei 14000 rpm abzentrifugiert und der Überstand anschließend $15 \mathrm{~min}$ bei $60^{\circ} \mathrm{C}$ denaturiert. Bei dieser Hitzefällung werden ein Großteil der Wirtsproteine zerstört und das hitzestabile Enzym bleibt bei der anschließenden Zentrifugation bei 14000 rpm im Überstand.

\subsubsection{Aufreinigung des von RPMI00511 kodierten Enzyms mittels FPLC}

Der Überstand aus der Hitzefällung wurde sterilfiltriert und anschließend an einem Anionentauscher Source 15Q aufgereinigt.

$\begin{array}{ll}\text { Parameter } & \\ \text { Medium : } & \text { Source } 15 \mathrm{Q} \\ \text { Säule : } & \text { XK } 26 \\ \text { Säulenvolumen : } & 50 \mathrm{ml} \\ \text { Puffer A : } & 20 \mathrm{mM} \text { Tris-Cl pH 7 } \\ \text { Puffer B : } & 20 \mathrm{mM} \text { Tris-Cl pH 7, 1M NaCl } \\ \text { Flußrate : } & 10 \mathrm{ml} / \mathrm{min} \\ \text { Fraktion : } & 10 \mathrm{ml} \\ \text { Equilibrierung : } & 2 \text { SV Puffer B, 10 SV Puffer A } \\ \text { Gradient : } & \text { siehe Elutionsprofil }\end{array}$




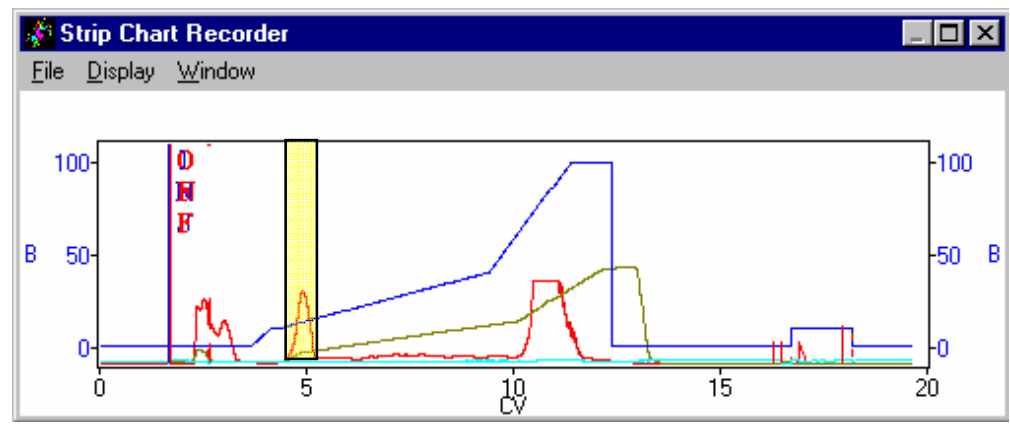

Abbildung 39: Chromatogramm des Source 15Q-Laufs. Blau: Gradient, grün: Leitfähigkeit, rot: Proteinkonzentration (aktive Fraktionen gelb hinterlegt)

Die gelb hinterlegten Fraktionen wurden gepoolt und mittels SDS-PAGE auf ihre Reinheit überprüft (Abbildung 40).

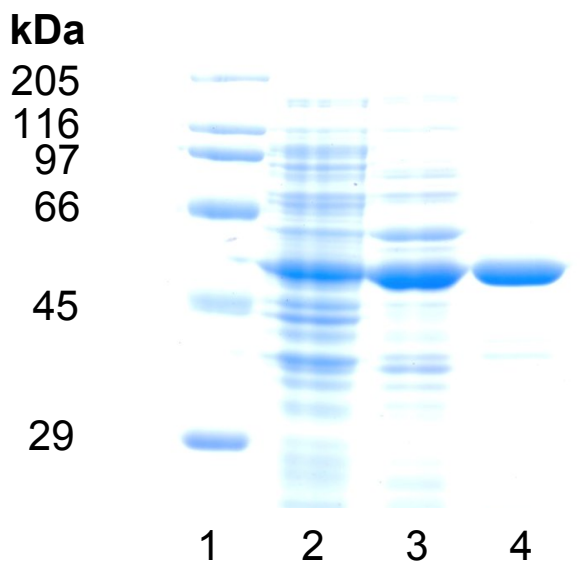

Abbildung 40: SDS-Page der Reinigungsschritte von RPMI00511 (Spur 1: Marker, Spur 2: Rohextrakt, Spur 3: hitzegefällter Rohextrakt, Spur 4: Source 15Q-Pool) 


\subsubsection{Untersuchungen zum Oligomerisierungsgrad des von RPMI00511 kodierten Enzyms}

Der Oligomerisierungsgrad mittels wurde wie in Abschnitt 3.3.1 mittels Gelfiltration bestimmt. Hierfür diente eine Superose-6-Gelfiltrationssäule der Firma Pharmacia. Für das RPMI00511-Produkt wurde ein Elutionsvolumen von 14,55 ml ermittelt; mit der aus der Regressionsgraden abgeleiteten Formel:

$$
\log M W[k D a]=-1,2767^{*} K_{a v}+5,9996
$$

errechnete sich daher für das native Enzym eine Molekularmasse von 283 kDa. Das entspricht etwa der fünffachen Masse der aus dem SDS-Gel abgeleiteten und aus der Proteinsequenz berechneten Größe von 54 kDa. Somit kann davon ausgegangen werden, daß die putative $\alpha$-Glukosidase als Pentamer vorliegt.

\subsubsection{Biochemische Charakterisierung}

\subsubsection{Substratspektrum}

Trotz intensiver Untersuchungen mit verschieden Substraten, die sowohl $\alpha$ - als auch $\beta$-Verknüpfungen und unterschiedliche Oligomerisierungsgrade aufwiesen, konnte keine Aktivität zugeordnet werden. 


\subsection{Untersuchung des ORFs RPMI00720}

\subsubsection{Klonierung des ORFs RPMI00720}

Die Isolierung des Templates für RPMI00720 erfolgte aus der genomischen DNA von P. miotherma mit Hilfe von Amplifikation durch PCR. Die verwendeten Primer waren 24 bp lang.

\begin{tabular}{|l|c|}
\hline Bezeichnung & Primersequenz $\left(5^{\prime} \rightarrow 3^{\prime}\right)$ \\
\hline $720 \_$for_+400 & ggg aat tcc ccc tgc ttt ttt tgt \\
\hline $720 \_r e v+200$ & ggg agc tat tcc tga aga agt gga \\
\hline
\end{tabular}

Der PCR-Ansatz wurde wie schon in 3.10.1 beschrieben gewählt, ebenso wie die PCR-Bedingungen.

\begin{tabular}{|l|c|}
\hline Bezeichnung & Primersequenz $\left(5^{\prime} \rightarrow 3^{\prime}\right)$ \\
\hline 1263_720_for_gen & ggg cat atg aca gct atc aag tta \\
\hline 1263_720_gen_rev & ggg aag ctt cta ttt ttt gct gta gtg ctt \\
\hline
\end{tabular}

Der PCR-Ansatz wurde bei den angegebenen Bedingungen inkubiert und anschließend extrahierte man das 1,4 kb PCR-Produkt auf einem 0,8 \%igen Agarosegel aufgetrennt und aus dem Gel herausgeschnitten und extrahiert. Dieses wurde nun mit dem EcoRV geschnittenen $\mathrm{pBSK}^{+}$-Vektor ligiert und in $E$. coli XL1blue transformiert. Nach Blau-Weiß-screening wurde ein Klon mit korrekt inseriertem PCR-Fragment ausgewählt und unter Verwendung der neu eingefügten Schnittstellen Ndel/ Hindlll in den Vektor pET24c kloniert (Abbildung 41). Dieses neue Konstrukt wurde nun zur heterologen Expression in den Stamm E. coli BL21 elektroporiert. 


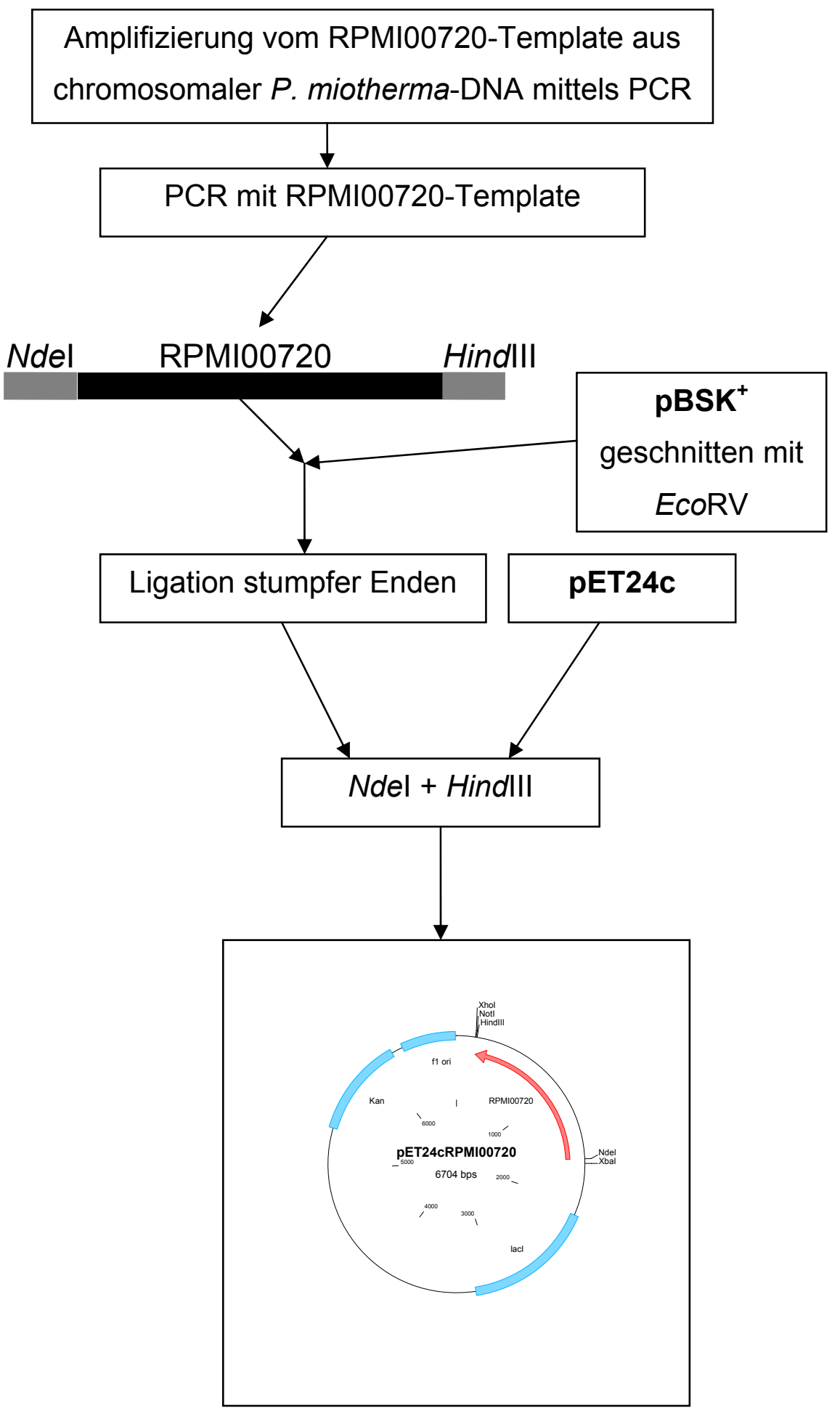

Abbildung 41: Klonierungsstrategie für ORF RPMI00720 


\subsubsection{Anzucht und Herstellung eines Rohextrakts}

Der RPMI00720 exprimierende Stamm E. coli BL21 wurde im großen Maßstab angezogen. Hierfür wurden 1,5 I LB Kan $_{\text {mit }} 30 \mathrm{ml}$ Inokulum angeimpft und bei einer $\mathrm{OD}_{600}$ von 0,5-0,6 mit 0,5 mM (Endkonzentration) IPTG induziert. Danach wurde über Nacht unter kräftiger Belüftung bei $37^{\circ} \mathrm{C}$ bebrütet. Die Zellen wurden anschließend bei $7000 \mathrm{Upm}$ in GS3-Bechern geerntet, in $20 \mathrm{mM}$ Tris-HCl pH 7 aufgenommen und mittels einer French Pressure Cell aufgeschlossen. Die Zelltrümmer wurden bei $14000 \mathrm{rpm}$ abzentrifugiert und der Überstand anschließend $15 \mathrm{~min}$ bei $60^{\circ} \mathrm{C}$ denaturiert. Bei dieser Hitzefällung wurden ein Großteil der Wirtsproteine zerstört und das hitzestabile Enzym blieb bei der anschließenden Zentrifugation bei 14000 rpm im Überstand.

\subsubsection{Aufreinigung des von RPMI00720 kodierten Enzyms mittels FPLC}

Der Überstand aus der Hitzefällung wurde sterilfiltriert und anschließend an einem Anionentauscher Source $15 Q$ aufgereinigt.

$\begin{array}{ll}\text { Parameter } & \\ \text { Medium : } & \text { Source } 15 \mathrm{Q} \\ \text { Säule : } & \text { XK } 26 \\ \text { Säulenvolumen : } & 50 \mathrm{ml} \\ \text { Puffer A : } & 20 \mathrm{mM} \text { Tris-Cl pH 7 } \\ \text { Puffer B : } & 20 \mathrm{mM} \text { Tris-Cl pH 7, 1M NaCl } \\ \text { Flußrate : } & 10 \mathrm{ml} / \mathrm{min} \\ \text { Fraktion : } & 10 \mathrm{ml} \\ \text { Equilibrierung : } & 2 \mathrm{SV} \text { Puffer B, 10 SV Puffer A } \\ \text { Gradient : } & \text { siehe Elutionsprofil }\end{array}$




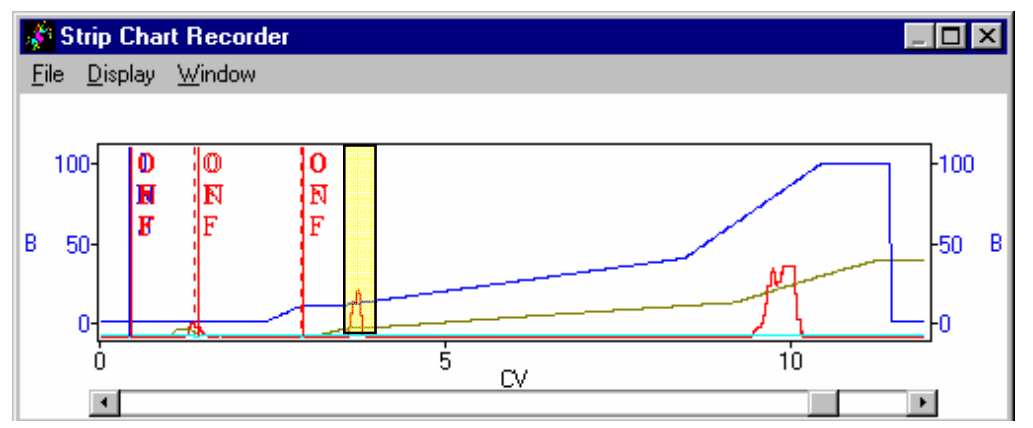

Abbildung 42: Chromatogramm des Source 15Q-Laufs, blau: Gradient, grün: Leitfähigkeit, rot: Proteinkonzentration (aktive Fraktionen gelb hinterlegt)

Die gelb hinterlegten Fraktionen wurden gepoolt und mittels SDS-PAGE auf ihre Reinheit überprüft (Abbildung 43).

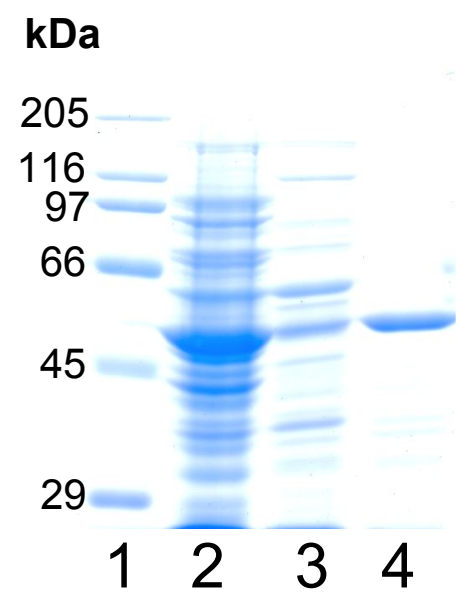

Abbildung 43: SDS-PAGE der Reinigungsschritte von RPMI00720 (Spur 1: Marker, Spur 2: Rohextrakt, Spur 3: hitzegefällter Rohextrakt, Spur 4: Source 15Q-Pool) 


\subsubsection{Untersuchungen zum Oligomerisierungsgrad von RPMI00720}

Wie schon in 3.3.1 beschrieben, wurde der Oligomerisierungsgrad mittels Gelfiltration ermittelt. Hierfür diente eine Superose-6-Gelfiltrationssäule der Firma Pharmacia. Für RPMI00720 wurde ein Elutionsvolumen von $15,70 \mathrm{ml}$ ermittelt; mit der aus der Regressionsgraden abgeleiteten Formel:

$$
\log M W[k D a]=-1,2767^{*} K_{a v}+5,9996
$$

errechnete sich daher für das native Enzym eine Molekularmasse von 228 kDa. Das entspricht etwa der vierfachen Masse der aus dem SDS-Gel abgeleiteten Größe von $55,5 \mathrm{kDa}$. Somit kann davon ausgegangen werden, daß die putative $\alpha-G l u k o s i d a s e$ als Tetramer vorliegt.

\subsubsection{Biochemische Charakterisierung}

\subsubsection{Substratspektrum}

Ein breit angelegtes Screening (2.4.3.4) mit verschiedenen $\alpha$-, $\beta$-Substraten und unterschiedlichem Oligomerisierungsgrad zeigte, daß von ORF RPMI00720 kodierte Enzym genauso wie AglA aus T. maritima (Raasch et al., 2001), sowohl $\alpha$ galaktosidische, als auch a-glukosidische Bindungen spalten kann. Wie bei AgIA wurde eine höhere Aktivität gegenüber $\alpha$-glukosidischen Verknüpfungen festgestellt.

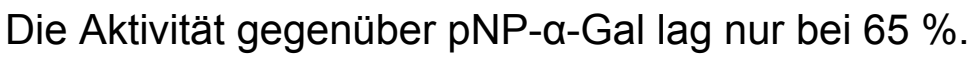




\begin{tabular}{|l|c|}
\hline Substrate & 720 \\
\hline Polymere & \\
\hline$\beta$-Dextran, Glycogen, Dextran, & - \\
Amylopectin & \\
Stärke & \\
\hline Maltoologosaccharide & - \\
\hline Maltotriose, Maltotetraose, Maltopantaose, \\
Maltohexaose, Maltoheptaose & \\
\hline Cyclodextrine & \\
\hline Y-Cyclodextrin, $\beta$-Cydclodextrin, & - \\
$\alpha-C y c l o d e x t r i n$ & \\
\hline Disccharide & + \\
\hline Maltose & + \\
Raffinose & + \\
Saccharose & - \\
Cellobiose & + \\
Melibiose & + \\
Lactose & - \\
\hline Synthetische Substrate & \\
\hline pNP- $\alpha-D-G l u k o s e$ & + \\
pNP- $\beta-D-G l u k o s e$ & \\
pNP- $\alpha-D-G a l a k t o s e$ & \\
pNP- $\beta-D-G a l a k t o s e$ & \\
\hline
\end{tabular}

\subsubsection{Enzymkinetik}

Für die Ermittlung der kinetischen Daten der RPMI00720- $\alpha$-Glukosidase wurde die Aktivität des Enzyms mit steigender Konzentration an para-Nitrophenyl-a-Dglukopyranosid (pNP- $\alpha-G l u$ ) bestimmt (2.4.2.9) (Abbildung 44). In folgenden Abbildungen finden sich die entsprechenden Michaelis-Menten-, Lineweaver-Burkeund Eadie-Hofstee-Auftragungen zu Berechnung von $K_{\mathrm{m}}$ und $v_{\max }$. 


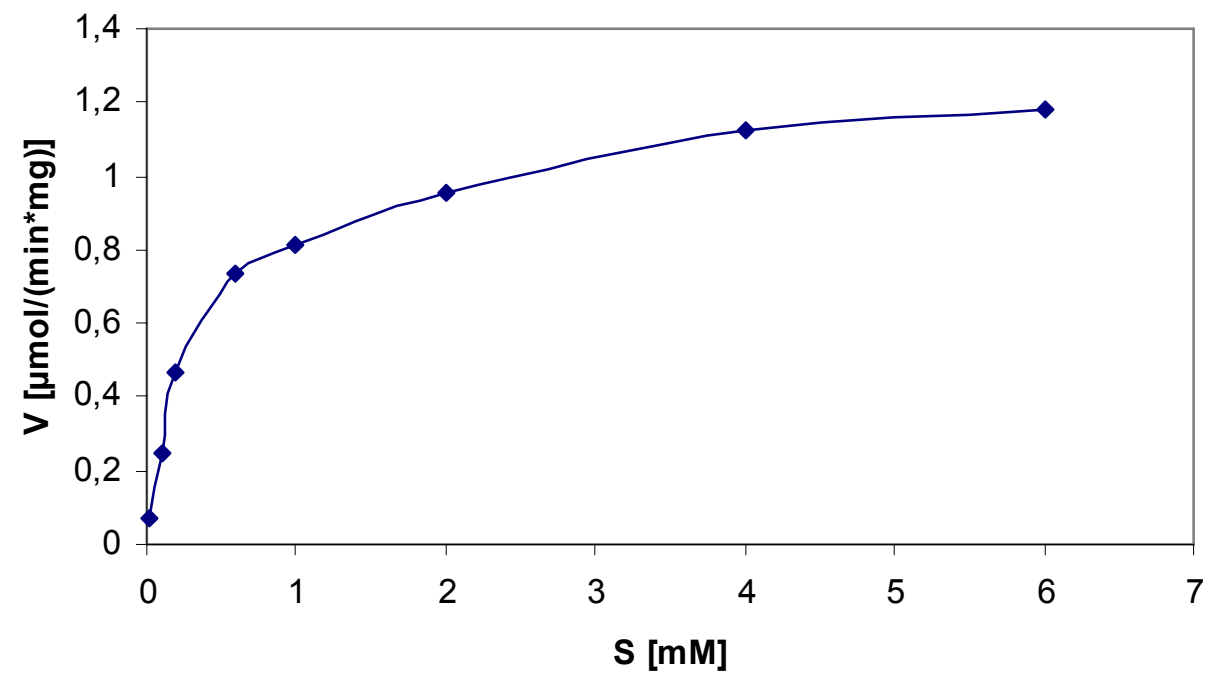

Abbildung 44: Abhängigkeit der Aktivität von der pNP-a-Glu-Konzentration (Michalis-MentenDiagramm).

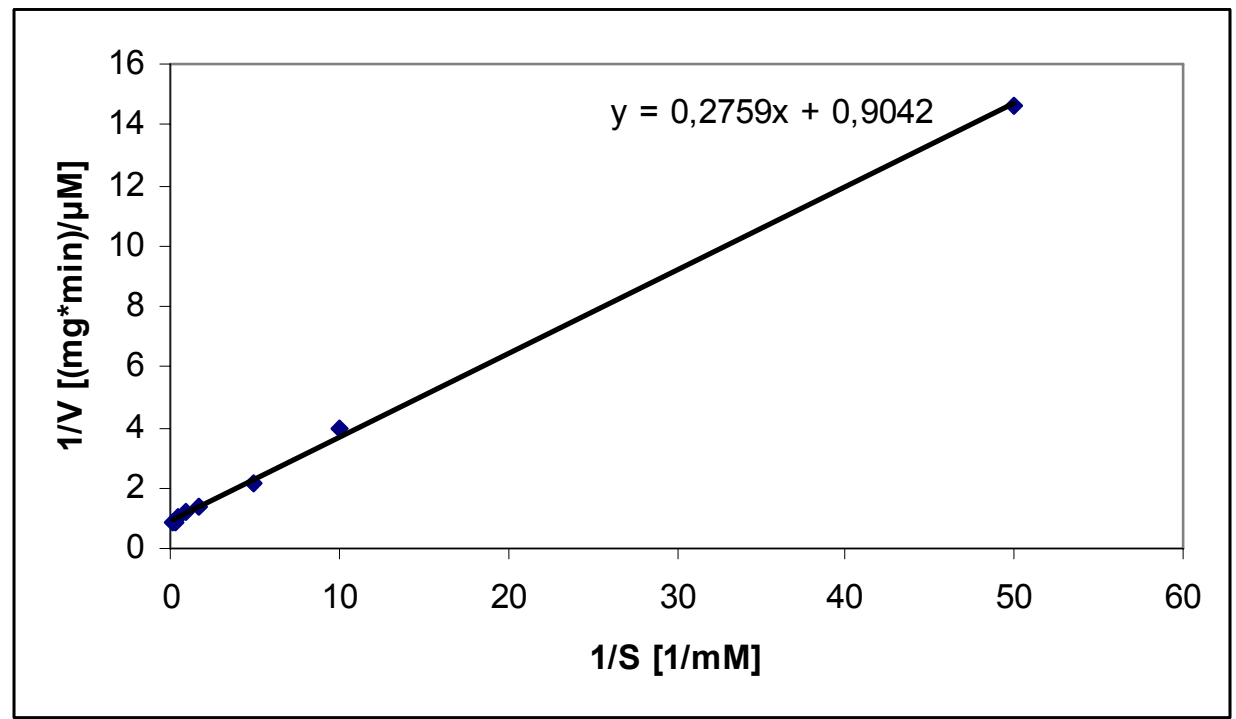

Abbildung 45: Darstellung der Daten aus Abbildung 44 als Lineweaver-Burke-Diagramm 


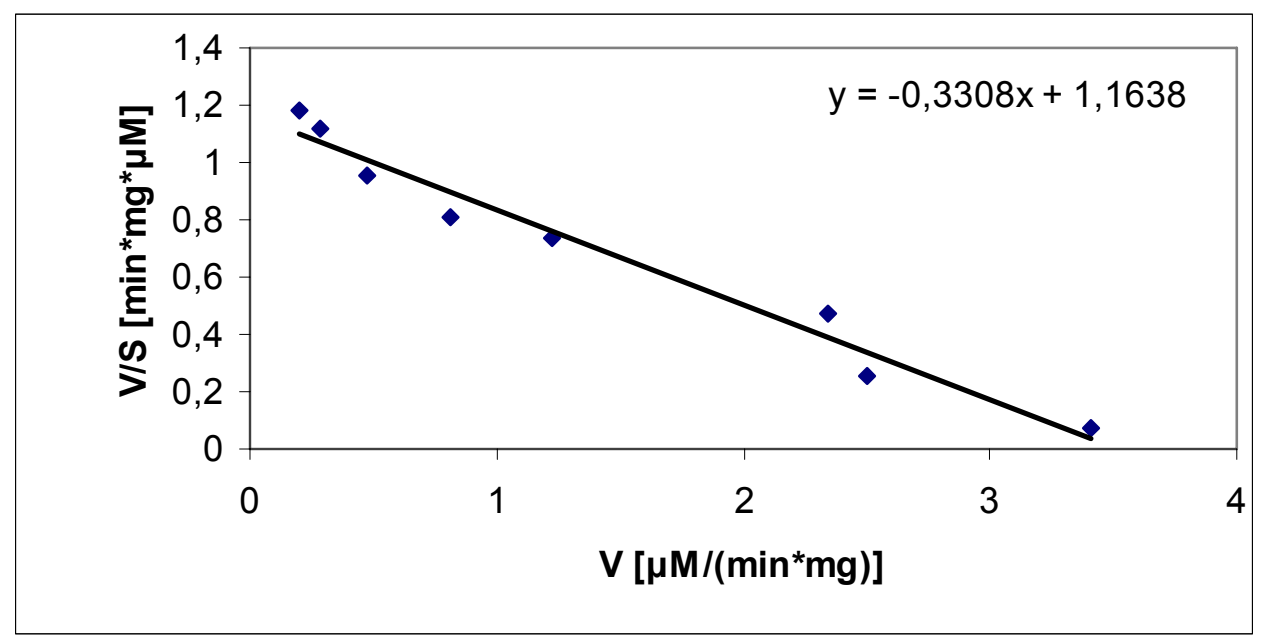

Abbildung 46: Darstellung der Daten aus Abbildung 44 als Eadie-Hofstee-Diagramm

Für die Aktivität an pNP-a-Glu ergeben sich aus dem Lineweaver-Burke- und EadieHofstee-Diagramm folgende Werte für $K_{m}$ und $v_{\max }$ für RPMI00720:

\begin{tabular}{|c|c|c|}
\hline & Lineweaver-Burke & Eadie-Hofstee \\
\hline$K_{\mathrm{m}}$ & $0,31 \mathrm{mM}$ & $0,33 \mathrm{mM}$ \\
\hline $\mathrm{v}_{\max }$ & $1,11 \mu \mathrm{mol} / \mathrm{min}^{*} \mathrm{mg}$ & $1,16 \mu \mathrm{mol} / \mathrm{min}^{*} \mathrm{mg}$ \\
\hline
\end{tabular}

\subsubsection{Bestimmung des pH-Optimums}

Hierfür wurde die Aktivität der a-Glukosidase mit pNP-a-Glu in einem pH-Bereich zwischen 5,5 und 10 bestimmt (2.4.2.9). Es wurden folgende Puffer für die verschieden $\mathrm{pH}-B e r e i c h e$ verwendet: Natriumsuccinat $(\mathrm{pH}$ 5.5-7.0), HEPES $(\mathrm{pH} 7.0-$ 8.5), 3-(cyclohexylamino)-1-propanesulfonsäure (CAPS; pH 9.0-10). Die Puffer wurden bei $60^{\circ} \mathrm{C}$ eingestellt. 


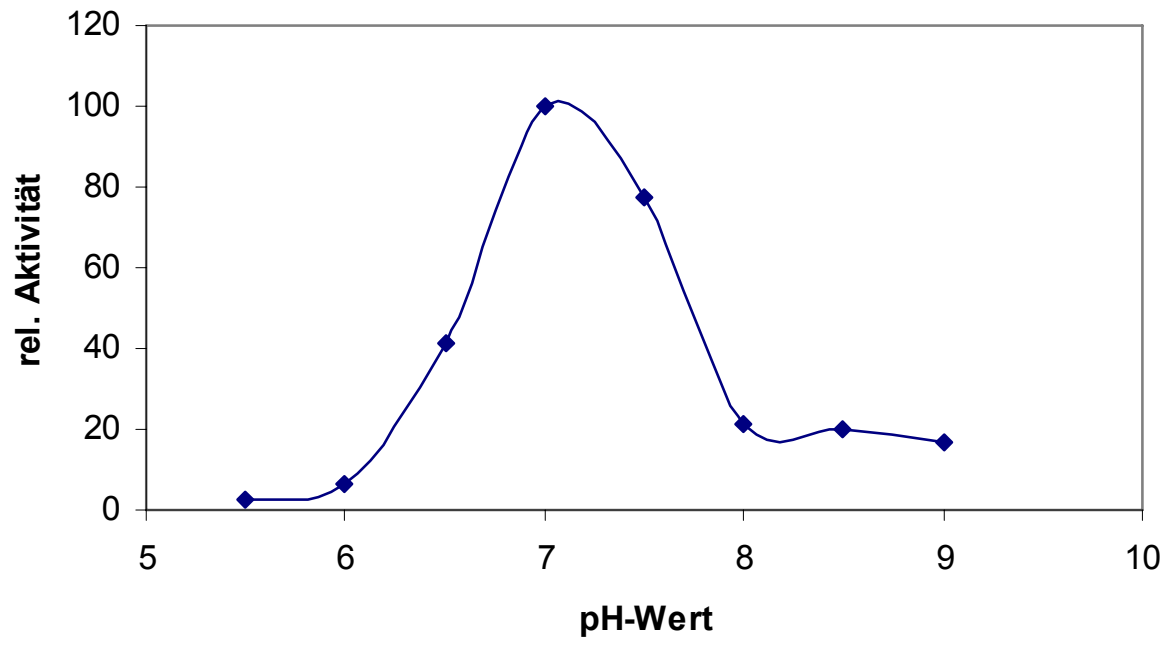

Abbildung 47: pH-Kurve

Es zeigte sich ein Aktivitätsmaximum bei einem $\mathrm{pH} \mathrm{7,} \mathrm{wobei} \mathrm{alle} \mathrm{Messpunkte}$ prozentual in Relation zur höchsten Aktivität gesetzt wurden.

\subsubsection{Bestimmung des „Temperaturoptimums“}

Analog zur Messung der optimalen Aktivität in Abhängigkeit der $\mathrm{H}^{+}$lonenkonzentration wurde in diesem Fall der Temperaturbereich gesucht, in dem das Enzym seine maximale Aktivität an pNP- $\alpha$-Glu entfaltet.

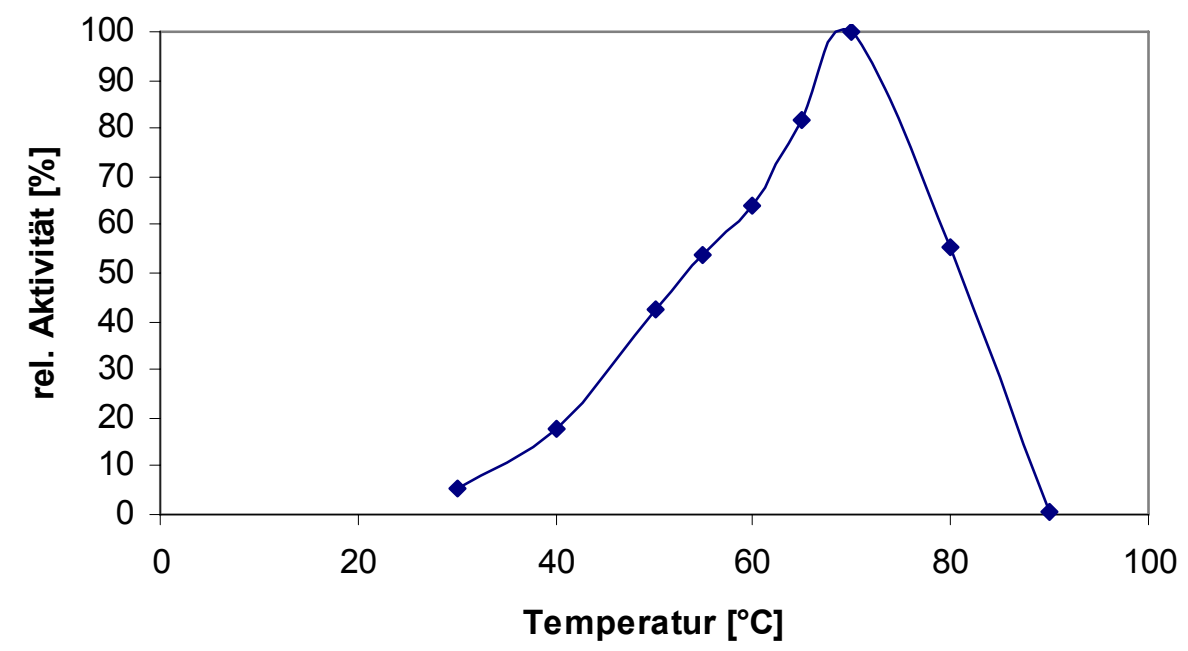

Abbildung 48: „Temperaturoptimum“ der RPMI00720-kodierten a-Glukosidase 
Die höchste Aktivität des Enzyms wurde bei $70^{\circ} \mathrm{C}$ ermittelt. Alle nachfolgenden Tests wurden dann bei $60^{\circ} \mathrm{C}$ durchgeführt. Eine Inkubationstemperatur von $10^{\circ} \mathrm{C}$ unter dem Temperaturoptimum sollte verhindern, daß das Enzym während der Aktivitätsbestimmung zu stark inaktiviert wurde und somit die Messung verfälschte.

\subsubsection{Bestimmung der Thermostabilität}

Die Ansätze (2.4.3.3) wurden bei den entsprechenden Temperaturen vorinkubiert. Dabei wurden 4,2 $\mu \mathrm{g}$ Enzym pro Messung eingesetzt. Die Vorinkubation erfolgte bei 40, 50, 60, 70, 80 und $90^{\circ} \mathrm{C}$. Das Ergebnis der thermischen Inaktivierung ist in (Abbildung 48) dargestellt.

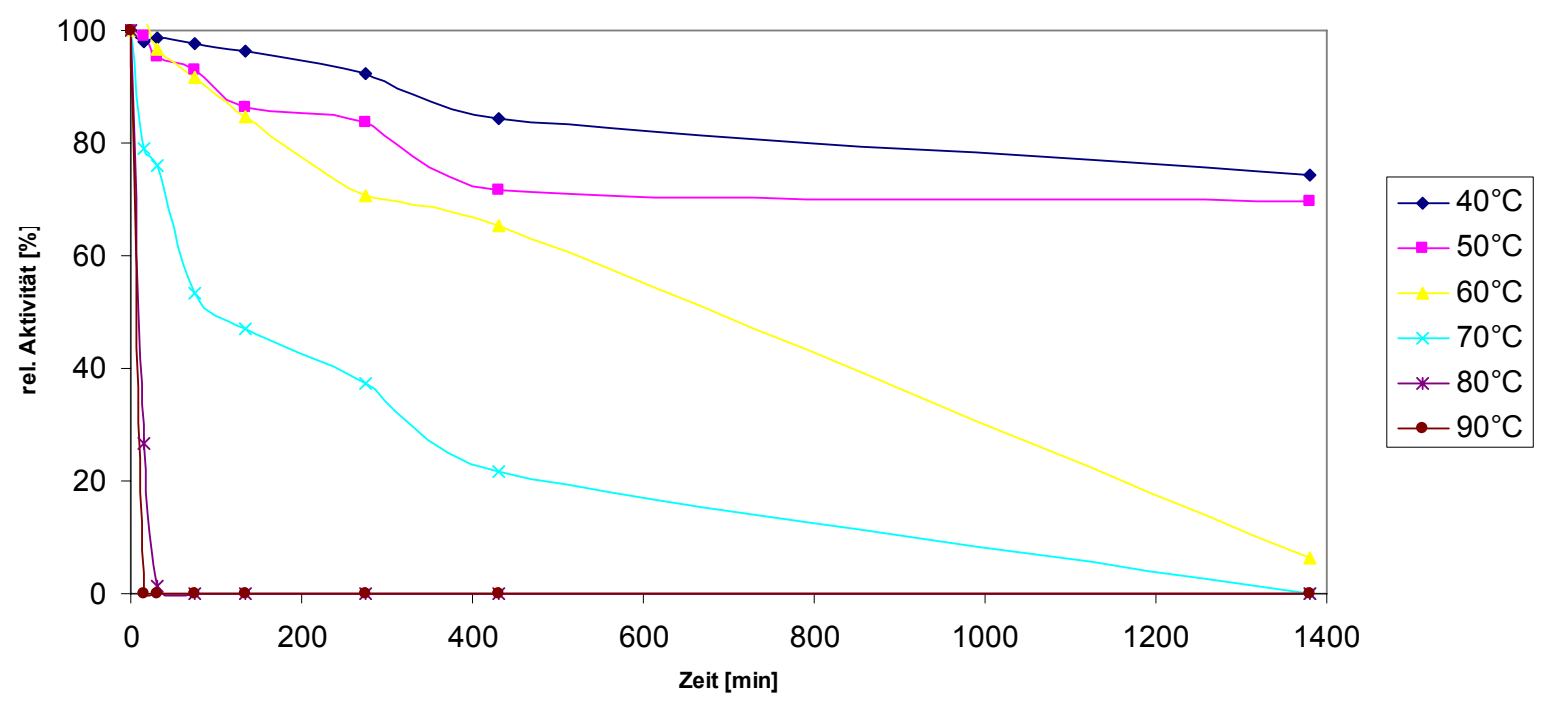

Abbildung 49: Temperaturinaktivierung

Wie aus Abbildung 49 hervorgeht, verliert das Enzym über $60^{\circ} \mathrm{C}$ sehr schnell seine Aktivität. Im Temperaturbereich bis $60^{\circ} \mathrm{C}$ zeigt RPMI00720 eine hohe Toleranz gegenüber Inaktivierung durch Hitzeeinwirkung. 


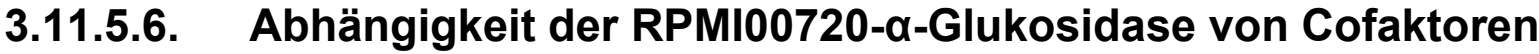

Die von RPMI00720 abgeleitete Aminosäuresequenz weist die typischen konservierten Bereiche auf, wie alle Enzyme der GHF4. Dementsprechend wurde für das Enzym die Abhängigkeit von den für die GHF4-Enzyme üblichen Cofaktoren festgestellt (2.4.2.10). Optimale Aktivität wurde bei folgenden Konzentrationen der Cofaktoren erreicht:
$\mathrm{NAD}^{+}$
2, $7 \mathrm{mM}$
DTT
$0,25 \mathrm{M}$
$\mathrm{Mn}^{2+}$
0, $6 \mathrm{mM}$
Tris- $\mathrm{HCl} \mathrm{pH} 7^{60^{\circ} \mathrm{C}}$
$0,1 \mathrm{M}$
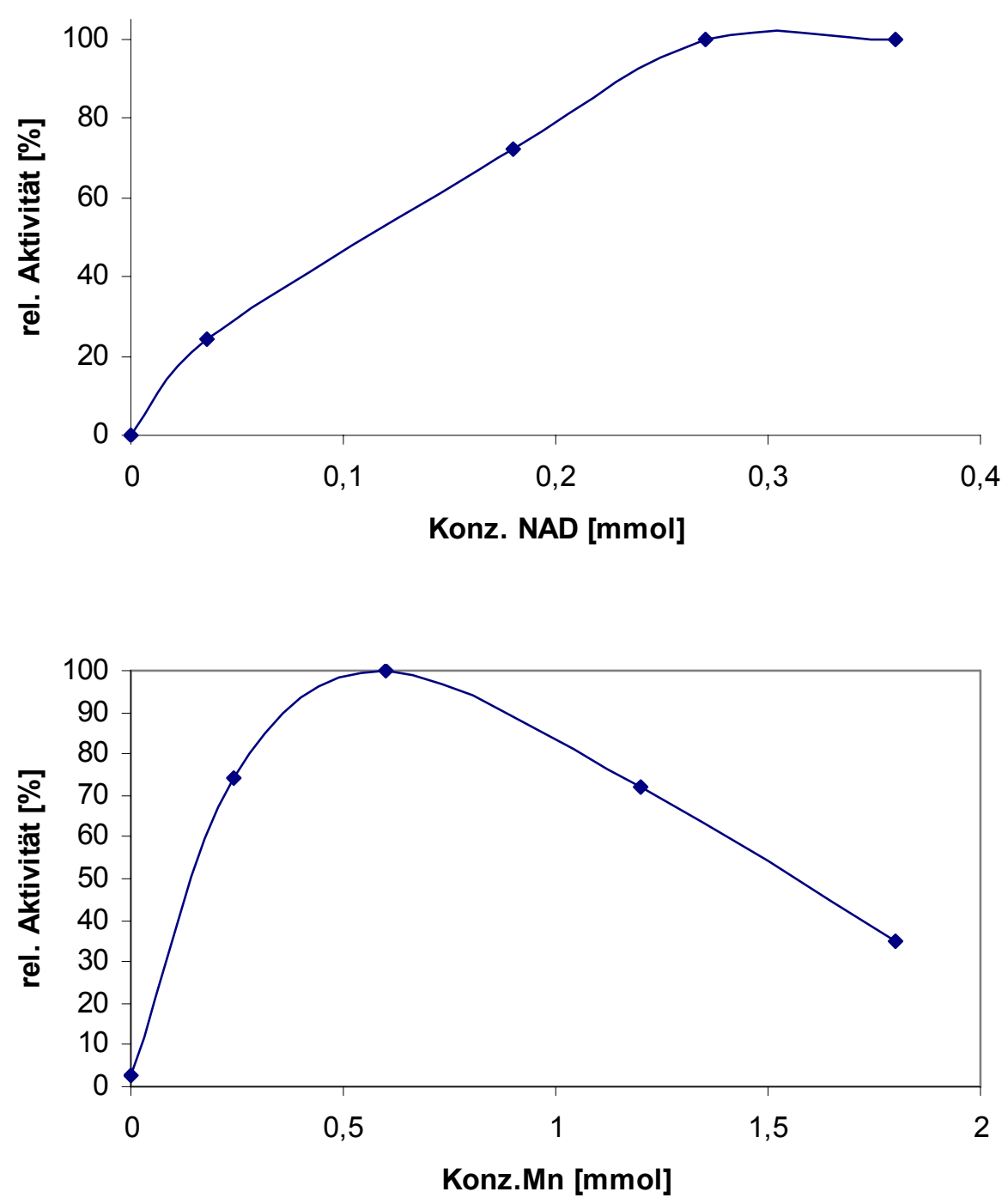


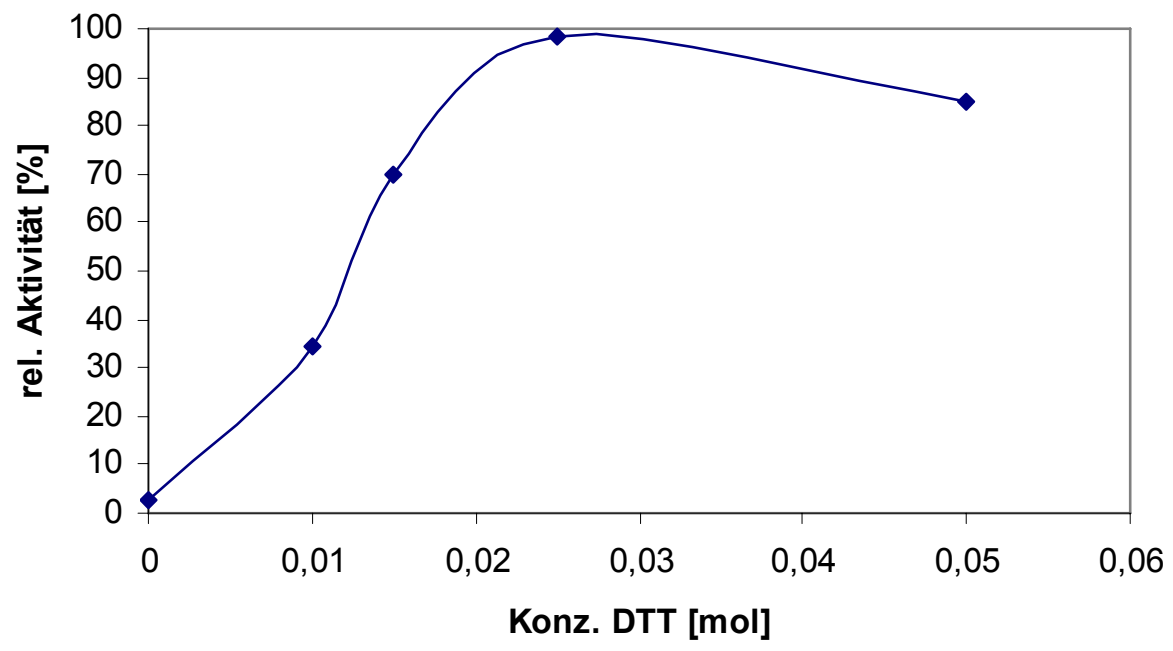

Abbildung 50: Effekt der Konzentration von $\mathrm{NAD}^{+}, \mathrm{Mn}^{2+}$ und DTT auf die Aktivität von gereinigtem RPMI00720. Zur Messung wurde die Konzentration des jeweiligen Parameters variiert, während die beiden anderen Cofaktoren in optimaler Konzentration zugesetzt wurden.

Für die volle enzymatische Aktivität war die Anwesenheit aller drei Cofaktoren notwendig. Fehlte auch nur eine der drei Komponenten $\mathrm{Mn}^{2+}, \mathrm{NAD}^{+}$oder DTT, so war ein dramatischer Einbruch der maximalen Aktivität zu verzeichnen.

Weitere Tests mit zweiwertigen lonen $\left(\mathrm{Ca}^{2+}, \mathrm{Co}^{2+}, \mathrm{Zn}^{2+}, \mathrm{Ba}^{2+}, \mathrm{Ni}^{2+}, \mathrm{Cu}^{2+}, \mathrm{Sr}^{2+}, \mathrm{Mg}^{2+}\right.$ und $\left.\mathrm{Fe}^{2+}\right)$ zeigten keine signifikante Aktivität.

DTT zeigte eine deutliche Aktivitätssteigerung gegenüber Mercaptoethanol. Im folgenden Diagramm (Abbildung 51) sind beide Reduktionsmittel gegenübergestellt.

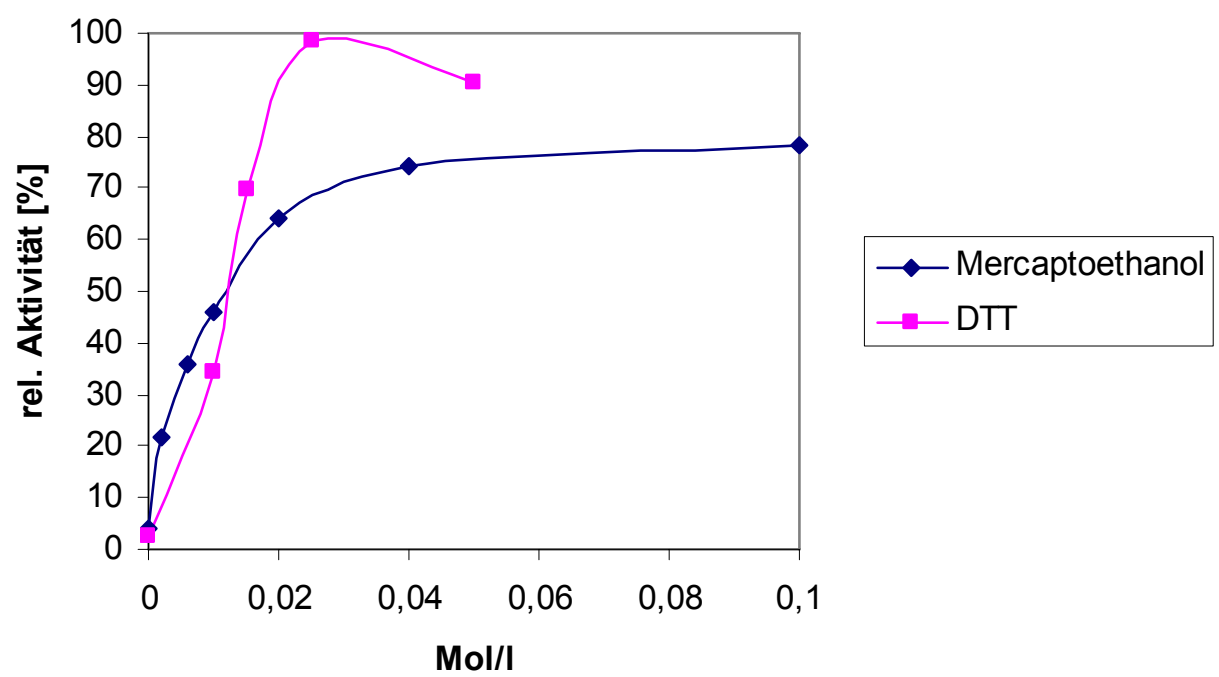

Abbildung 51: Vergleich der Aktivitätssteigerung von DTT und Mercaptoethanol 
Mercaptoethanol erreicht selbst in höheren Konzentrationen nur etwa $78 \%$ der maximalen Aktivität.

\subsection{Untersuchung des ORFs RPMI01263}

\subsubsection{Klonierung von RPMI01263 aus $P$. miotherma in E. coli}

Die Isolierung des Templates für RPMI01263 erfolgte aus der genomischen DNA von P. miotherma mit Hilfe von Amplifikation durch PCR. Die verwendeten Primer waren 24 bzw. 27 bp lang.

\begin{tabular}{|l|c|}
\hline Bezeichnung & Primersequenz $\left(5^{\prime} \rightarrow 3^{\prime}\right)$ \\
\hline 1263 _or +400 & ggg tag tgg ctc ctg agg aga tat \\
\hline 1263 rev+200 & ggg gat cgt tgg aga aaa ttg taa tga \\
\hline
\end{tabular}

Der PCR-Ansatz wurde, wie schon in 3.10.1 beschrieben, gewählt, ebenso wie die PCR-Bedingungen.

\begin{tabular}{|l|c|}
\hline Bezeichnung & Primersequenz $\left(5^{\prime} \rightarrow 3^{\prime}\right)$ \\
\hline 1263_720_for_gen & ggg cat atg aca gct atc aag tta \\
\hline 1263_720_gen_rev & ggg aag ctt cta ttt ttt gct gta gtg ctt \\
\hline
\end{tabular}

Der PCR-Ansatz wurde bei den angegebenen Bedingungen inkubiert. Anschließend wurde das 1,4 kb PCR-Produkt auf einem 0,8 \%igen Agarose-Gel aufgetrennt und aus dem Gel herausgeschnitten und extrahiert. Dieses wurde nun mit dem EcoRV geschnittenen $\mathrm{pBSK}^{+}$-Vektor ligiert und in E. coli XL1blue transformiert. Nach BlauWeiß-screening wurde ein Klon mit korrekt inseriertem PCR-Fragment ausgewählt und unter Verwendung der neu eingefügten Schnittstellen Ndel/ HindIII in den Vektor 
pET24c kloniert (Abbildung 52). Dieses neue Konstrukt wurde nun zur heterologen Expression in den Stamm E. coli BL21 elektroporiert. 


\subsubsection{Klonierungsstrategie}

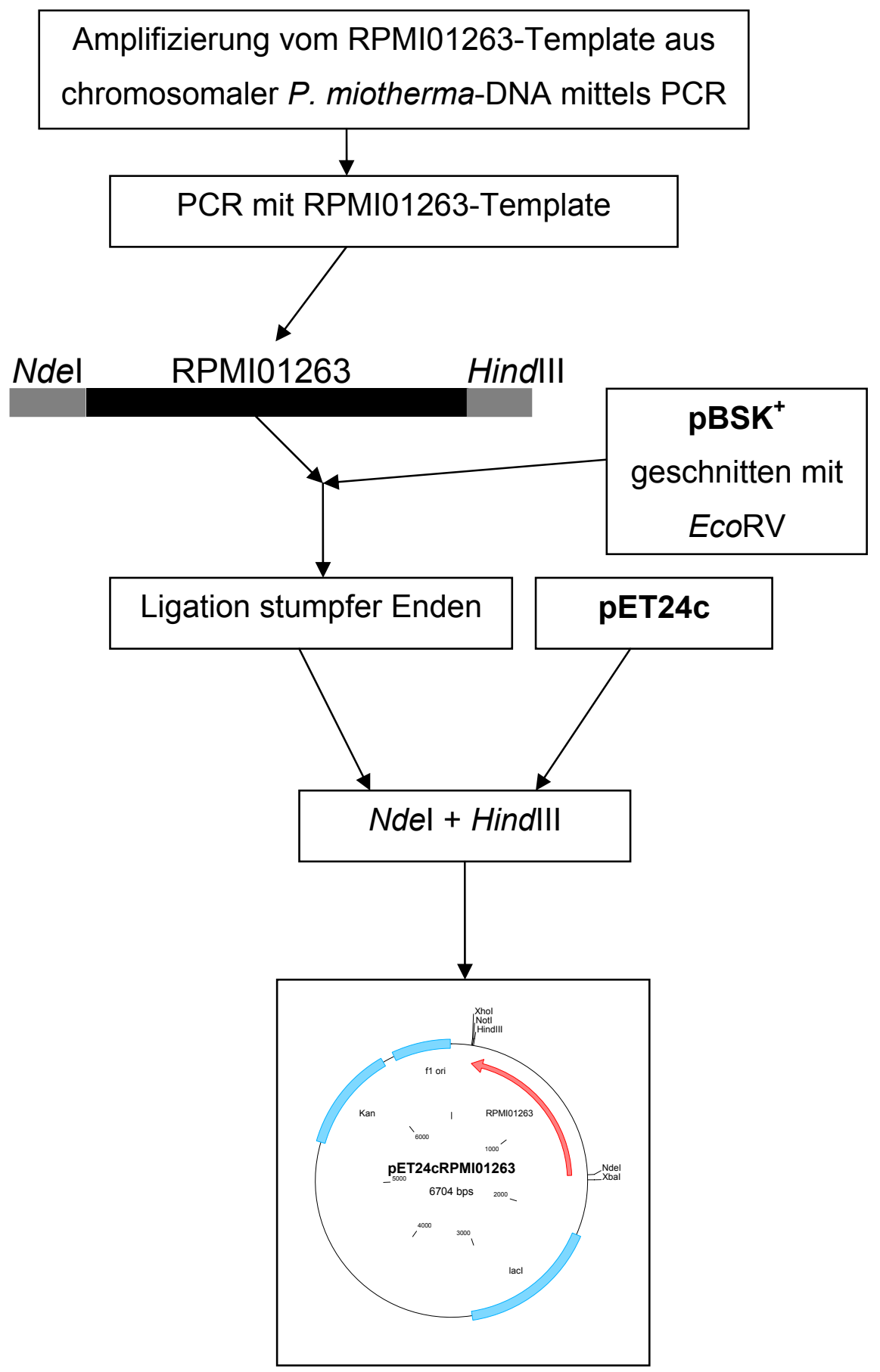




\subsubsection{Anzucht und Herstellung eines Rohextraktes}

Für eine Charakterisierung wurde RPMI01263 im präparativen Maßstab gewonnen. Hierfür wurden 1,5 I LB Kan mit $30 \mathrm{ml}$ Inokulum angeimpft und bei einer $\mathrm{OD}_{600}$ von 0,50,6 mit 0,5 mM (Endkonzentration) IPTG induziert. Danach wurde über Nacht unter kräftiger Belüftung bei $37^{\circ} \mathrm{C}$ inkubiert. Die Zellen wurden anschließend bei $7000 \mathrm{Upm}$ in GS3-Bechern geerntet, in $20 \mathrm{mM}$ Tris- $\mathrm{HCl} \mathrm{pH} 7$ aufgenommen und mittels einer French Pressure Cell aufgeschlossen. Die Zelltrümmer wurden bei $14000 \mathrm{rpm}$ abzentrifugiert und der Überstand anschließend $15 \mathrm{~min}$ bei $60^{\circ} \mathrm{C}$ denaturiert. Bei dieser Hitzefällung wurden ein Großteil der Wirtsproteine zerstört, und das hitzestabile Enzym blieb bei der anschließenden Zentrifugation bei 14000 rpm im Überstand.

\subsubsection{Aufreinigung des von RPMI01263 kodierten Enzyms mittels FPLC}

Der Überstand aus der Hitzefällung wurde sterilfiltriert und anschließend an einem Anionentauscher Source $15 \mathrm{Q}$ aufgereinigt.

$\begin{array}{ll}\text { Parameter } & \\ \text { Medium : } & \text { Source } 15 \mathrm{Q} \\ \text { Säule : } & \text { XK } 26 \\ \text { Säulenvolumen : } & 50 \mathrm{ml} \\ \text { Puffer A : } & 20 \mathrm{mM} \text { Tris-Cl pH 7 } \\ \text { Puffer B : } & 20 \mathrm{mM} \text { Tris-Cl pH 7, 1M NaCl } \\ \text { Flußrate : } & 10 \mathrm{ml} / \mathrm{min} \\ \text { Fraktion : } & 10 \mathrm{ml} \\ \text { Equilibrierung : } & 2 \text { SV Puffer B, 10 SV Puffer A } \\ \text { Gradient : } & \text { siehe Elutionsprofil }\end{array}$




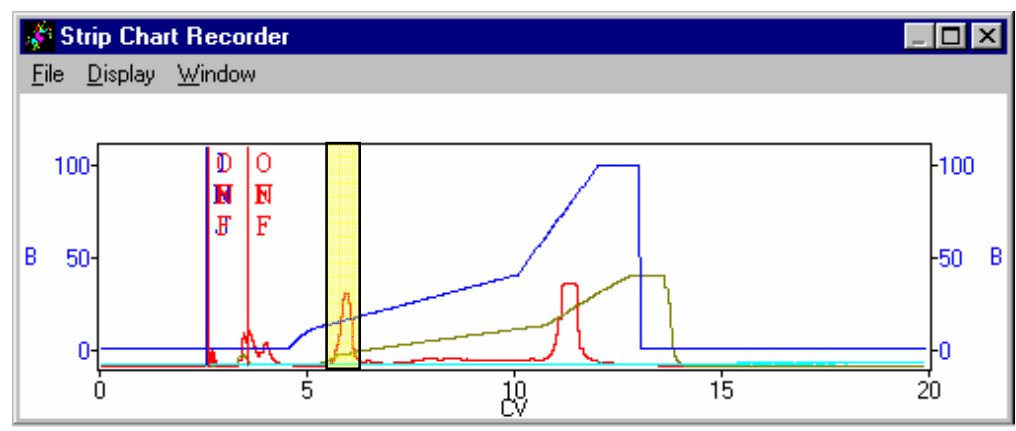

Abbildung 53: Chromatogramm des Source 15Q-Laufs, blau: Gradient, grün: Leitfähigkeit, rot: Proteinkonzentration (aktive Fraktionen gelb hinterlegt)

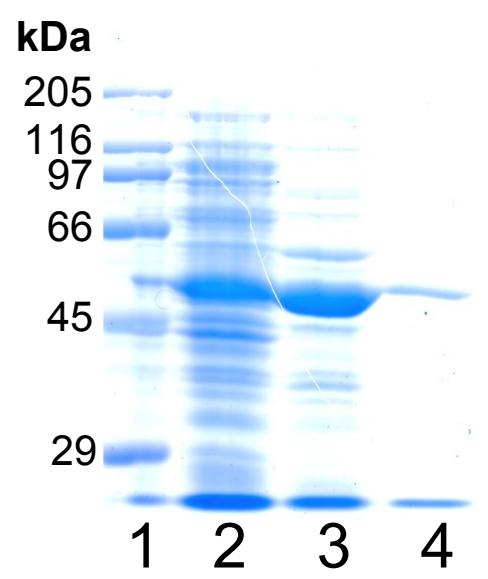

Abbildung 54: SDS-PAGE der Reinigungsschritte von RPMI01263 (Spur 1: Marker, Spur 2: Rohextrakt, Spur 3: hitzegefällter Rohextrakt, Spur 4: Source 15Q-Pool)

\subsubsection{Untersuchungen zum Oligomerisierungsgrad von RPMI01263}

Wie schon in 3.3.1 beschrieben, wurde der Oligomerisierungsgrad mittels Gelfiltration ermittelt. Hierfür wurde eine Superose-6-Gelfiltrationssäule der Firma Pharmacia verwendet. Für RPMI01263 erhielt man ein Elutionsvolumen von 15,70 ml; mit der aus der Regressionsgraden abgeleiteten Formel:

$$
\log M W[k D a]=-1,2767^{\star} K_{a v}+5,9996
$$

errechnete sich daher für das native Enzym eine Molekularmasse von 228 kDa. Das entspricht etwa der fünffachen Masse der aus dem SDS-Gel abgeleiteten Größe von 
55,5 kDa. Somit kann davon ausgegangen werden, daß die putative $\alpha-G l u k o s i d a s e$ als Tetramer vorliegt.

\subsubsection{Substratspektrum}

Ein breit angelegtes Screening (2.4.3.4) mit verschiedenen $\alpha-, \beta$-Substraten und unterschiedlichem Oligomerisierungsgrad zeigte, daß von ORF RPMI00720 kodierte Enzym genauso wie AglA aus T. maritima (Raasch et al., 2001), sowohl agalaktosidische, als auch a-glukosidische Bindungen spalten kann. Wie bei AgIA wurde eine höhere Aktivität gegenüber a-glukosidischen Verknüpfungen festgestellt. Die Aktivität gegenüber pNP- $\alpha-G a l$ lag nur bei $60 \%$.

\begin{tabular}{|l|c|}
\hline Substrate & 1263 \\
\hline Polymere & \\
\hline$\beta$-Dextran, Glycogen, Dextran, & - \\
Amylopectin & \\
Stärke & \\
\hline Maltoologosaccharide & - \\
\hline Maltotriose, Maltotetraose, Maltopantaose, \\
Maltohexaose, Maltoheptaose & \\
\hline Cyclodextrine & \\
\hline Y-Cyclodextrin, $\beta$-Cydclodextrin, & - \\
$\alpha-C y c l o d e x t r i n$ & \\
\hline Disccharide & + \\
\hline Maltose & + \\
Raffinose & + \\
Saccharose & - \\
Cellobiose & + \\
Melibiose & + \\
Lactose & - \\
\hline Synthetische Substrate & \\
\hline pNP- $\alpha-D-G l u k o s e$ & \\
pNP- $\beta-D-G l u k o s e$ & \\
pNP- $\alpha-D-G a l a k t o s e$ & \\
pNP- $\beta-D-G a l a k t o s e$ & \\
\hline
\end{tabular}




\subsubsection{Enzymkinetik}

Für die Ermittlung der kinetischen Daten von RPMI01263 wurde die Aktivität des Enzyms mit steigender Konzentration (2.4.2.9) an pNP-a-Glu bestimmt (Abbildung 55). In folgenden Abbildungen finden sich die entsprechenden Michaelis-Menten-, Lineweaver-Burke- und Eadie-Hofstee-Auftragungen zur Berechnung von $K_{m}$ und $\mathrm{V}_{\max }$.

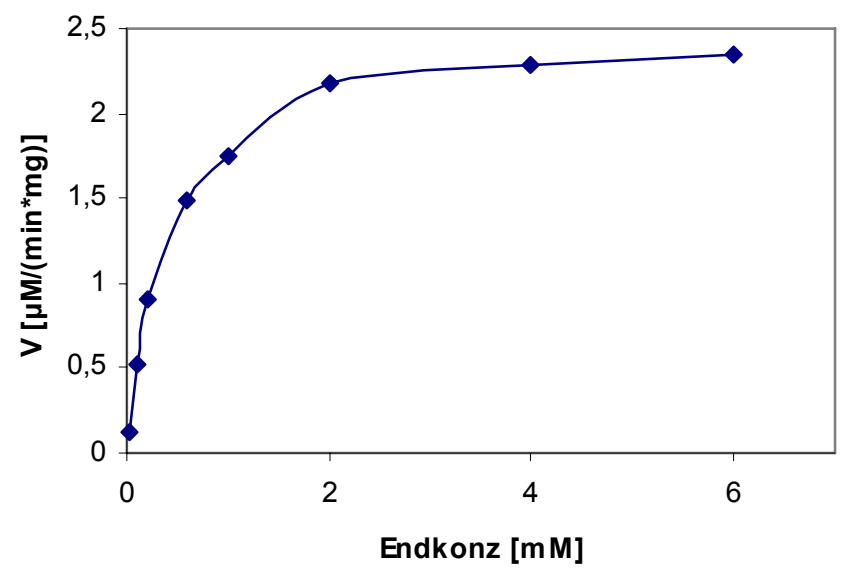

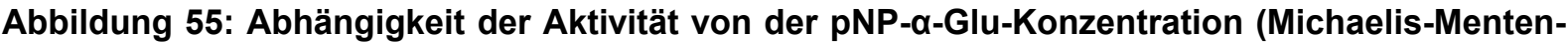
Diagramm)

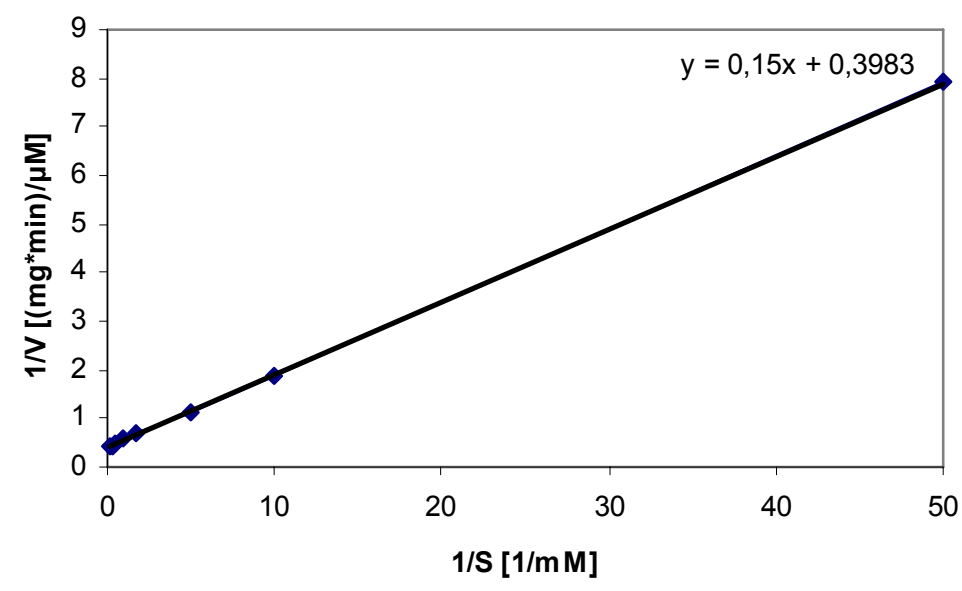

Abbildung 56: Darstellung der Daten aus Abbildung 55 als Lineweaver-Burke-Diagramm 


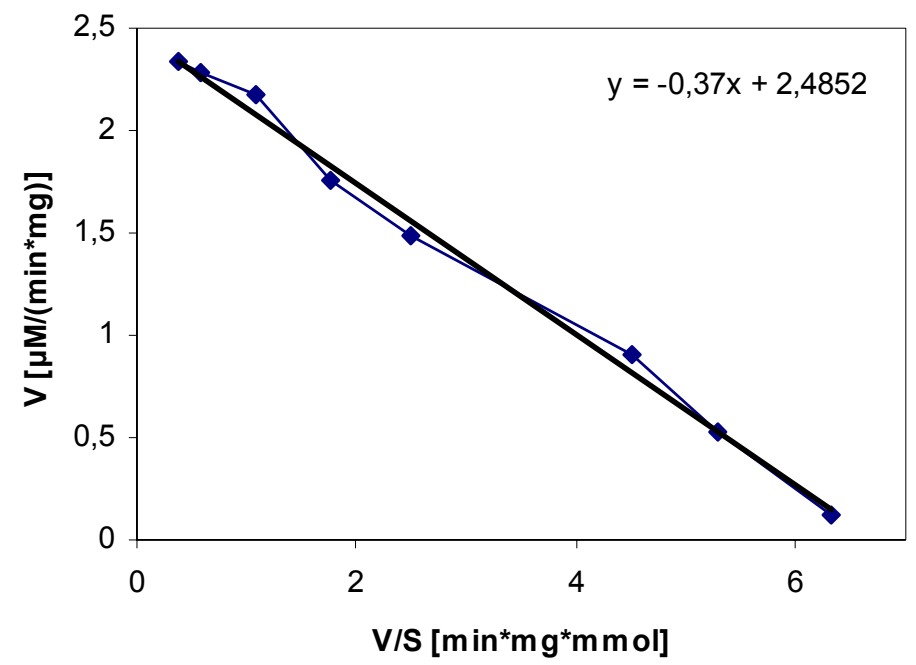

Abbildung 57: Darstellung der Daten aus Abbildung 55 als Eadie-Hofstee

Tabelle 15: Zusammenfassung der kinetischen Daten

\begin{tabular}{|c|c|c|}
\hline & Lineweaver-Burke & Eadie-Hofstee \\
\hline$K_{\mathrm{m}}$ & $0,40 \mathrm{mM}$ & $0,37 \mathrm{mM}$ \\
\hline $\mathrm{V}_{\max }$ & $2,51 \mu \mathrm{mol} / \mathrm{min}^{*} \mathrm{mg}$ & $2,49 \mu \mathrm{mol} / \mathrm{min}^{*} \mathrm{mg}$ \\
\hline
\end{tabular}

\subsubsection{Biochemische Charakterisierung}

\subsubsection{Bestimmung des pH-Optimum}

Hierfür wurde die Aktivität der $\alpha$-Glukosidase mit pNP-a-Glu in einem pH-Bereich zwischen 5,5 und 10 bestimmt (2.4.3.1). Es wurden folgende Puffer für die verschieden $\mathrm{pH}$-Bereiche verwendet: Natriumsuccinat $(\mathrm{pH}$ 5.5-7.0), HEPES $(\mathrm{pH} 7.0-$ 8.5), 3-(cyclohexylamino)-1-propansulfonsäure (CAPS; pH 9.0-10). Die Puffer wurden bei $60^{\circ} \mathrm{C}$ eingestellt. 


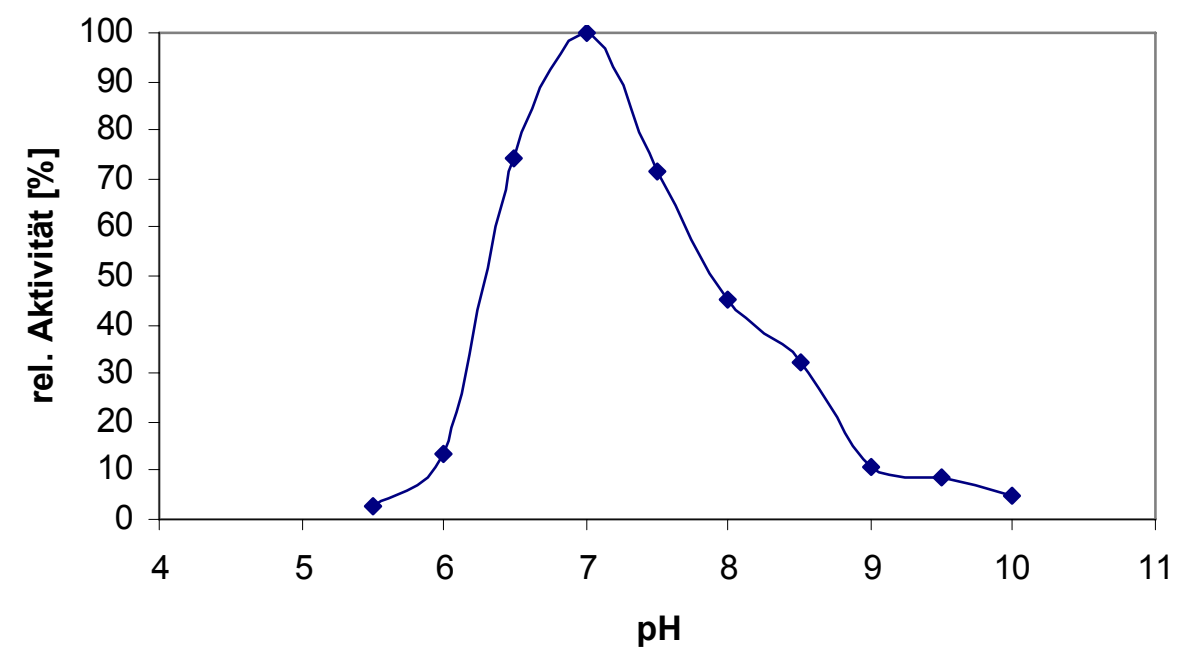

Abbildung 58: Bestimmung des pH-Optimums von RPMI01263

Es zeigte sich ein $\mathrm{pH}$-Optimum bei einem $\mathrm{pH}-$ Wert von 7 , wobei alle Messpunkte prozentual in Relation zur höchsten Aktivität gesetzt wurden.

\subsubsection{Bestimmung des Temperaturoptimums}

Analog zur Messung der optimalen Aktivität in Abhängigkeit der $\mathrm{H}^{+}-$ Ionenkonzentration, wurde in diesem Fall der Temperaturbereich gesucht, in dem das Enzym seine höchste Aktivität an pNP-a-Glu entfaltet (2.4.3.2).

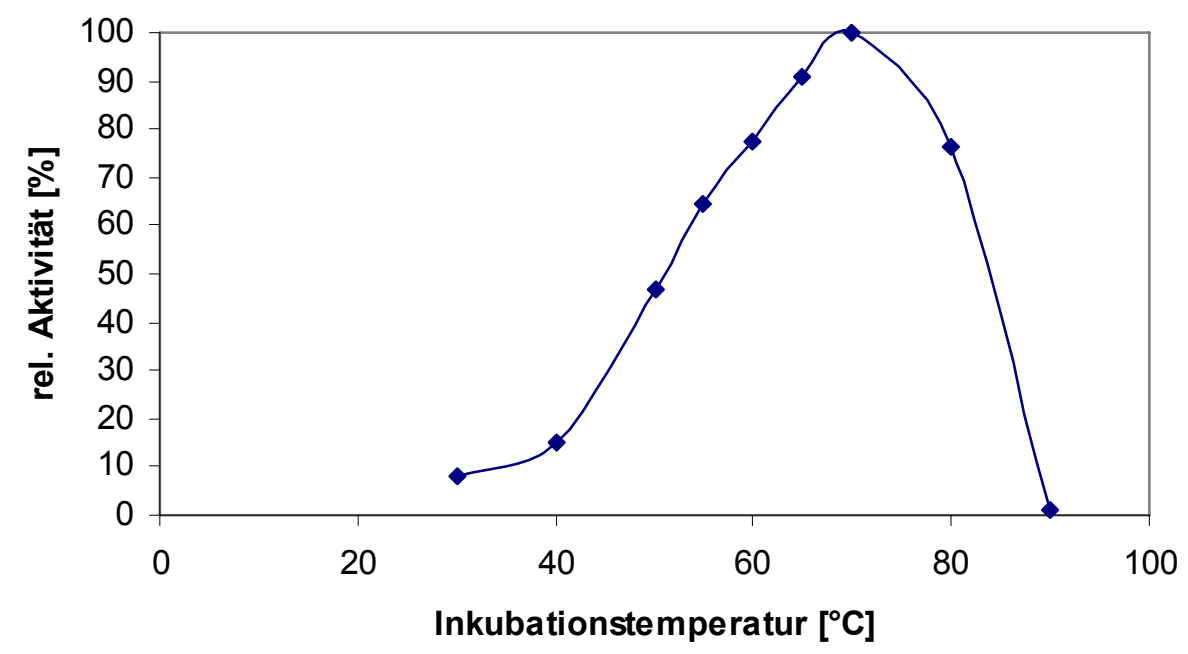

Abbildung 59: Bestimmung des „Temperaturoptimums“ der RPMI01263-kodierten aGlukosidase 
Die höchste Aktivität hatte das Enzym bei $70^{\circ} \mathrm{C}$. Alle nachfolgenden Tests wurden dann bei $60^{\circ} \mathrm{C}$ durchgeführt. Eine Inkubationstemperatur von $10^{\circ} \mathrm{C}$ unter dem Temperaturoptimum sollte verhindern, daß das Enzym während der Aktivitätsbestimmung zu stark inaktiviert wurde und somit die Messung verfälschte.

\subsubsection{Bestimmung der Thermostabilität}

Es wurde wie unter 3.11.5.5 beschrieben vorgegangen. Die Ansätze wurden bei den entsprechenden Temperaturen vorinkubiert. Dabei wurden jeweils $10 \mu \mathrm{g}$ Enzym pro Messung eingesetzt. Die Vorinkubation erfolgte bei $40,50,60,70,80$ und $90^{\circ} \mathrm{C}$. Das Ergebnis der thermischen Inaktivierung ist in Abbildung 60 dargestellt.

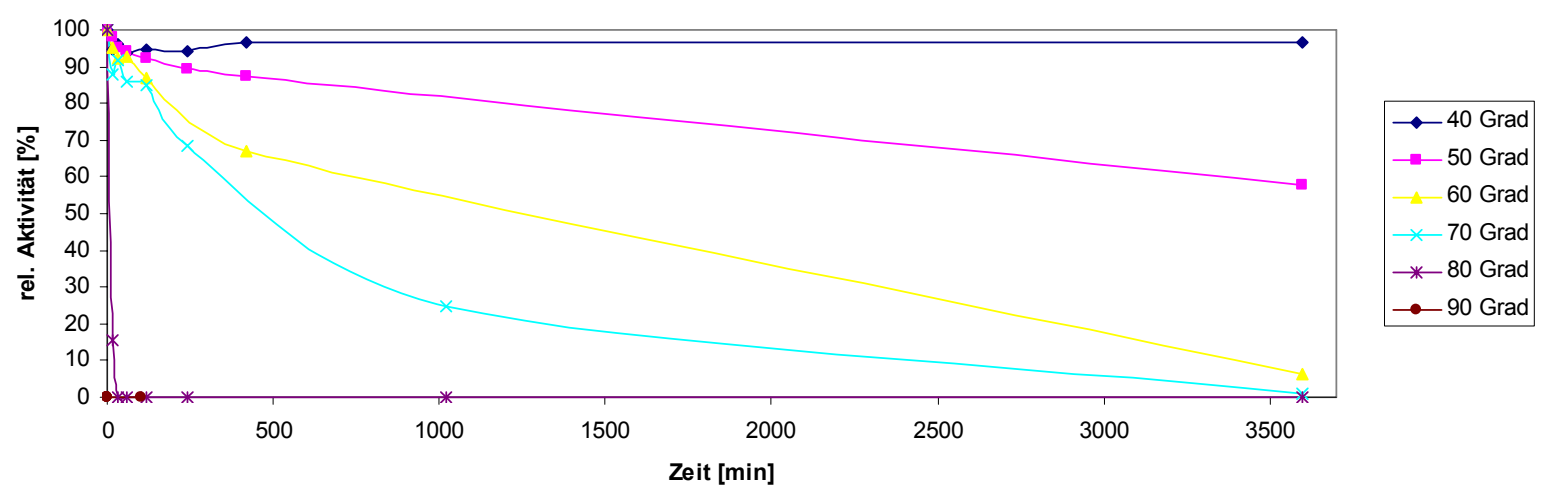

\section{Abbildung 60: Temperaturinaktivierung}

Wie aus Abbildung 60 hervorgeht, wurde die Aktivität nach über sieben Stunden bei $50^{\circ} \mathrm{C}$ fast nicht beeinträchtigt. Bei Temperaturen über $60^{\circ} \mathrm{C}$ tritt jedoch nach zwei Stunden ein zügiger Aktivitätsverlust ein. 


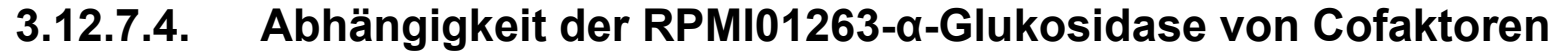

Die von RPMI00720 abgeleitete Aminosäuresequenz weist die typischen konservierten Bereiche vor, wie alle Enzyme der GHF4. Dementsprechend wurde für das Enzym die Abhängigkeit von den für die GHF4-Enzyme üblichen Cofaktoren festgestellt (2.4.2.10). Optimale Aktivität wurde bei folgenden Konzentrationen der Cofaktoren erreicht:

$\begin{array}{ll}\mathrm{NAD}^{+} & 0,9 \mathrm{mM} \\ \text { DTT } & 0,25 \mathrm{M} \\ \mathrm{Mn}^{2+} & 0,6 \mathrm{mM} \\ \text { Tris- } \mathrm{HCl} \mathrm{pH} 7^{60^{\circ} \mathrm{C}} & 0,1 \mathrm{M}\end{array}$
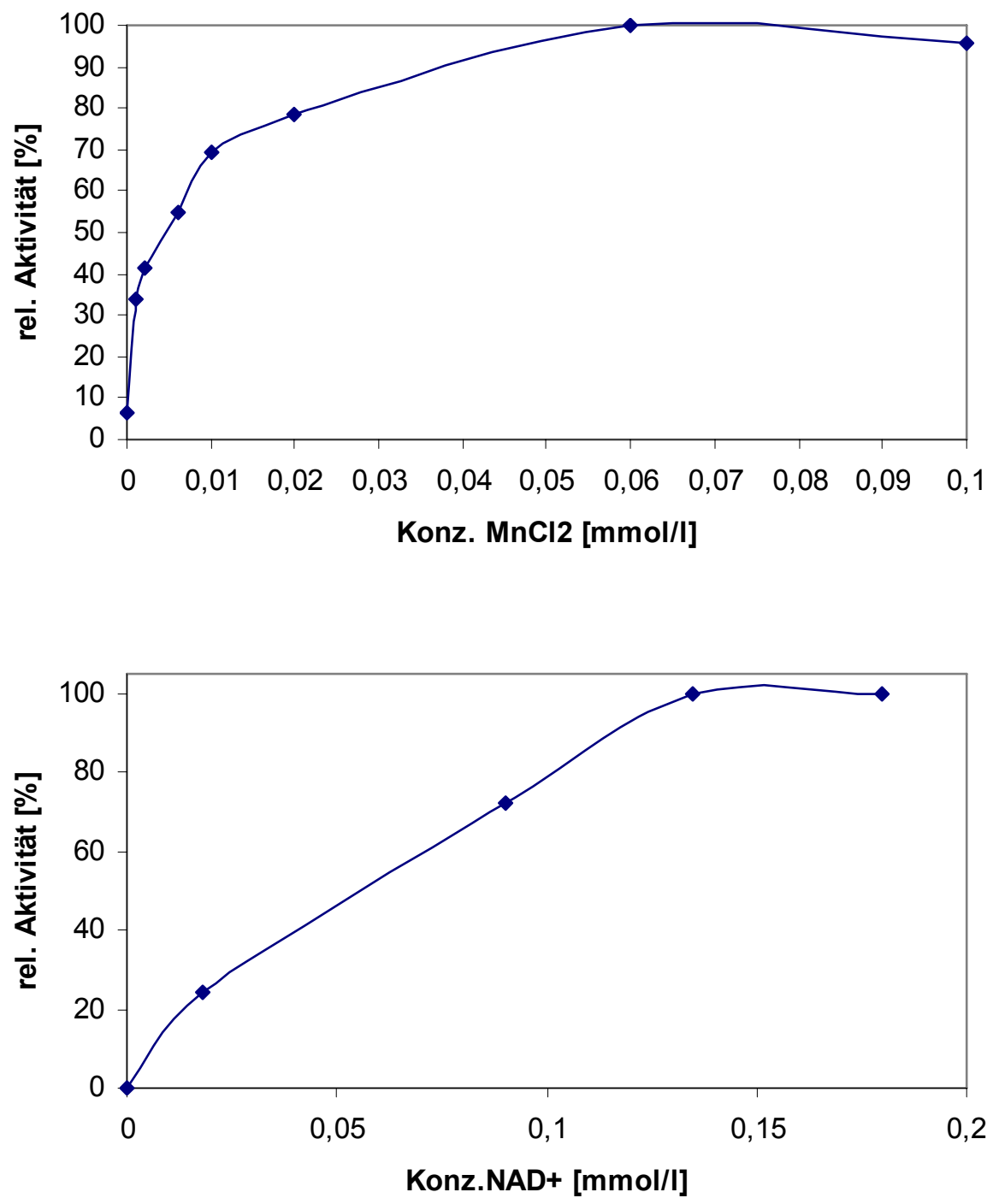


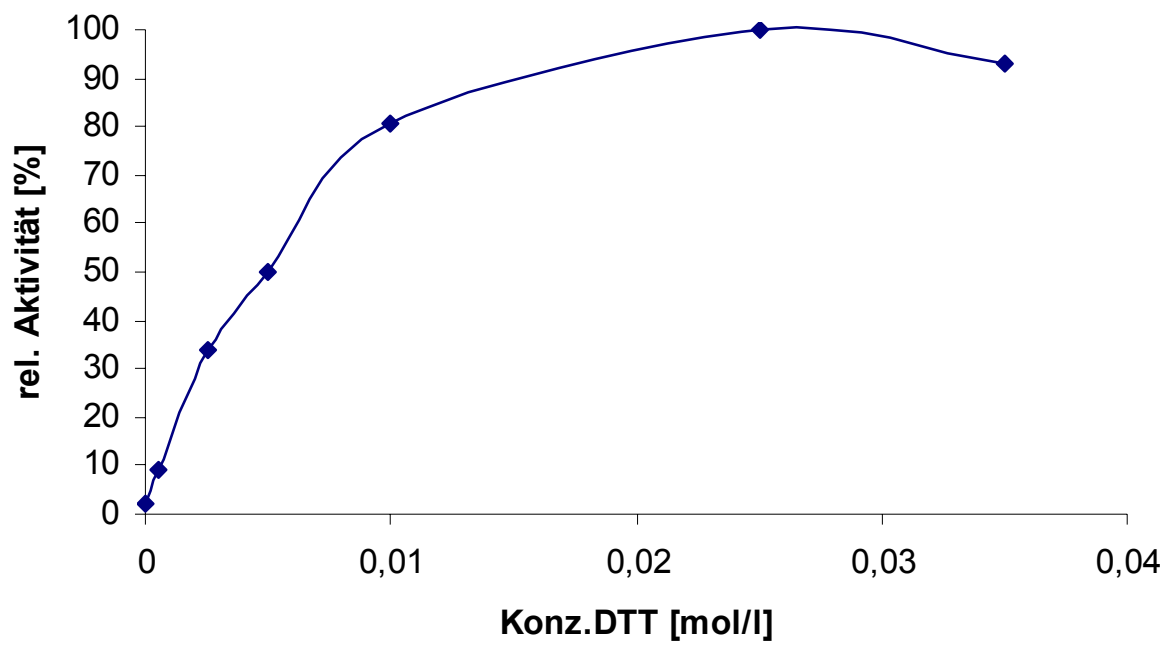

Abbildung 61: Effekt der Konzentration von $\mathrm{NAD}^{+}, \mathrm{Mn}^{2+}$ und DTT auf die Aktivität von gereinigtem RPMI01263. Zur Messung wurde die Konzentration des jeweiligen Parameters variiert, während die beiden anderen Cofaktoren in optimaler Konzentration zugesetzt wurden.

Für die volle enzymatische Aktivität war die Anwesenheit aller drei Cofaktoren notwendig. Fehlte auch nur eine der drei Komponenten $\mathrm{Mn}^{2+}, \mathrm{NAD}^{+}$oder DTT so war ein dramatischer Einbruch der maximalen Aktivität zu verzeichnen.

Weitere Tests mit zweiwertigen lonen $\left(\mathrm{Ca}^{2+}, \mathrm{Co}^{2+}, \mathrm{Zn}^{2+}, \mathrm{Ba}^{2+}, \mathrm{Ni}^{2+}, \mathrm{Cu}^{2+}, \mathrm{Sr}^{2+}, \mathrm{Mg}^{2+}\right.$ und $\mathrm{Fe}^{2+}$ ) zeigten keine signifikante Aktivität.

DTT zeigte eine deutliche Aktivitätssteigerung gegenüber Mercaptoethanol. Im folgenden Diagramm (Abbildung 62) sind beide Reduktionsmittel gegenübergestellt.

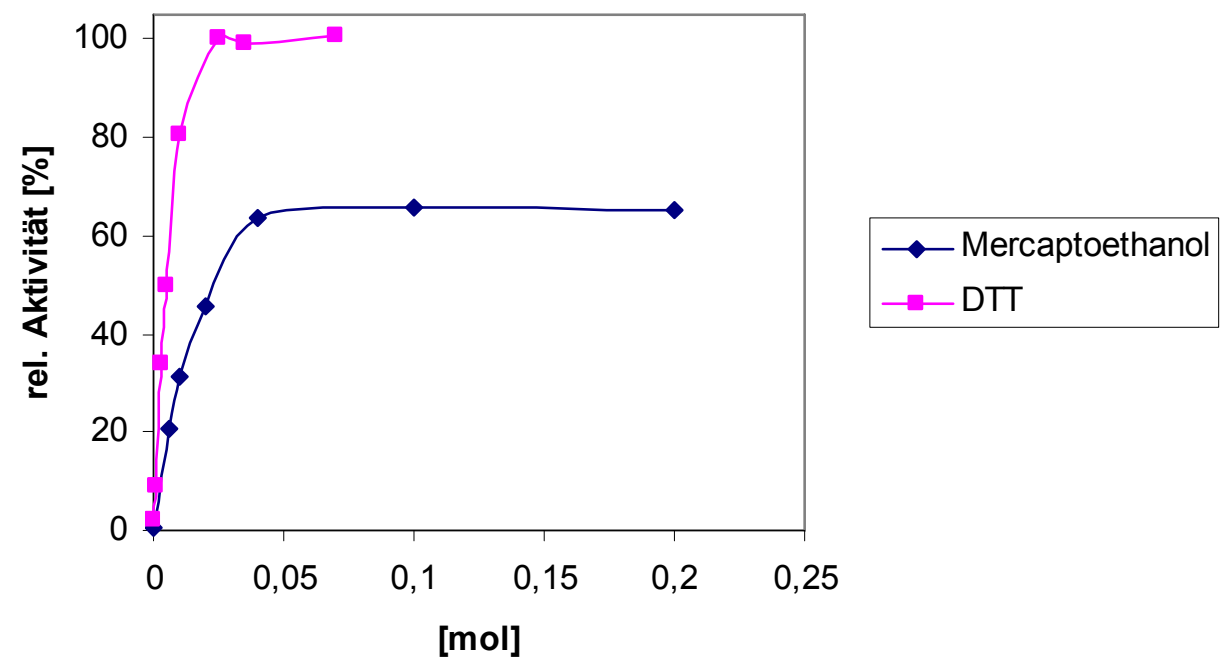

Abbildung 62: Gegenüberstellung von DTT und Mercaptoethanol 
Mercaptoethanol erreicht selbst in höheren Konzentrationen nur etwa $65 \%$ der Aktivität.

\subsection{ESR-Untersuchungen an E. coli MelA und das in ORF RPMI01263 kodierte Enzym}

Die Elektronenspinresonanz handelt von der Wechselwirkung von elektromagnetischer Strahlung mit magnetischen Momenten von Elektronen und Kernen in Materie. Vieles über die Struktur von Molekülen entstammt dem Studium von Absorptionsspektren. Solche Spektren werden erhalten, wenn man die Dämpfung einer elektromagnetischen Welle, die Materie durchdringt, als Funktion der Frequenz misst. Jede Absorptionslinie im Spektrum entspricht einem Übergang zwischen zwei Energiezuständen der absorbierenden Spezies. Die Frequenz der Linie misst den Energieabstand. Nur wenige aller möglichen Übergänge werden tatsächlich beobachtet. Geführt durch eine geeignete Theorie und entsprechende Auswahlregeln kann aus einem beobachteten Spektrum auf die Struktur geschlossen werden.

In den weitaus meisten Fällen rührt das magnetische Moment des Elektrons überwiegend von seinem Spin her, und die Bahnbewegung liefert nur einen kleinen Beitrag zum gesamten magnetischen Moment. Ein wichtiger Vorteil der ESR ist dabei, daß bei ungepaartem Elektronenspin die Moleküle nur in ihrem elektronischen Grundzustand untersucht werden müssen.

Folgende Systeme sind Gegenstand von ESR Untersuchungen:

-Freie Radikale in Festkörpern, Lösungen und Gasen, z.B. Spin-Label

-Übergangsmetallionen, z.B. in Enzymen

-Punktdefekte in Festkörpern, z.B. Farbzentren

Systeme mit mehreren ungepaarten Elektronen: Triplettzustände, Biradikale In biologischen Systemen treten paramagnetische Spezies in vielfältiger Form auf, beispielsweise als Übergangsmetallkomplexe, als Zwischenprodukte bei Elektronenübertragungsmechanismen oder als Folgeprodukte von Biomolekülen, die mit Licht oder ionisierender Strahlung geschädigt wurden. 
Bei bisherigen Untersuchungen zum Mechanismus der Bindungsspaltung bei den GHF4-Enzymen konnte die Rolle des Mangans noch nicht genau geklärt werden. Bei GlvA aus B. subtilis konnte Mangan im Kristall in der Nähe des aktiven Zentrums nachgewiesen werden und ein Mechanismus davon abgeleitet werden (Shyamala et al, 2004). Mangan verlässt in diesem Mechanismus seinen oktaedrischen Komplex mit $\mathrm{H}_{2} \mathrm{O}$. Der Mangan- $\mathrm{H}_{2} \mathrm{O}-$ Komplex besitzt ein sehr eindeutiges ESR-Spektrum (Abbildung 63).

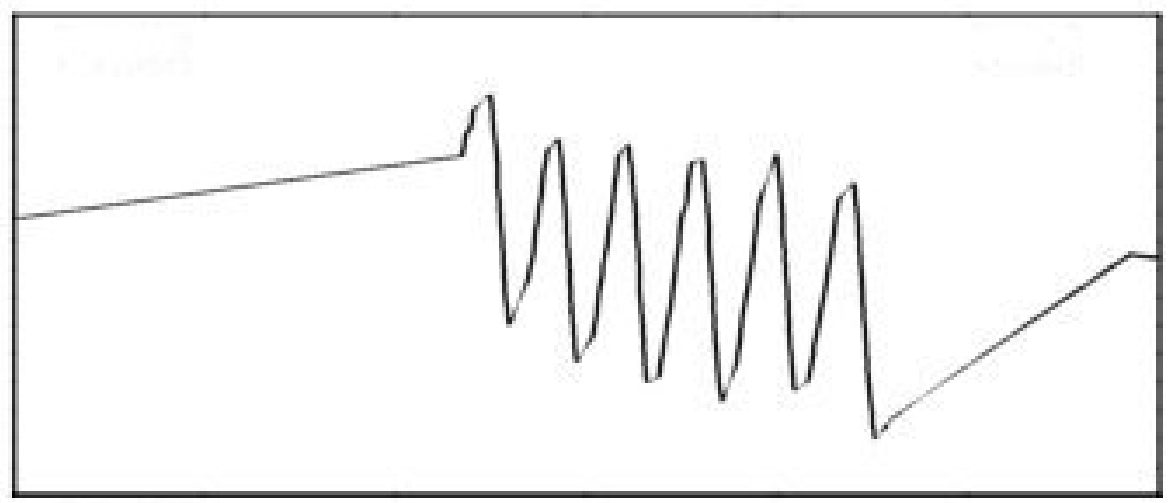

Abbildung 63: ESR-Spektrum von $\left[\mathrm{Mn}\left(\mathrm{H}_{2} \mathrm{O}\right)_{6}\right]^{2+}$ bei $180 \mathrm{~K}$

Bei unseren Messungen sollte nun untersucht werden, ob das Mangan diesen Komplex verlässt und vollständig im Enzym gebunden ist. Für diese Testreihe wurden die Enzyme MelA aus E. coli und die in ORF RPMI01263 kodierte $\alpha$ Glukosidase ausgewählt. In Vorversuchen wurden die einzelnen Cofaktoren und Puffer einzeln und in Kombination gemessen, um diese Koordinationen auszuschließen. Zunächst wurde jeweils ein 1:1-Verhältnis von Enzym und Mangan gemessen, um es anschließend mit den Spektren zu vergleichen, in denen das jeweilige Enzym im Überschuß vorhanden ist (Abbildung 64, Abbildung 65). 


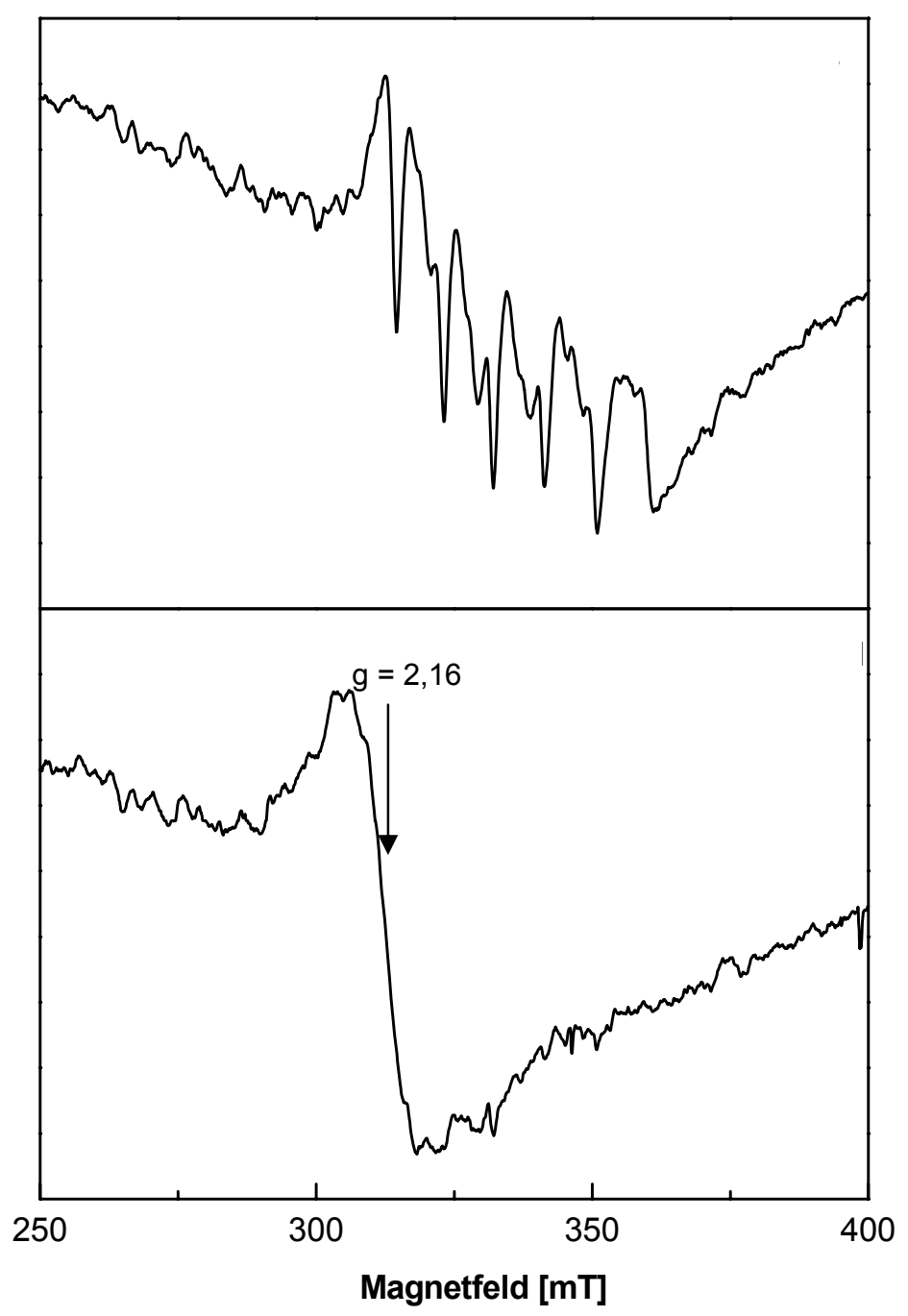

Abbildung 64: ESR-Spektren von MelA. Oben: (1:1 Verhältnis Mn zu Enzym (MelA, $40 \mathrm{mg} / \mathrm{ml}$ ) $91 \mu \mathrm{l}, \mathrm{MnCl}_{2}[10 \mathrm{mM}] 14 \mu \mathrm{l}, \mathrm{NAD}[0,6 \mathrm{mM}] 88 \mu \mathrm{l}$, pNP- $\alpha-G a l$ [0,1 M] $10 \mu \mathrm{l}$, unten: $(1: 0,25$ Verhältnis Mn zu Enzym (MelA, 40 mg/ml) $191 \mu \mathrm{l}$, MnCl$_{2}$ [10 mM] 3,5 $\mu \mathrm{l}, 176 \mu \mathrm{l}$ NAD [0,6], pNP- $\alpha-$ Gal $[0,1 \mathrm{M}] 20 \mu \mathrm{l})$. 


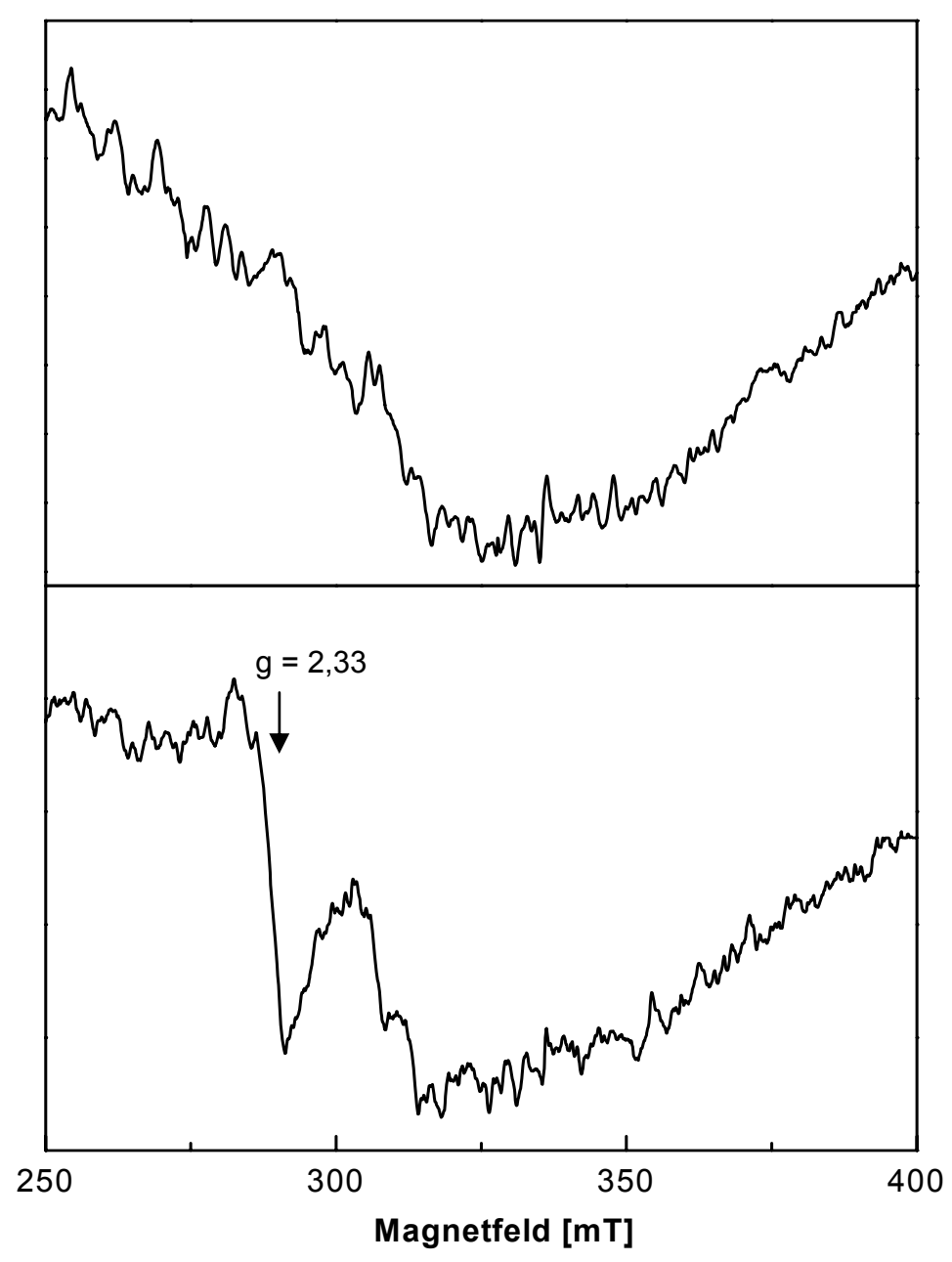

Abbildung 65: ESR-Spektrum des in ORF RPMI01263 kodierten Enzyms, oben: $196 \mu$ I Enzym [28,5 mg/ml], $1 \mu \mathrm{l} \mathrm{MnCl} 2$ [10 mM], $5 \mu \mathrm{l} \mathrm{NAD}{ }^{+}[0,6 \mathrm{mM}$ ], $5 \mu \mathrm{l}$ DTT [0,25 M], $5 \mu \mathrm{l} \mathrm{pNP- \alpha -Glu} \mathrm{[0,1} \mathrm{M],}$

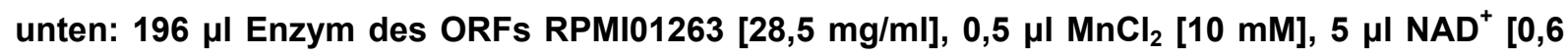
$\mathrm{mM}$ ], $5 \mu \mathrm{I}$ DTT [0,25 M], $5 \mu \mathrm{l}$ pNP- $\alpha-$ Glu [0,1 M]

Bei schrittweiser Zugabe von Enzym ist zu sehen, daß sich das typische Manganspektrum zurückbildet. Beim Konzentrationsverhältnis von 1:4 im Falle von MelA und beim Konzentrationsverhältnis 1:2 im Falle der a-Glukosidase aus $P$. miotherma zeigt sich schließlich ein völlig neues ESR-Signal, das nicht mehr aus dem ursprünglichen Spektrum eines $\left[\mathrm{Mn}\left(\mathrm{H}_{2} \mathrm{O}\right)_{6}\right]^{2+}-$ Komplexes abzuleiten ist. Eine weitere Veränderung des Konzentrationsverhältnisses Mangan-Enzym führt nur noch zu einer Signalabschwächung. Gleichzeitig wird auch die Messgenauigkeit erreicht. Niedrigere Konzentrationen entzogen sich hierdurch einer weiteren Untersuchung. 
Weiterhin wurde das Enzym AglA aus T. maritima unter optimalen Konzentrationen der entsprechenden Cofaktoren (Raasch et al., 2001) gemessen (Abbildung 66).

$\begin{array}{llll}\text { Ansatz: } & \text { Enzym (AglA) } & 7 \mathrm{mg} / \mathrm{ml} & 10 \mu \mathrm{l} \\ & \mathrm{MnCl}_{2} & 10 \mathrm{mM} & 20 \mu \mathrm{l} \\ & \mathrm{NAD}^{+} & 9 \mathrm{mM} & 20 \mu \mathrm{l} \\ \text { DTT } & 1 \mathrm{M} & 10 \mu \mathrm{l} \\ \text { Tris-Cl } & 0,5 \mathrm{M} & 20 \mu \mathrm{l} \\ \text { Glycerin } & 99,9 \% & 110 \mu \mathrm{l} \\ \text { pNP-a-Glu } & 0,1 \mathrm{M} & 10 \mu \mathrm{l}\end{array}$




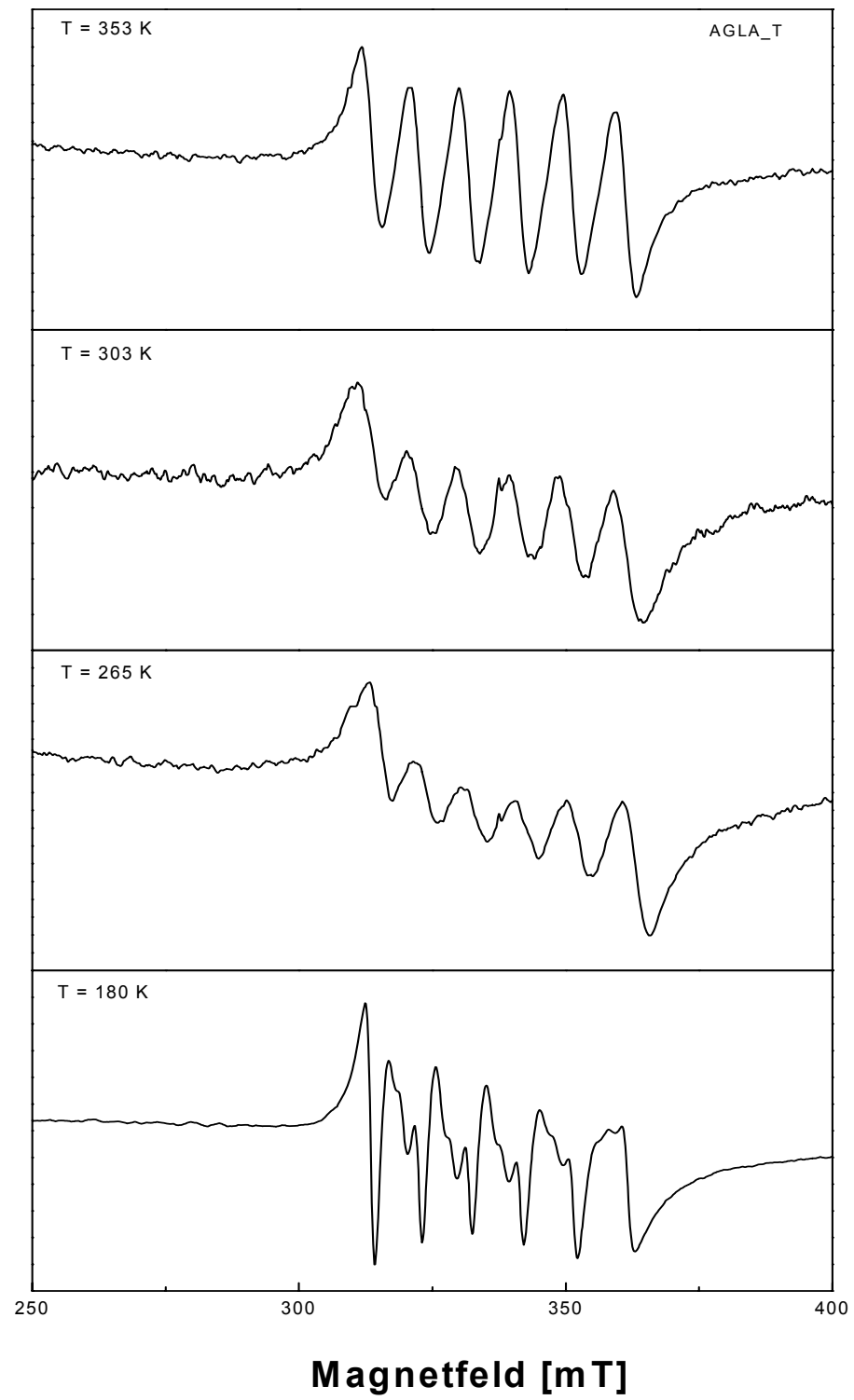

Abbildung 66: ESR-Spektrum des physiologischen Ansatzes bei den Temperaturen: $180 \mathrm{~K}, 265$ K, $303 \mathrm{~K}, 353 \mathrm{~K}$.

Dieser Ansatz wurde bei steigenden Temperaturen gemessen. Bei der Temperaturshift zeigt sich, daß die Feinstruktur des Spektrums aufgehoben wird.

Bei einer Temperatur von $180 \mathrm{~K}$ sind die beteiligten Reaktanten in einer Matrix eingefroren. Bei höheren Temperaturen treten Diffusionseffekte auf. Durch die stärkere Molekularbewegung wird die Feinstruktur des ESR-Signals undeutlicher. Trotzdem sind noch anisotrope Effekte zu erkennen, woraus abgeleitet werden kann, daß der ideale oktaedrische Komplex zugunsten eines verzerrten oktaedrischen Komlexes aufgegeben wurde. 


\section{Diskussion}

\subsection{Einordnung der O-Glukosidasen}

Bei den O-Glukosidasen handelt es sich um eine sehr umfangreiche Gruppe von Enzymen, die sowohl zwischen zwei und mehr Kohlenhydratbausteinen, als auch zwischen Kohlenhydrat- und Nichtkohlenhydratbausteinen die glykosidische Bindung hydrolysieren. Eine bestehende Enzymnomenklatur (International Union of Biochemistry and Molecular Biologyl $\rightarrow$ IUB-MB) beschränkte sich lediglich auf eine Einteilung der Glykosylhydrolasen, die sich an ihrer Substratspezifität und teilweise ihrem molekularen Mechanismus orientierte. Eine neue Datenbank (http://afmb.cnrsmrs.fr/CAZY/) verfeinert die Kriterien zur Einordnung der Enzyme in einzelne Familien, den Glykosidhydrolase Familien (GHF) (Henrissat et al., 1991; Henrissat et al., 1993; Henrissat et al., 1996 und Henrissat et al., 1995). Sie unterteilen sich zurzeit in 99 Familien. Hier werden Ähnlichkeiten in der Aminosäuresequenz zugrunde gelegt. Welches Vorteile gegenüber der alten Klassifizierung hat. Die strukturellen Eigenschaften der Enzyme treten in den Vordergrund und man kann die evolutionären Beziehungen unter den Enzymen aufdecken. Weiterhin ist es möglich, Erkenntnisse über den Mechanismus auf andere strukturell ähnliche Enzyme zu übertragen. In dieser Arbeit wurden fünf Enzyme der GHF4 untersucht.

\subsection{Glukosidasen der GHF4}

Die Mitglieder der GHF4 zeichnen sich durch hochkonservierte Bereiche der Aminosäuresequenz und einen ungewöhnlichen Bedarf an Cofaktoren aus. Alle Mitglieder der Familie 4 sind $\mathrm{NAD}^{+}$-abhängig und besitzen $\mathrm{N}$-terminal gelegen eine hochkonservierte Sequenz Gly-Xxx-Gly-Ser (GXGS). Dieses Motiv hat große Ähnlichkeit mit dem sogenannten Rossmann-Fold, bestehend aus einer alternierenden Abfolge von $\beta$-Strängen und $\alpha$-Helices ( $\beta \alpha \beta \alpha \beta)$, die eine konservierte strukturelle Region für die Bindung eines Cofaktors in Proteinen darstellt. Im klassischen Rossmann-Fold Motiv ist eine glycinreiche Sequenz innerhalb des ersten $\beta$-Strangs wichtig (GXGXXG), die über eine Schleife den ersten $\beta$-Strang mit der folgenden $\alpha-H e l i x$ verbindet. Durch gezielte Mutation konnte nachgewiesen werden, 
daß das GXGS-Motiv der GHF4 maßgeblich an der NAD ${ }^{+}$-Bindung beteiligt ist (Armbrecht et al., 2002). Zusätzliche Daten aus der Kristallisation von AglA aus T. maritima bestätigen, daß $\mathrm{NAD}^{+}$genau in dem Rossman-Fold-ähnlichen Bereich liegt und bis in das aktive Zentrum reicht (Lodge et al., 2002). Alle bisher untersuchten Mitglieder der GHF4 benötigen zusätzlich ein zweiwertiges Metallion. Dies ist für eine Vielzahl von amylolytischen Enzymen noch nichts Ungewöhnliches, da sie auch $\mathrm{Ca}^{2+}$-Ionen für ihre Aktivität benötigen (z.B. a-Amylasen, CGTasen; Janeck, 1997). In dieser Familie werden jedoch vorwiegend $\mathrm{Mn}^{2+}$-Ionen benötigt, die in bisherigen Untersuchungen eher zu einer Hemmung der Aktivität geführt haben (Suzuki et al., 1992). Die GHF4 ist die einzige Enzymfamilie, in der die Enzyme sowohl a-, als auch $\beta$-spezifische Substrate umsetzen (Thompson et al., 1999). Die Enzyme benötigen für eine vollständige Aktivierung stark reduzierende Bedingungen in Form von DTT oder Mercaptoethanol. Erst vor kurzem konnte ein vermutlicher Mechanismus für die Enzyme der GHF4 vorgeschlagen werden (Shyamala et al., 2004). Bei GlvA aus $B$. subtilis geht man davon aus, daß die 6-Phospho-a-glukosidase unter Retention ein Wasserstoffatom an C2 aus dem umgebenden Wasser einbaut. Hierfür wird das $\mathrm{O} 3$ durch $\mathrm{NAD}^{+}$oxidiert, dadurch wird das Wasserstoffatom $\mathrm{H} 2$ deutlich azider und Tyr265 kann es abstrahieren. Zusätzlich polarisiert $\mathrm{Mn}^{2+}$ die Bindung über eine Koordination mit dem Keto-Sauerstoff. Anschließend folgt eine Elimination und ein 1,2-ungesättigter Michaelakzeptor entsteht als Intermediat. Dieser wird von $\mathrm{H}_{2} \mathrm{O}$ angegriffen und das C3-Keton kann durch das NADH wieder reduziert werden. Die Retention an C1 des Zuckers erfolgt wieder über Tyr265, welches seinen abstrahierten Wasserstoff wieder an C2 zurückbindet und damit ein Angriff des Wassers nur von der a-Seite erfolgen kann, koordiniert über Asp172.

Dies alles ist nur möglich, weil bei der Reaktion $\mathrm{Mn}^{2+}$ durch seine Koordination die Reaktanten in den entsprechenden Positionen hält. Dieser Befund stützt sich einerseits auf die Daten der Kristallisation und zusätzlich auf NMR-Messungen, bei denen ein Protonenaustausch an C2 gegen ein Deuteriumatom nachgewiesen werden konnte (Shyamala et al., 2004). Das 2-[ $\left.{ }^{2} \mathrm{H}\right]-\mathrm{D}-$-Glukose-6-phosphat entstand nur bei enzymatischer Umsetzung und nicht bei Kontrollexperimenten ohne Enzym. Dieser Mechanismus konnte die Rolle des DTT und Mercaptoethanol nicht klären. 


\subsection{Enzymaktivitäten der GHF4}

\subsubsection{Optimierte Aufreinigung und Charakterisierung von Mela aus E. coli}

Bereits 1971 konnten Burnstein und Kepes nachweisen, daß die $\alpha$-Galaktosidase MelA aus $E$. coli eine ungewöhnliche Kombination der Cofaktoren $\mathrm{NAD}^{+}, \mathrm{Mn}^{2+}$ und stark reduzierenden Bedingungen in Form von DTT oder Mercaptoethanol benötigt. Damit begründete MelA eine neue Enzymfamilie, die Glycosidhydrolase-Familie 4 (GHF4). MelA liegt in einem Gencluster, der für Enzyme kodiert, die maßgeblich für den Transport von Melibiose in die Zelle zuständig sind und weiterhin für Enzyme kodiert, die in den Kohlenhydratabbau eingebunden sind (Abbildung 67). Durch seine hohe Instabilität entzog sich das Enzym einer Charakterisierung (Tamai et al., 1988). Es erfolgte lediglich eine Teilcharkterisierung im Rohextrakt. Um eine möglichst schnelle Aufreinigung zu gewährleisten, wurde es im Zuge dieser Arbeit mit einem 6x His tag kloniert. Wie schon in 3.2 beschrieben, ließ sich keine reproduzierbare Anfangsaktivität messen. Erst nachdem das Standardlösungsmittel DMSO gegen $\mathrm{H}_{2} \mathrm{O}$ ersetzt wurde, konnten stabile Werte ermittelt werden. Dies schien durch eine starke Koordination von DMSO an das Substrat erschwert worden zu sein, wodurch eine schnelle Freisetzung des Substrates verhindert worden zu sein scheint. Dies könnte mit der relativ hohen Viskosität begründet sein, die DMSO bei Temperaturen um $37^{\circ} \mathrm{C}$ zeigt. Dieser Effekt trat bei den thermophilen Assays nicht auf, die bei Temperaturen von $60^{\circ} \mathrm{C}$ durchgeführt wurden. Trotzdem verlor das Enzym innerhalb weniger Stunden irreversibel seine Aktivität. Erst durch Zugabe eines oder mehrerer Cofaktoren ließ sie sich konservieren (Thompson et al., 1999). $\mathrm{NAD}^{+}$und $\mathrm{Mn}^{2+}$ konnten bereits im aktiven Zentrum im Rahmen von Kristallisationsversuchen nachgewiesen werden (Thompson et al., 2003; Lodge et al., 2004). Die Cofaktoren koordinieren mit den Cystein im aktiven Zentrum und scheinen es vor Oxidation zu einer Sulfinsäure zu schützen. Erstaunlicherweise zeigten die Reduktionsmittel DTT und Mercaptoethanol allein nicht die Eigenschaft, die Aktivität ähnlich lang zu konservieren. Es ist bisher noch fraglich, ob sie tatsächlich direkt an dem Reaktionsmechanismus beteiligt sind.

Bei der Bestimmung des Oligomerisierungsgrades fiel auf, daß bei teilinaktiviertem Enzym ein zusätzlicher Peak auftrat (3.3.1), der ungefähr dem einfachen der 
Molekülmasse von MelA entsprach. Thompson beschrieb einen ähnlichen Sachverhalt (Thompson et al., 1999) und es konnte dem Peak ein Monomer des Enzymoligomers zugeordnet werden. Auch hier spielte die Zugabe von Cofaktoren eine große Rolle. Insbesondere Mangan hatte einen großen Einfluß auf den Oligomerisierungsgrad. In Abwesenheit zerfiel das Molekül relativ schnell in monomere und dimere inaktive Teile des Oligomers. Auch bei MelA verlief der Zerfall parallel mit einem deutlich meßbaren Aktivitätsverlust.

Dazu kommt noch der Befund, daß bei ESR-Versuchen eine deutliche Veränderung der Koorinationsphäre um das Mangan zu beobachten ist. Der oktaedrische Komplex mit $\mathrm{H}_{2} \mathrm{O}$ wurde deutlich aufgebrochen. Weiterhin auffällig ist, daß kein anderes zweiwertige Ion eine signifikante Aktivität zeigte und daß ausschließlich galaktosidische Bindungen gespalten werden. Diese hohe Spezifität ist bisher in der GHF4 eher ungewöhnlich, da insbesondere die thermophilen Mitglieder zum Teil sowohl glukosidische, als auch galaktosidische Bindungen spalten und sich durch weitere zweiwertige lonen aktivieren lassen.

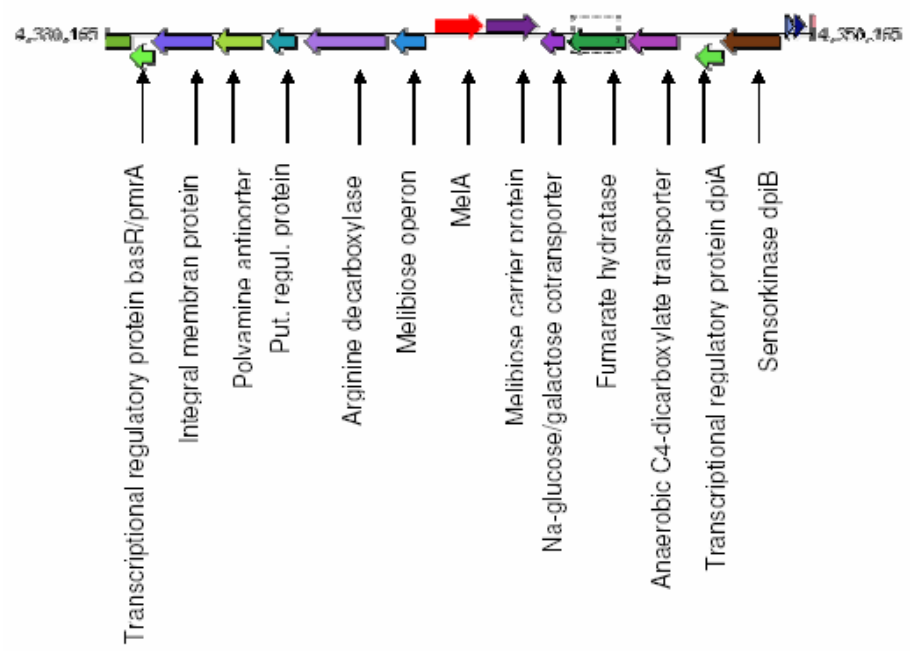

Abbildung 67: Genetisches Umfeld von MelA 


\subsection{2. putative $\alpha$-Glukosidase aus ORF RPMI00511 aus $P$. miotherma}

Im Gegensatz zu den ORFs RPMI00720 und RPMI01263 von P. miotherma ist das ORF RPMI00511 nicht in einem Gencluster lokalisiert, welches für Enzyme, die an der Umsetzung und dem Abbau von Stärke beteiligt sind (Abbildung 68). Es konnte dem Enzym bisher noch kein Substrat zugeordnet werden. Aufgrund seiner hohen Sequenzähnlichkeit zu den Enzymen der GHF4 wurden den Reaktionsansätzen schon die entsprechenden Cofaktoren beigefügt, die für eine optimale Aktivität bei den Enzymen, die durch die ORFs RPMI00720 und RPMI01263 kodiert sind, benötigt wurden. Für die nicht vorhandene Aktivität kann es mehrere Gründe geben. Entweder braucht das Enzym phosphorylierte Substrate, die leider nicht verfügbar waren, oder das Substratspektrum war nicht weit genug gewählt. Weiterhin möglich wäre, daß das Enzym inaktiv vorlag. Die Anaylse des Oligomerisierungsgrades zeigte, daß das Enzym, das in RPMI00511 kodiert wird, anscheinend als Pentamer vorliegt, was in dieser Enzymfamilie noch nicht beobachtet wurde. Dieser hohe Grad kann zweierlei bedeuten. Entweder könnte eine falsche Faltung des Proteins vorliegen und darin seine Inaktivität begründet liegen oder das richtige Substrat liegt noch nicht vor, da bisherige Untersuchungen gezeigt haben, daß aktive Enzyme dieser Familie als Oligomer, zumeist als Tetramer, vorliegen 


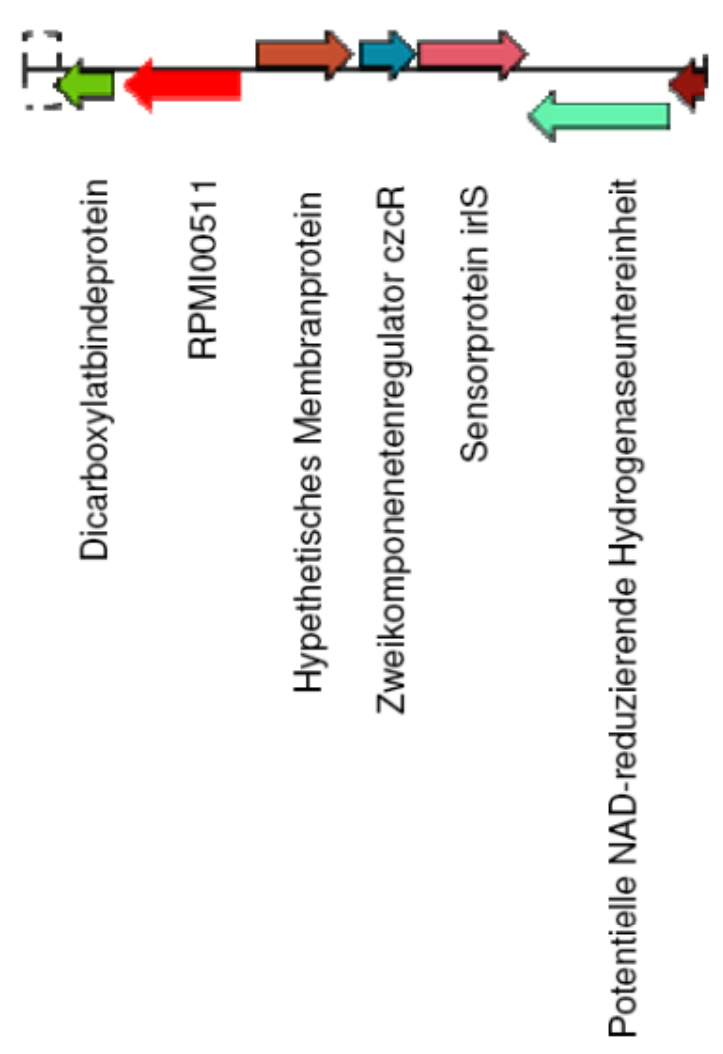

Abbildung 68: Genetisches Umfeld des ORFs RPMI00511

\subsubsection{RPMI00720 und RPMI01263 aus $P$. miotherma}

ORF RPMI00720 liegt in einem Gencluster, der für Enzyme kodiert, die für den Kohlenhydratabbau und Transport zuständig sind, wohingegen RPMI01263 mehr von ORFs umgeben ist, die für Enzyme kodieren (Abbildung 69, Abbildung 70), die für den Umbau von Kohlenhydraten zuständig sind. RPMI00720 (3.11.5.1) setzt ebenso wie RPMI01263 (3.12.5) sowohl a-glukosidische als auch a-galaktosidische Bindungen um. Beide Enzyme besitzen keine Spezifität in Bezug auf das C4 der Glukose bzw. Galaktose. 


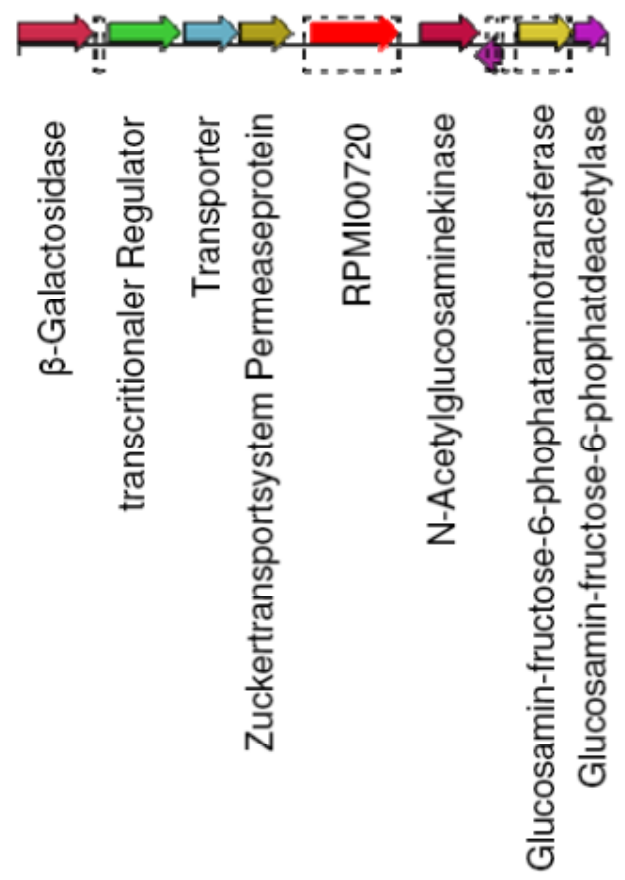

Abbildung 69: Gentisches Umfeld von ORF RPM100720

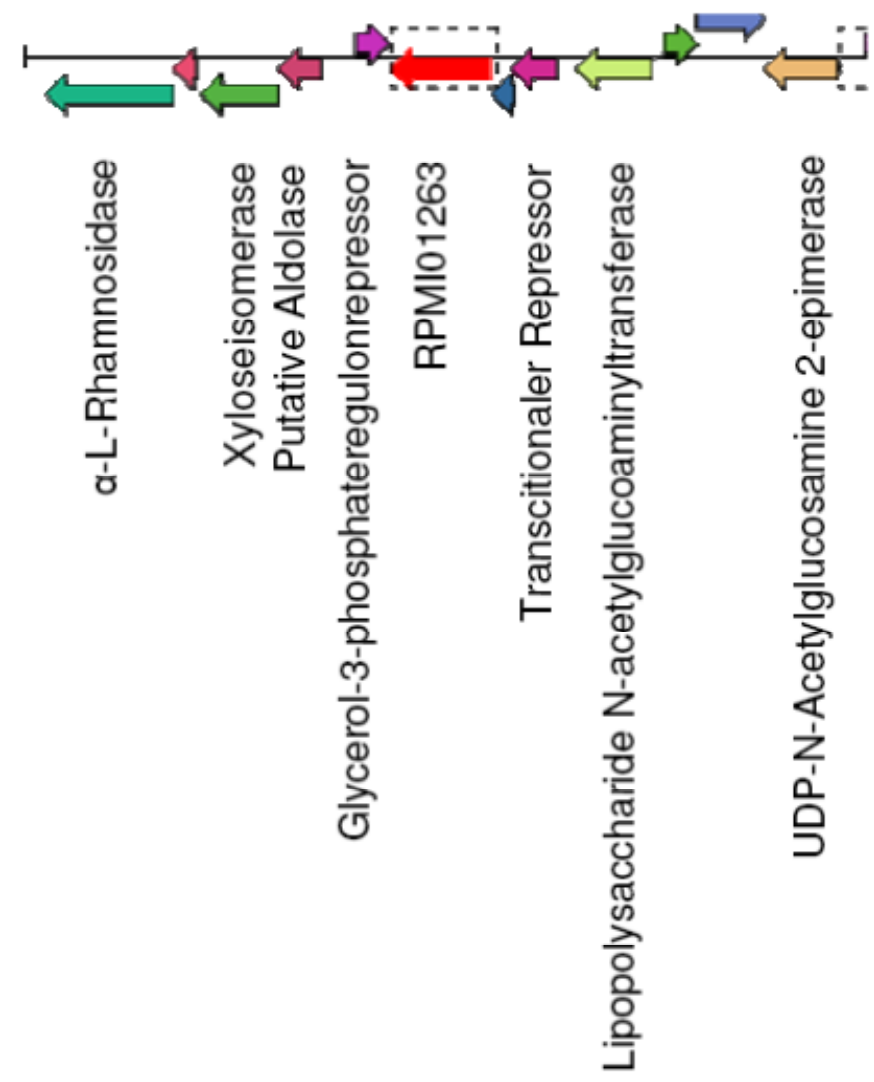

Abbildung 70: Genetisches Umfeld von ORF RPMI01263 
Bei der Untersuchung zum Oligomerisierungsgrad stellte sich heraus, daß beide Enzyme der ORFs RPMI00720 und RPMI01263, ebenso wie GIvA aus B. subtilis, als Tetramer vorliegen, was recht typisch für Vertreter dieser Enzymfamilie ist (Henrissat et al., 1997).

RPMI00720

RPMI01263

Clustal Consensus

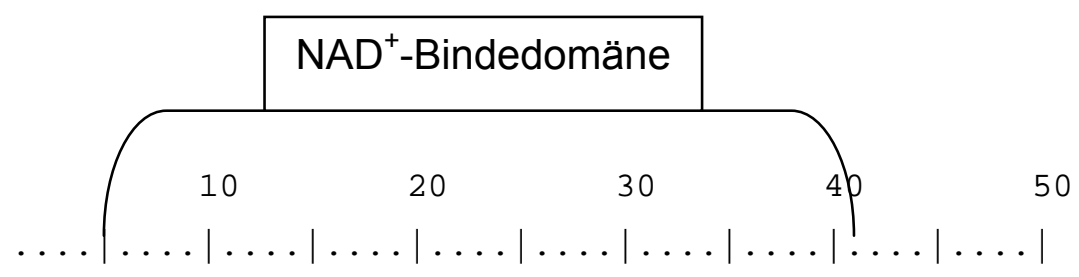

MTAIKLGIIGAGSAAFSLRLVSDLCKTKGLSGSLVSLMDIDKDRLNAVHM

MTAIKLGIIGAGSAAFSLRLVTDLCKTKGLSGSLVSLMDIDKDRLNAVHM

Abbildung 71: Vergleich der Aminosäuresequenzen des $\mathrm{NAD}^{+}$-Bindemotivs von den Enzymen aus den ORFs RPMI00720 und RPMI01263

Ein Alignment der beiden ORFs zeigt, daß sie auf Aminosäuresequenzebene eine 98\%ige und auf DNA-Sequenzebene noch eine 95\%ige Identität besitzen, d.h. sie unterscheiden sich nur in acht Aminosäuren. Dies zeigt sich auch in ihren biochemischen Eigenschaften. Beide Enzyme zeigen gleiches Verhalten gegenüber verschiedenen Substraten, $\mathrm{pH}$ und Temperatur $(3.11 .5,3.12 .7)$. Sie unterscheiden sich aber in zwei Eigenschaften. Die Unterschiede liegen bei $\mathrm{V}_{\max }$ und der optimalen Konzentration an NAD ${ }^{+}$. Obwohl die a-Glukosidase des ORFs RPMI00720 dreimal mehr $\mathrm{NAD}^{+}$für die maximale Aktivität benötigt, ist $\mathrm{v}_{\max }$ nur etwa halb so groß wie die aus RPMI01263. Erstaunlich ist der große Unterschied in der optimalen NAD ${ }^{+}$ Konzentration. In der $\mathrm{NAD}^{+}$-Bindedomäne gibt es nur einen Aminosäurenaustausch, der anscheinend einen großen Einfluß auf die Bindeeingenschaften hat. AglA aus $T$. maritima und die a-Glukosidase aus ORF RPMI00720 haben einen identischen Rossmann-Fold. Hingegen ist bei der a-Glukosidase aus ORF RPMI01263 ein Austausch von Serin gegen Threonin zu verzeichnen (Abbildung 71). Trotzdem liegt die optimale $\mathrm{NAD}^{+}-$Konzentration bei der a-Glukosidase aus RPMI01263 und AgIA bei 0, $9 \mathrm{mM}$ und die $\alpha$-Glukosidase des ORFs RPMI00720 benötigt eine dreimal höhere Konzentration, nämlich 2, 7 mM. Die ORFs RPMI01263 und RPMI00720 besitzen eine so hohe Identität sowohl auf Aminosäureebene als auch auf 
genetischer Genebene, daß es sehr wahrscheinlich ist, daß es sich bei den beiden Genen um paraloge Gene handelt, die durch eine Genduplikation entstanden sind.

\subsection{Mechanistische Untersuchungen}

\subsubsection{Fluorenszenz- und Absorbtionsspektren}

Da die Enzyme der GHF4 NAD ${ }^{+}$für eine vollständige Aktivierung benötigen, sollte ein Redox-Mechanismus für die Spaltung der glykosidischen Bindung zugrunde liegen, bei dem intermediär NADH entsteht. Im Gegensatz zu NAD ${ }^{+}$zeigt NADH zwei sehr herausragende Eigenschaften. Zum einen hat $\mathrm{NADH}$ ein sehr eindeutiges Absorbtionsspektrum bei $340 \mathrm{~nm}$ und zum anderen fluoresziert es bei Anregung mit $340 \mathrm{~nm}$ bei $460 \mathrm{~nm}$. Das Absorbtionsspektrum von AglA aus T. maritima zeigt ein sehr schwaches Signal bei $340 \mathrm{~nm}$ (Abbildung 72).

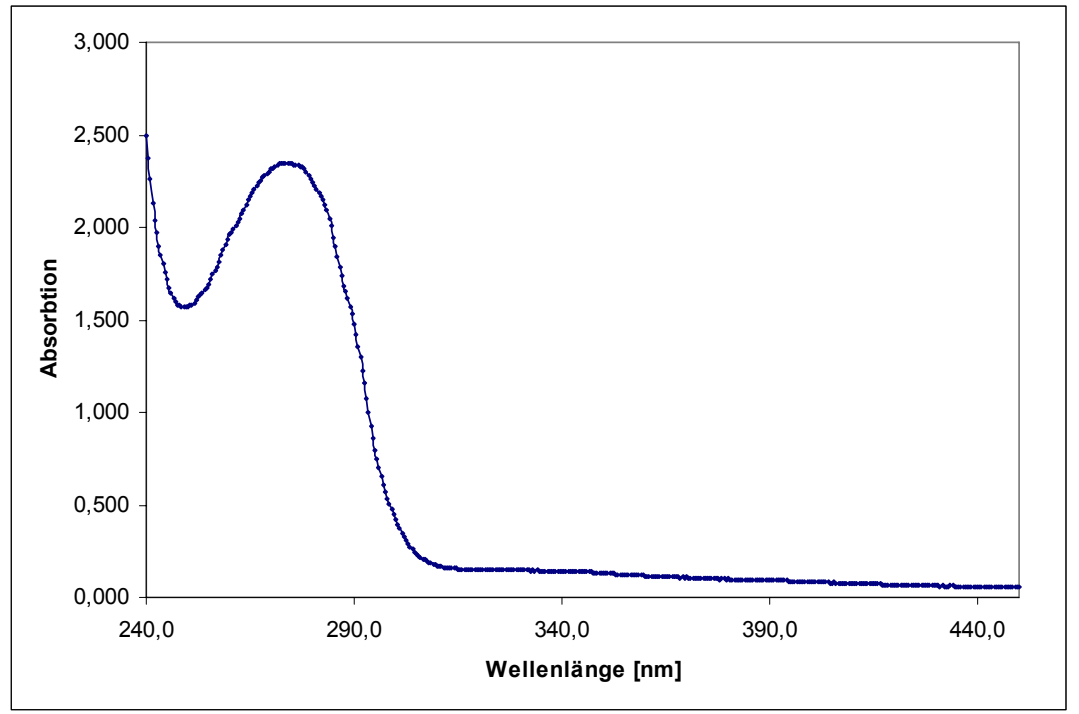

Abbildung 72: Absorbtionsspektrum von AgIA aus T. maritima

Es scheint in reinem Enzym etwas NADH gebunden $z u$ haben. Weitere Untersuchungen mit Fluoreszenz zeigten, daß das Enzym bei Anregung mit $340 \mathrm{~nm}$ ein sehr deutliches Signal bei $460 \mathrm{~nm}$ lieferte (Abbildung 73). 


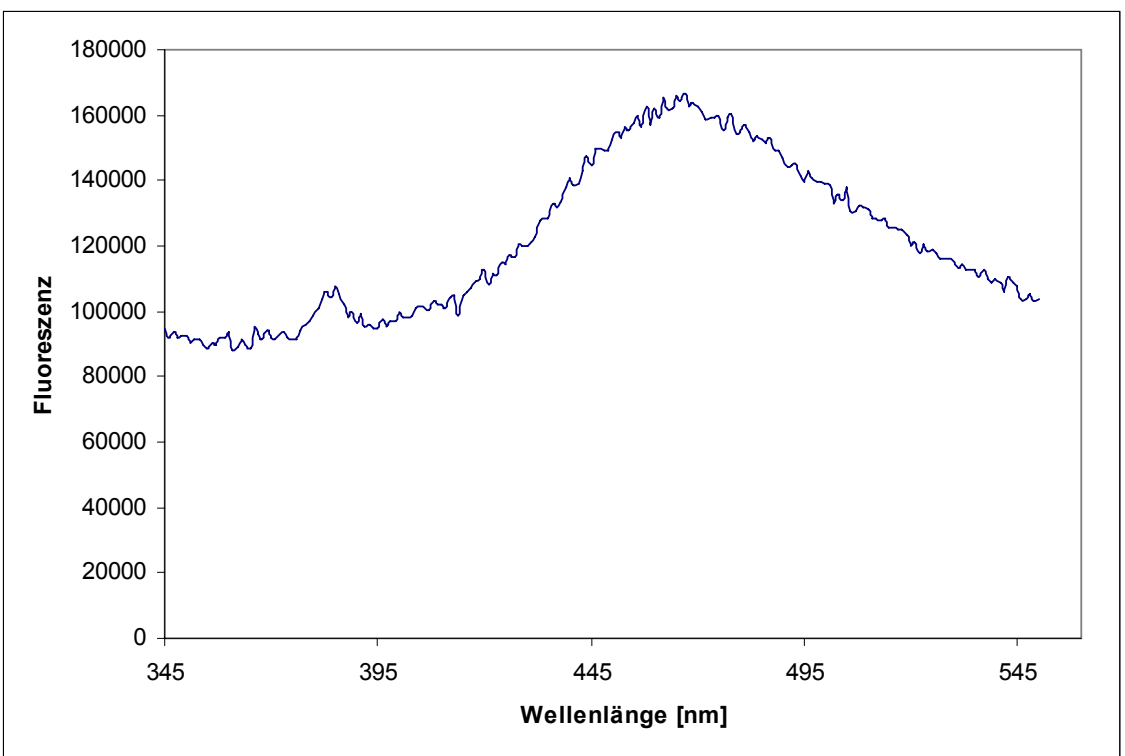

Abbildung 73: Fluoreszenzspektrum von AgIA allein ohne Cofaktoren

Eine äquimolare Menge NADH zu AglA zeigt eine ca. 20-fach niedrigere Fluoreszenz, als das reine Enzym (Abbildung 74).

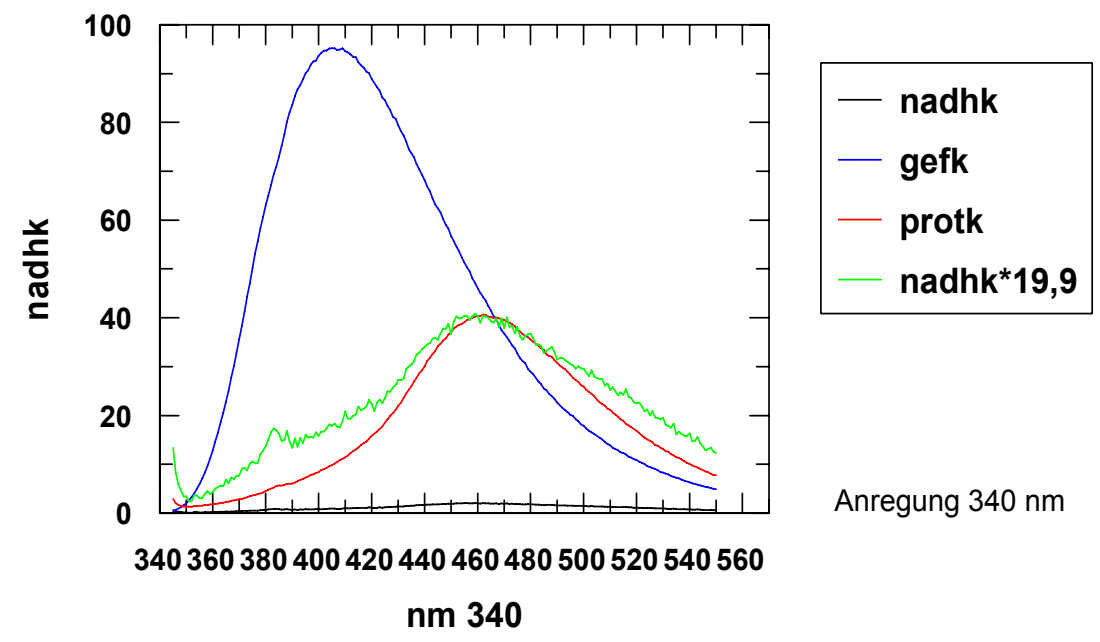

Abbildung 74: Überlagerung der Emissionsspektren. NADH Stammlösung (5 $\mu M)$ (schwarz), AglA (5 $\mu \mathrm{M})$ (rot), AglA (gefällt) (blau) und NADH Stammlösung (5 $\mu \mathrm{M})$ mit dem Faktor 19,9 multipliziert (grün).

Die Zugabe von Cofaktoren, insbesondere $\mathrm{NAD}^{+}$, konnte bei MelA aus E. coli eine Inaktivierung des Enzyms verhindern. Anscheinend wird das $\mathrm{NAD}^{+}$im Enzym reduziert und überträgt die Fluoreszenz des entstandenen NADH auf das Enzym. Diese Übertragung scheint zu einer Verstärkung des Signals führen oder Enzym selbst zeigt eine Eigenfluoreszenz bei genau $460 \mathrm{~nm}$. 


\subsubsection{NMR-Untersuchungen zum Mechanismus}

Die anomeren Protonen von Kohlenhydraten sind mittels NMR-Spektroskopie sehr gut zugänglich aufgrund ihrer exponierten Position im NMR-Spektrum. Bereits früher wurde die Spezifität in Bezug auf Inversion oder Retention des Mechanismus der Hydrolyse von Kohlenhydraten untersucht (Gebler et al., 1992). Durch die verschiedene chemische Umgebung der anomeren Protonen besitzt das $\alpha$-anomere Proton im Falle der Glukose ca. $\Delta 7 \mathrm{ppm}$ und im Falle der Galaktose eine um ca. $\Delta 3$, 7 ppm weiter ins Tieffeld verschobene Position (http://www.aist.go.jp/RIODB /SDBS/cgi-bin/cre_index.cgi). Leider bewirken paramagnetische lonen, wie $\mathrm{Mn}^{2+}$, eine deutliche Signalverbreiterung. Deshalb kann man aus Abbildung 75 keine absolute Aussage treffen, daß auch das $\beta$-Anomer entsteht, da es unter dem $\mathrm{H}_{2} \mathrm{O}$ Signal liegen könnte. Dies erscheint aber bei den Messungen mit Glaktosesubstraten eher unwahrscheinlich. Man kann davon ausgehen, daß keine $\beta$-Glukose durch Inversion entstanden sein sollte, da das Signal für das $\beta$-amomere Proton bei ca 5,2 ppm in genügendem Abstand zum $\mathrm{H}_{2} \mathrm{O}$-Signal hätte erscheinen sollen.

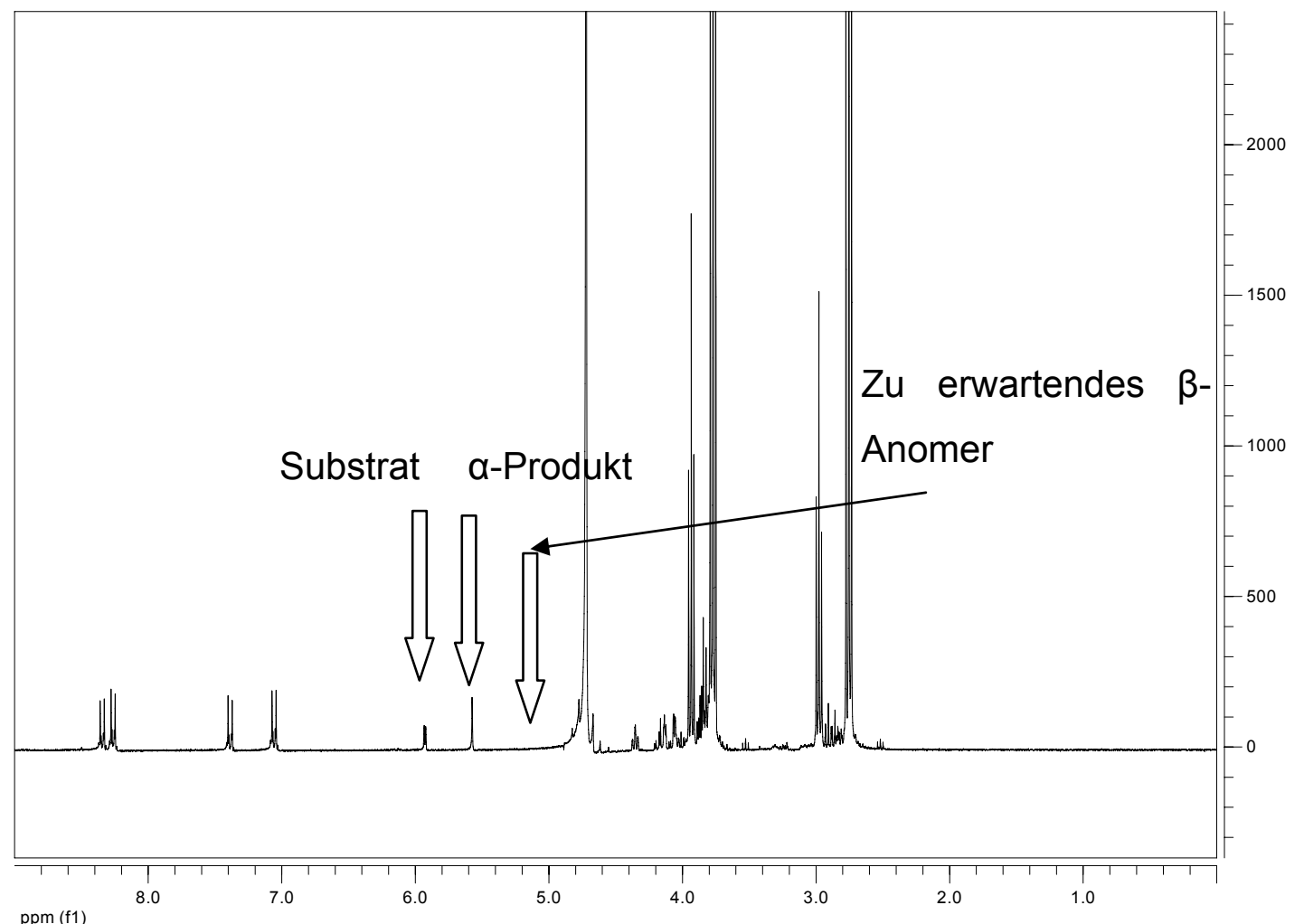

Abbildung 75: ${ }^{1} \mathrm{H}-\mathrm{NMR}\left(\mathrm{D}_{2} \mathrm{O}, 300 \mathrm{MHz}\right)$ von pNP- $\alpha-G a l$ und Enzym nach 15 min Inkubation bei $37^{\circ} \mathrm{C}$ 
Da nur eine suboptimale Mangankonzentration eingesetzt werden konnte, ließ sich leider kein vollständiger Umsatz unter den Bedingungen der Messung beobachten.

\subsubsection{Kristallisation von AgIA aus T. maritima}

In Cooperation mit Prof. N. Sträter wurde AglA kristallisiert und anschließend mittels Röntgenbeugung vermessen (Lodge et al, 2003). AglA ist die erste Glukosidase, die aus der GHF4 kristallisiert wurde. Im Kristall konnte die NAD ${ }^{+}$-Bindedomäne bestätigt werden. $\mathrm{NAD}^{+}$wurde gebunden an ein Rossmann-Fold gefunden, der Nicotinamidring ragt in das aktive Zentrum hinein. Wie aus anderen manganabhängigen Enzymen bereits bekannt ist, sind verschiedene Histidine an der Metallkoordination beteiligt. His-175 und His-177 konnten als wahrscheinliche Bindepartner verifiziert werden. Trotz der Anwesenheit von Mangan im Kristallisationsansatz ließ es sich nicht im aktiven Zentrum nachweisen. Hierfür sind zwei mögliche Erklärungen denkbar. Erstens ist der niedrige $\mathrm{pH}$ von 4,6 zu nennen, bei dem die Histidine protoniert vorliegen und zweitens der erstaunliche Befund, daß das Cys-174 doppelt oxidiert als Sulfinsäure vorliegt.

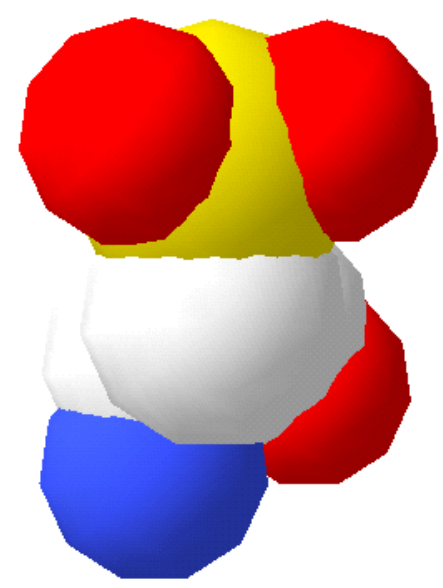

Abbildung 76: Cys174 als Sulfinsäure in AglA aus T. maritima als Elektronendichtedarstellung (gelb: Schwefel, rot: Sauerstoff, weiß: Kohlenstoff, blau: Stickstoff) 
Die Kristalle von AgIA aus T. maritima konnten bis auf 1,9 $\AA$ aufgelöst und der Raumgruppe P2 1 zugeordnet werden. Das Enzym liegt als Dimer vor, was in vorhergehenden Untersuchungen zum Oligomerisierungsgrad bereits beobachtet wurde (Raasch et al., 2001). Vor allem das in der GHF4 hochkonservierte Cys174 spielt eine wichtige Rolle für das aktive Zentrum. Dies wird vor allem auch durch die Tatsache gestützt, daß die Mutante C174S, in der das Cystein gegen ein Serin ausgetauscht wurde, keinerlei enzymatische Aktivität mehr zeigte. AglA liegt im Kristall anscheinend inaktiv vor, da das cokristallisierte Substrat Maltose nicht umgesetzt wurde. Das nichtreduzierende Ende der Maltose besitzt Wasserstoffbrückenbindungen mit Asn153, His203, Asp119 und Arg263. Zusätzlich liegt eine hydrophobe Wechselwirkung von Val117 mit dem $\beta$-Nicotinamidring des $\mathrm{NAD}^{+}$vor. Das reduzierende Ende der Maltose scheint sehr flexibel vorzuliegen. Ein Vergleich mit dem später kristallisierten GlvA aus B. subtilis zeigt, daß der Nicotinamidring des $\mathrm{NAD}^{+}$bei AglA aus dem aktiven Zentrum herausgedreht war (Abbildung 77). Sonst lag $\mathrm{NAD}^{+}$in beiden Kristallen fast deckungsgleich vor. Die Kristalle von GlvA konnten bis auf 2,05Á aufgelöst werden (Shyamala et al., 2004). Daß der Nicotinamidring des $\mathrm{NAD}^{+}$herausgedreht war, könnte damit erklärbar sein, daß einerseits der $\mathrm{pH}$ mit 4,6 relativ niedrig war und damit die Histidine protoniert vorlagen und andererseits das Cys174 doppelt oxidiert war. Damit ist auch zu erklären, warum kein Mangan im aktiven Zentrum gefunden wurde, da es nicht binden konnte. Die in Abbildung 77 darüber gelegte Kristallstruktur von GlvA konnte mit Mangan kristallisiert werden. Die GlvA-Struktur ist fast deckungsgleich mit der Struktur von AgIA. Das Substrat des GlvA ist gespalten und paßt tiefer in das aktive Zentrum, wohingegen die Maltose unverändert im Kristall von AglA liegt (Abbildung 77). Sie bindet zwar in die Tasche des Enzyms, hat aber deutlich größere Abstände im Vergleich zu den Bindungspartnern der Phosphoglukose des GIvA. 


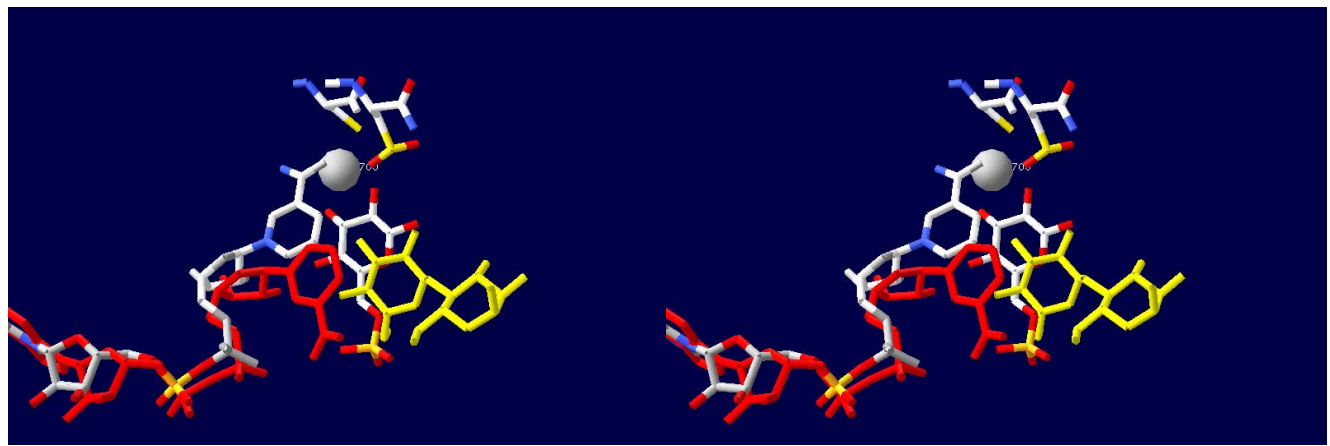

Abbildung 77: 3D-Ansicht der Überlagerung von den Kristallstrukturen (Daten für AglA aus T. maritima einfarbig, Daten für GIvA aus $B$. subtilis mehrfarbig)

\subsection{ESR- und Mechanismusuntersuchungen}

Mangan liegt im wässrigen Milieu normalerweise als $\mathrm{Mn}\left[\mathrm{H}_{2} \mathrm{O}_{6}{ }^{2+}\right.$ vor. Dieser Komplex ist hochsymmetrisch und zeigt im ESR ein ebenfalls hochsymmetrisches Spektrum, welches aus sechs nahezu äquidistanten Signalen besteht. Veränderungen der Koordinationssphäre zeigen sich auch in einer Veränderung des Spektrums. Außerdem gibt es nur ein stabiles Isotop $\left({ }^{55} \mathrm{Mn}\right)$, das einen Kernspin von $5 / 2$ aufweist. Sowohl der $g$-Tensor als auch der Hyperfeintensor sind nahezu isotrop,

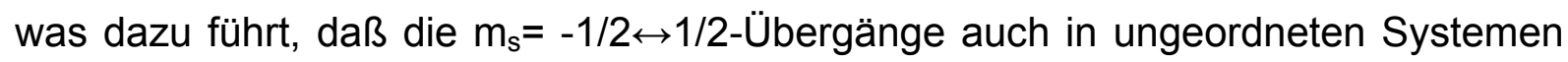
Anlaß zu relativ schmalen Linien geben. Die charakteristische Hyperfeinstruktur ist deshalb oft sehr gut erkennbar (sechs nahezu äquidistante Linien nahezu gleicher Intensität).

Die hier untersuchten Enzyme aus E. coli, $P$. miotherma und T. maritima sind stark manganabhängig. Shyamala (2004) schlug einen Mechanismus zur Hydrolyse unter direkter Beteiligung von $\mathrm{Mn}^{2+}$ vor. Dieser wurde aus der Kristallstruktur von GIvA aus B. subtilis abgeleitet (Shyamala et al., 2004). Das $\mathrm{Mn}^{2+}$-lon ist hier im aktiven Zentrum gebunden und koordiniert mit $\mathrm{NAD}^{+}$und verschiedenen Aminosäuren an das Substrat.

Spektren von AgIA, die unter optimalen Konzentrationen der benötigten Cofaktoren aufgenommen wurden, zeigen noch ein deutliches Manganspektrum, das aber bereits anisotrope Effekte aufweist (Abbildung 78). Das Spektrum zeigt Abweichungen vom hochsymmetrischen Spektrum des $\mathrm{Mn}\left[\mathrm{H}_{2} \mathrm{O}_{6}{ }^{2+}-\mathrm{Komplexes}_{\text {. }}\right.$ Zusätzlich taucht ein Signal (siehe Pfeil Abbildung 78) auf, das einen Hinweis auf ein 
radikalisches Intermediat geben könnte. Dieses Signal taucht erst bei Temperaturen auf, bei denen auch eine leichte Aktivität des Enzyms zu verzeichnen ist, nämlich bei Temperaturen $>8^{\circ} \mathrm{C}$.

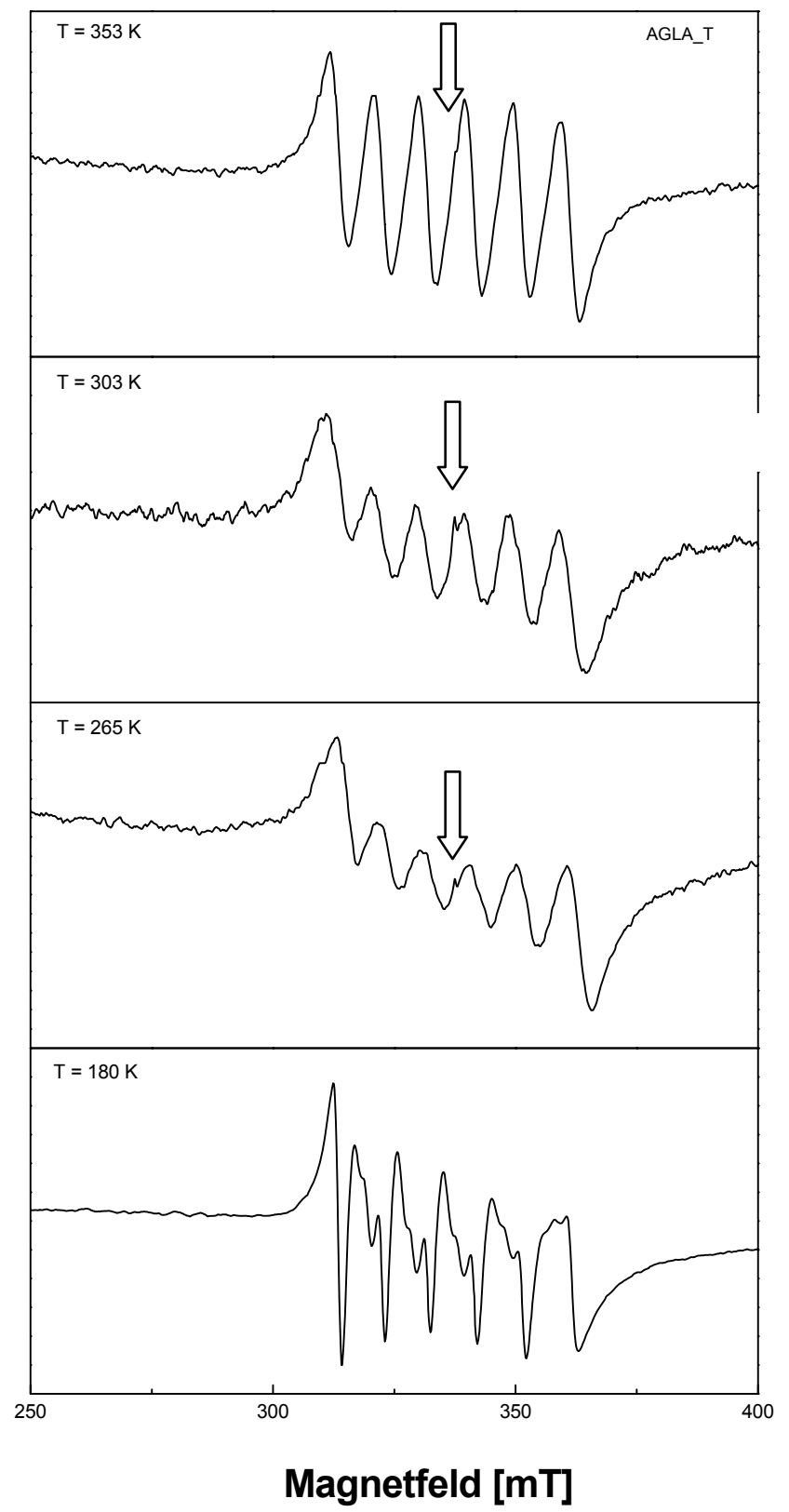

Abbildung 78: Temperaturscan des Assays unter optimalen Konzentrationen der Cofaktoren von AgIA aus T. maritima im Bereich von $180-353 \mathrm{~K}$ 
Da bereits unter optimalen Bedingungen eine Veränderung der Koorinationssphäre zu verzeichnen war, in denen noch ein deutlicher Überschuß an $\mathrm{Mn}^{2+}$-Ionen vorlag, sollte nun untersucht werden, wie sich das Spektrum verändert, wenn das jeweilige Enzym im Überschuß vorliegt. Bei diesen Messungen, die mit dem $P$. miotherma ORF RPMI01263-Enzym und E. coli MelA durchgeführt wurden, (Abbildung 64, Abbildung 65) ist die deutlichste Anisotropie im Spektrum zu sehen.

Da in den Messansätzen das jeweilige Enzym, die notwendigen Cofaktoren und das jeweilige Substrat vorlagen, kann man davon ausgehen, daß Mangan seine Hydrathülle, bestehend aus den sechs $\mathrm{H}_{2} \mathrm{O}$-Molekülen, zugunsten einer Koordination im aktiven Zentrum verlassen hat. Dies wird durch die Daten aus den Kristallisationsdaten von GlvA aus $B$. subtilis gestützt, in denen das $\mathrm{Mn}^{2+}$-lon im aktiven Zentrum gebunden ist (Abbildung 79). Zusätzlich fällt auf, daß der g-Wert des Signals des durch den ORF RPMI01263 kodierten Enzyms weiter ins Tieffeld verschoben ist, als der des Signals von MelA. Dieses gibt einen Hinweis auf eine festere Bindung des Mangans in das aktive Zentrum. Da es sich bei der in ORF RPMI01263 kodierten a-Glukosidase um ein thermophiles Enzym handelt, erscheint es sinnvoll, daß das $\mathrm{Mn}^{2+}$-Ion fester in die Enzymtasche gebunden ist und durch die thermische Bewegung nicht so leicht verdrängt werden kann. 

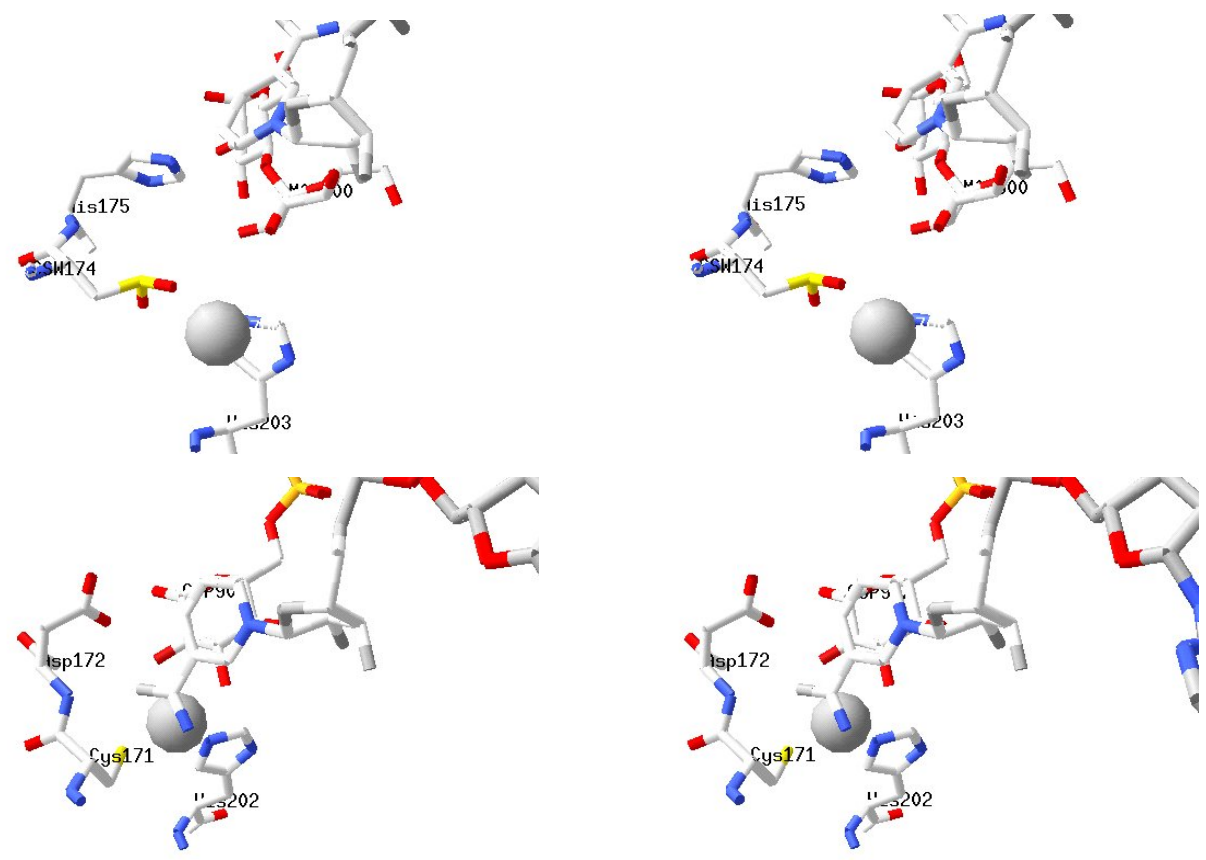

Abbildung 79:Vergleich der Kristallstrukturen von AglA (mit $\mathrm{Mn}^{2+}$ aus der Kristallstruktur des GIvA) aus T. maritima (oben) und GlvA aus $B$. subtilis (unten).

Bei dem direkten Vergleich der Kristallstrukturen um das aktive Zentrum (Abbildung 79) fällt auf, daß im GlvA aus $B$. subtilis ein Asparagin an Stelle eines Histidin im AgIA aus T. maritima sitzt. In die Kristallstruktur des AgIA aus T. maritima wurde das Mangan aus der des GlvA hineinprojiziert. Shyamala et al (2004) stellten für GlvA aus $B$. subtilis einen Reaktionsmechanismus unter Beteiligung des Asparagins vor. Dieser Mechanismus ist aufgrund dieses Aminosäurenaustauschs nicht direkt auf AglA übertragbar. Wie in Abbildung 80 zu sehen ist, trifft das auch auf die Enzyme MelA aus E. coli und die von den ORFs RPMI00511, RPMI00720 und RPMI01263 kodierten Enzyme zu. Auch hier ist statt des Asparagins ein Histidin in der Aminosäuresequenz vorhanden.

720

1263

AglA

511

MelA

Clustal Consensus
10

20

30

$4 \odot$

$\ldots|\ldots| \ldots|\ldots| \ldots|\ldots| \ldots|\ldots| \ldots|\ldots| \ldots \mid$

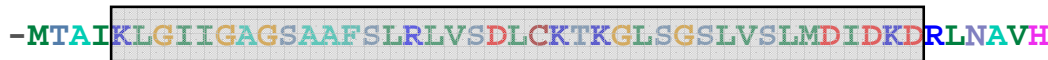

-MTAIKLGIIGAGSAAFSLRLVTDLCKTKGLSGSLVSLMDIDKDRLNAVH

-MPSVKIGIIGAGSAVFSLRLVSDLCKTPGLSGSTVTLIMDIDEERLDAIL

- - MPVKISFIGAGSVRYTMKLVGDLAKTKELNGSLISFMDIDE RLNAVD MMSAPKITFIGAGSTIFVKNILGDVFHREALKTAHIALMDIDPJ RLEESH 
720

1263

AglA

511

MelA

Clustal Consensus

720

1263

AglA

511

MelA

Clustal Consensus

60
$\ldots .|\ldots| \ldots|\ldots| \ldots|\ldots| \ldots|\ldots| \ldots|\ldots| \ldots \mid$

MLAKKFAEEFGADLRFETTTNVEDAIKDSSFVVNTALVG - - - - - GHSYF

MLAKKFAEEFGTDLRFETTTNVEDAIKDSSFVVNTALVG - - - - - - GHSYF

TIAKKYVEEVGADLKFEKTMNLDDVIIDADFVINTAMVG - - - - - - GHTYL

NLAKRYTEEIGGNLKFEKTTNREESLKDADFVINTALYRAPGHEDGYVSY IVVRKLMDSAGASGKITCHTQQKEALEDADFVVVAFQIG - - - - - - - - - GY

$: .::^{*} .:: \quad: \quad .:$ * $^{*}:{ }^{* *}:$ :

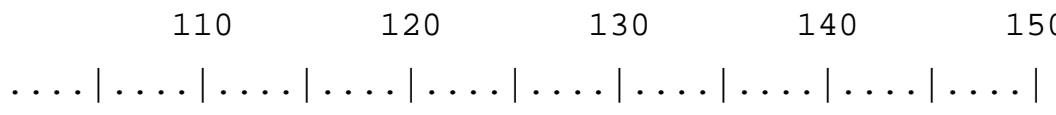
EQVRKISEKYGYYRGIDSQEFNMVSDYYTISNFNQLKFMHDVAKAIERIS EQVRKISEKYGYYRGIDSQEFNMVSDYYTISNFNQLKFMHDVAKAIERIS EKVRQIGEKYGYYRGIDAQEFNMVSDYYTFSNYNQLKYFVDIARKIEKLS EIMRDVGEKYGYYRGIDSQEFNMVSDYYTFTNYNHLKLSLDIAKSIEKIC EPCTVTDFEVCKRHGLEQTIADTLGPGGIMRALRTIPHLWQICEDMTEVC

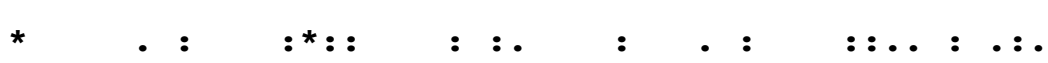

720

1263

AglA

511

MelA

Clustal Consensus

$$
\begin{aligned}
& \begin{array}{lllll}
160 & 170 & 180 & 190 & 200
\end{array} \\
& \ldots|\ldots| \ldots|\ldots| \ldots|\ldots| \ldots|\ldots| \ldots|\ldots|
\end{aligned}
$$
PKAWLLQAANPVFELT - NLITRTVPINMVG CHHHG -VDHIEKLGLDA PKAWLLQAANPVFELT - NLITRTVPINMVG ICH HHHG - VDHIIEKLGLDA PKAWYLQAANPIFEGT -TLVTRTVPIKAVG CH SHYG - VMEIVEKLGLEE PNAWLMQTANPVFEIT - QLIKRLTNVKVIGP CH SVVG - VQEVLKTLGLEE PDATMLNYVNPMAMNTWAMYARYPHIKQVGLCHSVQGTAEELARDLNIDP

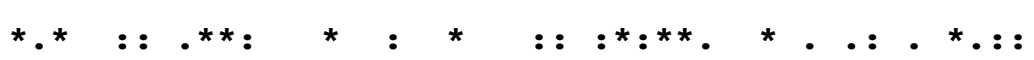

720

1263

AglA

511

MelA

Clustal Consensus

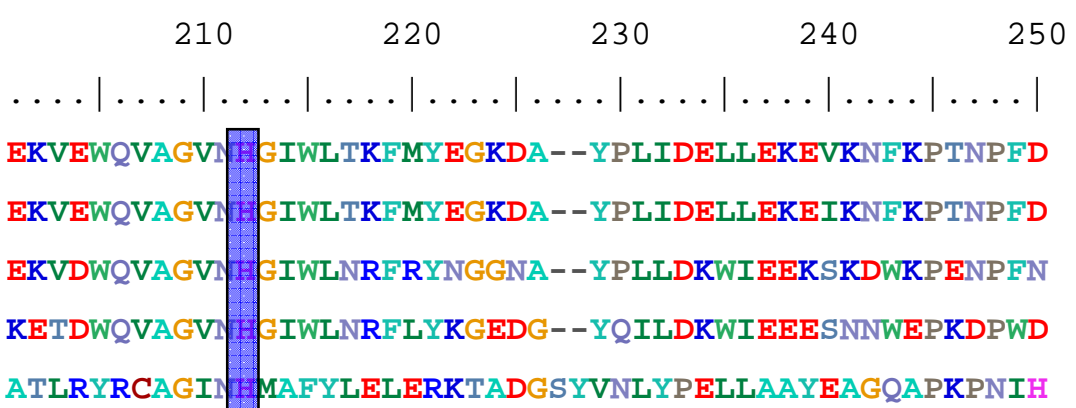

$: *^{* *}: * * \quad: \quad: \quad: \quad: \quad: \quad:$ : 
720

1263

AglA

511

MelA

Clustal Consensus

720

1263

AglA

511

MelA

Clustal Consensus

260
$\ldots \ldots|\ldots| \ldots|\ldots| \ldots|\ldots| \ldots|\ldots| \ldots|\ldots| \ldots|\ldots|$

DQLSPVAKDMYEFYGKMPIGDTVRNGSWKYHYNLETKKKWFGEPWGGVDS

DQLSPVAKDMYEFYGKMPIGDTVRNGSWKYHYNLETKKKWFGEPWGGVDS DQLSPAAIDMYRFYGVMPIGDTVRNSSWRYHRDLETKKKWYGEPWGGADS THLAPAVIDMYKFYGLLPIGDTTRNSTWKHHHSLQAKKKWYGK - FGGIDN GNTRCQNIVRYEMFKKLGYFVTESSE - - - - - HFAEYTPWFIKPGREDLI

$\begin{array}{lllll}310 & 320 & 330 & 340 & 350\end{array}$ $\ldots|\ldots| \ldots|\ldots| \ldots|\ldots| \ldots|\ldots| \ldots|\ldots| \ldots \mid$ ELGWKWYQDRQAEIATAMQKVAKYFQENKNAKLLSKDSLNEIISQTKNDV ELGWKWYQDRQAEIALAMQKVAKYFQENKNAKLLSKDSLNEIISQTKNDV EIGWKWYQDTLGKVTEITKKVAKFIKENPSVRLS - - - DLGSVLG - - KDLS EVERPKFYEELRQIKRMIIQVSK - - - - DPSIKIT - - - - - - - - - - - - - ETW ERYKVPLDEYPKRCVEQLANWHKELEEYKKASRID - - - - - - - - - - - - - -
720

1263

AglA

511

MelA

Clustal Consensus

720

1263

AglA

511

MelA

Clustal Consensus $\begin{array}{lllll}360 & 370 & 380 & 390 & 400\end{array}$ $\ldots|\ldots| \ldots|\ldots| \ldots|\ldots| \ldots|\ldots| \ldots|\ldots| \ldots \mid$ KEELTKEIYNLLDPQKKSGEQHILLANALLNDEKVDLVLNLPNNGTIPGI KEEFTKEICSLLDPQKKSGEQHILLANALLNDEKVDLVLNLPNNGTIPGI EKQFVLEVEKILDPERKSGEQHIPFIDALLNDNKARFVVNIPNKGIIHGI SEEFPKE - - - - - - - KMSGEQQIPFINALTNDVEARLFLNVLNNGTIKNI - - - - - - - - - - - IKPSREYASTIMNAIWTGEPSVIYGNVRNDGLIDNL $:{ }^{*} \quad::^{*}: \ldots \quad:{ }^{*}:{ }^{*} *^{*}$.: $\begin{array}{lllll}410 & 420 & 430 & 440 & 450\end{array}$ $\ldots|\ldots| \ldots|\ldots| \ldots|\ldots| \ldots|\ldots| \ldots|\ldots|$ PDDVAVEIPVYADKNGIHRYKIDPPLPERIKKMYLYPRIMRMEWALEAFL PDDVAVEIPVYADKNGIHRYKIDPPLPERIKKMYLYPRIMRMEWALEAFL DDDVVVEVPALVDKNGIHPEKIEPPLPDRVVKYYLRPRIMRMEMALEAFL PDDVVVEVPLKVNKNGMFPEKIEPDLPEKIKNYYIIPRITRMEMALESFI PQGCCVEVACLVDANGIQPTKVG - TLPSHLAALMQTN - INVQTLLTEAIL $\therefore{ }^{* *}: . \quad .{ }^{* *}:{ }^{*}:{ }^{* *} .:: \quad{ }^{*} \quad{ }^{*}::$ : $\begin{array}{llll}460 & 470 & 480 & 490\end{array}$ 
720

1263

AglA

511

MelA $\ldots|\ldots| \ldots|\ldots| \ldots|\ldots| \ldots|\ldots| \ldots|\ldots| \ldots$

TGDKRVLEEFLIRDPRTKSYDQVVKVIDEILALPGNE - EMRKHYSKK TGDKKVLEEFLIRDPRTKSYDQVVKVIDEILALPGNE - EMRKHYSKKTGDIRIIKELLYRDPRTKSDEQVEKVIEEILALPENE - EMRKHYLKR TGDRNILEEVLVRDPRTKNYDDIPKLWDEIFDLPFNK - GMKEHYRR - TENRDRVYHAAMMDPHTAAVLGIDEIYALVDDLIAAHGDWLPGWLHR -

Clustal Consensus

Abbildung 80: Allignment von GHF4 Enzymen; MelA aus E. coli; die Enzyme aus den ORFs RPMI00511, RPMI00720 und RPMI01263 aus $P$. miotherma; AgIA aus T. maritima. Der Rossmann-Fold-ähnliche Bereich ist grau hinterlegt und die an der Bindung des $\mathrm{Mn}^{2+}$-Ion beteiligten Aminosäuren sind blau hinterlegt.

Aus Abbildung 79 lassen sich folgende Koordinationen für das $\mathrm{Mn}^{2+}$-lon ableiten:

1. GlvA aus B. subtilis: $\mathrm{C} 2 \mathrm{OH}, \mathrm{C} 3 \mathrm{OH}, \mathrm{His} 202, \mathrm{NAD}^{+}, \mathrm{Cys} 172$ und Asp172

2. AglA aus T. maritima: $\mathrm{C} 2 \mathrm{OH}, \mathrm{C} 3 \mathrm{OH}, \mathrm{His} 203, \mathrm{NAD}^{+}, \mathrm{Cys} 174$ und His 175

Aus den Daten läßt sich folgender Mechanismus ableiten (Abbildung 81):
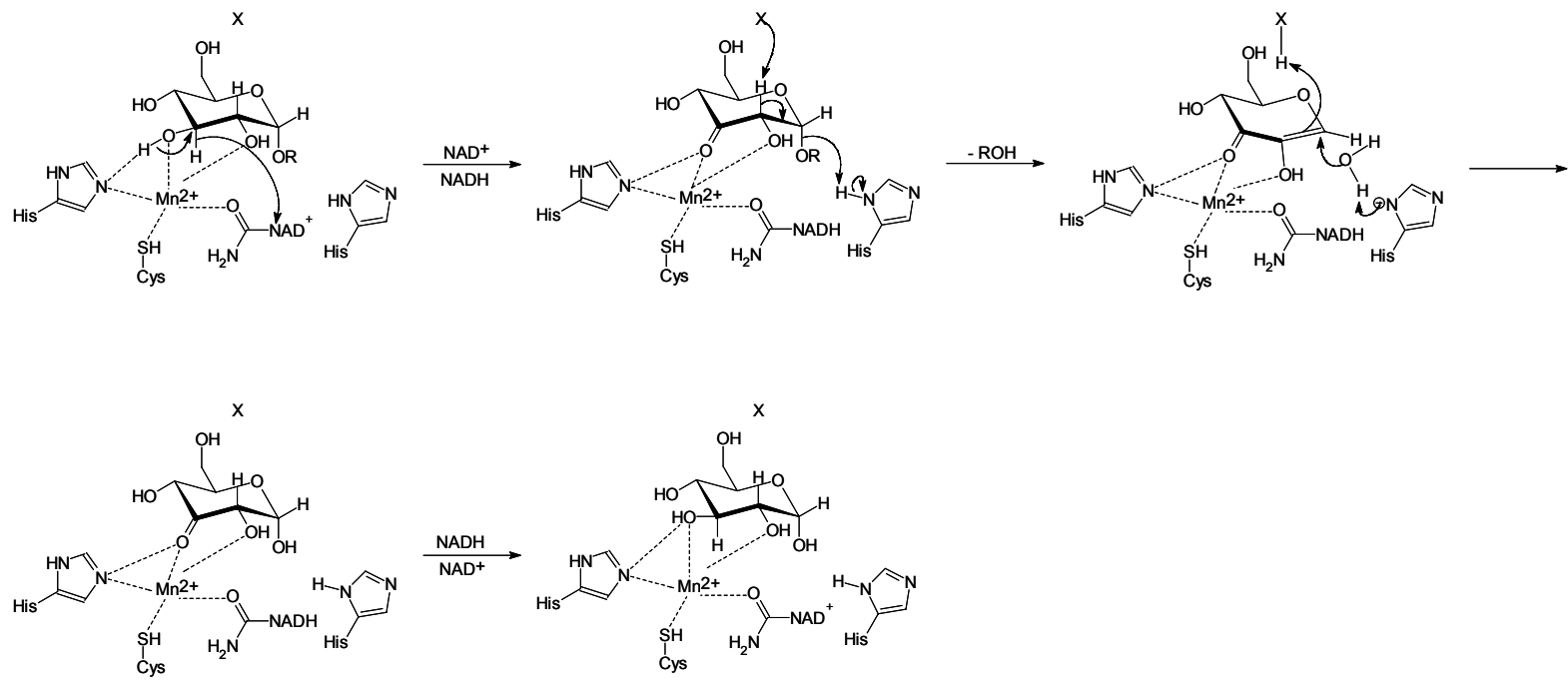

Abbildung 81: Allgemeiner Mechanismus der GHF4 (X steht für eine protonenakzeptierende Aminosäure). 
Bei diesem Mechanismus wird das Sauerstoffatom durch NAD ${ }^{+}$an $\mathrm{C} 3$ oxidiert. Das Proton an C2 wird durch eine protonenakzeptierende Aminosäure abstrahiert, die im Falles von MelA aus $E$. coli Arginin und im Falle der $\alpha$-Glukosidasen aus $P$. miotherma Glutamat ist. Hierbei entsteht ein 1,2-ungesättigter Michaelakzeptor und der zweite Zuckerrest wird abgespalten. Histidin koordiniert ein $\mathrm{H}_{2} \mathrm{O}$-Molekül und ein nucleophiler Angriff auf den 1,2-ungesättigten Michaelakzeptor findet statt. Anschließend wird der Sauerstoff an C3 durch NADH wieder reduziert und die Reaktionskaskade ist beendet. Erstaunlicherweise ist dort wo im Mechanismus ein X steht entweder eine saure oder eine basische Aminosäure kodiert (Abbildung 80). Der Mechanismus scheint hierdurch an die verschieden $\mathrm{pH}-$ Werte der Umgebung angepaßt zu sein. Durch diesen Mechanismus wird auch die Beobachtung aus den NMR-Versuchen gestützt, daß es sich hierbei um eine Bindungsspaltung mit Retention am anomeren Zentrum handelt (4.4.2).

\subsubsection{Auftreten eines unbekannten Produkts bei der AglA-Reaktion}

Nach der Auftrennung von Reaktionsprodukten der AglA-katalysierten Umsetzung von Substraten, trat auf Dünnschichtchromatogrammen ein Sonderspot auf und lief etwas über dem Glukosespot. Da er nur bei Enzymansätzen auftrat, die unter idealen Bedingungen durchgeführt wurden, ging man zunächst davon aus, es könnte sich um ein Zwischenprodukt der enzymatischen Umsetzung handeln.

SpotX ist nicht, wie zu erst vermutet, ein Zwischenprodukt der enzymatischen Umsetzung vom Substraten in Form eines speziell oxidierten Zuckers, sondern ein Nebenprodukt der stark reduzierenden Reaktionsbedingungen. Aus dem Massenund dem ${ }^{13} \mathrm{C}-\mathrm{NMR}-S p e k t r u m$ konnte folgende Verbindung abgeleitet werden: 2Hydroxymethyl-6-(2-hydroxypropylsulfanyl)-glukopyranosid. Die Addition von Thiolen ist in der Chemie bisher eher aus radikalischen Reaktionen bekannt. 


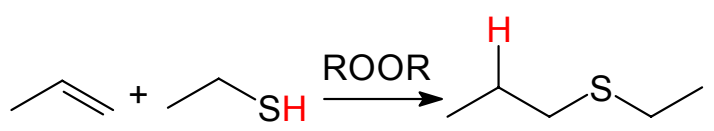

Abbildung 82: Radikalische Addition von Ethanthiol an Propen (K. Peter, C. Vollhardt; Organische Chemie, VCH, S. 497)

Der in Abbildung 81 vorgeschlagene Mechanismus verläuft über einen 1,2ungesättigten Michael-Akezeptor. Dieser ist für einen nucleophilen Angriff durch Wasser gut zugänglich. Da Schwefel nucleophiler als Wasser ist, kommt es anscheinend $\mathrm{zu}$ einer Konkurrenzreaktion und das Reduktionsmittel greift stattdessen am $\mathrm{C} 1$ der Glukose an. Es sind sowohl das $\alpha$-Anomer, als auch das $\beta$ Anomer entstanden, wie man dem ${ }^{13} \mathrm{C}-\mathrm{NMR}$-Spektrum entnehmen kann. Die Doppelsignale treten fast im 1:1-Verhältnis auf, was darauf hindeutet, daß die Reaktion nicht mehr enzymgesteuert zu sein scheint und recht unspezifisch verläuft.

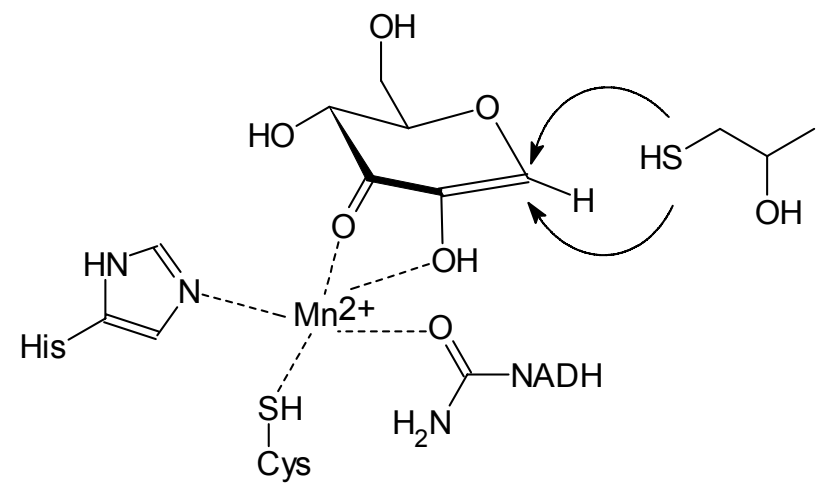

Abbildung 83: Möglicher Schritt der Konkurrenzreaktion.

Zwar lassen sich bei ${ }^{13} \mathrm{C}$-NMR-Spektren keine genauen Aussagen über die Konzentration der einzelnen Komponenten treffen, da sie sich nicht wie ${ }^{1} \mathrm{H}-\mathrm{NMR}$ Spektren integrieren lassen. Da sich aber nur eines der beiden Anomere bei dem vorhergesagten Mechanismus hätte bilden sollen, kann man trotzdem aus dem Spektrum ungefähre Aussagen über die Menge der entstandenen Anomere treffen. Das Nebenprodukt 2-Hydroxymethyl-6-(2-hydroxypropylsulfanyl)-glukopyranosid kann nicht direkt in der Enzymtasche entstanden sein, da beide Anomere entstanden sind. Es ist zu vermuten, daß es sich hierbei um eine Nebenreaktion der nicht physiologischen Bedingungen durch das DTT handelt. Es liegt in sehr hoher Konzentration im Reaktionsansatz vor und scheint den aus der Enzymtasche 
herausdiffundierten 1,2-ungesättigte Michealakzeptor abgefangen zu haben. Der Spot trat nur in geringer Konzentration auf. Durch die hohe Nukleophilie des Schwefels kam es zum Angriff auf die Doppelbindung. Das Reduktionsmittel scheint also nicht in der Enzymtasche zu agieren.

Wie aus den Versuchsbedingungen schon bekannt ist, läuft der enzymatische Umsatz ohne das Reduktionsmittel nicht ab. Dieser Widerspruch lässt sich aus diesen Daten noch nicht genau aufklären. 


\section{Zusammenfassung}

Die vorliegende Arbeit befasst sich mit der Untersuchung von Enzymen der GHF4, einer Gruppe von Enzymen, die $\mathrm{NAD}^{+}$-abhängig sind und an ihrem N-Terminus gelegen eine hochkonservierte Sequenz Gly-Xxx-Gly-Ser (GXGS) besitzen. Dieses Motiv hat gewisse Ähnlichkeit mit einem konservierten Sequenzmotiv des Rossmann-Fold, bestehend aus einer alternierenden Abfolge von $\beta$-Strängen und $\alpha-$ Helices $(\beta \alpha \beta \alpha \beta)$, die eine konservierte strukturelle Region für die Bindung eines Cofaktors in Proteinen darstellt. Im klassischen Rossmann-Fold Motiv ist eine glycinreiche Sequenz innerhalb des ersten $\beta$-Strangs wichtig (GXGXXG), die über eine Schleife den ersten $\beta$-Strang mit der folgenden $\alpha$-Helix verbindet. Diese ist maßgeblich an der $\mathrm{NAD}^{+}$-Bindung beteiligt. Neben der Abhängigkeit von $\mathrm{NAD}^{+}$ benötigen die Enzyme für ihre Funktion zweiwertige lonen, meist $\mathrm{Mn}^{2+}$-Ionen und stark reduzierende Bedingungen durch Anwesenheit von DTT.

Diese Arbeit beschäftigt sich mit drei $\alpha$-Glukosidasen aus $P$. miotherma, einer $\alpha-$ Galaktosidase aus E. coli K12 und einer $\alpha$-Glukosidase aus T. maritima.

Frühere Untersuchungen an der $\alpha$-Galaktosidase MelA aus E. coli K12 scheiterten aufgrund ihrer hohen Instabilität. Im Rahmen dieser Arbeit wurde das MelA-Gen aus chromosomaler DNA kloniert und als Fusion mit einem His Tag produziert. Es erfolgte eine Aufreinigung in nur einem Schritt an einer Protino ${ }^{\circledR} \mathrm{Ni} 2000$-Säule. Dabei wurden $5 \mathrm{mg}$ reines MelA mit einer Molekularmasse von $50 \mathrm{kDa}$ mit einer spezifischen $\alpha$-Galaktosidaseaktivität von $22 \mathrm{U} / \mathrm{mg}$ gewonnen. Weiterhin wurde die Aktivität durch Zugabe von $\mathrm{Mn}^{2+}$-Ionen so weit konserviert, daß eine biochemische Charakterisierung vorgenommen werden konnte. Eine optimale Substratumsetzung erfolgte bei $\mathrm{pH} 7,0$ und, unter Verwendung eines Assays in Gegenwart von $\mathrm{Mn}^{2+}$ $(0,15 \mathrm{mM}), \mathrm{NAD}^{+}(0,5 \mathrm{mM})$ und DTT $(0,25 \mathrm{M})$, bei einer Temperatur von $37^{\circ} \mathrm{C}$. MelA

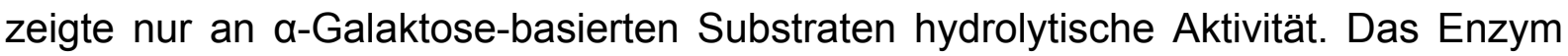
lag in aktiver Form als Hexamer vor. NMR-Spektroskopische Untersuchungen zum Substratumsatz belegen, daß die Hydrolyse über eine Retention am anomeren Zentrum verläuft. Zusätzliche Untersuchungen durch ESR-Spektroskopie ergaben, daß das $\mathrm{Mn}^{2+}$-Ion eine stark verzerrte oktaedrische Koordinationssphäre im aktiven Zentrum besitzt. Ein Ergebnis zur Kristallisation des Enzyms steht noch aus. 
Die a-Glukosidase aus T. maritima AglA ist in Kooperation mit Prof. N. Sträter kristallisiert und anschließend mittels Röntgenbeugung vermessen worden. AglA ist das erste Enzym, das aus der GHF4 kristallisiert wurde. Im Kristall konnte die NAD ${ }^{+}$ Bindedomäne bestätigt werden. Untersuchungen mit Absorbtions- und Fluoreszenzspektroskopie an AglA ergaben Hinweise auf die Anwesenheit von NADH während des enzymatischen Umsatzes.

Weiterhin wurden drei Gene für GHF4-Enzyme aus $P$. miotherma heterolog in $E$. coli überexprmiert. Die Aufreinigung der drei Enzyme erfolgte in zwei Schritten über eine denaturierende Hitzefällung und anschließend über eine Anionenaustauschchromatographie.

Das von ORF RPMI00511 kodierte Enzym konnte nicht weiter charakterisiert werden, da es anscheinend inaktiv in reiner Form vorlag.

Das in ORF RPMI00720 kodierte Enzym zeigte in reiner Form Aktivität sowohl an künstlichen a-Galaktosesubstraten (spezifische Aktivität 0,7 U/mg) als auch an $\alpha$ Glukosesubstraten (spezifische Aktivität von 1,16 U/mg). Das Enzym besitzt keine hohe Spezifität in Bezug auf das C4 des Substrates. Eine optimale Substratumsetzung erfolgte bei $\mathrm{pH}$ 7,0 und, unter Verwendung eines Assays in Gegenwart von $\mathrm{Mn}^{2+}(0,6 \mathrm{mM}), \mathrm{NAD}^{+}(2,7 \mathrm{mM})$ und DTT $(0,25 \mathrm{M})$, bei einer Temperatur von $60^{\circ} \mathrm{C}$.

Das von ORF RPMI01263 kodierte Enzym zeigte in reiner Form Aktivität sowohl an

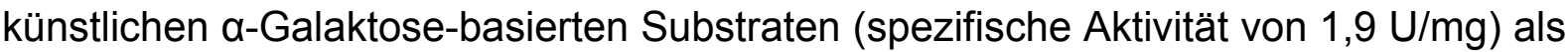
auch an $\alpha$-Glukosesubstraten (spezifische Aktivität von 2,50 U/mg). Das Enzym besitzt keine hohe Spezifität in Bezug auf das C4 des Substrates. Eine optimale Substratumsetzung erfolgte bei $\mathrm{pH}$ 7,0 und, unter Verwendung eines Assays in Gegenwart von $\mathrm{Mn}^{2+}(0,6 \mathrm{mM}), \mathrm{NAD}^{+}(0,9 \mathrm{mM})$ und DTT $(0,25 \mathrm{M})$, bei einer Temperatur von $60^{\circ} \mathrm{C}$. Untersuchungen durch ESR-Spektroskopie ergaben, daß das $\mathrm{Mn}^{2+}$-Ion eine stark verzerrte oktaedrische Koordinationssphäre im aktiven Zentrum besitzt.

Durch die Kombination von Kristallisationsdaten, ESR- und NMR-spektroskopischen Untersuchungen konnte der vorgeschlagene Mechanismus der GHF4 weiter verfeinert und allgemein dargestellt werden.

Weiterhin konnte ein Nebenprodukt der enzymatischen Umsetzung aufgereinigt und anschließend dessen chemische Struktur aufgeklärt werden. 


\section{Literatur}

Andrade, C. (1996)

Production and characterization of extremly thermostable xylanolytic and amylolytic enzymes from the hyperthermophilic archaeon P. abyssi

Ph. D. Thesis Technische Universität Hamburg-Harburg

Andrade, M.M.C., Pereireá, N., Antranikian, G. (1999)

Extremly thermophilic microorganism and their polymerhydrolytic enzymes Revista de Microbiologia 30: 287-298.

Bragger, J. M.; Daniel, R. M.; Coolbear, T.; Morgan, H. W. (1989)

Very stable enzymes from extremely thermophilic archaebacteria and eubacteria. Appl. Microbiol. Biotechnol. 31:556-561.

Becker P, Abu-Reesh I, Markossian S, Antranikian G, MärkI H. (1997)

Determination of the kinetic parameters during continuous cultivation of the lipaseproducing thermophile Bacillus sp. IHI-91 on olive oil.

Appl Microbiol Biotechnol;48:184-90.

Bertoldo C., Antranikian G. (2001)

Amylolytic enzymes from hyperthermophiles,

Methods Enzymol. 330:269-89

Birnboim, H.C., Doly, J. (1979)

A rapid alkaline extraction procedure for screening recombinant plasmid DNA Nucleic Acid Res. 7, 1513-1518 


\section{Bradford, M.M. (1976)}

A rapid sensitive method for the quantitation of microgram quantities of protein utilizing the principle of protein dye-binding

Anal. Biochem. 72: 248-254

\section{Brown, D.H. \& Brown, B.I. (1966)}

Enzymes of glycogen debranching: amylo-1,6-glucosidase (I) and oligo $1,4 \rightarrow 1,4-$ glucantransferase (II)

Methods Enzymol. 8: 515-524

Brown, S. H.; Kelly, R. M. (1993)

Characterization of Amylolytic Enzymes, Having Both a-1,4 and a-1,6 Hydrolytic Activity, from the Thermophilic Archaea Pyrococcus furiosus and Thermococcus litoralis. Appl. Environ. Microbiol. 59(8): 2614-2621.

\section{Bullock, W.O., Fernandez, J.M., Short, J.M. (1987)}

XL1-Blue: a high efficiency plasmid DNA transforming recA Escherichia coli strain with beta-galactosidase selection

Bio Techniques 5: 376-379

Burstein, C., Kepes, A., (1971)

The a-galactosidase from Escherichis coli K12.

Biochim. Biophys. Acta 230, 52-63

Cowan D. (1996)

The Outer Reaches of Life TIBTECH 13: 177 
Crabb, WB., Mitchinson, C. (1996)

Enzymes involved in the processing of starch to sugars

TIBTECH 15: 349-352

Daniel, R. M., Dines, M., Petach, H. H. (1996)

Stability and folding of dihydrofolate reductase from the hyperthermophilic bacterium T. maritima

Biochem. J. 317: 1-11

Davey, M.E., Wood, W.A., Key, R., Nakamura, K., Stahl, D.A. (1993)

Isolation of three Species of Geotoga and Petrotoga: Two New Genera, Representing a New Lineage in the Bacterial Line of Descent Distantly Related to the “Thermotogales" System. Appl. Microbiol. 16: 191-200

Eichler, J. (2001)

Biotechnological uses of archaeal extremozymes

Biotechnology Advances 19: 261-278

Ferreira-Filho, E. X. (1994)

The xylan-dagrading enzyme system

Brazilian J. Med. Res. 27: 1093-1109

Friebolin, $\mathbf{H}$.

Ein- und Zweidimensionale NMR-Spektroskopie,

2. Aufl., VCH, Weinheim 1992 
Gebler, J,. Gilkes, N. R., Claeyssens, M. (1992)

Stereoselective Hydrolysis Catalysed by Related $\beta-1,4-G l u c a n a s e s$ and $\beta-1,4-$ xylanases

J Biol Chem. ;267(18):12559-12561.

Grote, R., Antranikian, G. (2001)

Extremophile Biotechnologie - Life Science für eine bessere Zukunft Hamburg Aktuell, Mensch \& Technik, Ausgabe II/2001

\section{Günther, $\mathbf{H}$.}

NMR-Spektroskopie, 2. Aufl.,

G. ThiemeVerlag, Stuttgart 1983

Hall, T.A., 1999

Bio Edit: a user-friendly biological sequence alignment editor for Windows 95/98/NT Nucl. Acids. Symp. Ser. 41:95-98

Hanahan, D. (1983)

Studies on transformation of Escherichia coli with plasmids J. Mol. Biol. 166: 557-580

Henrissat B., (1991)

A classification of glycosyl hydrolases based on amino-acid sequence similarities. Biochem. J. 280:309-316. 
Henrissat B., Bairoch A. (1993)

New families in the classification of glycosyl hydrolases based on amino- acid sequence similarities.

Biochem. J. 293:781-788.

Henrissat B., Bairoch A. (1996)

Updating the sequence-based classification of glycosyl hydrolases.

Biochem. J. 316:695-696.

Henrissat B., Davies G. (1995)

Structures and mechanisms of glycosyl hydrolases.

Structure 3:853-859.

Huber, R., Langworthy, T.A., König, H., Thomm, M., Woese, C.R., Sleytr, U.B., Stetter, K.O., (1986)

Thermotoga maritima sp. nov. represents a new genus of unique extremely thermophilic eubacteria growing up to $90^{\circ} \mathrm{C}$

Arch. Microbiol. 144: 324-333

Inoue, H., Nojima, H., Okayama, H. (1990)

High efficiency transformation of Escherichia coli with plasmids

Gene 96: 23-28

Janecek, Š., (1997)

a-Amylase family: Molecular biology and evolution.

Prog. Biophys. Molec. Biol. 67, 67-97 
Jaenicke, R. and Böhm, G. (1998)

The stability of proteins in extreme environments

Curr. Opin. Struct. Biol. 8: 738-748

Krahe, M., Antranician, G., Märkl, H. (1996)

Fermentation of extremophilic mocroorganisms

FEMS Micribiol. Rev.: 18: 271-85

Laemmli, U. (1970)

Cleavage of structural proteins during the assembly of the head of bacteriophage T4

Nature 227: 680-685

Lien T., Madsen M., Rainey F.A., Birkeland N.K. (1998)

Petrotoga mobilis sp. nov., from a North Sea oil-production well

Int. J. Syst. Bacteriol. (Pt 3):1007-13

L'Haridon, S., Miroshnichenko, M.L., Hippe, H., Fardeau, M.L., BonchOsmolovskaya, E.A., Stackebrandt, E., Jeanthon, C. (2002)

Petrotoga olearia sp. Nov. and Petrotoga sibirica sp. Nov., two thermophilic bacteria isolated from a continental petroleum reservoir in Western Siberia Int. J. Syst. Evol. Microbiol.52(Pt 5):1715-22

Mirando-Tello, E., Fardeau, M-L., Thomas, P., Ramirez, F. Petrotoga mexicana sp. Nov., a novel thermophilic, anaerobic and xylanolytic bacterium isolated from an oil-producing well in the Gulf of Mexico. Int. J. Syst. Evol. Microbiol.54:169-174. 


\section{Lodge JA, Maier T, Liebl W, Hoffmann V, Sträter N.(2003)}

Crystal structure of Thermotoga maritima alpha-glucosidase AglA defines a new clan of $\mathrm{NAD}^{+}$-dependent glycosidases.

J. Biol. Chem. ;278(21):19151-8.

Lundberg KS, Shoemaker DD, Adams MW, Short JM, Sorge JA, Mathur EJ. (1991)

High-fidelity amplification using a thermostable DNA polymerase isolated from Pyrococcus furiosus.

Gene;108:1-6.

Madigan, M.T., Martinko, J.M., Parker, J. (2001)

Brock Mikrobiologie

Spektrum Akademischer Verlag GmbH Heidelberg, Berlin

Nagao, Y., Nakada, T., Imoto, M., Shimamoto, T., Sakai, S., Tsuda, M., Tsuchiya, T. (1988)

Purification and analysis of the structure of alpha-galactosidase from Escherichia coli. Biochem Biophys Res Commun. Feb 29;151(1):236-41.

Niehaus F, Bertoldo C, Kahler M, Antranikian G. (1999)

Extremophiles as a source of novel enzymes for industrial application, Appl Microbiol Biotechnol. 51(6): 711-29 
Nissen, A. N.; Anker, L.; Munk, N.; Lange, N. K. (1992)

Xylanases for the Pulp and Paper Industry. In: Visser J, Beldman G, Kusters - van Someren MA, Voragen AGJ (eds) Xylan and Xylanases,

Elsevier Science Publishers, Amsterdam, p.325-337.

Raasch, C. (2001)

Molekulare, biochemische und strukturelle Untersuchungen von amylolytischen Enzymen von Thermotoga maritima MSB8

Dissertation am Institut für Mikrobiologie und Genetik der Georg-August Universität München

Raasch C, Armbrecht M, Streit W, Hocker B, Strater N, Liebl W. (2002)

Identification of residues important for $\mathrm{NAD}^{+}$binding by the Thermotoga maritima alpha-glucosidase AgIA, a member of glycoside hydrolase family 4.

FEBS Lett:;517(1-3):267-71.

Raasch C, Streit W, Schanzer J, Bibel M, Gosslar U, Liebl W. (2000)

Thermotoga maritima AgIA, an extremely thermostable $\mathrm{NAD}^{+}-, \mathrm{Mn}^{2+}-$, and thioldependent alpha-glucosidase.

Extremophiles. (4):189-200.

Sambrook, J., Fritsch, E.F., Maniatis, T. (1989)

Molecular cloning: a laboratory manual.

$2^{\text {nd }}$ Edition Cold Spring Harbor Laboratory, Cold Spring Harbor, N.Y.

Schlegel, H.G. (1992)

Allgemeine Mikrobiologie

Georg-Thieme-Verlag, Stuttgart 
Selig, M., Xavier, K.B., Santos, H., Schönheit, P. (1997)

Comparative analysis of the Emden-Meyerhof and Entner-Doudoroff glycolytic pathways in hyperthermophilic archaea and the bacterium Thermotoga

Arch. Microbiol. 167: 217-232

Shyamala S. Rajan, Xiaojing Yang, Frank Collart, Vivian L.Y. Yip, Stephen G. Withers, Annabelle Varrot, John Thompson, Gideon J. Davies, and Wayne F. Anderson1 (2004)

Novel Catalytic Mechanism of Glycoside Hydrolysis Based on the Structure of an $\mathrm{NAD}^{+} / \mathrm{Mn}^{2+}$-Dependent Phospho- $\alpha-$ Glucosidase from Bacillus subtilis

Structure, Vol. 12, 1619-1629,

Sterner R., Liebl W. (2001)

Thermophilic Adaptation of Proteins

Critical Reviews in Biochemistry and Molecular Biology, 36 (1): 39-106 (2001)

Stetter, K.O. (1996)

Hyperhermophilic procaryotes

FEMS Microbiol. Rev. 18: 149-158

Suzuki, Y., Yonezawa, K., Hattori, M., Takii, Y., (1992),

Assignment of Bacillus thermoamyloliquefaciens KP1071 a-glucosidase I to an exo$\alpha-1,4$-glucosidase, and its striking similarity to bacillary oligo-1,6-glucosidases in Nterminal sequence and in structural parameters calculated from the amino acid composition.

Eur. J. Biochem. 205, 249-256 
Takagi M, Nishioka M, Kakihara H, Kitabayashi M, Inoue H, Kawakami B, Oka M, Imanaka T. (1997)

Characterization of DNA polymerase from Pyrococcus sp. strain KOD1 and its application to PCR.

Appl Environ Microbiol;63:4504-10.

Tamai E, Shimamoto T, Tsuda M, Mizushima T, Tsuchiya T. (1998)

Conversion of temperature-sensitive to -resistant gene expression due to mutations in the promoter region of the melibiose operon in Escherichia coli.

J. Biol. Chem.;273(27):16860-4.

Thompson J, Ruvinov SB, Freedberg DI, Hall BG. (1999)

Cellobiose-6-phosphate hydrolase (CelF) of Escherichia coli: characterization and assignment to the unusual family 4 of glycosylhydrolases.

J. Bacteriol. ;181(23):7339-45.

Widdel, F., Pfennig, N. (1984)

Dissimilatory sulfate- or sulfur-reducing bacteria.

Bergey's manual of systematic bacteriology, 1: 663-679

Richard Wolfenden, Xiangdong Lu, and Gregory Young (1998)

Spontaneous Hydrolysis of Glycosides

J. Am. Chem. Soc., 120, 6814-6815 


\section{Anhang}

\begin{tabular}{|c|c|c|c|c|c|}
\hline $\begin{array}{l}0,05 \mathrm{M} \mathrm{Zn(OAc)} 2 \\
5 \% \text { Isopropanol } \\
0,1 \mathrm{M} \mathrm{NaCacodylat} \\
\mathrm{pH} 6,5\end{array}$ & 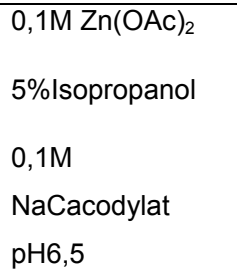 & 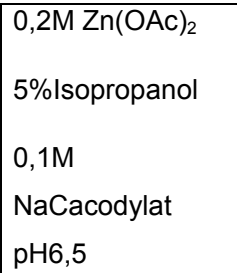 & $\begin{array}{l}\text { 0,05M Zn(OAc) })_{2} \\
\text { 5\%lsopropanol } \\
0,1 \mathrm{M} \text { Hepes pH7,5 }\end{array}$ & 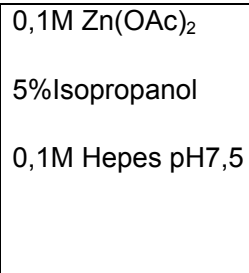 & $\begin{array}{l}\text { 0,2M Zn(OAc) })_{2} \\
\text { 5\%Isopropanol } \\
0,1 \mathrm{M} \text { Hepes } \mathrm{pH} 7,5\end{array}$ \\
\hline $\begin{array}{l}0,05 \mathrm{M} \mathrm{Zn(OAc})_{2} \\
7,5 \% \text { Isopropanol } \\
0,1 \mathrm{M} \mathrm{NaCacodylat} \\
\mathrm{pH} 6,5\end{array}$ & 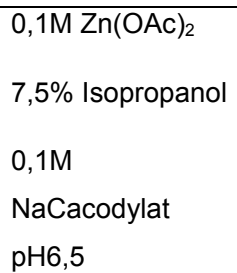 & $\begin{array}{l}\text { 0,2M Zn(OAc) })_{2} \\
7,5 \% \text { Isopropanol } \\
0,1 \mathrm{M} \\
\text { NaCacodylat } \\
\text { pH6,5 }\end{array}$ & 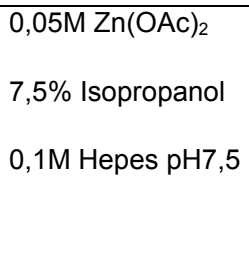 & 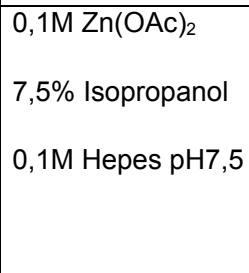 & $\begin{array}{l}0,2 \mathrm{M} \mathrm{Zn}(\mathrm{OAc})_{2} \\
7,5 \% \text { Isopropanol } \\
0,1 \mathrm{M} \text { Hepes } \mathrm{pH} 7,5\end{array}$ \\
\hline $\begin{array}{l}0,05 \mathrm{M} \mathrm{Zn(OAc)} 2 \\
10 \% \text { Isopropanol } \\
0,1 \mathrm{M} \mathrm{NaCacodylat} \\
\mathrm{pH} 6,5\end{array}$ & $\begin{array}{l}0,1 \mathrm{M} \mathrm{Zn(OAc)})_{2} \\
10 \% \text { Isopropanol } \\
0,1 \mathrm{M} \\
\text { NaCacodylat } \\
\text { pH6,5 }\end{array}$ & $\begin{array}{l}0,2 \mathrm{M} \mathrm{Zn}(\mathrm{OAc})_{2} \\
10 \% \text { Isopropanol } \\
0,1 \mathrm{M} \\
\text { NaCacodylat } \\
\mathrm{pH} 6,5\end{array}$ & 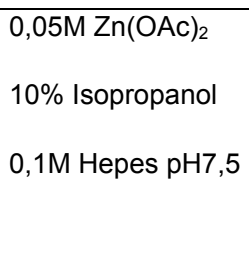 & 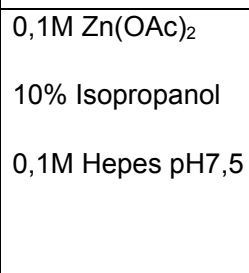 & $\begin{array}{l}0,2 \mathrm{M} \mathrm{Zn}(\mathrm{OAc})_{2} \\
10 \% \text { Isopropanol } \\
0,1 \mathrm{M} \text { Hepes } \mathrm{pH} 7,5\end{array}$ \\
\hline $\begin{array}{l}0,05 \mathrm{M} \mathrm{Zn(OAc)} 2 \\
15 \% \text { Isopropanol } \\
0,1 \mathrm{M} \mathrm{NaCacodylat} \\
\mathrm{pH} 6,5\end{array}$ & $\begin{array}{l}0,1 \mathrm{M} \mathrm{Zn(OAc)})_{2} \\
15 \% \text { Isopropanol } \\
0,1 \mathrm{M} \\
\text { NaCacodylat } \\
\text { pH6,5 }\end{array}$ & $\begin{array}{l}\text { 0,2M Zn(OAc) } 2 \\
15 \% \text { Isopropanol } \\
0,1 \mathrm{M} \\
\text { NaCacodylat } \\
\text { pH6,5 }\end{array}$ & 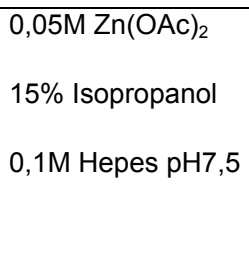 & 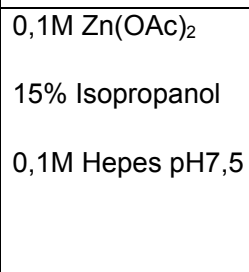 & $\begin{array}{l}0,2 \mathrm{M} \mathrm{Zn}(\mathrm{OAc})_{2} \\
15 \% \text { Isopropanol } \\
0,1 \mathrm{M} \text { Hepes } \mathrm{pH} 7,5\end{array}$ \\
\hline
\end{tabular}




\begin{tabular}{|c|c|c|c|c|c|}
\hline $\begin{array}{l}0,05 \mathrm{M} \mathrm{Mn}(\mathrm{OAc})_{2} \\
5 \% \text { Isopropanol } \\
0,1 \mathrm{M} \mathrm{NaCacodylat} \\
\mathrm{pH} 6,5\end{array}$ & $\begin{array}{l}0,1 \mathrm{M} \mathrm{Mn}(\mathrm{OAc})_{2} \\
5 \% \text { Isopropanol } \\
0,1 \mathrm{M} \\
\mathrm{NaCacodylat} \\
\mathrm{pH} 6,5\end{array}$ & $\begin{array}{l}0,2 \mathrm{M} \mathrm{Mn}(\mathrm{OAc})_{2} \\
5 \% \text { Isopropanol } \\
0,1 \mathrm{M} \\
\mathrm{NaCacodylat} \\
\mathrm{pH} 6,5\end{array}$ & $\begin{array}{l}0,05 \mathrm{M} \mathrm{Mn}(\mathrm{OAc})_{2} \\
5 \% \text { Isopropanol } \\
0,1 \mathrm{M} \text { Hepes } \mathrm{pH} 7,5\end{array}$ & $\begin{array}{l}0,1 \mathrm{M} \mathrm{Mn}(\mathrm{OAc})_{2} \\
5 \% \text { Isopropanol } \\
0,1 \mathrm{M} \text { Hepes } \mathrm{pH} 7,5\end{array}$ & $\begin{array}{l}0,2 \mathrm{M} \mathrm{Mn}(\mathrm{OAc})_{2} \\
5 \% \text { Isopropanol } \\
0,1 \mathrm{M} \text { Hepes } \mathrm{pH} 7,5\end{array}$ \\
\hline $\begin{array}{l}0,05 \mathrm{M} \mathrm{Mn}(\mathrm{OAc})_{2} \\
7,5 \% \text { Isopropanol } \\
0,1 \mathrm{M} \mathrm{NaCacodylat} \\
\mathrm{pH} 6,5\end{array}$ & $\begin{array}{l}\text { 0,1M Mn(OAc) } 2 \\
7,5 \% \text { Isopropanol } \\
0,1 \mathrm{M} \\
\mathrm{NaCacodylat} \\
\mathrm{pH} 6,5\end{array}$ & $\begin{array}{l}\text { 0,2M Mn(OAc) } 2 \\
7,5 \% \text { Isopropanol } \\
0,1 \mathrm{M} \\
\mathrm{NaCacodylat} \\
\mathrm{pH} 6,5\end{array}$ & $\begin{array}{l}0,05 \mathrm{M} \mathrm{Mn}(\mathrm{OAc})_{2} \\
7,5 \% \text { Isopropanol } \\
0,1 \mathrm{M} \text { Hepes } \mathrm{pH} 7,5\end{array}$ & $\begin{array}{l}0,1 \mathrm{M} \mathrm{Mn}(\mathrm{OAc})_{2} \\
7,5 \% \text { Isopropanol } \\
0,1 \mathrm{M} \text { Hepes } \mathrm{pH} 7,5\end{array}$ & $\begin{array}{l}0,2 \mathrm{M} \mathrm{Mn}(\mathrm{OAc})_{2} \\
7,5 \% \text { Isopropanol } \\
0,1 \mathrm{M} \text { Hepes } \mathrm{pH} 7,5\end{array}$ \\
\hline $\begin{array}{l}0,05 \mathrm{M} \mathrm{Mn}(\mathrm{OAc})_{2} \\
10 \% \text { Isopropanol } \\
0,1 \mathrm{M} \mathrm{NaCacodylat} \\
\mathrm{pH} 6,5\end{array}$ & $\begin{array}{l}0,1 \mathrm{M} \mathrm{Mn}(\mathrm{OAc})_{2} \\
10 \% \text { Isopropanol } \\
0,1 \mathrm{M} \\
\text { NaCacodylat } \\
\mathrm{pH} 6,5\end{array}$ & $\begin{array}{l}0,2 \mathrm{M} \mathrm{Mn}(\mathrm{OAc})_{2} \\
10 \% \text { Isopropanol } \\
0,1 \mathrm{M} \\
\mathrm{NaCacodylat} \\
\mathrm{pH} 6,5\end{array}$ & $\begin{array}{l}0,05 \mathrm{M} \mathrm{Mn}(\mathrm{OAc})_{2} \\
10 \% \text { Isopropanol } \\
0,1 \mathrm{M} \text { Hepes } \mathrm{pH} 7,5\end{array}$ & $\begin{array}{l}0,1 \mathrm{M} \mathrm{Mn}(\mathrm{OAc})_{2} \\
10 \% \text { Isopropanol } \\
0,1 \mathrm{M} \text { Hepes } \mathrm{pH} 7,5\end{array}$ & $\begin{array}{l}0,2 \mathrm{M} \mathrm{Mn}(\mathrm{OAc})_{2} \\
10 \% \text { Isopropanol } \\
0,1 \mathrm{M} \text { Hepes } \mathrm{pH} 7,5\end{array}$ \\
\hline $\begin{array}{l}0,05 \mathrm{M} \mathrm{Mn}(\mathrm{OAc})_{2} \\
15 \% \text { Isopropanol } \\
0,1 \mathrm{M} \mathrm{NaCacodylat} \\
\mathrm{pH} 6,5\end{array}$ & $\begin{array}{l}0,1 \mathrm{M} \mathrm{Mn}(\mathrm{OAc})_{2} \\
15 \% \text { Isopropanol } \\
0,1 \mathrm{M} \\
\text { NaCacodylat } \\
\mathrm{pH} 6,5\end{array}$ & $\begin{array}{l}0,2 \mathrm{M} \mathrm{Mn}(\mathrm{OAc})_{2} \\
15 \% \text { Isopropanol } \\
0,1 \mathrm{M} \\
\text { NaCacodylat } \\
\mathrm{pH} 6,5\end{array}$ & $\begin{array}{l}0,05 \mathrm{M} \mathrm{Mn}(\mathrm{OAc})_{2} \\
15 \% \text { Isopropanol } \\
0,1 \mathrm{M} \text { Hepes } \mathrm{pH} 7,5\end{array}$ & $\begin{array}{l}0,1 \mathrm{M} \mathrm{Mn}(\mathrm{OAc})_{2} \\
15 \% \text { Isopropanol } \\
0,1 \mathrm{M} \text { Hepes } \mathrm{pH} 7,5\end{array}$ & $\begin{array}{l}0,2 \mathrm{M} \mathrm{Mn}(\mathrm{OAc})_{2} \\
15 \% \text { Isopropanol } \\
0,1 \mathrm{M} \text { Hepes } \mathrm{pH} 7,5\end{array}$ \\
\hline
\end{tabular}

\begin{tabular}{|c|c|c|c|c|c|}
\hline $\begin{array}{l}0,05 \mathrm{M} \mathrm{Ca}(\mathrm{OAc})_{2} \\
5 \% \text { Isopropanol }\end{array}$ & $\begin{array}{l}0,1 \mathrm{M} \mathrm{Ca}(\mathrm{OAc})_{2} \\
5 \% \text { Isopropanol }\end{array}$ & $\begin{array}{l}0,2 \mathrm{M} \mathrm{Ca}(\mathrm{OAc})_{2} \\
5 \% \text { Isopropanol }\end{array}$ & $0,05 \mathrm{M} \mathrm{Ca}(\mathrm{OAc})_{2}$ & $0,1 \mathrm{M} \mathrm{Ca}(\mathrm{OAc})_{2}$ & $0,2 \mathrm{M} \mathrm{Ca}(\mathrm{OAc})_{2}$ \\
\hline $\begin{array}{l}0,1 \mathrm{M} \text { NaCacodylat } \\
\mathrm{pH} 6,5\end{array}$ & $\begin{array}{l}0,1 \mathrm{M} \text { NaCacodylat } \\
\mathrm{pH} 6,5\end{array}$ & $\begin{array}{l}0,1 \mathrm{M} \text { NaCacodylat } \\
\mathrm{pH} 6,5\end{array}$ & $0,1 \mathrm{M}$ Hepes $\mathrm{pH} 7,5$ & $0,1 \mathrm{M}$ Hepes $\mathrm{pH} 7,5$ & $0,1 \mathrm{M}$ Hepes $\mathrm{pH} 7,5$ \\
\hline $0,05 \mathrm{M} \mathrm{Ca}(\mathrm{OAc})_{2}$ & $0,1 \mathrm{M} \mathrm{Ca}(\mathrm{OAc})_{2}$ & $0,2 \mathrm{M} \mathrm{Ca}(\mathrm{OAc})_{2}$ & $0,05 \mathrm{M} \mathrm{Ca}(\mathrm{OAc})_{2}$ & $0,1 \mathrm{M} \mathrm{Ca}(\mathrm{OAc})_{2}$ & $0,2 \mathrm{M} \mathrm{Ca}(\mathrm{OAc})_{2}$ \\
\hline $\begin{array}{l}0,1 \mathrm{M} \text { NaCacodylat } \\
\mathrm{pH} 6,5\end{array}$ & $\begin{array}{l}0,1 \mathrm{M} \text { NaCacodylat } \\
\mathrm{pH} 6,5\end{array}$ & $\begin{array}{l}\text { 0,1M NaCacodylat } \\
\mathrm{pH} 6,5\end{array}$ & 0,1M Hepes $\mathrm{pH} 7,5$ & $0,1 \mathrm{M}$ Hepes $\mathrm{pH} 7,5$ & 0,1M Hepes pH7,5 \\
\hline $0,05 \mathrm{M} \mathrm{Ca}(\mathrm{OAc})_{2}$ & $0,1 \mathrm{M} \mathrm{Ca}(\mathrm{OAc})_{2}$ & $0,2 \mathrm{M} \mathrm{Ca}(\mathrm{OAc})_{2}$ & $0,05 \mathrm{M} \mathrm{Ca}(\mathrm{OAc})_{2}$ & $0,1 \mathrm{M} \mathrm{Ca}(\mathrm{OAc})_{2}$ & \\
\hline $10 \%$ Isopropanol & $10 \%$ Isopropanol & $10 \%$ Isopropanol & $10 \%$ Isopropanol & $10 \%$ Isopropanol & $10 \%$ Isopropanol \\
\hline $\begin{array}{l}0,1 \mathrm{M} \text { NaCacodylat } \\
\mathrm{pH} 6,5\end{array}$ & $\begin{array}{l}0,1 \mathrm{M} \text { NaCacodylat } \\
\mathrm{pH} 6,5\end{array}$ & $\begin{array}{l}0,1 \mathrm{M} \text { NaCacodylat } \\
\mathrm{pH} 6,5\end{array}$ & 0,1M Hepes pH7,5 & $0,1 \mathrm{M}$ Hepes $\mathrm{pH} 7,5$ & 0,1M Hepes $\mathrm{pH} 7,5$ \\
\hline $0,05 \mathrm{M} \mathrm{Ca}(\mathrm{OAc})_{2}$ & $0,1 \mathrm{M} \mathrm{Ca}(\mathrm{OAc})_{2}$ & $0,2 \mathrm{M} \mathrm{Ca}(\mathrm{OAc})_{2}$ & $0,05 \mathrm{M} \mathrm{Ca}(\mathrm{OAc})_{2}$ & $0,1 \mathrm{M} \mathrm{Ca}(\mathrm{OAc})_{2}$ & $0,2 \mathrm{M} \mathrm{Ca}(\mathrm{OAc})_{2}$ \\
\hline $15 \%$ Isopropanol & $15 \%$ Isopropanol & 15\% Isopropanol & 15\% Isopropanol & $15 \%$ Isopropanol & $15 \%$ Isopropanol \\
\hline $\begin{array}{l}0,1 \mathrm{M} \text { NaCacodylat } \\
\mathrm{pH} 6,5\end{array}$ & $\begin{array}{l}0,1 \mathrm{M} \text { NaCacodylat } \\
\mathrm{pH} 6,5\end{array}$ & $\begin{array}{l}0,1 \mathrm{M} \text { NaCacodylat } \\
\mathrm{pH} 6,5\end{array}$ & 0,1M Hepes $\mathrm{pH} 7,5$ & $0,1 \mathrm{M}$ Hepes $\mathrm{pH} 7,5$ & $0,1 \mathrm{M}$ Hepes $\mathrm{pH} 7,5$ \\
\hline
\end{tabular}




\begin{tabular}{|c|c|c|c|c|c|}
\hline $\begin{array}{l}8 \% \text { PEG } 3350 \\
5 \% \text { Isopropanol } \\
0,1 \mathrm{M} \\
\mathrm{NaCacodylat} \\
\mathrm{pH} 6,5\end{array}$ & $\begin{array}{l}8 \% \text { PEG } 4000 \\
0,2 \mathrm{M} \mathrm{Zn}(\mathrm{OAc})_{2} \\
0,1 \mathrm{M} \quad \mathrm{NaCacodylat} \\
\mathrm{pH} 6,5\end{array}$ & $\begin{array}{l}8 \% \text { PEG } 8000 \\
5 \% \text { MPD } \\
0,1 \mathrm{M} \mathrm{NaCacodylat} \\
\mathrm{pH} 6,5\end{array}$ & $\begin{array}{l}\text { 8\% PEG } 3350 \\
\text { 5\%Isopropanol } \\
\text { 0,1M Hepes } \mathrm{pH} 7,5\end{array}$ & 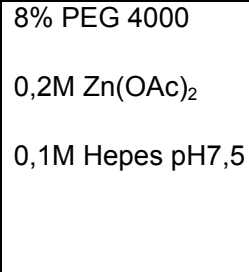 & $\begin{array}{l}8 \% \text { PEG } 8000 \\
5 \% \mathrm{MpD} \\
0,1 \mathrm{M} \text { Hepes } \mathrm{pH} 7,5\end{array}$ \\
\hline $\begin{array}{l}\text { 10\% PEG } 3350 \\
5 \% \text { Isopropanol } \\
0,1 \mathrm{M} \\
\mathrm{NaCacodylat} \\
\mathrm{pH} 6,5\end{array}$ & $\begin{array}{l}\text { 10\% PEG } 4000 \\
5 \% \text { Isopropanol } \\
0,1 \mathrm{M} \text { NaCacodylat } \\
\mathrm{pH} 6,5\end{array}$ & $\begin{array}{l}\text { 10\% PEG } 8000 \\
0,1 \mathrm{M} \text { NaCacodylat } \\
\mathrm{pH} 6,5\end{array}$ & $\begin{array}{l}\text { 10\% PEG } 3350 \\
5 \% \text { Isopropanol } \\
\text { 0,1M Hepes } \mathrm{pH} 7,5\end{array}$ & $\begin{array}{l}\text { 10\% PEG } 4000 \\
\text { 5\%Isopropanol } \\
\text { 0,1M Hepes } \mathrm{pH} 7,5\end{array}$ & $\begin{array}{l}10 \% \text { PEG } 8000 \\
0,1 \mathrm{M} \text { Hepes } \mathrm{pH} 7,5\end{array}$ \\
\hline $\begin{array}{l}14 \% \text { PEG } 3350 \\
0,1 \mathrm{M} \mathrm{Zn(OAc)} 2 \\
0,1 \mathrm{M} \\
\text { NaCacodylat } \\
\mathrm{pH} 6,5\end{array}$ & $\begin{array}{l}14 \% \text { PEG } 4000 \\
2 \% \text { MPD } \\
0,1 \mathrm{M} \text { NaCacodylat } \\
\mathrm{pH} 6,5\end{array}$ & $\begin{array}{l}\text { 14\% PEG } 8000 \\
5 \% \text { Isopropanol } \\
0,1 \mathrm{M} \mathrm{NaCacodylat} \\
\mathrm{pH} 6,5\end{array}$ & $\begin{array}{l}14 \% \text { PEG } 3350 \\
0,1 \mathrm{M} \mathrm{Zn}(\mathrm{OAc})_{2} \\
0,1 \mathrm{M} \text { Hepes } \mathrm{pH} 7,5\end{array}$ & $\begin{array}{l}14 \% \text { PEG } 4000 \\
2 \% \text { MPD } \\
0,1 \mathrm{M} \text { Hepes } \mathrm{pH} 7,5\end{array}$ & $\begin{array}{l}14 \% \text { PEG } 8000 \\
5 \% \text { Isopropanol } \\
\text { 0,1M Hepes } \mathrm{pH} 7,5\end{array}$ \\
\hline $\begin{array}{l}18 \% \text { PEG } 3350 \\
1 \% \text { MPD } \\
0,1 \mathrm{M} \\
\text { NaCacodylat } \\
\text { pH6,5 }\end{array}$ & $\begin{array}{l}18 \% \text { PEG } 4000 \\
0,05 \mathrm{M} \mathrm{Zn}(\mathrm{OAc})_{2} \\
0,1 \mathrm{M} \text { NaCacodylat } \\
\mathrm{pH} 6,5\end{array}$ & $\begin{array}{l}18 \% \text { PEG } 8000 \\
0,1 \mathrm{M} \text { NaCacodylat } \\
\mathrm{pH} 6,5\end{array}$ & $\begin{array}{l}18 \% \text { PEG } 3350 \\
1 \% \text { MPD } \\
0,1 \mathrm{M} \text { Hepes } \mathrm{pH} 7,5\end{array}$ & $\begin{array}{l}18 \% \text { PEG } 4000 \\
0,05 \mathrm{M} \mathrm{Zn}(\mathrm{OAc})_{2} \\
0,1 \mathrm{M} \text { Hepes } \mathrm{pH} 7,5\end{array}$ & $\begin{array}{l}\text { 18\% PEG } 8000 \\
0,1 \mathrm{M} \text { Hepes } \mathrm{pH} 7,5\end{array}$ \\
\hline
\end{tabular}




\begin{tabular}{|c|c|c|c|c|c|}
\hline $\begin{array}{l}8 \% \text { PEG } 3350 \\
0,05 \mathrm{M} \mathrm{Ca}(\mathrm{OAc})_{2} \\
0,1 \mathrm{M} \mathrm{NaCacodylat} \\
\mathrm{pH} 6,5\end{array}$ & $\begin{array}{l}8 \% \text { PEG } 4000 \\
0,05 \mathrm{M} \mathrm{Mn}(\mathrm{OAc})_{2} \\
0,1 \mathrm{M} \mathrm{NaCacodylat} \\
\mathrm{pH} 6,5\end{array}$ & $\begin{array}{l}\text { 8\% PEG } 8000 \\
0,05 \mathrm{M} \text { NaKTartrate } \\
0,1 \mathrm{M} \text { NaCacodylat } \\
\mathrm{pH} 6,5\end{array}$ & $\begin{array}{l}\text { 8\% PEG } 3350 \\
0,05 \mathrm{M} \mathrm{Ca}(\mathrm{OAc})_{2} \\
0,1 \mathrm{M} \text { Hepes } \mathrm{pH} 7,5\end{array}$ & $\begin{array}{l}8 \% \text { PEG } 4000 \\
0,05 \mathrm{M} \mathrm{Mn}(\mathrm{OAc})_{2} \\
0,1 \mathrm{M} \text { Hepes } \mathrm{pH} 7,5\end{array}$ & $\begin{array}{l}\text { 8\% PEG } 8000 \\
\text { 0,05M NaKTartrate } \\
\text { 0,1M Hepes } \mathrm{pH} 7,5\end{array}$ \\
\hline $\begin{array}{l}10 \% \text { PEG } 3350 \\
0,1 \mathrm{M} \mathrm{Ca}(\mathrm{OAc})_{2} \\
0,1 \mathrm{M} \mathrm{NaCacodylat} \\
\mathrm{pH} 6,5\end{array}$ & $\begin{array}{l}10 \% \text { PEG } 4000 \\
0,1 \mathrm{M} \mathrm{Mn}(\mathrm{OAc})_{2} \\
0,1 \mathrm{M} \mathrm{NaCacodylat} \\
\mathrm{pH} 6,5\end{array}$ & $\begin{array}{l}\text { 10\% PEG } 8000 \\
0,1 \mathrm{M} \text { NaKTartrate } \\
0,1 \mathrm{M} \text { NaCacodylat } \\
\mathrm{pH} 6,5\end{array}$ & $\begin{array}{l}10 \% \text { PEG } 3350 \\
0,1 \mathrm{M} \mathrm{Ca}(\mathrm{OAc})_{2} \\
0,1 \mathrm{M} \text { Hepes } \mathrm{pH} 7,5\end{array}$ & 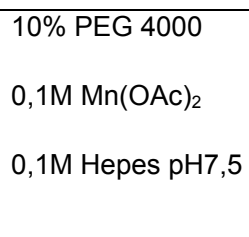 & $\begin{array}{l}\text { 10\% PEG } 8000 \\
0,1 \mathrm{M} \text { NaKTartrate } \\
0,1 \mathrm{M} \text { Hepes } \mathrm{pH} 7,5\end{array}$ \\
\hline $\begin{array}{l}\text { 14\% PEG } 3350 \\
0,15 \mathrm{M} \mathrm{Ca}(\mathrm{OAc})_{2} \\
0,1 \mathrm{M} \mathrm{NaCacodylat} \\
\text { pH6,5 }\end{array}$ & $\begin{array}{l}14 \% \text { PEG } 4000 \\
0,15 \mathrm{M} \mathrm{Mn}(\mathrm{OAc})_{2} \\
0,1 \mathrm{M} \mathrm{NaCacodylat} \\
\mathrm{pH} 6,5\end{array}$ & $\begin{array}{l}\text { 14\% PEG } 8000 \\
0,15 \mathrm{M} \text { NaKTartrate } \\
0,1 \mathrm{M} \text { NaCacodylat } \\
\mathrm{pH} 6,5\end{array}$ & $\begin{array}{l}\text { 14\% PEG } 3350 \\
0,15 \mathrm{M} \mathrm{Ca}(\mathrm{OAc})_{2} \\
0,1 \mathrm{M} \text { Hepes } \mathrm{pH} 7,5\end{array}$ & $\begin{array}{l}\text { 14\% PEG } 4000 \\
0,15 \mathrm{M} \mathrm{Mn}(\mathrm{OAc})_{2} \\
0,1 \mathrm{M} \text { Hepes } \mathrm{pH} 7,5\end{array}$ & $\begin{array}{l}\text { 14\% PEG } 8000 \\
0,15 \mathrm{M} \text { NaKTartrate } \\
0,1 \mathrm{M} \text { Hepes } \mathrm{pH} 7,5\end{array}$ \\
\hline $\begin{array}{l}18 \% \text { PEG } 3350 \\
0,2 \mathrm{M} \mathrm{Ca}(\mathrm{OAc})_{2} \\
0,1 \mathrm{M} \mathrm{NaCacodylat} \\
\mathrm{pH} 6,5\end{array}$ & $\begin{array}{l}18 \% \text { PEG } 4000 \\
0,2 \mathrm{M} \mathrm{Mn}(\mathrm{OAc})_{2} \\
0,1 \mathrm{M} \text { NaCacodylat } \\
\mathrm{pH} 6,5\end{array}$ & $\begin{array}{l}18 \% \text { PEG } 8000 \\
0,2 \mathrm{M} \text { NaKTartrate } \\
0,1 \mathrm{M} \text { NaCacodylat } \\
\mathrm{pH} 6,5\end{array}$ & $\begin{array}{l}18 \% \text { PEG } 3350 \\
0,2 \mathrm{M} \mathrm{Ca}(\mathrm{OAc})_{2} \\
0,1 \mathrm{M} \text { Hepes } \mathrm{pH} 7,5\end{array}$ & $\begin{array}{l}18 \% \text { PEG } 4000 \\
0,2 \mathrm{M} \mathrm{Mn}(\mathrm{OAc})_{2} \\
0,1 \mathrm{M} \text { Hepes } \mathrm{pH} 7,5\end{array}$ & $\begin{array}{l}\text { 18\% PEG } 8000 \\
0,2 \mathrm{M} \text { NaKTartrate } \\
\text { 0,1M Hepes } \mathrm{pH} 7,5\end{array}$ \\
\hline
\end{tabular}

\begin{tabular}{|c|c|c|c|c|c|}
\hline $\begin{array}{l}0,05 \mathrm{M} \mathrm{Zn}(\mathrm{OAc})_{2} \\
5 \% \mathrm{MPD}\end{array}$ & $\begin{array}{l}0,1 \mathrm{M} \mathrm{Zn}(\mathrm{OAc})_{2} \\
5 \% \mathrm{MPD}\end{array}$ & $\begin{array}{l}0,2 \mathrm{M} \mathrm{Zn}(\mathrm{OAc})_{2} \\
5 \% \mathrm{MPD}\end{array}$ & $\begin{array}{l}0,05 \mathrm{M} \mathrm{Zn}(\mathrm{OAc})_{2} \\
5 \% \mathrm{MPD}\end{array}$ & $\begin{array}{l}0,1 \mathrm{M} \mathrm{Zn}(\mathrm{OAc})_{2} \\
5 \% \mathrm{MPD}\end{array}$ & $\begin{array}{l}0,2 \mathrm{M} \mathrm{Zn}(\mathrm{OAc})_{2} \\
5 \% \mathrm{MPD}\end{array}$ \\
\hline $\begin{array}{l}0,1 \mathrm{M} \text { NaCacodylat } \\
\mathrm{pH} 6,5\end{array}$ & $\begin{array}{l}0,1 \mathrm{M} \text { NaCacodylat } \\
\mathrm{pH} 6,5\end{array}$ & $\begin{array}{l}0,1 \mathrm{M} \text { NaCacodylat } \\
\mathrm{pH} 6,5\end{array}$ & $0,1 \mathrm{M}$ Hepes $\mathrm{pH} 7,5$ & 0,1M Hepes $\mathrm{pH} 7,5$ & 0,1M Hepes pH7,5 \\
\hline $0,05 \mathrm{M} \mathrm{Zn}(\mathrm{OAc})_{2}$ & $0,1 \mathrm{M} \mathrm{Zn}(\mathrm{OAc})_{2}$ & $0,2 \mathrm{M} \mathrm{Zn}(\mathrm{OAc})_{2}$ & $0,05 \mathrm{M} \mathrm{Zn}(\mathrm{OAc})_{2}$ & $0,1 \mathrm{M} \mathrm{Zn}(\mathrm{OAc})_{2}$ & $0,2 \mathrm{M} \mathrm{Zn}(\mathrm{OAc})_{2}$ \\
\hline 7,5\% MPD & 7,5\% MPD & 7,5\% MPD & 7,5\% MPD & 7,5\% MPD & 7,5\% MPD \\
\hline $\begin{array}{l}0,1 \mathrm{M} \text { NaCacodylat } \\
\mathrm{pH} 6,5\end{array}$ & $\begin{array}{l}0,1 \mathrm{M} \text { NaCacodylat } \\
\mathrm{pH} 6,5\end{array}$ & $\begin{array}{l}0,1 \mathrm{M} \text { NaCacodylat } \\
\mathrm{pH} 6,5\end{array}$ & $0,1 \mathrm{M}$ Hepes $\mathrm{pH} 7,5$ & 0,1M Hepes $\mathrm{pH} 7,5$ & 0,1M Hepes $\mathrm{pH} 7,5$ \\
\hline $0,05 \mathrm{M} \mathrm{Zn}(\mathrm{OAc})_{2}$ & $0,1 \mathrm{M} \mathrm{Zn}(\mathrm{OAc})_{2}$ & $0,2 \mathrm{M} \mathrm{Zn}(\mathrm{OAc})_{2}$ & & & \\
\hline $10 \%$ MPD & $10 \%$ MPD & $10 \%$ MPD & $10 \%$ MPD & $10 \%$ MPD & \\
\hline $\begin{array}{l}0,1 \mathrm{M} \text { NaCacodylat } \\
\mathrm{pH} 6,5\end{array}$ & $\begin{array}{l}0,1 \mathrm{M} \text { NaCacodylat } \\
\mathrm{pH} 6,5\end{array}$ & $\begin{array}{l}0,1 \mathrm{M} \text { NaCacodylat } \\
\mathrm{pH} 6,5\end{array}$ & $0,1 \mathrm{M}$ Hepes $\mathrm{pH} 7,5$ & 0,1M Hepes $\mathrm{pH} 7,5$ & 0,1M Hepes pH7,5 \\
\hline 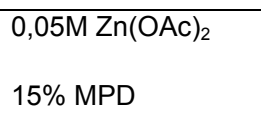 & $\begin{array}{l}0,1 \mathrm{M} \mathrm{Zn}(\mathrm{OAc})_{2} \\
15 \% \mathrm{MPD}\end{array}$ & $\begin{array}{l}0,2 \mathrm{M} \mathrm{Zn}(\mathrm{OAc})_{2} \\
15 \% \mathrm{MPD}\end{array}$ & 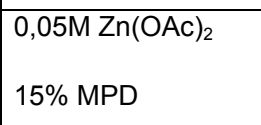 & $\begin{array}{l}0,1 \mathrm{M} \mathrm{Zn(OAc)} 2 \\
15 \% \text { MPD }\end{array}$ & 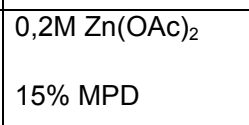 \\
\hline $\begin{array}{l}0,1 \mathrm{M} \text { NaCacodylat } \\
\mathrm{pH} 6,5\end{array}$ & $\begin{array}{l}0,1 \mathrm{M} \text { NaCacodylat } \\
\mathrm{pH} 6,5\end{array}$ & $\begin{array}{l}0,1 \mathrm{M} \text { NaCacodylat } \\
\mathrm{pH} 6,5\end{array}$ & 0,1M Hepes $\mathrm{pH} 7,5$ & $0,1 \mathrm{M}$ Hepes $\mathrm{pH} 7,5$ & 0,1M Hepes pH7,5 \\
\hline
\end{tabular}




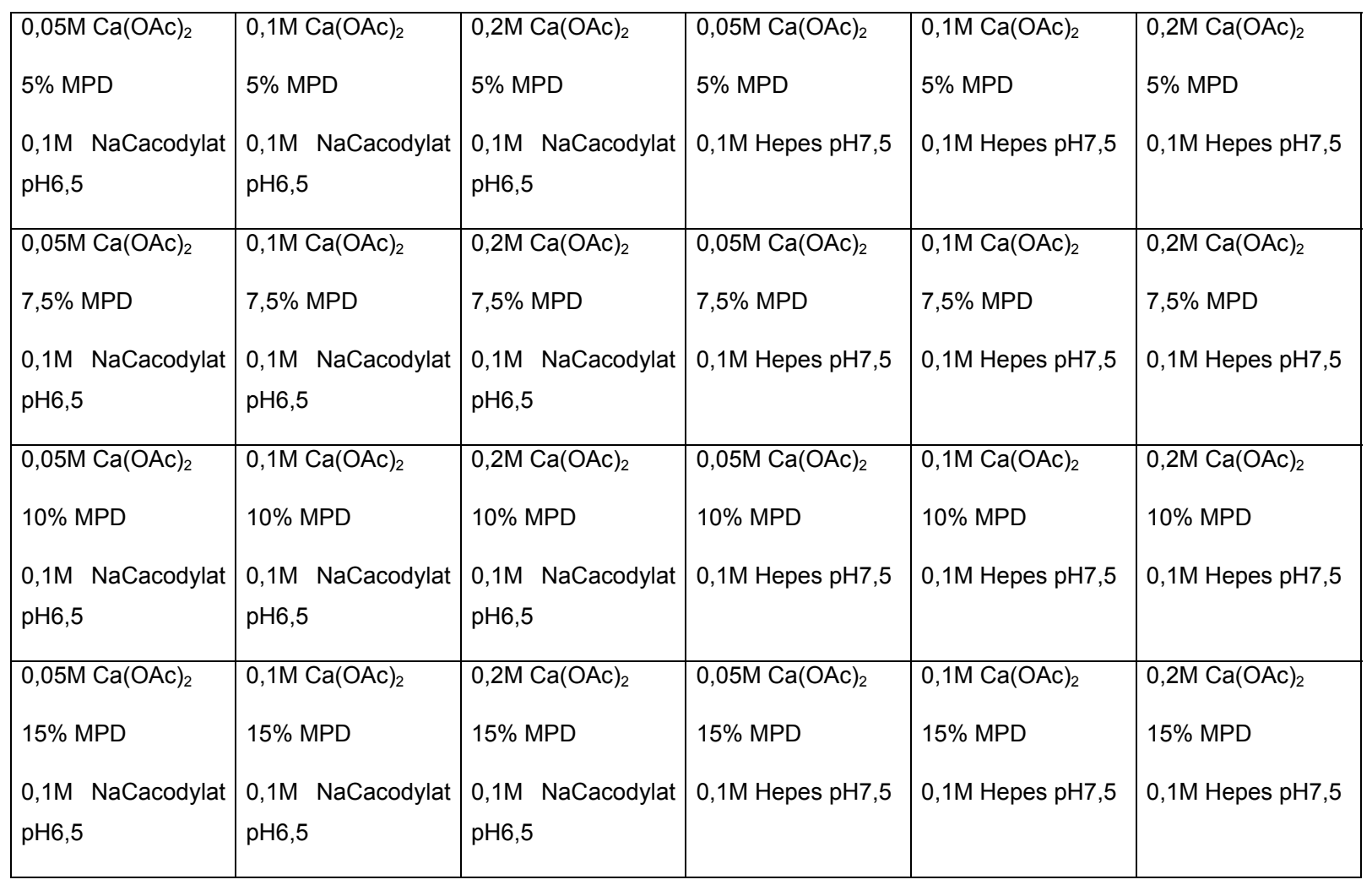

\begin{tabular}{|c|c|c|c|c|c|}
\hline $\begin{array}{l}0,05 \mathrm{M} \mathrm{Mn}(\mathrm{OAc})_{2} \\
5 \% \mathrm{MPD}\end{array}$ & $\begin{array}{l}0,1 \mathrm{M} \mathrm{Mn}(\mathrm{OAc})_{2} \\
5 \% \mathrm{MPD}\end{array}$ & $\begin{array}{l}0,2 \mathrm{M} \mathrm{Mn}(\mathrm{OAc})_{2} \\
5 \% \mathrm{MPD}\end{array}$ & $\begin{array}{l}0,05 \mathrm{M} \mathrm{Mn}(\mathrm{OAc})_{2} \\
5 \% \mathrm{MPD}\end{array}$ & $\begin{array}{l}0,1 \mathrm{M} \mathrm{Mn}(\mathrm{OAc})_{2} \\
5 \% \mathrm{MPD}\end{array}$ & $\begin{array}{l}0,2 \mathrm{M} \mathrm{Mn}(\mathrm{OAc})_{2} \\
5 \% \mathrm{MPD}\end{array}$ \\
\hline $\begin{array}{l}0,1 \mathrm{M} \text { NaCacodylat } \\
\mathrm{pH} 6,5\end{array}$ & $\begin{array}{l}0,1 \mathrm{M} \text { NaCacodylat } \\
\mathrm{pH} 6,5\end{array}$ & $\begin{array}{l}0,1 \mathrm{M} \text { NaCacodylat } \\
\mathrm{pH} 6,5\end{array}$ & $0,1 \mathrm{M}$ Hepes $\mathrm{pH} 7,5$ & $0,1 \mathrm{M}$ Hepes $\mathrm{pH} 7,5$ & $\begin{array}{ll}0,1 \mathrm{M} & \text { Hepes } \\
\mathrm{pH} 7,5 & \end{array}$ \\
\hline $\begin{array}{l}0,05 \mathrm{M} \mathrm{Mn}(\mathrm{OAc})_{2} \\
7,5 \% \mathrm{MPD}\end{array}$ & $\begin{array}{l}0,1 \mathrm{M} \mathrm{Mn}(\mathrm{OAc})_{2} \\
7,5 \% \mathrm{MPD}\end{array}$ & $\begin{array}{l}0,2 \mathrm{M} \mathrm{Mn}(\mathrm{OAc})_{2} \\
7,5 \% \mathrm{MPD}\end{array}$ & $\begin{array}{l}0,05 \mathrm{M} \mathrm{Mn}(\mathrm{OAc})_{2} \\
7,5 \% \mathrm{MPD}\end{array}$ & $\begin{array}{l}0,1 \mathrm{M} \mathrm{Mn}(\mathrm{OAc})_{2} \\
7,5 \% \mathrm{MPD}\end{array}$ & $\begin{array}{l}0,2 \mathrm{M} \mathrm{Mn}(\mathrm{OAc})_{2} \\
7,5 \% \mathrm{MPD}\end{array}$ \\
\hline $\begin{array}{l}0,1 \mathrm{M} \text { NaCacodylat } \\
\mathrm{pH} 6,5\end{array}$ & $\begin{array}{l}0,1 \mathrm{M} \text { NaCacodylat } \\
\mathrm{pH} 6,5\end{array}$ & $\begin{array}{l}0,1 \mathrm{M} \text { NaCacodylat } \\
\mathrm{pH} 6,5\end{array}$ & $0,1 \mathrm{M}$ Hepes $\mathrm{pH} 7,5$ & 0,1M Hepes $\mathrm{pH} 7,5$ & $\begin{array}{ll}0,1 \mathrm{M} & \text { Hepes } \\
\mathrm{pH} 7,5 & \end{array}$ \\
\hline $\begin{array}{l}0,05 \mathrm{M} \mathrm{Mn}(\mathrm{OAc})_{2} \\
10 \% \mathrm{MPD}\end{array}$ & $\begin{array}{l}0,1 \mathrm{M} \mathrm{Mn}(\mathrm{OAc})_{2} \\
10 \% \mathrm{MPD}\end{array}$ & $\begin{array}{l}0,2 \mathrm{M} \mathrm{Mn}(\mathrm{OAc})_{2} \\
10 \% \mathrm{MPD}\end{array}$ & $\begin{array}{l}0,05 \mathrm{M} \mathrm{Mn}(\mathrm{OAc})_{2} \\
10 \% \mathrm{MPD}\end{array}$ & $\begin{array}{l}0,1 \mathrm{M} \mathrm{Mn}(\mathrm{OAc})_{2} \\
10 \% \mathrm{MPD}\end{array}$ & $\begin{array}{l}0,2 \mathrm{M} \mathrm{Mn}(\mathrm{OAc})_{2} \\
10 \% \mathrm{MPD}\end{array}$ \\
\hline $\begin{array}{l}0,1 \mathrm{M} \text { NaCacodylat } \\
\mathrm{pH} 6,5\end{array}$ & $\begin{array}{l}0,1 \mathrm{M} \text { NaCacodylat } \\
\mathrm{pH} 6,5\end{array}$ & $\begin{array}{l}0,1 \mathrm{M} \text { NaCacodylat } \\
\mathrm{pH} 6,5\end{array}$ & 0,1M Hepes $\mathrm{pH} 7,5$ & 0,1M Hepes $\mathrm{pH} 7,5$ & $\begin{array}{ll}0,1 \mathrm{M} & \text { Hepes } \\
\mathrm{pH} 7,5 & \end{array}$ \\
\hline $\begin{array}{l}0,05 \mathrm{M} \mathrm{Mn}(\mathrm{OAC})_{2} \\
15 \% \mathrm{MPD}\end{array}$ & $\begin{array}{l}0,1 \mathrm{M} \mathrm{Mn}(\mathrm{OAc})_{2} \\
15 \% \mathrm{MPD}\end{array}$ & $\begin{array}{l}0,2 \mathrm{M} \mathrm{Mn}(\mathrm{OAc})_{2} \\
15 \% \mathrm{MPD}\end{array}$ & $\begin{array}{l}0,05 \mathrm{M} \mathrm{Mn}(\mathrm{OAC})_{2} \\
15 \% \mathrm{MPD}\end{array}$ & $\begin{array}{l}0,1 \mathrm{M} \mathrm{Mn}(\mathrm{OAc})_{2} \\
15 \% \mathrm{MPD}\end{array}$ & $\begin{array}{l}0,2 \mathrm{M} \mathrm{Mn}(\mathrm{OAc})_{2} \\
15 \% \mathrm{MPD}\end{array}$ \\
\hline $\begin{array}{l}0,1 \mathrm{M} \text { NaCacodylat } \\
\mathrm{pH} 6,5\end{array}$ & $\begin{array}{l}0,1 \mathrm{M} \text { NaCacodylat } \\
\mathrm{pH} 6,5\end{array}$ & $\begin{array}{l}0,1 \mathrm{M} \text { NaCacodylat } \\
\mathrm{pH} 6,5\end{array}$ & 0,1M Hepes $\mathrm{pH} 7,5$ & 0,1M Hepes $\mathrm{pH} 7,5$ & $\begin{array}{ll}0,1 \mathrm{M} & \text { Hepes } \\
\mathrm{pH} 7,5 & \end{array}$ \\
\hline
\end{tabular}




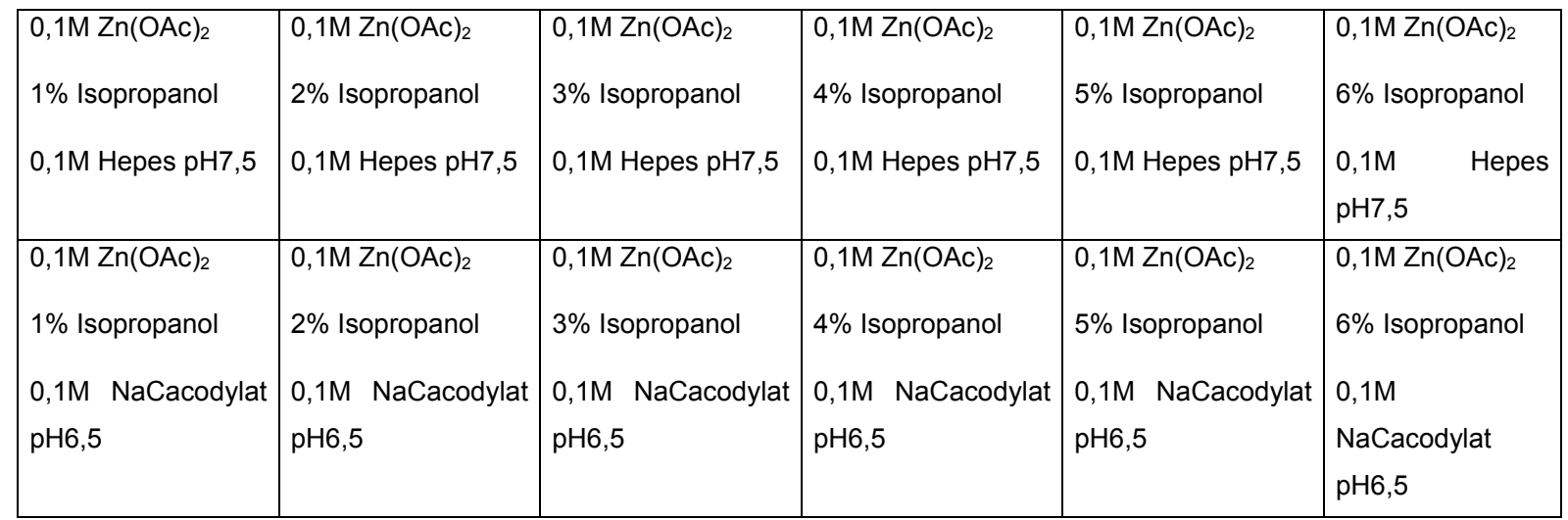




\section{Danksagungen}

Herrn Prof. Wolfgang Liebl sei für die Bereitstellung des Themas, seinem Interesse am Fortgang der Arbeit und seiner kompetenten Betreuung herzlich gedankt. Herrn Prof. Gerhard Gottschalk danke ich für die Übernahme des Korreferats. Herrn Dr. Markus Rudolph danke ich für die freundliche Hilfe bei den Fluoreszenzspektren und den Kristallisationsversuchen.

Ein besonderer Dank geht an Herrn Prof. Franc Meyer und insbesondere an Frau Dr. A. Claudia Stückl für die Versuche am ESR. Unmögliches wurde sofort erledigt und manchmal kleine Wunder vollbracht.

Ein großer Dank geht an alle meine Kollegen: Ute Ludwig, Mechthild Bömeke, Elke Heinz, Prof. Dr. Wolfgang Streit, Ole Fütterer, Carsten Raasch, Mladen Tzvetkov, Christel Schmeißer, Sonja Voget, Meike Ballschmiter, Angel Angelov, Julia Busse, Steve Klopfleisch, Krasimira Ivanova, Inga Schulte, Alexandra Uesbeck, Monika Nöller, Susan Brandenburg, Christian Elend, Jörg Kleine, Anika Appelles, Monika Nöller, Katrin Grage, Jessica Jabin, Sabrina Koßmehl, Christina Schipper, Jörn Voß, Susanne Keese, Marta Brewinska, usw...... (Bitte nicht schlagen, falls ich jemanden vergessen habe!).

Für die sehr schnelle und gründliche Korrektur meiner Arbeit danke ich Sonja Voget, Christel Schmeißer und Angel Angelov.

Ein weiterer Dank geht an Martin Mollenhauer für die Unterstützung bei den „Petrotoga's“.

Ein riesiger Dank geht an meine Eltern, die mir dieses Studium ermöglicht und mich in jeder Form voll unterstützt haben.

Der größte Dank geht an Boris Müller! Danke, daß du mich in der ganzen Zeit voll unterstützt und ertragen hast. Es war bestimmt nicht immer einfach. DANKE! 


\section{Lebenslauf}

Persönliche Angaben:

Schule

Ersatzdienst

Studium

Sprachkenntnisse
Familienstand: ledig

Staatsangehörigkeit: deutsch

Geburtstag: 28.09.1972

Geburtsort: Celle

Eltern: Helga Hoffmann (geb. Gast), Ewald Hoffmann

1979 - 1983 Grundschule Wietze

$1983-1985$ Orientierungsstufe Winsen / Aller

1985 - 1992 Hermann-Billung-Gymnasium Celle

19.05.1992 Abitur am Hermann-Billung-Gymnasium Celle

$01.08 .1992-$

31.10.1993 Zivildienst bei der Johanniter-Unfall-Hilfe Celle

22.09.1993 Immatrikulation an der Georg-August-Universität Göttingen

11.02.1998 Diplomvorprüfung in Chemie

06.07.2001 Diplomprüfung in Chemie

$01.10 .2001-$

06.05.2005 Promotion am Institut für Mikrobiologie und Genetik in Göttingen 